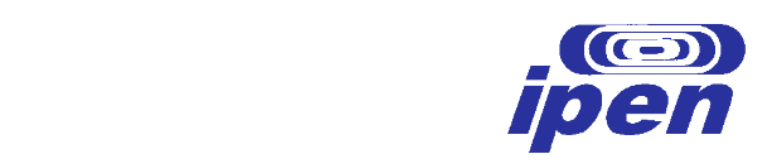

AUTARQUIA ASSOCIADA À UNIVERSIDADE DE SÃO PAULO

REMOÇÃO DE CORANTES DE EFLUENTE TEXTIL POR ZEÓLITA DE CINZAS DE CARVÃO MODIFICADA POR SURFACTANTE E AVALIAÇÃO DOS EFEITOS TÓXICOS

PATRICIA CUNICO FERREIRA

Tese apresentada como parte dos requisitos para obtenção do Grau de Doutor em Ciências na Área de Tecnologia Nuclear - Materiais.

Orientadora:

Dra. Denise Alves Fungaro 


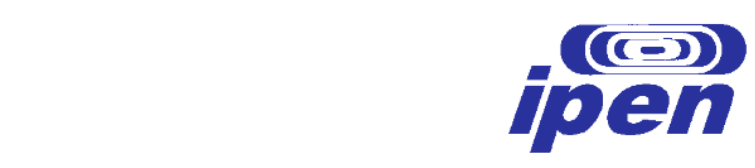

AUTARQUIA ASSOCIADA À UNIVERSIDADE DE SÃO PAULO

REMOÇÃO DE CORANTES DE EFLUENTE TEXTIL POR ZEÓLITA DE CINZAS DE CARVÃO MODIFICADA POR SURFACTANTE E AVALIAÇÃO DOS EFEITOS TÓXICOS

PATRICIA CUNICO FERREIRA

Tese apresentada como parte dos requisitos para obtenção do Grau de Doutor em Ciências na Área de Tecnologia Nuclear - Materiais.

Orientadora:

Dra. Denise Alves Fungaro 


\section{DEDICATÓRIA}

Dedico esse trabalho a toda a minha família, em especial a minha mãe Mirtes e ao meu marido Danillo. 


\section{AGRADECIMENTOS}

Agradeço aqui de coração a todas as pessoas que de alguma forma foram importantes e essenciais para a realização desse trabalho.

Obrigada a minha família pelo incentivo, por todo apoio, paciência e compreensão; em especial a minha mãe Mirtes por estar sempre presente em todas as horas, mesmo à distância, por todo seu amor e dedicação, por todas as palavras doces e de incentivo, por sempre acreditar em mim; ao meu marido Danillo pelos anos de companheirismo, de paciência, de ajuda, apoio, de amor, pelos desabafos nos momentos difíceis, obrigada por estar ao meu lado sempre; ao meu irmão Renato e a minha tia Elenize.

À Dra. Denise Alves Fungaro pela orientação de mais um trabalho juntas, pela paciência, incentivo, pelo apoio, amizade e pelos ensinamentos que perduram a muitos anos.

À Dra. Anu Kumar pela orientação, amizade e ensinamentos pelo tempo que estive em sua instituição.

À Dra. Sueli Ivone Borrely e Dra. Nilce Ortiz pela constante participação em todos os processos, por todos os conselhos e ajuda.

lara.

À banca examinadora composta pela Dra. Juliana, Dr. Camilo, Dr. Deovaldo e Dra.

Ao Centro de Química e Meio Ambiente e ao Instituto de Pesquisas Enérgicas e Nucleares por toda a infraestrutura oferecida para a realização desse trabalho e de tantos outros tão importantes, assim como seus funcionários e ao Commonwealth Scientific and Industrial Research Organisation (Austrália) pela infraestrutura e parceria oferecida por essa instituição.

À Companhia Carbonífera do Cambuí Ltda. e Usina Termoelétrica de Figueira pela recepção e amostras de cinzas.

Ao Cnpq, Ciência sem Fronteiras e IPEN pelo apoio financeiro.

Às amigas do CQMA Juliana Izidoro, Terezinha, Raquel, Tharcila, Gisela, Carina e Juliana Ikebe pela amizade, companheirismo, cumplicidade e pelo constante apoio.

Aos amigos e amigas Nayara, Ana Carolina, Amanda Fernandes, Lucas Justo, Thatiane Lima pelos momentos de descontração e de suporte, por sempre estarem lá, em especial as amigas Eliane Santos, Fernanda Fuzeto, Gisela Lopes, Juliana Lúcio e Priscila Schults por todas as palavras de apoio e de ânimo, pelos conselhos, pelas conversas fiadas, pelas risadas, por toda paciência e principalmente pela amizade.

Ao amigo Fábio Pusceddu por toda ajuda e paciência nos momentos de necessidade.

As pessoas que ajudaram com toda a caracterização dos materais: Liana Nakamura, pelo auxílio na realização das análises de difração de raios $X$, Felipe Ferrufino pela realização das análises de massa específica, Dra. Sandra Cunha por realizar as análises de espectrometria de infravermelho e de área superficial, a Flávia Rodrigues de Oliveira Silva por realizar as análises de microscopia de varredura.

A Deus por me ajudar em mais essa etapa.

A todos que não foram aqui citados, mas ajudaram na realização desse trabalho.

Obrigada de coração! 
"E de repente, um dia qualquer, acordamos e percebemos que já podemos lidar com aquilo que julgávamos maior que nós mesmos. Não foram os abismos que diminuíram, mas nós que crescemos"

Fabiola Simões 


\title{
REMOÇÃO DE CORANTES DE EFLUENTE TEXTIL POR ZEÓLITA DE CINZA DE CARVÃO MODIFICADA POR SURFACTANTE E AVALIAÇÃO DOS EFEITOS TÓXICOS
}

\author{
Patricia Cunico Ferreira \\ RESUMO
}

\begin{abstract}
Zeólitas sintetizadas a partir de cinzas leves e pesadas de carvão e modificadas com hexadeciltrimetilamônio (HDTMA) foram usadas como adsorvente para remoção dos corantes Solophenyl Navy (SN) e Solophenyl Turquesa (ST) e suas formas hidrolisadas, Solophenyl Navy hidrolisada (SNH) e Solophenyl Turquesa hidrolisada (STH), de efluente simulado de indústria têxtil. As zeólitas leve modificada (ZLM) e pesada modificada (ZPM) foram caracterizadas por diferentes técnicas, tais como, espectrometria de fluorescência de raios- $X$, difração de raios- $X$ e microscopia eletrônica de varredura. As ZLM e ZPM apresentaram carga estrutural negativa devido à formação de uma bicamada parcial de HDTMA na superfície externa da zeólita. A concentração inicial dos corantes, o tempo de contato e o equilíbrio de adsorção foram avaliados. A cinética de adsorção de SN, ST, SNH e STH sobre as zeólitas seguiu o modelo de pseudo segunda- ordem. $O$ tempo de equilíbrio foi de 20 min para SN e ST e 30 min para SNH e STH sobre ZLM, enquanto sobre ZPM foi de 60 min para SN e ST e 20 e 30 min para SNH e STH, respectivamente. Os modelos de Langmuir, Freundlich e Temkin foram aplicados para descrever as isotermas de adsorção. A adsorção dos corantes foi melhor descrita pelo modelo de Langmuir, com exceção dos sistemas SN/ZPM, SNH/ZPM e SNH/ZLM que seguiram modelo de Freundlich. As capacidades máximas de adsorção foram 3,64; 3,57; 2,91 e 4,93 $\mathrm{mgL}^{-1}$ para SN, ST, SNH e STH pela ZLM, respectivamente e 0,$235 ; 0,492 ; 1,26$ e $1,86 \mathrm{mgL}^{-1}$ pela ZPM, nesta mesma ordem. O melhor desempenho dos corantes hidrolisados foi atribuído à redução do tamanho das moléculas dos corantes durante o processo de hidrólise. A toxicidade aguda dos corantes foi avaliada por diferentes organismos teste. O microcrustáceo $C$. dubia apresentou valores de $\mathrm{EC}_{50}$ de 1,$25 ; 54,5 ; 0,78$ e $2,56 \mathrm{mgL}^{-1}$ para SN, ST, SNH e STH, respectivamente. A macrófita $L$. minor mostrou valores de $\mathrm{EC}_{50}$ de 18,$9 ; 69,4 ; 10,9$ e $70,9 \mathrm{mgL}^{-1}$ para SN, ST, SNH e STH, respectivamente. As larvas de mosquitos $C$. tepperi mostraram valores de $\mathrm{EC}_{50}$ de 119 e $440 \mathrm{mgL}^{-1}$ para a SN e ST, respectivamente. Com relação ao processo de adsorção, os efeitos agudos foram substancialmente reduzidos após o tratamento da solução aquosa de SN e ST com ZLM, assim como de suas formas hidrolisadas, apresentando nenhuma toxicidade após a remoção de $100 \%$ da cor. Após o tratamento dos corantes com ZPM houve um aumento da toxicidade, com exceção dos corantes SNH e STH que não apresentaram toxicidade após o tratamento. Testes de Avaliação e Identificação da Toxicidade foram realizados a fim de identificar quais substâncias estariam causando a toxicidade nos corantes SN, ST e no lixiviado de ZLM e ZPM. Os efeitos tóxicos foram reduzidos significativamente após a manipulação com Extração de Fase Sólida (SPE) e ácido etilenodiaminotetracético (EDTA) para o lixiviado de ZLM e ZPM. Os corantes mostraram redução na toxicidade após a manipulação com EDTA indicando que as substâncias tóxicas eram principalmente metais catiônicos.
\end{abstract}




\title{
DYES REMOVAL OF TEXTILE WASTEWATER ONTO SURFACTANT MODIFIED ZEOLITE FROM COAL ASH AND EVALUATION OF THE TOXIC EFFECTS
}

\author{
Patricia Cunico Ferreira
}

\begin{abstract}
Zeolites synthesized from fly and bottom ashes and modified with hexadecyltrimethylamonium (HDTMA) were used as adsorbent to remove dyes Solophenyl Navy (SN) and Solophenyl Turquoise (ST) and their hydrolysed forms Solophenyl Navy Hydrolysed (SNH) and Solophenyl Turquoise Hydrolysed (STH), from simulated textile wastewater. The HDTMA-modified fly zeolite (ZMF) and HDTMA-modified bottom zeolite $(\mathrm{ZMB})$ were characterized by different techniques, as X-ray fluorescence spectrometry, X-ray diffraction and scanning electron microscopy, etc. The ZMF and ZMB presented negative charge probably due to the formation of a partial bilayer of HDTMA on exchangeable active sites on the external surface of unmodified zeolite. Initial dye concentration, contact time and equilibrium adsorption were evaluated. The adsorption kinetic for $\mathrm{SN}$, ST, SNH and STH onto the zeolites followed the pseudo second-order model. The equilibrium time was $20 \mathrm{~min}$ for SN and ST and $30 \mathrm{~min}$ for SNH and STH, respectively. Langmuir, Freundlich and Temkin models were applied to describe the adsorption isotherms. Adsorption of the dyes were best described by the Langmuir model, with exception to SN/ZPM, SNH/ZPM and SNH/ZLM systems that followed Freundlich model. The maximum adsorption capacities were 3,64 ; 3,$57 ; 2,91$ e 4,93 for SN, ST, SNH e STH by ZLM, respectively and 0,235; 0,492; 1,26 e 1,86 by ZPM, in this order. The best performance for hydrolyzed dyes has been attributed to reduction of the size of dyes molecules during the hydrolysis process. Acute toxicity of the dyes to a different organism were evaluated by different test-organisms. Waterflea, Ceriodaphnia dubia showed $\mathrm{EC}_{50}$ value of 1,$25 ; 54,5 ; 0,78$ and $2,56 \mathrm{mgL}^{-1}$ for SN, ST, SNH and STH, respectively. The plant Lemna minor showed $\mathrm{EC}_{50}$ values of 18,$9 ; 69,4 ; 10,9$ and $70,9 \mathrm{mgL}^{-1}$ for SN, ST, SNH and STH, respectively. Midges larvae of Chironomus tepperi showed $\mathrm{EC}_{50}$ values of 119 and $440 \mathrm{mgL}^{-1}$ for SN and ST, respectively. Regarding the adsorption process, acute effects were substantially reduced after adsorption treatment of aqueous solution with SN and ST by ZMF, as well as their hydrolysed forms, showing no toxicity after removal of $100 \%$ of colour. After treatment with ZPM there was an increase of the toxicity, with exception of SHN and STH dyes that do not show toxicity after the treatment. Toxicity Identification Evaluation tests (TIE) were realized in order to identify what substances were causing the observed toxicity for the SN, ST and the leached of ZMF and ZMB. The acute effects were significantly reduced after manipulation with Solid-Phase Extraction (SPE) and Ethylenediaminetetraacetic acid (EDTA) for the leached of ZMB and ZMF. The dyes showed reduced in the toxicity after manipulation with EDTA indicating that the toxicants are mostly cationic metals.
\end{abstract}




\section{SUMÁRIO}

1 INTRODUÇÃO

2 OBJETIVOS 2

2.1 Objetivo geral $\quad 2$

2.2 Objetivos específicos $\quad 2$

3 REVISÃO DA LITERATURA 3

3.1 Corantes têxteis 3

3.2 Corantes Solophneyl Navy e Solophenyl Turquesa 3

3.3 Setor têxtil no Brasil 5

3.4 Efluentes têxteis $\quad 5$

3.5 Processos de tratamento de efluentes têxteis 6

3.6 Adsorção 6

$\begin{array}{ll}3.7 \text { Adsorvente de baixo custo } & 7\end{array}$

$\begin{array}{ll}3.8 \text { Cinzas de carvão } & 7\end{array}$

3.9 Disposição e aplicação das cinzas de carvão 8

$\begin{array}{ll}3.10 \text { Zeólita } & 10\end{array}$

$\begin{array}{ll}3.11 \text { Síntese hidrotérmica } & 11\end{array}$

3.12 Zeólita modificada por surfactante $\quad 12$

$\begin{array}{ll}3.13 \text { Modelagem cinética } & 15\end{array}$

3.14 Isotermas de adsorção 16

$\begin{array}{ll}3.14 .1 \text { Isoterma de Langmuir } & 17\end{array}$

$\begin{array}{ll}3.14 .2 \text { Isoterma de Freundlich } & 18\end{array}$

$\begin{array}{ll}\text { 3.14.3 Isoterma de Temkin } & 18\end{array}$

$\begin{array}{ll}3.15 \text { Estimativas do melhor ajuste } & 18\end{array}$

3.16 Testes de toxicidade e toxicologia dos corantes 19

$\begin{array}{ll}3.17 \text { Organismos teste } & 20\end{array}$

3.18 Testes preliminares e de sensibilidade 21 
4.1 Área de amostragem 22

4.2 Amostras de cinzas de carvão 22

4.2.1 Cinza leve de carvão 22

4.2.2 Cinza pesada de carvão 22

4.3 Materiais utilizados $\quad 22$

4.4 Preparação das soluções dos corantes 23

4.4.1 Corantes da forma industrial 23

4.4.2 Corantes da forma hidrolisada 23

4.5 Síntese 23

4.5.1 Síntese da zeólita a partir de cinza leve e pesada de carvão 23

4.5.2 Síntese da zeólita de cinza de carvão modificada por surfactante 23

4.6 Caracterização das cinzas de carvão e materiais adsorventes 24

4.6.1 Determinação do $\mathrm{pH}$ e condutividade 24

4.6.2 Determinação do ponto de carga zero 24

4.6.3 Capacidade de troca catiônica e capacidade de troca catiônica 25 externa

4.6.4 Grau de hidrofobicidade $\quad 25$

4.6.5 Massa específica 26

4.6.6 Área específica 26

4.6.7 Difração de raios-X 26

$\begin{array}{ll}\text { 4.6.8 Florescência de raios-X } & 27\end{array}$

$\begin{array}{ll}\text { 4.6.9 Microscopia eletrônica de varredura } & 27\end{array}$

4.6.10 Espectroscopia no infravermelho 27

$\begin{array}{ll}4.7 \text { Estudos de adsorção } & 27\end{array}$

4.8 Isotermas de adsorção 28

4.9 Testes de toxicidade 28 
4.9.1 Testes agudo com Ceriodaphnia dubia 28

4.9.2 Testes agudo com Lemna minor 29

4.9.2.1 Extração de clorofila das amostras de L. minor 31

4.9.3 Testes com Chironomus tepperi 31

4.9.3.1 Testes crônicos "Spiked Water" com C. tepperi 32

4.9.3.2 Testes crônicos "Skiped Sediment" com C. tepperi 33

4.10 Avaliação e Identificação da Toxicidade 33

4.10.1 Adição do agente quelante EDTA 33

4.10.2 Extração em fase sólida 34

4.11 Análise química dos testes de toxicidade 34

5 RESULTADOS E DISCUSSÃO 35

5.1 Caracterização dos adsorventes $\quad 35$

5.1.1 Determinação do $\mathrm{pH}$ e condutividade $\quad 35$

5.1.2 Determinação do ponto de carga zero 35

5.1.3 Determinação da massa específica e área específica 36

$\begin{array}{ll}5.1 .4 \text { Morfologia } & 37\end{array}$

5.1.5 Composição química 38

5.1.6 Composição mineralógica 40

5.1.7 Determinação da troca catiônica 43

5.1.8 Identificação dos grupos funcionais $\quad 43$

$\begin{array}{ll}5.2 \text { Mecanismo de hidrólise } & 47\end{array}$

5.3 Estudos com as zeólitas leve e pesada modificada de cinza de carvão $\quad 47$

5.3.1 Efeito do tempo de contato e concentração inicial dos corantes na $\quad 47$ adsorção

5.3.2 Modelagem cinética $\quad 50$

5.4 Isotermas de adsorção 58

5.5 Mecanismos de adsorção 64 
5.6 Testes toxicológicos 65

5.6.1 Testes toxicológicos com os corantes 66

5.6.1.1 Avaliação da toxicidade aguda dos corantes por Lemna minor $\quad 66$

5.6.1.2 Avaliação da toxicidade aguda por Ceriodaphnia dubia antes e $\quad 72$ após processo de adsorção

5.6.1.3 Avaliação da toxicidade aguda e crônica por Chironomus tepperi $\quad 74$

5.6.2 Avaliação da toxicidade em sedimento por Chironomus tepperi $\quad 77$

5.6.2.1 "Spiked Sediment"

$\begin{array}{ll}\text { 5.6.2.2 "Spiked Water" } & 79\end{array}$

5.7 Avaliação e Identificação da Toxicidade 82

5.7.1 Avaliação e Identificação da Toxicidade dos corantes 82

5.8 Testes de toxicidade aguda com C. dubia e Avaliação e Identificação 82 da Toxicidade das zeólitas modificadas por surfactante

5.9 Sensibilidade de diferentes organismos 84

6 CONCLUSÕES $\quad 85$

7 Sugestões para futuros trabalhos $\quad 86$

$\begin{array}{ll}\text { Anexos } & 88\end{array}$

$\begin{array}{ll}\text { Apêndices } & 94\end{array}$

$\begin{array}{ll}\text { REFERÊNCIAS } & 98\end{array}$ 



\section{INTRODUÇÃO}

A poluição das águas está se tornando um fenômeno muito preocupante. As indústrias têxteis contribuem para a deterioração da água por conta da descarga de grandes volumes de efluentes no meio ambiente, sendo esses efluentes considerados como um dos mais poluentes entre todos os setores industriais (Savin e Butnaru, 2008; Soupilas et al, 2008). Esses efluentes são misturas complexas de poluentes tóxicos, geralmente muito concentrados, compostos de corantes e pigmentos, sais, metais pesados, biocidas, surfactantes e outros componentes orgânicos e inorgânicos. (Eremektar et al., 2007; Sharma et al, 2007; Verma, 2008).

A toxicidade desses efluentes é uma das principais causas do fracasso nos tratamento biológicos, geralmente, resultando em não conformidade com os limites de descargas permitidos (Vijayaraghavan e Ramanujam, 1999; Aguayo et al., 2004; Alinsafi et al., 2006). Assim, os efluentes têxteis podem levar a sérias consequências ambientais, principalmente para os ambientes aquáticos, se não tratados adequadamente.

Métodos de tratamento tradicionais, tais como troca iônica, precipitação química, e de separação por membrana são muitas vezes ineficazes e de alto custo quando utilizados para a remoção de corantes (Balci et al., 2011). Entre os vários tipos de tratamentos de efluentes, a adsorção usando carvão ativado é uma das técnicas que têm sido empregada com sucesso na efetiva remoção de corantes (Kunz et al., 2002). Uma alternativa viável ao carvão ativado é a utilização de resíduos sólidos que podem ser reciclados e usados como adsorventes de baixo custo e, para este fim, diversos resíduos orgânicos e industriais tem sido avaliados (Gupta e Suas, 2009).

Dentre os potenciais resíduos aplicados como adsorventes, o uso de material zeolítico se destaca, gerado por meio das cinzas de carvão. As cinzas de carvão mineral são constituídas basicamente de sílica e alumina sendo possível convertê-las em material zeolítico por tratamento hidrotérmico com hidróxido de sódio (Henmi, 1987; Querol et al., 2002; Rayalu et al., 2006).

Zeólitas são aluminossilicatos hidratados de metais alcalinos e alcalinos terrosos (principalmente $\mathrm{Na}, \mathrm{K}, \mathrm{Mg}$ e $\mathrm{Ca}$ ), estruturados em redes cristalinas tridimensionais, compostas de tetraedros do tipo $\mathrm{SiO}_{4}$ e $\mathrm{AlO}_{4}$ unidos nos vértices por meio de dos átomos de oxigênio (Breck, 1984). Este material possui carga estrutural negativa resultante da substituição isomórfica de cátions $\mathrm{Si}^{4+}$ por $\mathrm{Al}^{3+}$ na estrutura cristalina, a qual é balanceada pelas cargas positivas de cátions trocáveis. Além da carga negativa que apresentam, as zeólitas são hidrofílicas e, portanto, têm pouca ou nenhuma afinidade por espécies aniônicas e compostos orgânicos hidrofóbicos. As propriedades químicas superficiais da zeólita podem ser modificadas pelo processo de adsorção por surfactantes catiônicos. Esses compostos possuem alto grau de hidrofobicidade (Haggerly e Bowman, 1994; Bowman, 2003).

As zeólitas modificadas são capazes de adsorver outras classes de compostos (ânions e orgânicos apolares), resultando em uma melhora no custoefetividade do produto (Li, 1999; Bowman, 2003).

Além dos estudos de adsorção visando o tratamento de efluentes, dentro da Ecotoxicologia se faz necessário a realização de testes de toxicidade com o efluente bruto e após tratamento com zeólita modificada com surfactante foram realizados com o propósito de avaliar evidências de uma possível contaminação desses corantes quando lançados no corpo hídrico receptor.

Atualmente regulamentações rigorosas têm sido estabelecidas em muitos países referentes ao descarte de efluentes coloridos. No Brasil as resoluções do Conselho Nacional do Meio Ambiente, CONAMA n॰357 e $n^{\circ} 430$, dispõem sobre as condições e padrões de lançamento de efluentes e da diluição e fator de toxicidade, 
respectivamente. Nessa situação, efluentes a serem lançados em ambiente aquático não devem causar ou possuir potenciais efeitos tóxicos para os seus organismos.

Essas resoluções estabelecem os limites de lançamento para garantir que, após a diluição do efluente no rio, esse não sofra declínio na qualidade da água. No âmbito federal, o Conselho Nacional do Meio Ambiente passou a incluir a obrigatoriedade do Controle Ecotoxicológico para Efluentes, direcionando a exigência para o Órgão Ambiental Estadual.

Para atingir tais metas, as contribuições inéditas deste trabalho foram: (1) A avaliação da remoção do ST e SN, e suas formas hidrolisadas, de solução aquosa por processo de adsorção usando adsorvente modificado de baixo custo. Embora estes corantes sejam extensivamente usados na indústria têxtil, há poucos estudos relatados em literatura até o momento sobre sua remoção com adsorvente de baixo custo e não foram encontrados em literatura estudos sobre o tratamento usando adsorvente baseado em zeólita modificada; (2) Para simular um efluente contaminado por corante no processo de tingimento de tecido foi realizada uma hidrólise dos corantes SN e ST esse processo não foi relatado em literatura.; (3) Além disso, esse trabalho também avaliou o uso de zeólita de cinzas pesadas modificada como material adsorvente. Sabese que as cinzas pesadas, ao contrário das cinzas leves, não tem nenhum tipo de aplicação comercial; (4) A fim de avaliar os efeitos tóxicos, testes de ecotoxicidade foram realizados com os corantes e suas formas hidrolisadas, assim como dos adsorventes deste estudo.

Para esse fim, a presente tese verificou as seguintes hipóteses:

1- $\quad$ Corantes direto SN e ST, assim como suas formas hidrolisadas removem efluentes simulados de lavanderia têxtil usando zeólitas modificadas de cinza de carvão por método descontínuo;

2- $\quad$ Efluentes contendo corantes SN e ST, assim como suas formas hidrolisadas são tóxicos para os organismos $C$. dubia, L. minor e C. tepperi;

3- $\quad$ O processo de adsorção por ZLM e ZPM remove a cor e elimina a toxicidade do efluente simulado.

\section{OBJETIVOS}

\subsection{Objetivo Geral}

O objetivo geral deste estudo foi sintetizar zeólitas a partir de cinzas de carvão e avaliar o seu uso na remoção de corantes Solophenyl de solução aquosa, assim como a avaliar a toxicidade antes e após tratamento com zeólitas.

\subsection{Objetivos Específicos}

Para a consolidação do objetivo geral, fez-se necessária a execução das etapas pertinentes ao trabalho.

a) Sintetizar zeólita a partir de cinzas de carvão;

b) Sintetizar zeólita de cinzas de carvão modificada por surfactante;

c) Caracterizar os materiais adsorventes;

d) Estudar o processo de adsorção em leito móvel utilizando efluentes simulados com dois tipos de corantes sobre as zeólitas: modelagem cinética e de equilíbrio;

e) Estudar o processo de adsorção em leito móvel utilizando efluentes hidrolisados com dois tipos de corantes sobre as zeólitas: modelagem cinética e de equilíbrio; 
f) Realizar os testes de ecotoxicidade e fitotoxicidade, crônicos e agudos com os organismos Ceriodaphnia dubia, Lemna minor e Chironomus tepperi para a avaliação toxicidade por meio de da $\mathrm{CE}_{50}$ e $\mathrm{CL}_{50}$;

g) Identificar os compostos tóxicos por meio de testes de Avaliação e Identificação da Toxicidade;

h) Avaliação da toxicidade no sedimento e na água intersticial com o organismo $C$. tepperi com o intuito de simular uma real contaminação nos corpos d'água receptores.

\section{REVISÃO DA LITERATURA \\ 3.1. Corantes Têxteis}

Diferentes tipos de corantes são usados em muitas indústrias, tais como, têxteis, de tintas, alimentícias, plásticas, de cosméticos, gráfica, fotográfica, como aditivos em derivados de petróleo, etc. (Guaratini e Zanoni, 2000; Kunz et al.,2002).

Conforme Zollinger (1991), os corantes fazem parte de um grupo de materiais chamados colorantes, que por sua vez são caracterizados por sua habilidade em absorver luz visível (400 a $700 \eta \mathrm{nm}$ ). Os corantes diferem dos pigmentos por serem completamente ou parcialmente solúveis quando aplicados em solução aquosa em vários substratos.

Segundo Vandevivere et al. (1998), a molécula do corante possui uma estrutura principal chamada de grupo cromóforo que é responsável pela absorção da radiação visível e exposição da cor. O grupo cromóforo mais utilizado é o da família dos "azo" corantes (representado por uma ligação dupla entre dois nitrogênios), que corresponde a aproximadamente 60 a $70 \%$ de todos os corantes têxteis produzidos.

A outra parte da molécula do corante é constituída pelo grupo auxocromo, responsável pela fixação do corante à fibra têxtil e intensificação da sua cor (Sales et al., 2003). Os grupos auxocromos mais comuns são: etila, nitro, amino, sulfônico, hidroxila, metóxi, etóxi, cloro e bromo (Kimura et al., 1999).

A classificação dos corantes pode ser realizada de acordo com sua estrutura química ou de acordo com o modo de fixação da molécula na fibra (Gupta e Suhas, 2009; Guaratini e Zanoni, 2000).

Com base na estrutura química do grupo cromóforo, os corantes são classificados como azo, antraquinona, trifenilmetano, heterocíclico e corantes poliméricos (ABIQUIM, 2013; Zanoni e Carneiro, 2001).

Os principais grupos de corantes classificados pelo modo de fixação à fibra são: reativos, diretos, azóicos, ácidos, básicos, a cuba, dispersivos, de enxofre, prémetalizados e branqueadores (Gupta e Suhas, 2009; Robinson et al., 2001; Zanoni e Carneiro, 2001).

\subsection{Corantes Solophenyl Navy e Solophenyl Turquesa}

Para avaliar o uso de materiais zeolíticos modificados de cinza de carvão na remoção de efluente simulado de indústria têxtil, os corantes Solophenyl Navy e Solophenyl Turquesa foram escolhidos como modelo.

Solophenyl® é a marca registrada de produtos químicos usados para propósito de tingimento que pertence à empresa Huntsman International, Geigy Company, Inc. Esses tipos de corantes são utilizados para tingimento de fibras celulósicas, principalmente o algodão. No Brasil o corante Solophenyl Navy (SN) é amplamente utilizado para tingimento do jeans, e aplicado em praticamente todas as lavanderias industriais da área têxtil. Esse corante também é utilizado por diversas 
empresas em combinação com outros corantes de diferentes colorações para tingimento de tecidos de algodão (Melo, 2007).

O corante Solophenyl Turquesa (ST) também é um dos principais corantes utilizados na produção de novas tonalidades azuis juntamente com o Solophenyl Navy e - Azul G5 para aplicação em tecidos do tipo jeans (Schimmel, 2008). Os corantes Solophenyl possuem estrutura química do tipo metal-ftalocianina e suas características gerais estão apresentadas na TAB. 1.

TABELA 1: Característica dos corantes Solophenyl Navy e Solophenyl Turquesa

\begin{tabular}{lcc}
\hline Corante & Solophenyl Turquesa & Solophenyl Navy \\
& BRLE $400 \%$ & BRLE 250\% \\
\hline Classe & Direto & Direto \\
Cl & BL 199 & BL mix \\
Descrição Química & Metal-ftalocianina & Metal-ftalocianina \\
Fórmula Molecular & Desconhecida & Desconhecida \\
Peso Molecular $\left(\mathrm{g} \mathrm{mol}^{-1}\right)$ & Desconhecido & Desconhecido \\
\hline
\end{tabular}

$\overline{\mathrm{Cl}}=$ Número de classificação em Português (Color Index em Inglês)

A ftalocianina de cobre e seus derivados oferecem excelente resistência ao calor e à luz, a ataques ácidos ou alcalinos e por isso estão presentes em praticamente todos os tipos de tintas para impressão e pinturas em geral, plásticos, tecidos, argamassas, sabões, detergentes e outros produtos de limpeza. São pigmentos de cor azul que podem adquirir tons de verde ou mesmo tomarem-se verdes sendo clorados ou bromados (Morse e Thomas, 1964).

O uso de ftalocianinas juntamente com outros pigmentos para gerar os chamados "pigmentos de efeitos" podem produzir diferentes pigmentos com melhores propriedades, como: propagação, cor brilhante, alta intensidade de cor e estabilidade (Topuz et al., 2013). A maioria desses corantes são de ftalocianina a base de cobre. Estes por sua vez são potencialmente mutagênicos, gerando uma preocupação especial com a toxicidade devido ao seu teor de Cu (Aspland, 1997).

A literatura reporta alguns estudos de adsorção com corantes tipo ftalocianina, que são apresentados da TAB. 2

TABELA 2: Revisão da literatura da adsorção de corantes azuis do tipo ftalocianina

\begin{tabular}{|c|c|c|c|c|}
\hline Corante & Adsorvente & Condição & $\mathbf{Q}_{0}{ }^{1}$ & Referência \\
\hline ST & $\begin{array}{c}\text { Cinza de } \\
\text { carvão+lama de } \\
\text { acetileno+gesso }\end{array}$ & $\begin{array}{c}\mathrm{Te}^{2}=4 \mathrm{~h} \\
\mathrm{~T}^{3}=20^{\circ} \mathrm{C}\end{array}$ & 35 & $\begin{array}{l}\text { Rebelo } \\
(2000)\end{array}$ \\
\hline SN e ST & $\begin{array}{l}\text { Argila esmectita "in } \\
\text { natura" e ativada }\end{array}$ & $\begin{array}{c}\mathrm{Te}=20 \mathrm{~min}-\text { ativada; } \\
7 \mathrm{~h} \text { "in natura" } \\
\mathrm{T}=300^{\circ} \mathrm{C}\end{array}$ & 10 & Silva (2005) \\
\hline $\begin{array}{l}\text { Remazol } \\
\text { Azul } \\
\text { Turquesa } \\
\text { G133 }\end{array}$ & Zeólita leve & $\begin{array}{c}\mathrm{Te}=16 \mathrm{~h} \\
\mathrm{~T}=25^{\circ} \mathrm{C}\end{array}$ & 106 & $\begin{array}{l}\text { Demirbas e } \\
\text { Nas (2008) }\end{array}$ \\
\hline $\begin{array}{l}\text { Reactive } \\
\text { Blue } 21\end{array}$ & Zeólita clinoptilolite & $\begin{aligned} \mathrm{Te} & =90 \mathrm{~min} \\
\mathrm{~T} & =25^{\circ} \mathrm{C}\end{aligned}$ & 10 & $\begin{array}{l}\text { Sismanoglu } \\
\text { et al. (2010) }\end{array}$ \\
\hline $\begin{array}{l}\text { Turquesa } \\
\text { Remazol }\end{array}$ & $\begin{array}{l}\text { Mesocarpo e } \\
\text { epicarpo de } \\
\text { Babassu }\end{array}$ & $\begin{array}{c}\mathrm{Te}=20-\text { mesocarpo; } \\
60 \mathrm{~min}-\text { epicarpo } \\
\mathrm{T}=25^{\circ} \mathrm{C}\end{array}$ & 1,5 e 2,3 & $\begin{array}{c}\text { Vieira et al. } \\
(2011)\end{array}$ \\
\hline
\end{tabular}

1- Capacidade máxima de adsorção segundo modelo de Langmuir (mg/g); 2- Te = tempo de equilíbrio; 3-T temperatura 


\subsection{Setor têxtil no Brasil}

O Brasil tem o sexto maior parque têxtil do mundo, com mais de 30 mil empresas em toda a cadeia produtiva, que emprega 1,65 milhão de pessoas (Mariuzo, 2007).

Os principais polos têxteis do Brasil estão localizados nos estados de (a) São Paulo, no município de Americana, o maior polo têxtil do país; (b) Santa Catariana, no Vale do Itajaí como centro a cidade de Blumenau e (c), Pernambuco, nos município de Toritama, Caruaru e Santa Cruz do Capibaribe, o segundo maior polo têxtil do Brasil, formando o triângulo das confecções (Agência Estadual de Meio Ambiente e Recursos Hídricos, 2005).

O município de Toritama encontra-se localizado no agreste setentrional de Pernambuco e possui como principal atividade a indústria de confecções e lavanderias industriais. A região é responsável por aproximadamente de $14 \%$ da produção do país, com aproximadamente de 2 milhões de peças/ano, perfazendo um montante de 6 milhões de reais/ano (Agência Estadual de Meio Ambiente e Recursos Hídricos, 2005).

Por conta da atividade de lavagem de jeans é responsável pelo maior problema de poluição observada na região, sendo caracterizada pela grande geração de poluentes hídricos ( 50.000 a $300.000 \mathrm{~L} /$ dia), proveniente da etapa de tingimento das peças de jeans (Silva, et al., 2005; Monteiro et al., 2010).

\subsection{Efluentes têxteis}

O consumo diário de água de uma fábrica têxtil de médio porte com uma produção de cerca de $8000 \mathrm{~kg}$ de tecido por dia é cerca de 1,6 milhões de litros. $\mathrm{O}$ consumo de água específico para o tingimento varia de 30 - 50 litros por $\mathrm{kg}$ de tecido, dependendo do tipo de corante usado. O consumo total de água de tingimento de fios é de cerca de 60 litros por kg de fio (Kant, 2012).

A maioria dos corantes é comercializada na forma sulfatoetilsulfona $\left(\mathrm{SO}_{2} \mathrm{CH}_{2} \mathrm{CH}_{2} \mathrm{OSO}_{3} \mathrm{Na}\right)$. Para que ocorra a ligação do corante com a fibra, a forma reativa do corante (vinilsufona - $\mathrm{SO}_{2} \mathrm{CHCH}_{2}$ ) é gerada durante a etapa de tingimento pelo aumento do $\mathrm{pH}$ e temperatura. Sob essas condições o agrupamento vinilsufona reage formando uma ligação covalente com os grupos amino e hidroxila das fibras, levando a fixação do corante. Essa reação é representada pelas equações 1 e 2 (Wang et al., 2003).

$$
\begin{aligned}
& \mathrm{R}-\underbrace{\mathrm{SO}_{2}-\mathrm{CH}_{2}-\mathrm{CH}_{2}-\mathrm{OSO}_{3} \mathrm{Na}}_{\text {sulfatoetilsulfona }} \stackrel{\text { OH- }}{\longrightarrow} \mathrm{R}-\underbrace{\mathrm{SO}_{2}-\mathrm{CH}=\mathrm{CH}_{2}}_{\text {vinilsulfona }}+\mathrm{Na}_{2} \mathrm{SO}_{4} \\
& \mathrm{R}-\mathrm{SO}_{2}-\mathrm{CH}_{2}=\mathrm{CH}_{2}+\mathrm{O}-\text { celulose } \stackrel{\mathrm{OH}-}{\longrightarrow} \mathrm{R}-\mathrm{SO}_{2}-\mathrm{CH}_{2}-\mathrm{CH}_{2}-\mathrm{O}-\text { celulose }
\end{aligned}
$$

O tingimento é um processo químico que pode ser contínuo ou descontínuo. O grau de fixação do corante ao tecido é de 50 a $90 \%$, o restante do rejeito vai para o efluente final. Essa perda é decorrente da possível reação do corante com a água, que hidrolisa o grupo vinilsufona e gera a forma hidroxietilsufona $\left(-\mathrm{SO}_{2} \mathrm{CH}_{2} \mathrm{CH}_{2} \mathrm{OH}\right)$ durante o tingimento, sendo incapaz de se ligar a fibra (Pearce et al., 2003).

Portanto o efluente final podem ocorrer concentrações dos corantes que variam de 5 a $1500 \mathrm{mgL}^{-1}$ (Gottilieb et al., 2003) em diferentes formas químicas, além de altas concentrações de sal e elevados valores de $\mathrm{pH}$ (11-13) (Epolito et al., 2005).

De acordo com Robinson et al. (2001), a água residuária proveniente de indústrias têxteis não são adequadamente tratadas em uma estação de tratamento de 
efluentes convencional, principalmente no que se relaciona a sua coloração pois o corante proveniente do tingimento não é degradado durante o curto tempo em que o efluente colorido permanece no tratamento primário e secundário. Assim faz-se necessário a aplicação de técnicas mais efetivas para a remoção destes corantes, uma vez que podem ser prejudiciais à saúde humana e à biota aquática.

\subsection{Processos de tratamento de efluentes têxteis}

Muitos processos têm sido estudados para o tratamento de efluentes têxteis. Os processos de tratamentos convencionais incluem: (1) processos físicos: sedimentação, decantação, filtração, centrifugação e flotação; (2) processos químicos: oxidação biológica e química, fotocatálize, filtração por membrana, troca iônica, radiação UV, eletroflotação, método de oxidação convencional por agentes oxidantes (ozônio), precipitação, irradiação ou processos eletroquímicos, adsorção entre outros; (3) processos biológicos: lodo ativado entre outros (Guaratini, 2000; Kunz, 2002; Lee, 2006).

Algumas vantagens e desvantagens dos principais métodos de tratamento de efluentes são mostrados na TAB. 3. Entre todos os métodos físico-químicos de descolorização de efluentes, a adsorção é uma das técnicas mais promissoras e efetivas na remoção de corantes.

TABELA 3: Vantagens e desvantagens dos métodos atuais para a remoção de corantes de efluentes na indústria têxtil

\begin{tabular}{|c|c|c|}
\hline Método & Vantagem & Desvantagem \\
\hline Reagente Fenton & Efetiva descolorização de corantes & Geração de lodo \\
\hline Ozonização & $\begin{array}{l}\text { Aplicado no estado gasoso: não há } \\
\text { alteração de volume }\end{array}$ & $\begin{array}{l}\text { Tempo de meia-vida } \\
\text { curto ( } 20 \text { min) }\end{array}$ \\
\hline Fotoquímico & Não há produção de lodo & Formação de produtos \\
\hline $\begin{array}{l}\text { Destruição } \\
\text { eletroquímica }\end{array}$ & $\begin{array}{c}\text { Destruição de compostos não } \\
\text { perigosos }\end{array}$ & Alto custo da eletricidade \\
\hline Carvão ativado & $\begin{array}{c}\text { Boa remoção de uma ampla } \\
\text { variedade de corantes }\end{array}$ & Alto custo \\
\hline Turfa & $\begin{array}{l}\text { Bom adsorvente devido a estrutura } \\
\text { molecular }\end{array}$ & $\begin{array}{c}\text { Baixas áreas de } \\
\text { superfície de adsorção }\end{array}$ \\
\hline $\begin{array}{l}\text { Lascas de } \\
\text { madeira }\end{array}$ & $\begin{array}{l}\text { Boa capacidade de sorção de } \\
\text { corantes ácidos }\end{array}$ & $\begin{array}{l}\text { Produção de lodo } \\
\text { concentrado }\end{array}$ \\
\hline Troca de íons & $\begin{array}{l}\text { Regeneração: não perde } \\
\text { adsorvente }\end{array}$ & $\begin{array}{c}\text { Não é efetivo para todos } \\
\text { os corantes }\end{array}$ \\
\hline Irradiação & $\begin{array}{c}\text { Oxidação efetiva em escala } \\
\text { laboratorial }\end{array}$ & $\begin{array}{l}\text { Requer muito } \mathrm{O}_{2} \\
\text { dissolvido }\end{array}$ \\
\hline
\end{tabular}

\subsection{Adsorção}

O termo sorção é uma expressão geral para processos que envolvem o acúmulo de substâncias que migram de uma fase para outra, principalmente quando a fase receptora for um sólido (Baldissarelli, 2008). Essa transferência ocorre de forma seletiva dos componentes da fase fluida para a superfície do sólido (adsorvente), ocorrendo apenas um fenômeno físico de separação, isto é, uma transferência de massa. Quando ocorre o contato entre as duas fases, o soluto (adsorbato) desloca-se por difusão do seio da fase fluida até a interface líquido-sólido devido à diferença de concentração entre a solução e a superfície do adsorvente. 
Após atingir à superfície, o soluto difunde-se por meio de dos microporos do adsorvente e finalmente é adsorvido pelos sítios ativos. A capacidade de remoção do soluto está relacionada com a área superficial disponível no material e com o tamanho da molécula do adsorbato (McCabe et al., 1985).

Alguns fatores podem afetam a adsorção, tais como a estrutura molecular ou natureza do adsorvente, a solubilidade do soluto, o $\mathrm{pH}$ no meio e a temperatura. Além desses fatores, o diâmetro molecular do adsorbato também afeta a adsorção. Compostos com diâmetro moleculares menores têm mais facilidade em difundir-se para o interior do sólido e consequentemente a adsorção é maior (Vasques, 2008).

Segundo Immich (2006), a adsorção tem sido considerada superior a outras técnicas para reuso de água em termos de custo inicial, flexibilidade e simplicidade de projeto, facilidade de operação, etc. Contudo, o primeiro passo, para um processo de adsorção eficiente é a escolha de um adsorvente com alta seletividade, alta capacidade e longa vida. Este deve também estar disponível em quantidades suficientes e a um baixo custo.

Os tratamentos por processos de adsorção encontram maior aplicação industrial do que outras técnicas, pois associam baixo custo a elevadas taxas de remoção. Além disso, em alguns casos, por não se tratar de um método destrutivo, possibilita a recuperação do corante sem perda de sua identidade química (Banat et al., 1996).

\subsection{Adsorventes de baixo custo}

Os materiais adsorventes são substâncias naturais ou sintéticas com estrutura cristalina, cuja superfície interna dos poros é acessível a uma combinação seletiva entre o sólido e o soluto (Magdalena, 2010).

Atualmente, o material que apresenta maior capacidade de adsorção, sendo amplamente utilizado para o tratamento de efluentes, é o carvão ativado. Entretanto, devido às perdas durante o processo de recuperação do adsorvente sua utilização tornase onerosa.

Assim, existe um crescente interesse pela busca de materiais alternativos de baixo custo que possam ser utilizados como adsorventes em substituição ao carvão ativado.

Outros materiais são empregados como adsorventes em processos de adsorção. Na maioria das vezes, o uso destes adsorventes alternativos visa à diminuição do custo do processo e a utilização de materiais abundantes provenientes de resíduos industriais e agrícolas ou naturais (Baldissareli, 2006). O enfoque será dado a zeólita, o qual foi alvo de estudos do presente trabalho.

\subsection{Cinzas de carvão}

De modo geral, cinzas de carvão constituem-se de um pó de grãos finos com propriedades pozolânicas (capacidade de reagir com cal em presença de água) e, sendo minerais aluminossilicatos, são compostos principalmente por partículas vítreas e esféricas constituídas tanto pela fase amorfa quanto pela fase cristalina (Querol et al., 2002).

Os principais minerais encontrados nas cinzas de carvão relatados em literatura e identificados por difração de raios $X$ são quartzo, hematita, magnetita, mulita, anidrita, entre outros (Ferret, 2004).

$\mathrm{Na}$ usina termoelétrica a base de carvão, um dos principais problemas ambientais ocasionados é a geração de cinzas, além dos aspectos relacionados à mineração, transporte, estocagem e beneficiamento do carvão. Apesar dos esforços da 
comunidade científica para o desenvolvimento de energias limpas e renováveis, a matriz energética mundial ainda é altamente dependente das fontes não renováveis e amplamente poluidoras (Lange, 2012).

As características físicas, químicas e mineralógicas das cinzas dependem de uma variedade de fatores, incluindo: a composição do carvão que lhes deram origem (precursor), as condições de combustão, do tipo e eficiência do sistema de controle de emissões, e os métodos de disposição utilizados (Ortiz e Teixeira, 2002). Consequentemente, é difícil generalizar acerca da composição das cinzas, ou sobre o seu comportamento no ambiente.

\subsection{Disposição e aplicação das cinzas de carvão}

Historicamente as cinzas de carvão produzidas principalmente do Sul do país tem sido dispostas em depósitos clandestinos (FIG. 1), chamados "bota-fora", sendo localizados acerca das fontes geradoras. Atualmente, os excedentes das cinzas nas cinco principais unidades geradores do Sul do país, depositam suas cinzas excedentes em minas abandonadas, aterros, lagoas de sedimentação bacias de decantação, a céu aberto, etc. (Rohde et al., 2006).
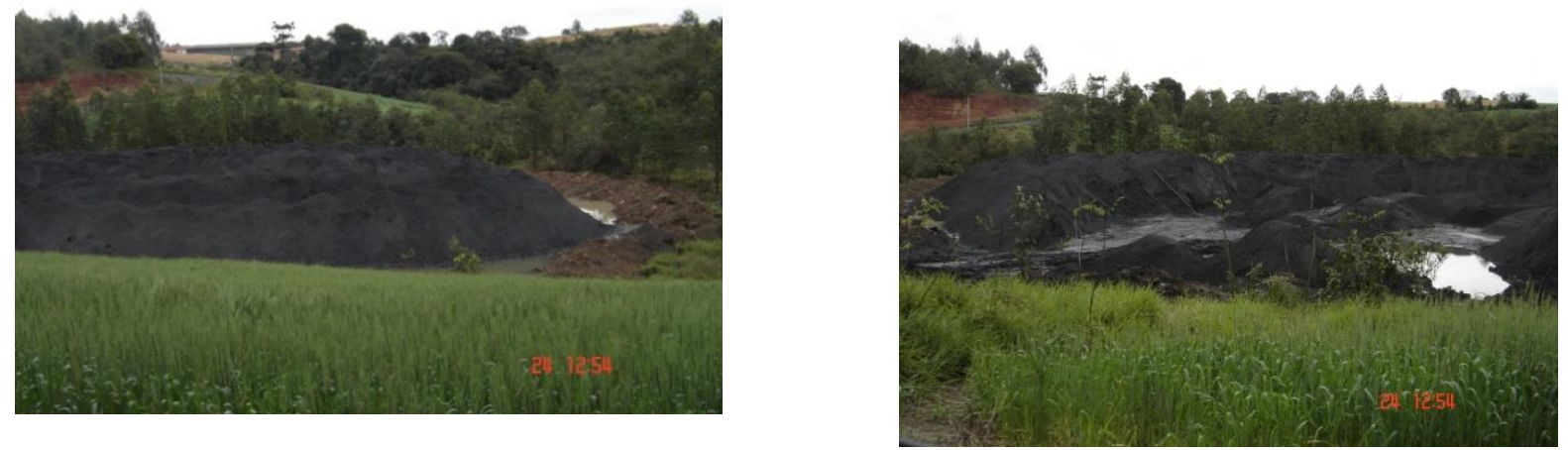

FIGURA 1: Depósitos de cinza de carvão a céu aberto na cidade de Figueira/PR.

A necessidade de retirar a baixo custo as cinzas geradas na usina fez com que fossem adotadas práticas de disposição em áreas impróprias e sem medidas de proteção necessária (Binotto et al., 2000). As cinzas de carvão se forem dispostas de maneira inadequada a céu aberto podem causar impacto ambiental no solo e nas águas subterrâneas e superficiais devido à lixiviação de elementos tóxicos presentes em sua composição. Em virtude das cinzas de carvão (principalmente as da usina termelétrica de Figueira) conterem altos teores de alguns elementos tóxicos (tais como: $\mathrm{As}, \mathrm{Hg}, \mathrm{Pb}$, e Cd) e estes serem facilmente lixiviados pela água, deve-se ter um rigoroso critério para a sua deposição (Depoi et al., 2007).

A radioatividade de carvão e cinzas da Usina de Figueira/PR a carvão foi investigada por Flues et al. (2006). O carvão desta usina apresenta alta concentração de urânio quando comparado com outros carvões no Brasil. A avaliação radioativa do carvão e cinzas mostrou concentrações acima da média mundial de urânio série, principalmente para ${ }^{210} \mathrm{~Pb}$. Os mesmos fatores de enriquecimento foram observados para ${ }^{238} \mathrm{U},{ }^{226} \mathrm{Ra}$ e ${ }^{232} \mathrm{Th}$. De acordo com a Diretriz Brasileira CNEN-NN 4.01 a usina de Figueira é classificada na categoria III devido aos níveis de radioatividade presente nas cinzas (10700 Bq. $\mathrm{kg}^{-1}$ ). Assim, é aconselhável avaliar o impacto ambiental da instalação.

Depoi et al. (2008) avaliaram e compararam a composição química do carvão e dos produtos da sua combustão (cinzas leves e pesadas) das usinas termelétricas localizadas em Figueira/PR, Capivari de Baixo/SC, Candiota/RS, São Jerônimo/RS e 
Charqueadas/RS. Nas amostras de cinzas da Usina Termelétrica de Figueira foram encontrados os teores mais elevados de elementos tóxicos principalmente de As, Cd, $\mathrm{Mo}, \mathrm{Pb}, \mathrm{TI}, \mathrm{U}, \mathrm{Zn}$ e Hg. Os estudos também demonstraram que os carvões brasileiros são mais ricos em cinzas e mais pobre em carbono quando comparados com os carvões de outras partes do mundo.

O trabalho realizado por Lewandowski e Kalkreuth (2009) mostrou as características químicas e petrográficas do carvão e as características químicas das cinzas leves e das cinzas pesadas da Usina Termelétrica de Figueira, PR. Resultados semelhantes à Depoi et al. (2008) foram encontrados.

Flues et al., (2008) estudaram as concentrações de metais e As no solo, devido à deposição de cinzas na usina de carvão em Figueira $(P R)$, avaliando os macroelementos ( $\mathrm{Al}, \mathrm{Ca}, \mathrm{Fe}, \mathrm{Mg}, \mathrm{Mn}, \mathrm{Ti}, \mathrm{V}$ ) e microelementos ( $\mathrm{As}, \mathrm{Cd}, \mathrm{Co}, \mathrm{Cr}, \mathrm{Cu}$ ). A atividade da termoelétrica a carvão de Figueira, sem filtros durante 35 anos, causou um incremento pequeno na concentração parcial para a maioria dos elementos químicos no solo próximo à usina. Este incremento ficou restrito a uma distância aproximada de $1 \mathrm{~km}$ da termoelétrica e preferencialmente na direção predominante dos ventos (NW) e na fração superficial do solo. Os elementos químicos considerados contaminantes do solo foram As, Cd, Mo, Pb e Zn. A alta concentração de As no solo poderá contribuir a longo prazo em risco ao ecossistema e à saúde humana.

Um estudo realizado por Silva e Boit (2010) de nanominerais e nanopartículas na produção de carvão e de cinzas pesada foi realizado para avaliar as implicações dos efeitos destes materiais na saúde humana. Notou-se que a toxicidade causada nos pulmões estava relacionada com o tamanho das partículas em suspensão e a presença de metais de transição, como por exemplo, o ferro. Os dados mostraram claramente que a população que vive em pelo menos, uma área de estudo (Santa Catarina, Brasil) foi exposta a um maior risco ambiental devido a usina movida a carvão. Assim, monitoramento a longo prazo é necessário em torno destas usinas para melhor quantificar as emissões destes poluentes individuais no mundo.

Magdalena (2010) estudou a adsorção de corante reativo remazol vermelho RB de solução aquosa usando cinzas de carvão e avaliou a toxicidade aguda com Daphnia similis. Os resultados da toxicidade aguda mostraram que o efluente obtido após o tratamento para remoção do corante com a cinza foi extremamente tóxico, causando uma mortalidade de $100 \%$ dos organismos.

Estudos realizados por Quispe et al. (2012) mostraram que as cinzas leves e as cinzas pesadas de carvão são constituídas por uma parte orgânica e uma inorgânica. A parte inorgânica é constituída principalmente por materiais amorfos, tais como partículas vítreas e esféricas, angulares e irregulares, e por materiais cristalinos. A fração orgânica contém carvão não queimado.

Cunico (2011) estudou a adsorção do corante Reativo Preto 5 em solução aquosa utilizando cinzas de carvão como adsorvente. Resultados toxicológicos com o organismos Daphnia similis mostraram que o efluente após tratamento para remoção de cor foi tóxico aos organismos.

O trabalho realizado por Silva (2011) avaliou a viabilidade da incorporação do lodo e das cinzas em uma massa utilizada na fabricação de tijolos ecológicos. As amostras de cinzas leve do filtro ciclone da usina termelétrica de Figueira (PR) e o lodo de estação de tratamento de água localizada no município de Terra Preta (SP) foram utilizadas no estudo. Tijolos de cinzas leve-lodo e cinzas leve-lodo-solo-cimento foram moldados e testados de acordo com padrões brasileiros. O tijolo de construção maciça, com a composição de $60 \%$ de solo, $12 \%$ de cimento, $8 \%$ de cinzas leves de carvão e $20 \%$ de tratamento de água de lodos mostraram os resultados mais satisfatórios em relação às exigências mecânicas e físicas (resistência à compressão e absorção de 
água) estipulados pela padrões brasileiros. A incorporação destes resíduos para a produção de tijolos é uma alternativa adequada para caminhos atuais de disposição.

Castro (2013) estudou a avaliação ecotoxicológica de percolados das colunas de cinza de carvão e de solos com cinzas provenientes da Usina Termelétrica de Figueira utilizando organismos teste como Daphnia similis. Os resultados apresentaram toxicidade aguda aos organismos teste. A concentração de As, Cd e fluoreto contribuíram para a toxicidade destes percolados.

Somente uma parcela das cinzas de carvão no Brasil é reaproveitada principalmente na indústria da construção civil e como material fertilizante. Estas aplicações ainda ocorrem em pequena escala ( 15 - 30\%) e sem aumento de uso previsto. O pequeno nível de consumo das cinzas de carvão é inevitável devido à combinação de custos altos de transporte com produto de valor relativamente baixo no mercado (Magdalena 2010).

Como alternativa, as cinzas de carvão podem ser vistas como um recurso inexplorado com grande potencial. Há, portanto, interesse na expansão de outras vias para a exploração comercial de cinzas de carvão, particularmente como um substituto de outros recursos.

Jha et al. (2008) fizeram uma revisão sobre o uso de cinzas de carvão em produtos de valor agregado tais como vidro, cerâmica, filtros, zeólitas e geopolímeros. Eles apontaram que ainda existe pouca informação sobre os potenciais impactos ambientais das impurezas presentes no produto final associado com as cinzas. Até que estas questões ambientais sejam abordadas, muitas ideias promissoras não podem ser totalmente implementadas devido às restrições regulatórias.

O principal esforço no sentido de mitigar os impactos ambientais decorrentes da disposição destes resíduos no meio ambiente é dirigido no sentido de ampliar as potencialidades de utilização, em particular, com a transformação das cinzas de carvão em um produto de alto valor agregado.

\subsection{Zeólitas}

As zeólitas podem ter origem sintética ou mineral, sendo que mais de cento e trinta tipos já foram sintetizados em laboratório, enquanto que na natureza encontra-se cerca de quarenta (Guisnet e Ribeiro, 2004). Dos quarenta tipos de zeólitas naturais conhecidas, somente sete destas ocorrem em quantidades suficientes para serem consideradas como fonte mineral viável (Zamzow et al., 1990). A produção de zeólitas sintéticas possibilita o ajuste exato de suas propriedades como dimensões dos cristais, composição, polaridade, entre outros (Guisnet e Ribeiro, 2004).

Zeólitas são constituídas por tetraedros do tipo TO4, onde "T" representa diferentes átomos, com predominância do alumínio e do silício, resultando nos tetraedros de alumina $\left(\mathrm{AlO}_{4}\right)^{-5}$ e sílica $\left(\mathrm{SiO}_{4}\right)^{-4}$, respectivamente, como ilustrado pela $\mathrm{FIG}$. 2 . Os átomos centrais são ligados tridimensionalmente aos átomos de oxigênio, onde cada oxigênio pertence a dois tetraedros. Essa configuração tetraédrica é chamada de "unidade primária de construção" (Gianetto, 1990; Kerr, 1989).

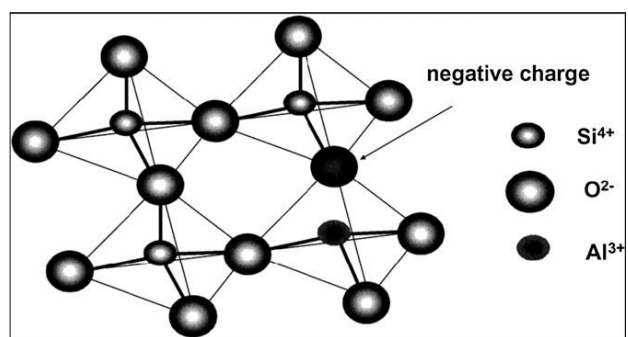

FIGURA 2: Exemplificação da estrutura de uma zeólita. (Fonte: Ahmaruzzaman, 2010) 
As redes tridimensionais formadas pelas unidades primárias de construção das zeólitas (tetraedros) leva a formação de unidades mais complexas, conhecidas como unidades secundárias de construção das zeólitas, que contém até 16T -átomos, tendose a formação de anéis simples ou duplos de quatro, seis ou oito tetraedros. A estrutura da zeólita é formada pelo conjunto destes anéis, fazendo com que estes materiais apresentem diferentes tipos de configuração estrutural, como canais e cavidades intermoleculares de dimensões moleculares variadas, nas quais se encontram os íons de compensação, moléculas de águas ou outros adsorbatos e sais (Paprocki, 2009).

De acordo com Shu et al. (1997) as características dos poros das zeólitas permitem a sorção de moléculas orgânicas de um dado tamanho e forma. Moléculas orgânicas com tamanhos maiores que as aberturas dos poros da zeólita podem ser adsorvidas somente na superfície e assim, adsorvidas com uma capacidade muito menor.

Estudos realizados por Shu et al. (1997) concluíram que quanto maior a razão $\mathrm{Si} / \mathrm{Al}$, maior a hidrofobicidade e maior a capacidade de adsorção frente à moléculas orgânicas. A capacidade de adsorção de moléculas orgânicas em solução aquosa não depende somente da estrutura química e física (tamanho e forma dos canais), mas também da competição entre o adsorbato orgânico e a água pelos sítios ativos das zeólitas.

Zeólitas são importantes trocadores de cátions inorgânicos. Atualmente, competem com resinas de troca iônica no processo de abrandamento de água e na purificação de efluentes e esgoto, além de mostram boa resistência a temperatura e radiações ionizantes, e excelente compatibilidade com o ambiente. São largamente utilizadas como adsorventes seletivos, como peneiras moleculares (como por exemplo, para retirar a umidade do ar) e como catalisadores, sendo sua propriedade de troca iônica empregada também como uma ferramenta para mudança de estrutura a fim de obter performances específicas (Corella, 1996).

\subsection{Síntese hidrotérmica}

As zeólitas de ocorrência natural possuem normalmente um teor elevado de impurezas, e/ou não possuem as propriedades necessárias ao seu uso, por isso, zeólitas começaram a ser sintetizadas.

Existe basicamente um único processo comercial de fabricação de zeólitas: o processo hidrotérmico, que é semelhante a um dos processos naturais de formação de zeólitas.

As cinzas são fontes de alumínio e silício, os quais são os principais elementos na composição das zeólitas, devido a isso, o alto conteúdo de fases reativas das cinzas e a granulometria fina das mesmas, são consideradas matéria-prima excelente para a síntese de zeólita (Querol et al., 2002).

Em 1985, estudos iniciais foram feitos por Höller e Wirsching (1985). Posteriormente, muitas patentes e artigos técnicos têm proposto diferentes métodos de ativação hidrotérmica para sintetizar diversos tipos de zeólitas a partir de cinzas leves (Henmi, 1987; Mondragon et al., 1990; Shigemoto et al., 1992, 1993, 1995; Kolousek et al., 1993; Bang-sup et al., 1995; Chang e Shih, 1995; Park e Choi, 1995; Querol et al., 1997, 2001; Singer e Bekgaut, 1995; Amrhein et al., 1996).

Dependendo das condições experimentais e da composição química da cinza utilizada, obtêm-se diferentes tipos de zeólitas. Os parâmetros mais importantes nos processos de zeolitização por processo hidrotérmico é a composição química da cinza, concentração e tipo de agente de ativação, a relação líquido/sólido, temperatura, tempo de reação e intensidade de agitação (Umanã, 2002) 
A síntese de zeólitas a partir de cinzas de carvão coletadas na Usina Termelétrica de Figueira (PR) e a utilização como material adsorvente têm sido avaliada. O material zeolítico mostrou-se eficiente nos seguintes casos: remoção de íons metálicos em água e em efluentes de galvanoplastia (Fungaro e Silva, 2002; Fungaro e Izidoro, 2004; Fungaro, 2004); remediação de solo contaminado com íon metálico (Fungaro et al., 2004), remoção de íons metálicos e azul de metileno em solução aquosa (Fungaro et al., 2005; Fungaro et al., 2009); tratamento de drenagem ácida de mina (Fungaro e Izidoro, 2006a; Fungaro, 2006); remoção de íons metálicos em solução aquosa (Fungaro e Izidoro, 2006b; Izidoro e Fungaro, 2007; Fungaro e Izidoro, 2008; Izidoro, 2008); remoção de azul de metileno de solução aquosa (Bruno, 2008; Fungaro e Bruno, 2009a , 2009b); remoção de zinco em solução aquosa usando compósito de zeólita: óxido de ferro (Fungaro e Graciano, 2007); remoção de vermelho do congo em solução aquosa (Fungaro et al., 2009b); remoção de metais (Izidoro, 2008) e remoção de corantes (Bruno, 2008; Carvalho, 2010;Carvalho et al., 2011; Magdalena, 2010; Ferreira, 2011; Cunico et al., 2011; Bertolini, 2013).

\subsection{Zeólitas modificadas por surfactante}

Os surfactantes são compostos que possuem atividade na superfície da interface entre duas fases, tais como a água, óleo-água, e na superfície de sólidos. Também são conhecidos como agentes tenso-ativos. Tais compostos caracterizam-se por possuir duas regiões distintas na mesma molécula: uma região polar (hidrofílica) e outra região não-polar (hidrofóbica), como observado na FIG. 3

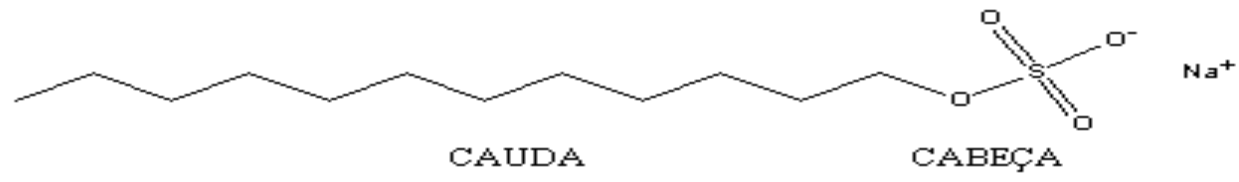

FIGURA 3: Estrutura do surfactante Dodecil Sulfato de Sódio (SDS): “cauda” hidrofóbica e "cabeça" hidrofílica

Os surfactantes catiônicos são a classe mais utilizada nas aplicações industriais, devido a seu baixo custo de manufatura e a sua ampla utilização em qualquer tipo de detergente (Tadros, 2005).

Uma das características comum a todos os surfactantes é a capacidade de formar agregados em solução aquosa a partir de uma determinada concentração. Estes agregados são denominados micelas. A concentração onde inicia o processo de formação das micelas (micelização) é chamada de concentração crítica micelar (cmc), que é uma propriedade intrínseca e característica do surfactante (FIG. 4).

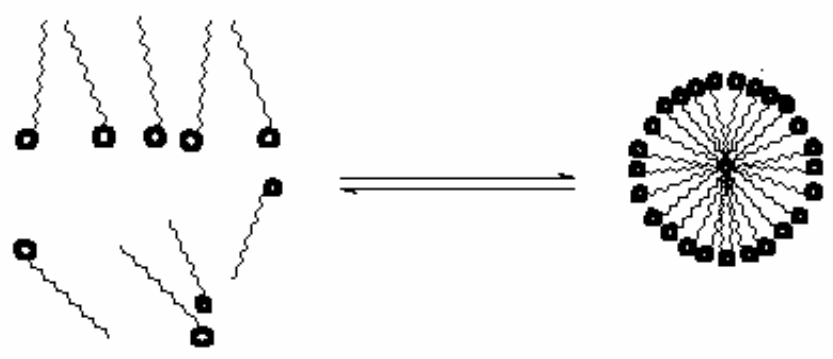

FIGURA 4: Ilustração do processo de micelização do surfactante em solução aquosa. Na CMC, os monômeros livres estão em equilíbrio com o surfactante micelizado. 
Uma das principais vantagens da zeólita é a possibilidade de adaptar as suas propriedades de superfície para aplicações específicas (Radovic e Rodrigués-Renoso, 1997; Rodrigués-Renoso, 1998). Esta abordagem tem sido utilizada nos últimos anos no campo de materiais de catálise de carbono (Pereira et al., 1999; Pereira et al., 1990).

As zeólitas possuem carga estrutural negativa resultante da substituição isomórfica de cátions na estrutura cristalina e, portanto, tem pouca ou nenhuma afinidade por espécies aniônicas. A propriedade de troca catiônica tem sido usada para modificar as propriedades superficiais de zeólitas naturais e sintéticas (Haggerly e Bowman, 1994; Li e Bowman, 1997; Li, 1998; Bowman, 2003; Ghiaci et al., 2004).

As aminas quaternárias, como o hexadeciltrimetilamônio, são surfactantes catiônicos de cadeia longa que possuem carga permanente positiva e, quando em contato com as zeólitas podem ser trocadas quantitativamente com os cátions da superfície externa formando uma estrutura de bicamada com propriedades de troca aniônica.

Quando uma zeólita é misturada com a solução de um surfactante catiônico em concentração menor do que a concentração crítica micelar (CMC), as moléculas catiônicas do surfactante formam uma monocamada na superfície externa da zeólita carregada negativamente via troca iônica, conforme FIG. 5a (Haggerly e Bowman, 1994; Li e Bowman, 1997).

Se a concentração do surfactante aumenta excedendo a CMC, então formase uma micela, a qual liga a si mesma em uma camada incompleta (FIG. 5b) e subsequentemente se rearranja para formar uma segunda camada sobre a primeira camada (FIG. 5c) via interação hidrofóbica entre as caudas do surfactante devido à forças coercivas fracas de Van der Waals. Devido a esta interação entre as caudas forma-se uma superfície carregada positivamente no material adsorvente. Estes grupos positivamente carregados da cabeça do surfactante são balanceados por contra-íons (por ex.: brometo, cloreto) que estão ligados fracamente e a adsorção de outros ânions presentes em solução ocorre por troca iônica.

(a)

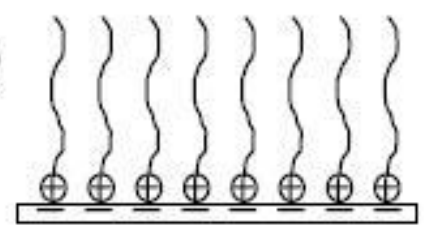

(b)

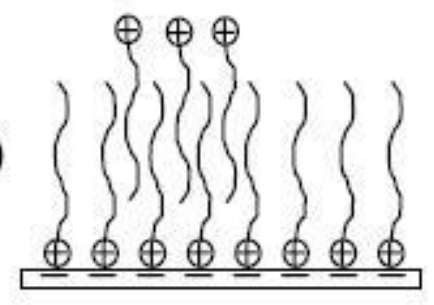

(c)

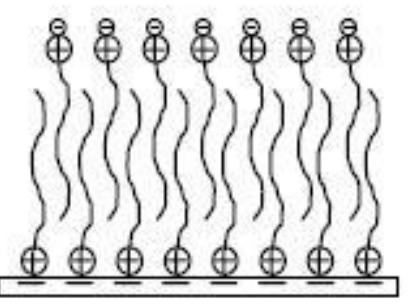

FIGURA 5: Adsorção de surfactante na superfície da zeólita como: (a) monocamada; (b) bicamada incompleta; (c) bicamada onde os ânions monovalentes contrabalanceiam a carga positiva dos grupos "cabeça" que apontam para fora. 
Os surfactantes possuem moléculas muito largas para entrar na estrutura de porosa interna da zeólita e, os sítios zeolíticos de troca internos permanecem disponíveis para adsorver íons catiônicos. Além do mais, a bicamada do surfactante aumenta o conteúdo de carbono orgânico total da zeólita por 5\% em massa tornando-se um meio similar a um solvente onde compostos orgânicos tendem a dissolver. Sendo assim, a zeólita modificada por surfactante é capaz de adsorver as três principais classes de contaminantes em água: ânions, cátions e moléculas orgânicas não-polar, simultaneamente, melhorando o custo-efetividade do produto.

Diversos estudos com zeólitas modificadas estão sendo investigados, entre os contaminantes alvos incluem: metais (Chutia et al., 2009; Li e Hong, 2009; Matijasevic et al., 2006), poluentes orgânicos (Sprynskyy et al., 2009; Zhang et al., 2007), corantes orgânicos em águas residuais e soluções aquosas (Ozdemir et al., 2009; Jin et al., 2008; Bertolini, 2013; Fungaro e Magdalena, 2012) e organismos patogênicos (SchulzeMakuch et al., 2003).

Estudos realizados por Cordoves, et al. (2008) mostraram a afinidade de sítio de ligação de uma clinoptilolita modificada por surfactante (SMZ). Os resultados mostraram a SMZ como um material heterogêneo com diferentes lugares de afinidade de ligação para $\mathrm{Cr}(\mathrm{VI})$. O equilíbrio de sorção sobre o $\mathrm{Cr}(\mathrm{VI})$ ocorreu em menos de 10 min em uma ampla faixa de $\mathrm{pH}$ (2-10), e o material mostrou alta capacidade de troca aniônica de $7,79 \mathrm{mg} \mathrm{g}^{-1}$ de $\mathrm{Cr}(\mathrm{VI})$. O Cr (III) não foi adsorvido pela zeólita modificada devido a sua superfície positivamente carregada e foi demonstrado que a melhor condição para a separação das espécies de cromo pode ser obtida quando a zeólita foi modificada com o HDTMA-Br

Kumar et al. (2007) estudaram zeólita-A modificada com HDTMA-Br e o brometo de tetrametilamônio (TBA-Br) para adsorver ânions de arsênio e cromo. A porcentagem de remoção aumentou com o aumento da concentração inicial de As, e para o cromo houve uma estabilidade na porcentagem com o aumento da concentração. A eficiência de remoção estava entre $75-77 \%$ para o As e de aproximadamente $75 \%$ para o $\mathrm{Cr}$. A concentração inicial de As reduziu de 1,15 - 0,203 $\mathrm{mgL}^{-1}$, indicando que as zeólitas modificadas podem ser um material promissor para a remoção desse ânion abaixo de $5 \mathrm{ppb}$. A zeólita modificada com HDTMA-Br foi mais seletiva para o cromo do que para o arsênio e o mecanismo de remoção proposto foi de troca iônica.

Kamble et al. (2008) estudaram a adsorção do fenol e o-clorofenol sobre peneiras moleculares constituídas de cinzas leves com superfície modificadas. A comparação da adsorção do fenol e o-clorofenol em zeólita-Y comercial, zeólita baseadas em cinzas leves (FAZ-Y) e zeólita a superfície modificada (SMZ-Y) foram estudadas. Observou-se que a adsorção de fenol sobre SMZ-Y foi de 4,05 e 3,24 vezes mais alta do que a FAZ-Y e zeólita-Y comercial, respectivamente. Para o o-clorofenol, a eficiência foi mais alta pelo fator de 2,29 e 1,8 para FAZ-Y e zeolita-Y comercial, respectivamente. A taxa de adsorção do fenol e $o$-clorofenol foi máxima em $\mathrm{pH}$ neutro. Os dados de equilíbrio de adsorção para o fenol e o-clorofenol foram analisados usando o modelo de isotermas de adsorção de Freundlich.

A adsorção do HDTMA-Br sobre quatro amostras de zeólita natural clinoptilolita (SMZ) foi investigada. Os materiais adsorventes foram utilizados para avaliar a remoção de nitrato e houve uma variação no desempenho de remoção. Os resultados mostraram que a SMZ preparada pelos EUA foram selecionadas e as zeólitas croatas foram mais eficientes na remoção de nitrato do que as duas zeólitas obtidas comercialmente da Austrália e China (Guan et al., 2010)

As capacidades de adsorção de zeólita modificada por surfactante para remover Laranja Reativo 16 de solução aquosa foi avaliada. A zeólita foi sintetizada a partir de cinzas leves de carvão e modificada com HDTMA-Br. Uma série de 
experimentos foi realizada para examinar os efeitos do tempo de contato, do $\mathrm{pH}$ da solução, e da massa do adsorvente na remoção de corante. Os resultados indicaram que a zeólita modificada foi mais eficiente na adsorção do corante em relação à zeólita não modificada (Fungaro et al., 2013)

Fungaro et al. (2014) utilizaram zeólita sintetizada a partir de cinzas ciclone não modificada (ZCA) e modificada com brometo de hexadeciltrimetilamônio (SMZCA) para a remoção da cor de efluentes reais coletados em indústrias. Os ensaios foram realizados em batelada. A ZCA não se mostrou adequada para o tratamento. A SMZCA apresentou eficiência de remoção da cor na faixa de $10-60 \%$ para efluentes têxteis e $39 \%$ para efluente de indústria de fabricação de corantes. Os valores de $\mathrm{pH}$ dos efluentes tratados estavam de acordo com a legislação Brasileira para descarte em corpos d'água.

Trabalhos descritos na literatura relatam o uso de zeólitas modificadas por surfactante no tratamento de efluentes contaminados em escala piloto.

Kartz et al. (2003) investigaram a utilização de zeólita natural modificada por surfactante (ZNMS) para remover BTEX (Benzeno, Tolueno, m-Xileno, o-Xileno, p-Xileno e Etilbenzeno) e outros contaminantes orgânicos de água produzida. Testes em batelada e em coluna de leito fixo foram realizados em escala de laboratório e em escala piloto. A ZNMS mostrou-se eficiente na remoção de BTEX em ambas as escalas e pode ser rapidamente regenerada. O sistema usando ZNMS foi considerado competitivo com outros tratamentos quanto aos custos e à parte operacional.

\subsection{Modelagem cinética}

O estudo da cinética de adsorção descreve a taxa de adsorção do soluto e, evidentemente, a taxa controle e o tempo de residência da adsorção do adsorbato na interface sólido-solução. Vários modelos cinéticos que estão disponíveis para compreender o comportamento dos adsorventes e para examinar o mecanismo de controle dos processos de adsorção. (Ho e McKay, 1998; Ozacar e Sengil, 2005).

Segundo Ho e Mckay (1999) é compreensível que calcular e entender os parâmetros cinéticos seja importante em processos de adsorção, pois além de descrever o tempo necessário para remover os contaminantes, a quantidade adsorvida e o tempo de residência do adsorbato na interface sólido-líquido, permite ainda calcular a velocidade de adsorção.

A velocidade de adsorção pode ser determinada por uma expressão de velocidade de pseudo primeira-ordem dada por Langergren para a adsorção em sistema líquido/sólido baseada na capacidade do sólido (Langergren, 1898).

A equação geral é expressa como:

$$
\log _{10}\left(q_{e}-q\right)=\log _{10} q_{e}-\frac{k_{1} t}{2,303}
$$

sendo $\mathrm{q}_{\mathrm{e}} \mathrm{e}$ q são as quantidades de corante adsorvida $\left(\mathrm{mg} \mathrm{g}^{-1}\right)$ no equilíbrio e no tempo $t$ ( $\min )$, respectivamente; $k_{1}$ é a constante de velocidade de adsorção $\left(\mathrm{min}^{-1}\right)$. As constantes $k_{1}$ e $q_{e}$ podem ser calculadas a partir da inclinação e intersecção da reta do gráfico $\log _{10}\left(q_{e}-q\right)$ em função de $t$, respectivamente.

Os dados cinéticos podem também ser analisados usando as cinéticas de pseudo segunda-ordem desenvolvida por Ho e colaboradores (Ho et al., 1996) onde a velocidade da reação é dependente da quantidade do soluto adsorvido na superfície do adsorvente e da quantidade adsorvida no equilíbrio.

O modelo linear de pseudo segunda-ordem pode ser representado por: 


$$
\frac{\mathrm{t}}{\mathrm{q}}=\frac{1}{\mathrm{k}_{2} \mathrm{q}_{\mathrm{e}}^{2}}+\frac{1}{\mathrm{q}_{\mathrm{e}}} \mathrm{t}
$$

sendo $\mathrm{k}_{2}$ é a constante de velocidade de pseudo segunda-ordem $\left(\mathrm{gmg}^{-1}\right.$ $\left.\min ^{-1}\right), q_{e}$ e q são as quantidades de corante adsorvida $\left(\mathrm{mg} \mathrm{g}^{-1}\right)$ no equilíbrio e no tempo $\mathrm{t}(\mathrm{min})$.

A partir das retas do gráfico de t/q em função de t, os valores das constantes $\mathrm{k}_{2}$ e $\mathrm{q}_{\mathrm{e}}$ podem ser calculados.

A constante $\mathrm{k}_{2}$ é usada para calcular a velocidade de adsorção inicial $h\left(\mathrm{mg} \mathrm{g}^{-1} \mathrm{~min}^{-1}\right)$, para $\mathrm{t} \rightarrow 0$, como segue:

$$
\mathrm{h}=\mathrm{k}_{2} \mathrm{q}_{\mathrm{e}}^{2}
$$

O mecanismo do processo de adsorção definitivo pode não ser obtido pelos modelos cinéticos descritos acima e, portanto, o modelo da difusão externa pode ser empregado.

Os modelos de pseudo primeira-ordem e pseudo segunda-ordem consideram as etapas de adsorção, mas não fornecem um mecanismo definitivo. Entretanto, é possível investigar qual etapa - transferência de massa externa, difusão externa ou difusão intrapartícula - é mais importante para a cinética do processo de adsorção utilizando outros modelos propostos baseados em difusão das espécies (Oliveira, 2007).

Após a transferência externa de massa inicial dá-se o transporte das moléculas do adsorbato na camada limite que circunda o adsorvente - difusão externa e essa etapa dos processos de adsorção tem sido investigada segundo um modelo de Lee et al. (1999). Se a difusão externa é a etapa limitante da velocidade, tem sido demonstrado que a equação 6 pode ser aplicada com sucesso aos dados experimentais (Oliveira, 2007). O coeficiente de difusão externa $\beta\left(\mathrm{m} \mathrm{s}^{-1}\right)$ pode ser determinado a partir da inclinação da curva descrita pela equação 6 para $t=0$ :

$$
\begin{aligned}
& \ln \left(\frac{C_{t}}{C_{0}}\right)=-\beta \mathrm{St} \\
& \mathrm{S}=\frac{\mathrm{m} \mathrm{A}}{\mathrm{V}}
\end{aligned}
$$

Nessa equação, Co e Ct são as concentrações do soluto inicial e no tempo $t$ $\left(\mathrm{mgL}^{-1}\right)$ e $S$ é a área de superfície externa do material adsorvente $\left(\mathrm{m}^{2} \mathrm{~m}^{-3}\right)$. Os valores de S podem ser estimados pela equação (7), em que A é a área de superfície $\left(\mathrm{m}^{2} \mathrm{~g}^{-1}\right)$, $\mathrm{m}$ é a quantidade do adsorvente $(\mathrm{g})$ e $\mathrm{V}$ o volume total de solução $\left(\mathrm{m}^{3}\right)$.

\subsection{Isotermas de adsorção}

Os estudos de equilíbrio demonstram a capacidade do adsorvente e descrevem a isoterma de adsorção por constantes, cujos valores expressam as propriedades da superfície e afinidade do adsorvente (Ho et al., 2005).

As isotermas de adsorção fornecem informações sobre como o adsorvente efetivamente adsorverá as impurezas presentes e se a purificação desejada poderá ser obtida. Além disso, pode se ter uma estimativa da quantidade máxima de impurezas que será adsorvida e, ainda, é útil na avaliação econômica do uso de um determinado 
adsorvente e na remoção de um contaminante específico durante o tratamento de efluentes (Roostaei e Teze, 2004).

O equilíbrio é atingido quando a quantidade de soluto adsorvida sobre o solvente é igual à quantidade dessorvida. Quando o equilíbrio for atingido, as concentrações do soluto na fase líquida e na fase sólida permanecem constantes. A condição de equilíbrio é descrita por meio de de gráficos que relacionam a quantidade de soluto adsorvida com a concentração de soluto que permanece em solução no equilíbrio (Allen, 2003).

Giles et al. (1960) dividiram as isotermas de adsorção em quatro classes principais, de acordo com sua inclinação inicial e, cada classe, por sua vez, em vários subgrupos, baseados na forma das partes superiores da curva. As quatro classes foram nomeadas de isotermas do tipo S ("Spherical"), L (“Langmuir"), H ("High affinity") e C ("Constant partition") e estão apresentadas na FIG.6.
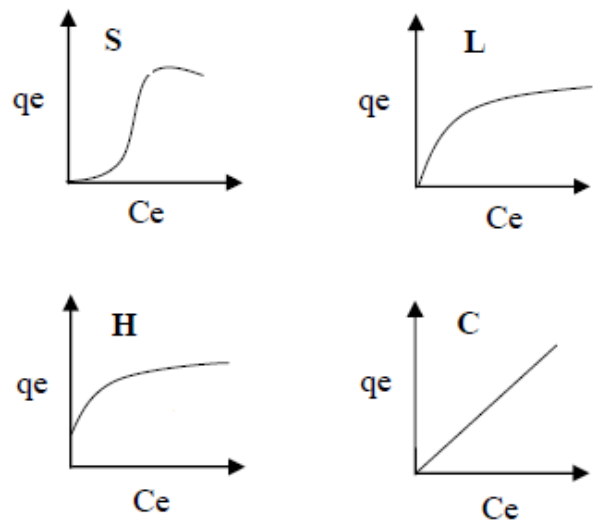

FIGURA 6: Classificação de isotermas de adsorção (Giles et al., 1960)

\subsubsection{Isoterma de Langmuir}

A equação de Langmuir é baseada em um modelo teórico e assume que a máxima adsorção ocorre em uma monocamada saturada com moléculas de adsorbato na superfície do adsorvente que é energicamente homogênea contendo um número finito de sítios idênticos (Namane, 2005). A formação da monocamada depende da suposição que as forças intermoleculares diminuem com a distância e com isso só deve ocorrer uma única camada de soluto adsorvido. O modelo assume energias uniformes de sorção na superfície e que não há transmigração do adsorbato no plano da superfície.

Segundo o modelo de Langmuir, a adsorção acontece em sítios específicos e igualmente disponíveis para a adsorção (Walker, 2001). Todos os sítios são equivalentes e a superfície é uniforme, uma molécula se liga a um sítio independentemente se os demais estão ocupados ou não. Teoricamente, o adsorvente tem capacidade finita pelo adsorbato (Özcan, 2004).

A expressão linear de Langmuir é:

$$
\frac{C_{e}}{q_{e}}=\frac{1}{Q_{o} b}+\frac{C_{e}}{Q_{o}}
$$

sendo $\mathrm{C}_{e}$ é a concentração do adsorbato no equilíbrio $\left(\mathrm{mgL}^{-1}\right), \mathrm{q}_{\mathrm{e}}$ a quantidade adsorvida no equilíbrio ( $\left.\mathrm{mg} \mathrm{g}^{-1}\right), \mathrm{Q}_{0}\left(\mathrm{mg} \mathrm{g}^{-1}\right)$ e b $\left(\mathrm{L} \mathrm{mg}^{-1}\right)$ as constantes relacionadas com a capacidade de adsorção máxima e a energia de adsorção, respectivamente. 
O gráfico linear de $\mathrm{C}_{e} / \mathrm{q}_{\mathrm{e}}$ em função de $\mathrm{C}_{\mathrm{e}}$ confirma a validade do modelo de Langmuir para o processo. A equação de reta obtida apresentará coeficiente angular correspondente a $1 / Q_{0}$ e coeficiente linear correspondente a 1/Qob.

\subsubsection{Isoterma de Freundlich}

A expressão da Isoterma de Freundlich é uma equação exponencial empírica que considera energias superficiais heterogêneas (Namane, 2005). Sendo a superfície heterogênea, os sítios de adsorção têm energias diferentes e por isso nem sempre estão disponíveis. A energia de adsorção sofre variação em função da cobertura da superfície (Walker, 2001).

A isoterma de Freundlich é usada para energias de superfície heterogêneas, onde o termo energia na equação de Langmuir varia como uma função da cobertura da superfície estritamente como um resultado das variações no calor de adsorção. Este modelo se aplica bem em dados experimentais de faixa de concentração limitada (Suzuki, 1990).

Este modelo descreve um processo reversível e não fica restrita a formação de uma monocamada (Özcan, 2004).

A forma linear da equação de Freundlich é dada pela equação:

$\log \mathrm{q}_{\mathrm{e}}=\log \mathrm{K}_{\mathrm{f}}+\frac{1}{n} \log C_{e}$

sendo $K_{f}\left[\left(\mathrm{mg} \mathrm{g} \mathrm{g}^{-1}\right)\left(\mathrm{L} \mathrm{mg}^{-1}\right)^{1 / \mathrm{n}}\right]$ e $\mathrm{n}$ são constantes relacionadas com a capacidade de adsorção e a intensidade de adsorção, respectivamente. Os valores de $\mathrm{K}_{\mathrm{f}}$ e $\mathrm{n}$ podem ser obtidos pela intersecção e inclinação do gráfico linear de log qe versus $\log \mathrm{C}_{\mathrm{e}}$. Segundo Helby (1952), o valor de $n$ entre 2 e 10 indica processo de adsorção favorável.

\subsubsection{Isoterma de Temkin}

Temkin (Temkin e Pyzhev, 1940) propôs um modelo em que são considerados os efeitos das interações indiretas entre as moléculas do adsorbato. O modelo de Temkin assume que: (i) $O$ calor de adsorção de todas as moléculas diminui linearmente com a cobertura, devido às interações adsorbato-adsorvente; (ii) A adsorção é caracterizada por uma distribuição uniforme de energias de ligação.

A forma linear da equação de Temkin é dada pela equação:

$$
\mathrm{qe}=\mathrm{B}_{\mathrm{T}}\left(\ln \mathrm{K}_{\mathrm{t}}\right)+\left(\ln \mathrm{C}_{\mathrm{e}}\right)
$$

sendo, $\mathrm{B}_{\mathrm{T}}$ é a constante que relaciona o calor de adsorção com o número de sítios, $\mathrm{K}_{\mathrm{T}}$ é a constante da isoterma de Temkin $\left(\mathrm{L} \mathrm{g}^{-1}\right)$ - constante de ligação de equilíbrio que corresponde a energia máxima de ligação, bt $\left(\mathrm{J} \mathrm{mol}^{-1}\right)$ é a constante de energia, $R$ é a constante universal dos gases $\left(8,314 \mathrm{~J} \cdot \mathrm{mol}^{-1} \cdot \mathrm{K}^{-1}\right)$.

\subsection{Estimativas do melhor ajuste}

A fim de aperfeiçoar o design de um sistema específico adsorbato/adsorvente para a remoção de corantes em efluentes é importante estabelecer a correlação mais adequada para os dados experimentais de equilíbrio (Ncibi, 2007).

Técnicas de otimização não lineares vêm sendo aplicadas para determinar os parâmetros de isotermas (Seidel e Gelbin, 1988; Seidel-Morgennstern e Guiochon, 1993). Assim, funções de erros foram definidas para permitir a otimização do processo e para determinar e avaliar os ajustes das equações das isotermas para os dados 
experimentais (Allen, 2002). As funções de erro adotadas nesse trabalho, assim como suas equações são mostradas na TAB. 4.

TABELA 4: Equações das funções de erro.

\begin{tabular}{|c|c|c|}
\hline Função de erro & Equação & \\
\hline $\begin{array}{l}\text { Erro Médio Relativo } \\
\text { (ARE) }\end{array}$ & $A R E=\frac{100}{N} \sum\left|\frac{\left(q_{\text {eexp }}-q_{\text {ecal }}\right)}{q_{\text {eexn }}}\right|$ & 11 \\
\hline $\begin{array}{c}\text { Estimativa do erro } \\
\text { da soma (SSE) }\end{array}$ & $\mathrm{SSE}=\sum\left(\mathrm{q}_{\mathrm{ecal}}-\mathrm{q}_{\mathrm{eexp}}\right)^{2}$ & 12 \\
\hline $\begin{array}{l}\text { Desvio Padrão } \\
\text { Percentual de } \\
\text { Marquard (MPSED) }\end{array}$ & MPSD $=100 \sqrt{\frac{1}{N-P} \sum\left|\frac{\left(q_{\text {eexp }}-q_{\text {ecal }}\right)^{2}}{q_{\text {eexp }}}\right|}$ & 13 \\
\hline $\begin{array}{l}\text { Função híbrida } \\
\text { fracionária } \\
\text { (HYBRID) }\end{array}$ & HYBRID $=\frac{100}{\mathrm{~N}-\mathrm{P}} \sum\left|\frac{\left(\mathrm{q}_{\text {eexp }}-\mathrm{q}_{\mathrm{ecal}}\right)^{2}}{\mathrm{q}_{\text {eexp }}}\right|$ & 14 \\
\hline $\begin{array}{l}\text { Soma dos erros } \\
\text { absolutos (SAE) }\end{array}$ & $\mathrm{SAE}=\sum\left|\mathrm{q}_{\text {ecal }}-\mathrm{q}_{\text {eexp }}\right|$ & 15 \\
\hline Qui-Quadrado $\left(x^{2}\right)$ & $X^{2}=\sum \frac{\left(q_{\text {eexp }}-q_{\text {ecal }}\right)^{2}}{q_{\text {ecal }}}$ & 16 \\
\hline
\end{tabular}

onde $\mathrm{N}$ é o número de pontos de dados experimentais, Qecal $(\mathrm{mg} / \mathrm{g})$ é a capacidade de adsorção calculada teoricamente em equilíbrio, Qeexp $(\mathrm{mg} / \mathrm{g})$ é a capacidade de adsorção em experimental no equilíbrio, $\mathrm{P}$ é o número de parâmetros em cada modelo de isoterma.

A avaliação do modelo de isoterma que for mais adequado para satisfatoriamente descrever o fenômeno da adsorção do sistema corante/adsorvente será baseada no valor mais alto de $R^{2}$ e nos valores mais baixos de ARE, SSE, MPSD, HYBRID, SAE e $X^{2}$.

\subsection{Testes de toxicidade e toxicologia dos corantes}

A avaliação dos efeitos biológicos de poluentes químicos baseia-se, principalmente, nos ensaios de toxicidade aguda e crônica. A letalidade e a imobilização em organismos jovens são os parâmetros mais usados nos ensaios de toxicidade aguda, que se caracterizam pela curta duração e esquema experimental simples. Os ensaios de toxicidade crônica por sua vez permitem a avaliação de efeitos adversos após exposições prolongadas a concentrações subletais dos contaminantes (Doust et al., 1994; Cooney, 1995).

Ensaios de toxicidade consistem em se expor organismos representativos durante um período de tempo determinado, à várias concentrações de uma ou mais substâncias e avaliar os efeitos causados.

Os resultados dos testes de toxicidade podem ser expressos por meio de valores de $\mathrm{CL}_{50}$, concentração de inibição, ou letalidade, à $50 \%$ dos organismos expostos e $\mathrm{CE}_{50}$, concentração efetiva que causa efeito à $50 \%$ dos organismos expostos.

Diferentes órgãos internacionais como, Environmental Protection Agency (US EPA), American Society for Testing and Materials (ASTM), Organization for Economic Cooperation and Development (OECD), vem buscando a padronização de ensaios de toxicidade com diversas espécies, que apresentam respostas diversas e significativas à compostos tóxicos, visando oferecer uma proteção ambiental mais abrangente (Aragão et al., 2008) 
Mais de $90 \%$ dos 4,000 corantes testados pela Ecological and Toxicological Association of Dyestuffs Manufacturing Industry (ETAD) apresentam altos valores de toxicidade. Vários corantes ácidos, básicos e diretos com agrupamento azo tem sido classificados como tóxicos para peixes, crustáceos, algas e bactérias (Novotny et al., 2005).

Pouco se sabe sobre os efeitos causados pelos corantes SN e ST pelas formas vinilsulfona e hidroxietilsulfona, assim como a exposição prolongada desse compostos. Além disso, ambos apresentam o agrupamento azo, que pode sofrer redução, e dependendo de sua estrutura, liberar compostos mutagênicos.

Nos últimos anos, regulamentações rigorosas têm sido estabelecidas em muitos países referentes ao descarte de efluentes coloridos. A legislação governamental está se tornando cada vez mais rigorosa, especialmente nos países desenvolvidos e em desenvolvimento, no que diz respeito à remoção de cor dos efluentes industriais.

No Brasil, o Conselho Nacional do Meio Ambiente (CONAMA) estabelece pelas Resolução $n^{\circ} 357$ e $n^{\circ} 430$ que não é permitida a presença, em corpos de água das classes 1,2 e 3 , de corantes provenientes de fontes antrópicas que não sejam removíveis por processos de coagulação, sedimentação e filtração convencionais, assim como sobre a classificação dos corpos d'água e diretrizes ambientais para seu enquadramento e padrões toxicológicos dos efluentes. A Resolução SMA $n^{\circ} 3$ de 22/2/2000 determina que o efluente não deverá causar ou possuir potencial para causar efeitos tóxicos aos organismos aquáticos no corpo receptor.

\subsection{Organismos teste}

A toxicidade é uma propriedade que reflete efeitos adversos que uma substância pode causar a um determinado organismo. A intensidade dos efeitos dependerá da concentração e propriedade químicas da substância, assim como da sensibilidade do organismo teste e tempo de exposição. Assim, é recomendável que o efeito tóxico de uma sustância seja avaliada com organismos teste de espécies diferentes e preferencialmente de níveis tróficos diversos (Costa et al., 2008).

Assim, as diferentes características biológicas entre as espécies de organismos teste refletem como esses organismos respondem a uma sustância tóxica a uma dada concentração, isto é, diferentes espécies têm sensibilidades diferentes (Posthuma et al., 2002)

Os organismos Ceriodaphnia dubia são pertencentes à Classe Cladocera. São encontrados em ambientes dulcícolas e rios e fazem parte do zooplâncton, sendo importante na cadeia alimentar. A sua importância ecológica constitui um dos fatores pelos quais são utilizados em ensaios de toxicidade, além de serem organismos facilmente cultivados em laboratório e apresentam sensibilidade a diversas classes de compostos químicos (Zaggato e Bertoletti, 2006).

A planta Lemna minor (Monoecia, Diandria) é utilizada como organismo teste no monitoramento de produtos químicos e efluentes, que apresentam uma vantagem adicional de detectar até mesmo uma ampla gama de poluentes estimuladores. Lentilhas d'água, tais como Lemna, são utilizadas em testes fitotoxicológicos principalmente pela sua ampla disseminação, crescimento e reprodução rápidos (Greenberg et al., 1992; Becker et al., 2002; Sharma et al., 2006).

O organismo bentônico Chironomus tepperi foi selecionado como organismo teste, pois larvas de Chironomus tendem a viver em ou nos sedimentos e, portanto, estão expostas a substâncias tóxicas nos mesmos (Burton, 1991). Chironomus tepperi (Diptera, Chironomidae) é encontrado em todo continente australiano, podendo também ser facilmente cultivados em laboratório, e, além disso, ocorre em habitats contaminados por metais. 
Chironomus tem ciclo de vida que duram em média 13 dias e possuem 4 estágios: ovo, larva, pulpa e adulto, com grande sobrevivência em todos os estágios larvais (Fonseca, 2004).

\subsection{Testes preliminares e de sensibilidade}

Para assegurar a viabilidade dos resultados obtidos nos ensaios realizados com organismos teste, substâncias de referências são empregadas para estabelecer uma faixa de resultados aceitáveis para a sensibilidade dos organismos (Zaggato et al., 2006). Dentre as substâncias de referências empregadas estão: dicromato de potássio, sulfato de cobre, sulfato de zinco, cloreto de cádmio, nitrato de chumbo, cloreto de mercúrio, sulfato de níquel, cloreto de sódio, cloreto de amônio, cloreto de potássio e fenol (Zaggato et al., 2006).

Seguindo as normas internas dos laboratórios de ecotoxicológica da Commonwealth Scientific and Industrial Research Organization (CSIRO) Austrália, testes de sensibilidade, ou controle positivos, foram realizados juntamente a cada teste com os corantes ou adsorventes para os organismos $L$. minor e $C$. tepperi. Para o organismo $C$. dubia, os testes foram realizados ou juntamente a cada teste ou semanalmente, se mais de um teste agudo foi realizado na mesma semana.

Testes preliminares foram realizados com os corante SN e ST e suas formas hidrolisadas SNH e STH, a fim de avaliar a toxicidade ou não dessas substâncias, assim como para identificação das concentrações que poderiam causar efeito tóxico a cada organismo teste. 


\section{MATERIAL E MÉTODO \\ 4.1 Locas de amostragem}

As cinzas de carvão foram amostradas na Usina Termelétrica de Figueira, localizada em Figueira, no norte do Estado do Paraná. A usina tem capacidade de geração de energia elétrica de $20 \mathrm{MW}$ e está em operação há aproximadamente 48 anos. Em 2009, a termoelétrica de Figueira queimou 78 mil ton. de carvão em um ano e foram geradas 19,5 ton. de cinzas no total, sendo que as cinzas do filtro ciclone e manga foram $12 \%$ e $84 \%$ do total gerado, respectivamente.

\subsection{Amostras de cinza de carvão 4.2.1 Cinzas leve de carvão}

As cinzas leve foram coletadas, pelos funcionários da usina, em filtro do tipo manga que retêm as frações dos grãos das cinzas antes de serem liberados para a atmosfera pela chaminé. O filtro manga retém as partículas com dimensão inferior a 0,10 $\mathrm{mm}$, sendo que $50 \%$ possuem diâmetro de $0,01 \mathrm{~mm}$. As cinzas leve do filtro de mangas lote 7, identificadas por serem do ano de 2007, foram denominadas nesse estudo de CL e foram usadas como matéria-prima na síntese da zeólita leve e zeólita leve modificada com surfactante (ZL, ZLMS).

\subsubsection{Cinzas pesada de carvão}

As cinzas pesadas, também conhecidas como cinzas de fundo tem frações granulométricas menores que $2 \mathrm{~mm}$ e frações finas inferiores a 0,075 $\mathrm{mm}$. Esse tipo de carvão é coletado nos fundos das fornalhas. As cinzas pesadas do fundo de caldeiras (CP) foram usadas como matéria-prima na síntese da zeólita pesada e zeólita pesada modificada com surfactante (ZP e ZPMS).

\subsection{Materiais utilizados}

Todos os reagentes usados foram de grau analítico. Os corantes utilizados no

presente trabalho foram Solophenyl Azul Marinho BLE 250\% (SN) e Solophenyl Turquesa BRLE $400 \%$ (ST) foram selecionados como compostos modelo do presente estudo e ambos foram cedidos pela empresa HUNTSMAN Co. A solução dos corantes foram preparadas a partir das diluições de solução estoque com água bidestilada. As características gerais dos corante encontram-se no item 3.1.1. Os espectros de varredura se encontram-se nos ANEXOS A e B, respectivamente. O brometo de hexadeciltrimetilamônio (HDTMA-Br) utilizado para a modificação das zeólitas, tem marca da empresa Merk. Agitador mecânico com temperatura controlada Ética - Modelo 430, centrífuga Quimis microprocessada - modelo Q-225M, estufa Fanen Orion 515 e espectrofotômetro Cary IE - Variam foram utilizados. Os pHs dos corantes foram medidos com papel indicador de Merck e peagômetro MPA - 210.

Para os ensaios de ecotoxicidade e fitotoxicidade foram utilizados Microscópio Olympus SZX9, espectrofotômetro Shimadzu UV-26000 e Spectra Max M4 Plate Reader, Lamina flow work station HLF Series, centrifuga Sarvall RC3C Plus e para medição de oxigênio dissolvido (OD), pH e condutividade (EC) aparelho da marca Hatch. 


\subsection{Preparação das soluções dos corantes}

\subsubsection{Corantes na forma industrial}

As soluções dos corantes foram preparadas a partir de receitas empregadas nas lavanderias industriais, onde no processo de tingimento utiliza-se uma solução de corante e cloreto de sódio (sal comercial) diluído em água. Baseado no trabalho de Silva (2005) definiu-se que a concentração da solução do efluente final seria $30 \%$ das quantidades da receita industrial. Assim, o seguinte procedimento foi utilizado: foram pesadas $0,067 \mathrm{~g}$ de corante (ST ou SN) e 1,005 $\mathrm{g}$ de $\mathrm{NaCl}$. As amostras foram misturadas com $10 \mathrm{~mL}$ de água. A solução foi submetida à agitação até a dissolução total do sal e corante. Esta solução com concentração de $5 \mathrm{~g} \mathrm{~L}^{-1}$ foi usada como solução estoque dos corantes e outras soluções foram obtidas a partir de sua diluição (FIG. 7).

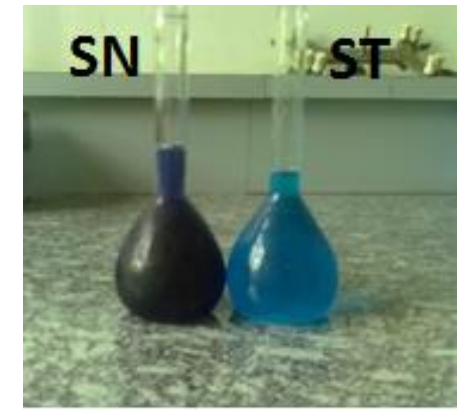

FIGURA 7: Corantes Solophenyl Navy (SN) e Solophenyl Turquesa (ST)

\subsubsection{Corantes na forma hidrolisada}

A fim de simular um efluente mais próximo ao real, contaminado por corante no processo de tingimento de tecidos com os corantes ST e SN, um processo de hidrólise foi realizado. A partir das soluções estoque $\left(5 \mathrm{~g} \mathrm{~L}^{-1}\right)$ de cada corante, o $\mathrm{pH}$ foi ajustado para $\sim 11-12$ adicionando-se $\mathrm{NaOH} 40 \%$. As soluções foram aquecidas em estufa entre 70 e $80^{\circ} \mathrm{C}$ por 90 min (Pinheiro, 2011). Após hidrólise, os corantes foram chamados de SNH, para Solophenyl Navy Hidrolisado e STH, para Solophenyl Turquesa Hidrolisado. Todos os corantes utilizados nesse estudos foram avaliados em suas concentrações reais, onde todas as concentrações foram medidas antes de cada testes, por meio de espectrofotômetro.

\subsection{Síntese}

\subsubsection{Síntese da zeólita a partir de cinzas leve e pesada de carvão}

Visando à preparação da zeólita por tratamento hidrotérmico alcalino foi utilizada a seguinte procedimento: $20 \mathrm{~g}$ de cinzas de carvão foram aquecidas em estufa à $90^{\circ} \mathrm{C}$, por $24 \mathrm{~h}$ com $160 \mathrm{~mL}$ de $\mathrm{NaOH} \mathrm{3,0} \mathrm{mol} \mathrm{L-1} \mathrm{(Henmi,} \mathrm{1987).} \mathrm{A} \mathrm{suspensão} \mathrm{foi} \mathrm{filtrada}$ em papel de filtro, o sólido repetidamente lavado com água deionizada até obter o $\mathrm{pH} 10$, e seco em estufa a $50^{\circ} \mathrm{C}$ por $12 \mathrm{~h}$. A solução de hidróxido de sódio produzida no processo de lavagem contém substâncias tóxicas provenientes da cinzas e, portanto pode ser encaminhada para tratamento posterior ou ser reutilizada, reduzindo o custo de sínteses posteriores. O produto zeolítico formado foi denominado zeólita leve (ZL), proveniente das cinzas leve e zeólita pesada (ZP) proveniente das cinzas pesadas.

\subsubsection{Síntese da zeólita de cinza de carvão modificada por surfactante}

Para a modificação da zeólita com surfactante, $20 \mathrm{~g}$ de ZL ou ZP foram adicionadas a $400 \mathrm{~mL}$ de solução aquosa de brometo de hexadeciltrimetilamônio 
(HDTMA-Br) 1,8 mmol L-1. A mistura foi agitada em Shaker por $7 \mathrm{~h}$ a $120 \mathrm{rpm}$ em temperatura ambiente. Após esse período a suspensão foi filtrada e o sólido levado a estufa para secagem por $12 \mathrm{~h}$ a $50^{\circ} \mathrm{C}$ (Fungaro e Borrely, 2012). Os materiais obtidos foram denominados zeólita leve modificada (ZLM) e zeólita pesada modificada (ZPM), como mostra a FIG. 8.

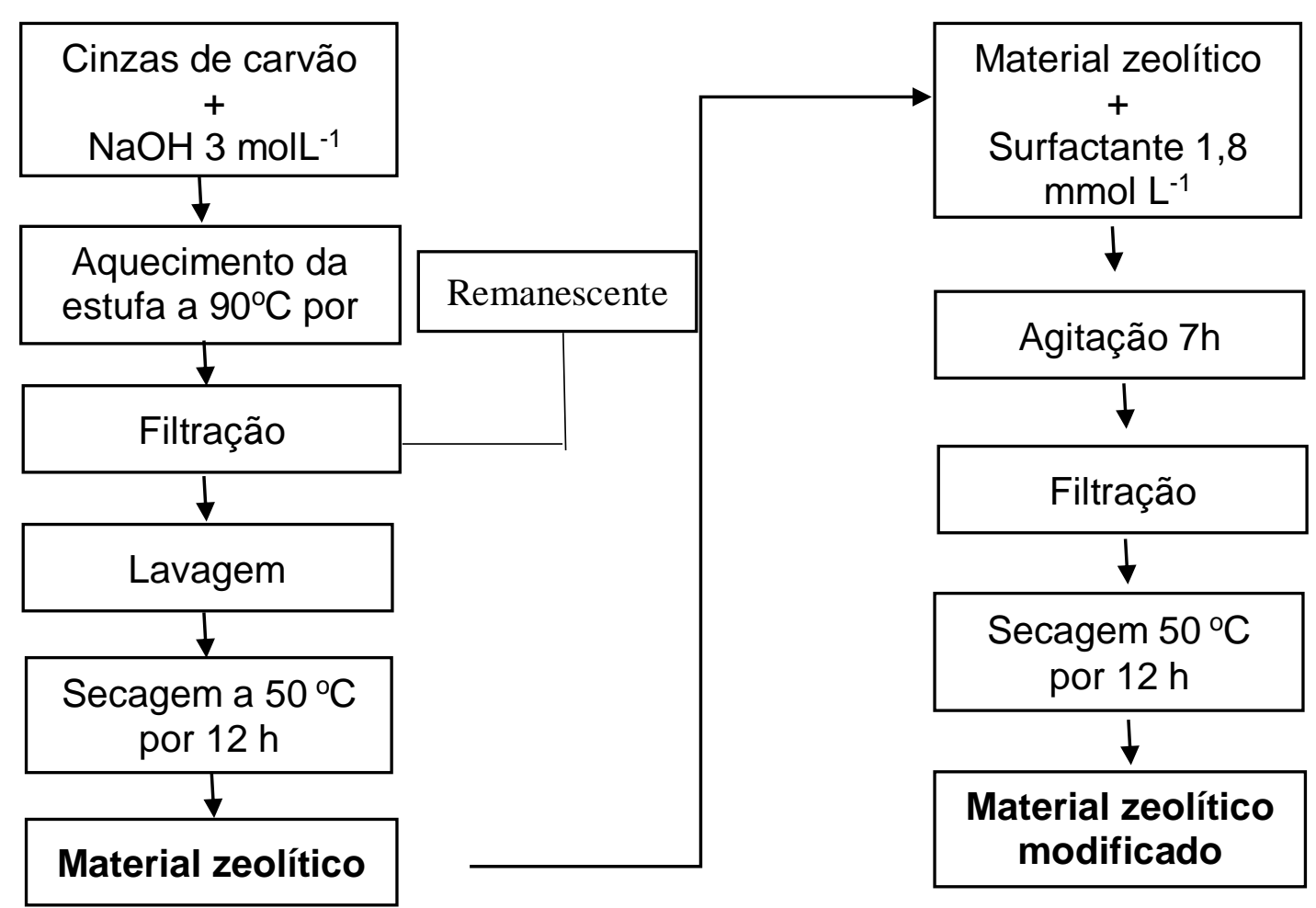

FIGURA 8: Fluxograma de síntese de zeólita método hidrotérmico alcalino e modificação a partir de cinzas de carvão

\subsection{Caracterização das cinzas de carvão e dos materiais adsorventes 4.6.1 Determinação do pH e condutividade}

O valor do $\mathrm{pH}$ da zeólita está relacionado com a sua habilidade de trocar os cátions $\mathrm{Na}^{+}$e/ou $\mathrm{K}^{+}$com $\circ \mathrm{H}^{+}$da água já que possui alta capacidade de troca catiônica. A capacidade de troca também contribui com a condutividade elétrica (CE) porque as zeólitas podem introduzir cátions na água que está sendo usada na medição da CE, assim, quanto maior a CE, maior a quantidade de íons introduzidos na água.

Para os ensaios de $\mathrm{pH}$ e condutividade, $0,25 \mathrm{~g}$ das amostras de cinzas e zeólitas foram colocadas em contato com $25 \mathrm{~mL}$ de água bidestilada. As misturas foram agitadas por $24 \mathrm{~h}$ em agitador mecânico (Ética - Mod. 430) a 120 rpm. Em seguida, as amostras foram filtradas e o pH (MS Tecnopon - Mod. MPA 210) e a condutividade (BEL Engineering - Mod. W12D) foram determinados (Umanã, 2002; Wang e Zhu, 2006).

\subsubsection{Determinação do ponto de carga zero}

O ponto de carga zero (PZC) é definido como o $\mathrm{pH}$ em que a superfície do adsorvente possui carga neutra. $\mathrm{O} P C Z$ foi determinado para os adsorventes avaliados nesse estudo (ZL, ZP, ZLM e ZPM) com o intuito de se verificar a partir de que pH a superfície do adsorvente muda de predominantemente positiva para negativa.

Os grupos funcionais tais como as hidroxilas dos óxidos existentes na superfície da zeólita podem ganhar ou perder prótons durante os tratamentos realizados 
ocasionando uma variação da carga líquida superficial com a variação do $\mathrm{pH}$. Em potenciais hidrogeniônicos abaixo do PZC os sítios superficiais estão protonados e a superfície carregada positivamente, enquanto que em $\mathrm{pH}$ acima do $\mathrm{PZC}$, os grupos ionizáveis perdem seus prótons e a superfície torna-se negativamente carregada.

O método de batelada foi empregada neste estudo para a determinação do ponto de carga zero (PZC). O procedimento consistiu em misturar $0,1 \mathrm{~g}$ do adsorvente com $50 \mathrm{~mL}$ de solução aquosa de NaNO3 $0,1 \mathrm{~mol} \mathrm{~L}^{-1}$ sob diferentes condições de $\mathrm{pH}$ inicial $(2,4,10,11,12,13)$ e determinar o pH final após $24 \mathrm{~h}$ de agitação no impulsor mecânico à $120 \mathrm{rpm}$ e temperatura ambiente. Os valores de $\mathrm{pHs}$ iniciais 48 foram ajustados pela adição de $\mathrm{HNO} 0,1,1$ e $3 \mathrm{~mol} \mathrm{~L}^{-1}$ ou $\mathrm{NaOH} 3 \mathrm{~mol} \mathrm{~L}^{-1}$. Os valores da diferença entre o $\mathrm{pH}$ inicial e final $(\Delta \mathrm{pH})$ foram colocados em gráfico em função do $\mathrm{pH}$ inicial. O ponto $x$ onde a curva intercepta o eixo y $=0$ é o valor do $\mathrm{pH}$ do PCZ.

\subsubsection{Capacidade de troca catiônica e capacidade de troca catiônica externa}

A adsorção de um surfactante catiônico sobre a superfície negativamente carregada da zeólita pode ser regida principalmente pela troca catiônica e pelas interações hidrofóbicas (Xu e Boyd, 1995). Nas zeólitas, as moléculas do surfactantes são muito grandes para entrar em seus poros e a adsorção fica limitada aos cátions trocáveis externos. Assim a capacidade de troca catiônica externa passa a ser um parâmetro importante na modificação (Taffarel, 2010).

Os estudos de Capacidade de Troca Catiônica (CTC) foram determinados por processo de duas etapas. A primeira etapa tem a finalidade de deslocar íons originalmente presentes nas cavidades dos adsorventes pelo $\mathrm{Na}^{+}$. $\mathrm{Na}$ primeira etapa, a amostra contendo $100 \mathrm{~mL}$ de solução de acetato de sódio $1 \mathrm{~mol} \mathrm{~L}^{-1}$ e $1 \mathrm{~g}$ de zeólita ou cinza foi agitada por $24 \mathrm{~h}$ em temperatura ambiente. Em seguida a suspensão foi filtrada, o sólido foi lavado com água destilada, recolhido e seco em estufa a $80{ }^{\circ} \mathrm{C}$.

$\mathrm{Na}$ segunda etapa, as amostras saturadas com sódio foram misturadas com acetato de amônio para provocar o deslocamento do $\mathrm{Na}^{+}$pelo $\mathrm{NH}_{4}$, assim, o sólido seco foi pesado e submetido à saturação com de acetato de amônio $1 \mathrm{~mol} \mathrm{~L}^{-1}$, mantendo a relação $0,01 \mathrm{~g} \mathrm{~mL}^{-1}$, por agitação durante $24 \mathrm{~h}$. A suspensão foi filtrada e no filtrado foi determinada a quantidade de sódio por absorção atômica (ICP-OES).

Para a determinação da Capacidade de Troca Catiônica Externa (CTCE), o mesmo procedimento da CTC foi utilizado, porém na segunda etapa foi usada solução de HDTMA-Br 0,9 mmol L-1 no lugar de acetato de amônio $1 \mathrm{~mol} \mathrm{~L}^{-1}$. A quantidade de íons sódio, expressa em $\mathrm{mgL}^{-1}$ foi convertida em unidades usuais de CTC, miliequivalentes-grama $\left(\right.$ meq $\left.^{-1}\right)$.

\subsubsection{Grau de hidrofobicidade}

O grau de hidrofobicidade da zeólita antes e após a modificação foi estimado de acordo com sua partição entre uma fase polar (água) e uma fase orgânica (hexano). A avaliação dessa propriedade é importante, uma vez que as interações existentes entre o corante, água e o adsorvente são determinantes nas taxas de adsorção. Assim, $1 \mathrm{~g}$ de zeólita ou zeólita modificada foram misturadas com $100 \mathrm{~mL}$ de água em um funil de separação. A mistura foi agitada manualmente por $3 \mathrm{~min}$. Adicionou-se $100 \mathrm{~mL}$ de hexano no funil e agitou-se manualmente por $3 \mathrm{~min}$. Após $5 \mathrm{~min}$ de repouso em suporte, a fase aquosa foi recolhida em um béquer e filtrada. $O$ sólido retido no papel de filtro foi seco ao ar e pesado (Taffarel e Rubio, 2010).

Calculou-se a massa do sólido transferido para a fase orgânica (morg) usandose a equação: 


$$
\mathrm{m}_{\mathrm{org}}=\mathrm{m}_{\mathrm{o}}-\mathrm{m}_{\text {aquo }}
$$

Em que $m_{\circ}(g)$ é a massa inicial do adsorvente e $m_{\text {aquo }}(g)$ é a massa do sólido que ficou retido no papel de filtro.

O grau de hidrofobicidade (\% em massa) foi calculado usando-se a equação:

$$
\text { Grau de Hidrofobicidade }=\frac{\mathrm{m}_{\mathrm{org}}}{\mathrm{m}_{0}}
$$

\subsubsection{Massa específica}

O volume e a massa específica dos materiais sólidos particulados são normalmente determinados pelo picnômetro de gás hélio, que penetra facilmente nos poros dos materiais. Assim, o volume verdadeiro da amostra é determinado.

A massa específica das cinzas e zeólitas de cinza de carvão, ou densidade real, foi determinada em picnômetro de hélio, no Centro do Combustível Nuclear (CCN) do Instituto de Pesquisas Energéticas e Nucleares (IPEN). Foi utilizado cilindro de gás hélio 4.5 (99,995\% de pureza).

A massa das amostras foram determinadas em balança analítica e serviu como dado de entrada nas condições de medida do equipamento, $\mathrm{O}$ equipamento utilizado era da marca Micromeritcs Instrument Corporation, modelo Accupyc 1330, de acordo com as seguintes condições de análise: número de purgas: 30 ; pressão de purga: 19,5 psig; número de repetições (corridas): 30; pressão de preenchimento: 19,5 psig; taxa de equilíbrio: 0,005 psig/min; porcentagem de variação: 0,05\%; temperatura de análise: $26,0^{\circ} \mathrm{C}$.

\subsection{6 Área específica}

A área específica é definida como a área da superfície externa das partículas por unidade de massa. A cinética dos processos de interação heterogênea "sólido-fluido" é dependente da área específica do sólido (Aguiar et al., 2002).

Para a determinação da área específica BET das cinzas de carvão e zeólitas, foi determinada pelo equipamento BET Surface Area Analyser, versão 3.11, QuantaChrome Corporation, Nova 1200. Onde, $1 \mathrm{~g}$ de cada amostra foi colocado primeiramente em porta-amostra e submetido ao desaseificador Nava 1000 Degasser, Modelo Nova 1000 para retirada de voláteis e umidade por um período de $12 \mathrm{~h}$ a $150^{\circ} \mathrm{C}$ no banho de areia. Em seguida, o porta-amostra foi retirado do sistema e inserido no equipamento de adsorção/dessorção. Houve então a adsorção de nitrogênio para garantir a atmosfera inerte, finalmente, a determinação foi feita por meio da adsorção e dessorção de nitrogênio nas amostras em condições de vácuo de $0,1 \mathrm{~mm} \mathrm{Hg}$. A massa específica e massa de cada amostra foram dados de entrada nas condições de medida do equipamento. Essa análise foi realizada no Centro de Ciência e Tecnologia dos Materiais (CCTM) do Instituto de Pesquisas Energéticas e Nucleares (IPEN).

\subsubsection{Difração de raios-X}

A difração de raios- $X$ é o método mais frequentemente utilizado para identificação de zeólita, que ocorrem principalmente como cristais (Ferreira, 1998). Assim as amostras de cinzas de carvão, zeólita de cinzas de carvão, zeólita modificada de cinzas de carvão e zeólita modificada saturada com SN e ST foram analisadas por sua composição mineralógica por um difratômetro de raios X Rigaku modelo Miniflex II 
com monocromador e com radiação Cu K-a, gerada a $30 \mathrm{kV}$ e $15 \mathrm{~mA}$, com velocidade de varredura de $0,5^{\circ} / \mathrm{min}$ e variação de 5 a $80^{\circ} 2 \Theta$.

A identificação das fases cristalinas se fez com auxílio dos padrões disponíveis no sistema International Centre for Diffraction Data / Joint Committee on Power Diffraction Standards (ICDD/JCPDS). Essa análise foi realizada no Centro de Ciência e Tecnologia dos Materiais (CCTM) do Instituto de Pesquisas Energéticas e Nucleares (IPEN).

\subsubsection{Fluorescência de raios-X}

A fluorescência de raios-X é uma técnica utilizada para a identificação e quantificação de elementos químicos em diversos materiais.

A composição química das amostras de cinzas de carvão e zeólitas de cinza de carvão foi determinada por fluorescência de raios $X$ (FR-X) O procedimento de preparação de amostra de zeólita utilizado para determinação dos elementos inorgânicos foi o de pastilha prensada de dupla camada, utilizando-se como aglutinante 8 gotas de uma solução de álcool polivinílico (PVA) $5 \% \mathrm{~m} / \mathrm{v}$ (Scapin, 2003). A amostra foi submetida em espectrômetro de fluorescência de raios X modelo RIX 3000, da marca Rigaku Company com sistema de dispersão de comprimento de onda (WDXRF). O método utilizado para determinação quantitativa foi de parâmetros fundamentais (FP) (Lanchance e Claisse, 1995; Buhrke et al., 1998; Scapin, 2003). Essa análise foi realizada no Centro de Química e Meio Ambiente (CQMA) do Instituto de Pesquisas Energéticas e Nucleares (IPEN).

\subsubsection{Microscopia eletrônica de varredura}

Para verificação da morfologia das cinzas e dos matérias zeolíticos utilizados nesse estudo, as amostras foram colocadas em suporte metálico e recobertas com uma fina camada de Au para torná-las condutora e gerar uma imagem de melhor resolução. O equipamento utilizado foi o microscópio eletrônico de varredura (MEV), modelo XL30, marca PHILIPS. Essa análise foi realizada no Centro de Ciência e Tecnologia dos Materiais (CCTM) do Instituto de Pesquisas Energéticas e Nucleares (IPEN).

\subsubsection{Espectroscopia no infravermelho}

A técnica de espectroscopia de infravermelho com transformada de Fourier (FTIR) foi usada para examinar as características estruturais principais das zeólitas antes e após a adsorção do corante e também a modificação por surfactante, sendo relevante para estudar a interação entre os grupos ativos do adsorbato e o absorvente. Os espectros em $\mathrm{KBr}$ foram feitos no espectrofotômetro Nexus 670 FTIR da Thermo Nicolet usando a técnica de disco prensado. Essa análise foi realizada no Centro de Ciência e Tecnologia dos Materiais (CCTM) do Instituto de Pesquisas Energéticas e Nucleares (IPEN).

\subsection{Estudos de adsorção}

O estudo da remoção dos corantes pelas zeólitas foi realizado utilizando-se processos descontínuos sob agitação.

Uma alíquota de $10 \mathrm{~mL}$ das soluções dos corantes com concentrações iniciais entre 16 à $31 \mathrm{mgL}^{-1}$ para SN e ST e de 16 à $30 \mathrm{mgL}^{-1}$ para SNH e STH, respectivamente, foram colocada com $0,10 \mathrm{~g}$ de ZLM e as suspensões foram agitadas à $120 \mathrm{rpm}$ por um intervalo de tempo de 5 à $120 \mathrm{mim}$. O sobrenadante foi separado por centrifugação por 
$3 \mathrm{mim}$ à $3000 \mathrm{rpm}$. Uma alíquota de $0,3 \mathrm{ml}$ do sobrenadante foi analisada por espectrofotometria UV-Visível $\left(\lambda_{\max }=535 \mathrm{~nm}\right.$ para ST e STH e $\lambda_{\max }=588 \mathrm{~nm}$ para SN e $\mathrm{SNH})$.

Para a ZPM, as concentrações variaram entre 6 à $17 \mathrm{mgL}^{-1}$. A mesma metodologia descrita para ZLM foi utilizada para a ZPM. Para os corantes na forma hidrolisada sob a ZPM, as concentrações variaram entre 6 e $15 \mathrm{mgL}^{-1}$ para ambos os corantes.

A concentração do corante adsorvido na fase adsorvente foi quantificada conforme a equação:

$$
\mathrm{q}=\frac{\mathrm{V}\left(\mathrm{C}_{0}-\mathrm{C}_{\mathrm{f}}\right)}{\mathrm{M}}
$$

em que $\mathrm{C}_{0}$ é a concentração inicial de corante $\left(\mathrm{mgL}^{-1}\right), \mathrm{C}_{\mathrm{f}}$ é a concentração final de corante $\left(\mathrm{mgL}^{-1}\right)$, V é o volume da solução de corante (L), M é a massa da zeólita (g). equação:

A eficiência de remoção em porcentagem $(R)$ foi calculada pela seguinte

$$
\mathrm{R}=\frac{100\left(\mathrm{C}_{0}-\mathrm{C}_{\mathrm{f}}\right)}{\mathrm{C}_{0}}
$$

em que $\mathrm{C}_{0}$ é a concentração inicial de corante $\left(\mathrm{mgL}^{-1}\right)$ e $\mathrm{C}_{f}$ é a concentração final de corante $\left(\mathrm{mgL}^{-1}\right)$.

Testes preliminares foram realizados com as amostras de CL e CP, que serviram de matéria-prima para a síntese das zeólitas, assim como para as ZL e ZP. As concentrações iniciais dos corantes foram de aproximadamente $22 \mathrm{mgL}^{-1}$ para SN e ST, sendo o tempo de agitação de 120 mim para ambos os corantes. Observou-se que para ambas as amostras após o tempo de agitação não houve remoção.

Para os corantes na forma hidrolisada as concentrações foram de 25 e 18 $\mathrm{mgL}^{-1}$ para SNH e STH, respectivamente, e não foi observada remoção após o tempo de equilíbrio.

\subsection{Isotermas de adsorção}

As isotermas de adsorção foram realizadas com amostras contendo $0,1 \mathrm{~g}$ de adsorvente em $10 \mathrm{~mL}^{-1}$ de solução dos corantes com concentrações que variaram de aproximadamente 11-53 $\mathrm{mgL}^{-1}$ para SN e ST pela ZLM e de aproximadamente $6-44 \mathrm{mgL}^{-}$ ${ }^{1}$ para ZPM, respectivamente. As amostras foram agitadas nos correspondentes tempos de equilíbrios determinados nos estudos cinéticos de cada corante.

Para os corantes na forma hidrolisada as concentrações iniciais variaram entre aproximadamente $10-61 \mathrm{mgL}^{-1}$ para SNH e STH pela ZLM e 6-41 $\mathrm{mgL}^{-1}$ para SNH e STH pela ZPM, respectivamente.

\subsection{Testes de toxicidade}

\subsubsection{Testes agudo com Ceriodaphnia dubia}

Os testes foram realizados de acordo com OECD Guideline for testing of chemicals 202 (2004). A linhagem de C. dubia foi cultivada no CSIRO, Austrália, pelo método padrão. $\mathrm{Na}$ TAB. 5 podem ser observados as condições utilizadas para realização dos ensaios, assim como a condição de manutenção das culturas.

Os ensaio de toxicidade foram realizados sob as mesmas condições ambientais controladas como utilizados para a cultura, e os organismos foram renovados e alimentados 3 vezes durante a semana. Parâmetros de qualidade de água de $\mathrm{pH}$, condutividade (EC), temperatura (T) e de oxigénio dissolvido (OD) foram medidas no início e no fim dos ensaios agudos. 
As concentrações que poderiam levar à imobilização de $50 \%$ dos organismos (CE/CL50) foram calculados a partir do número de organismos imobilizados por concentração da amostra e calculados estatisticamente com o programa Trimmed Spearman Karber (Hamilton et al., 1977).

Os resultados dos testes de sensibilidade se encontram no APÊNDICE C.

TABELA 5: Condições gerais utilizadas para os testes agudos com $C$. dubia e critérios de aceitabilidade

Tipo de ensaio
Número de organismos testélica
Número de réplicas
Volume da amostra
Água de diluição
Concentração das amostras
Recipiente do teste
Temperatura
Fotoperíodo
Alimentação
Duração do teste
Controle negativo
Controle positivo
Efeito avaliado
Critérios de aceitabilidade

\section{Estático}

5 com $24 \mathrm{~h}$ de idade

\section{4}

$10 \mathrm{ml}$

Agua reconstituída (uma mistura de $20 \%$ "Pierre" água mineral $+80 \%$ de água deionizada + vitamina B12 e selênio estoque) em pH 7,8 8,2 e condutividade de $180 \pm 20 \mathrm{mS} / \mathrm{cm}$ )

SN e ST- 0,1 à $200 \mathrm{mgL}^{-1}$

SNH e STH - 0,1 à $15 \mathrm{mgL}^{-1}$ com fator de diluição de $1: 2$

Béquer de $800 \mathrm{ml}$ para cultivo e $50 \mathrm{ml}$ para os testes

$25^{\circ} \mathrm{C} \pm 1^{\circ} \mathrm{C}$

16 de luz; 8h de escuro

Cultura de Selenstrum cultivadas em laboratório ( 200.000 células $/ \mathrm{mL}$ )

48 horas

Água de cultivo para C. dubia

Sulfato de Cobre

Mortalidade e/ou imobilidade

Mortalidade dos organismos no controle (água

de cultivo + organismos) não deve exceder $10 \%$

e a concentração de OD no final de cada teste

apresentou um valor de $\geq 3 \mathrm{mgL}^{-1}$.

\subsubsection{Testes com Lemna minor}

Os testes de fitotoxicidade foram realizados com a planta $L$ minor de acordo com o método padrão da OECD Guideline 221 (2002). Na TAB. 6 podem ser observados as condições utilizadas para realização dos ensaios, assim como a condição de manutenção das culturas.

Todo o material utilizado para cultura e renovação das culturas foram esterilizados previamente em autoclave à $121^{\circ} \mathrm{C}$. Tanto a cultura como a renovação das culturas foram realizadas em capela esterilizada "Laminar flow".

A solução de SIS, que é um meio rico em nutrientes, preparados de acordo com a OECD Guideline 221 (2004), cuja composição está apresentada no ANEXO A, foram previamente filtrada com filtros de seringa de $0,2 \mu \mathrm{M}$. 
TABELA 6: Condições gerais utilizadas para os testes agudos com L. minor e critérios de aceitabilidade

\begin{tabular}{|c|c|}
\hline Tipo de ensaio & Estático \\
\hline $\begin{array}{l}\text { Número de organismos teste } \\
\text { por réplica }\end{array}$ & 12 frondes entre $7-10$ dias \\
\hline Número de réplicas & 4 \\
\hline Volume da amostra & $100 \mathrm{ml}$ \\
\hline Água de diluição & Solução de SIS \\
\hline Concentração das amostras & $\begin{array}{l}\mathrm{ST}-400 \mathrm{mgL}^{-1} ; \mathrm{SN}-74 \mathrm{mgL}^{-1} \\
\text { STH- } 200 \mathrm{mgL}^{-1} \text { e SNH-76 mgL-1 com fator de } \\
\text { diluição } 1: 2\end{array}$ \\
\hline $\begin{array}{l}\text { Recipiente do teste } \\
\text { Temperatura }\end{array}$ & $\begin{array}{l}\text { Frasco de vidro de } 800 \mathrm{ml} \\
24 \pm 1^{\circ} \mathrm{C}\end{array}$ \\
\hline Fotoperíodo & Luz contínua \\
\hline Duração do teste & 7 dias \\
\hline Controle negativo & Solução de SIS \\
\hline Controle positivo & $\mathrm{KCl}$ \\
\hline Efeito avaliado & Número de frondes, biomassa e clorofila \\
\hline Critérios de aceitabilidade & $\begin{array}{l}\text { Taxa média de crescimento para o controle for } \\
\text { maior ou igual a } 0,28 / \text { dia (ou seja, o valor médio } \\
\text { para controles } \mu \geq 0,28 \text { ). Para um teste de } 7 \text { dias, } \\
\text { deve haver pelo menos um aumento de } 7 \text { vezes } \\
\text { no número de frondes desde início do teste }\end{array}$ \\
\hline
\end{tabular}

na TAB. 7.

Os parâmetros utilizados para cultura e renovação de L. minor se encontram

TABELA 7: Condições gerais utilizadas para cultura e renovação de L. minor

\begin{tabular}{ll}
\hline Temperatura & $24 \pm 1^{\circ} \mathrm{C}$ \\
Fotoperíodo & $16 \mathrm{~h}$ de luz, 8h de escuro \\
Recipiente das culturas & Fraco cônico de $500 \mathrm{ml}$ esterilizado \\
Volume da solução & $250 \mathrm{ml}$ de solução SIS estéril \\
Número de réplicas & 4 (mais uma antiga guardada até a próxima \\
& renovação) \\
Densidade de frondes iniciais & 12 frondes \\
em cada frasco & \\
Água de diluição & Solução SIS \\
Renovação & $14-21$ dias - período sem teste \\
& 7 dias - período de teste \\
\hline
\end{tabular}

Alguns estudos têm sido relatados que L. minor tem o potencial de servir como indicadores em estudos biológicos por conta de sua habilidade de absorver algumas substâncias em seus tecidos (Frick, 1985; Davis al., 2002; Marín and Oron, 2007). Por essa razão, observações biológicas para cada concentração como: clorose, necrose, descoloração amarela, tamanho anormal de frondes, destruição das colônias, destruição da raiz e perda da flutuabilidade, assim como parâmetros de qualidade da água, incluindo $\mathrm{pH}, \mathrm{OD}, \mathrm{EC}$ e $\mathrm{T}$ foram medidos ao final de cada teste.

O número de frondes foi contado utilizando o Software cellSens padrão $1.9 \mathrm{e}$ os frondes foram secos delicadamente em papel toalha e pesados. As análises estatísticas foram realizadas com o programa estatístico Excel da Microsoft, que calculou os valores de $\mathrm{CE}_{50}$ com base na redução de $50 \%$ das folhas após 7 dias de exposição. 
D.

\subsubsection{Extração de clorofila das amostras de L. minor}

Os experimentos de determinação de clorofila foram realizados em condições de semiescuro, tendo em vista que a clorofila é sensível a luz. Frondes de $L$. minor após a exposição com corantes foram separados por concentração, secos delicadamente em papel toalha e colocados em frascos individuais de cintilação. Para a extração da clorofila, $5 \mathrm{ml}$ de acetona $80 \%$, em temperatura de $5^{\circ} \mathrm{C}( \pm 2)$, foram adicionados aos frascos de cintilação que imediatamente foram colocados em uma caixa preta e levados a geladeira de 48 a $167 \mathrm{~h}$ no escuro a $5^{\circ} \mathrm{C}( \pm 2)$ (Geider e Osborne 1992)

Condições frias e escuras são muito importantes para a extração máxima dos pigmentos. Assim, os frondes devem estar completamente esbranquiçados antes das análises espectrofotométricas.

A absorbância da clorofila foi medida pelo espectrofotômetro Spectra Max M4 Molecular nos comprimentos de onda 470, 646, 663 e $750 \mathrm{~nm}$, e a quantidade de clorofila $A$, $B$ e carotenoides foi calculada usando as equações:

Chl-a $=12.25 x\left(\Delta \mathrm{A}_{663}-\Delta \mathrm{A}_{750}\right)-2.55 x\left(\Delta \mathrm{A}_{646}-\Delta \mathrm{A} 750\right)$

Chl-b $=20.31 \times\left(\Delta \mathrm{A}_{646}-\Delta \mathrm{A}_{750}\right)-4.91 \times\left(\Delta \mathrm{A}_{663}-\Delta \mathrm{A}_{750}\right)$

Caro $=\left(1000 \times \Delta \mathrm{A}_{470}-3.27 \times \mathrm{Chl}-\mathrm{a}-104 \times \mathrm{Chl}-\mathrm{b}\right) / 198$

em que, $\Delta \mathrm{A} \lambda=\Delta \lambda$ amostra- $\Delta \lambda$ branco, Chl-a correnponde a clorofila $\mathrm{A}, \mathrm{Chl}-\mathrm{b}$ a clorofila B e Caro aos carotenoides de cada amostra.

\subsubsection{Testes com Chironomus tepperi}

C. tepperi foi cultivado em aquários na CSIRO, Austrália, pelo método padrão (EPA, 2001). Na TAB. 9 pode-se observar as condições utilizadas para cultura do organismos teste.

Com relação à coleta de ovos dos tanques, de 4 a 6 massas de ovos foram colocados em cada béquer com $800 \mathrm{~mL}$ de água de controle aeradas juntamente com uma pequena quantidade de comida de peixe. Os béqueres foram cobertos com uma plástico filme a fim de evitar contaminação e reduzir a evaporação e foram mantidos numa sala de ambiente controlado a $22 \pm 1^{\circ} \mathrm{C}$ com 16:08 h de luz: fotoperíodo.

Após 48 horas, 6 béqueres foram renovados e 3 béqueres de cada concentração foram fixados em formal $10 \%$, para posterior medição. Após $96 \mathrm{~h}$ e $168 \mathrm{~h}$ o mesmo procedimento foi realizado para todas as concentrações e controle. Os animais não encontrados foram dados como mortos. Parâmetros de qualidade de água de $\mathrm{pH}$, EC, T e OD foram medidas no início e no fim dos ensaios.

Após 7 dias em formol, os animais fixados foram medidos no microscópio Olympus SZX9 com o software CellSens Standard 1.9. Os resultados dos controle positivos são encontrados no APÊNDICE D. 
TABELA 9: Condições gerais utilizadas para os testes e manutenção de $C$. tepperi e critérios de aceitabilidade

\begin{tabular}{|c|c|}
\hline Tipo de ensaio & Semi-estático \\
\hline Duração do testes & 7 dias \\
\hline Renovação das soluções & A cada $24 \mathrm{~h}$ \\
\hline $\begin{array}{l}\text { Número de organismos } \\
\text { teste por réplica }\end{array}$ & 5 organismos com 5 dias de vida \\
\hline Número de réplicas & 9 \\
\hline Volume da amostra & $25 \mathrm{ml}$ \\
\hline Água de diluição & $\begin{array}{l}\text { Agua reconstituída (uma mistura de } 20 \% \text { "Pierre" } \\
\text { água mineral + } 80 \% \text { de água deionizada + vitamina } \\
\text { B12 e selênio estoque) em pH } 7,8 \sim 8,2 \text { e } \\
\text { condutividade de } 180 \pm 20 \mathrm{mS} / \mathrm{cm} \text { ) }\end{array}$ \\
\hline Substrato artificial & Papel toalha lavado com etanol e agua Mili Q \\
\hline Alimentação & $\begin{array}{l}50 \mu \mathrm{L} \text { de comida de flocos de peixes a cada } \\
\text { renovação }\end{array}$ \\
\hline $\begin{array}{l}\text { Concentração das } \\
\text { amostras }\end{array}$ & $\begin{array}{l}\mathrm{SN}-39 \mathrm{mgL}^{-1} ; \mathrm{ST}-440 \mathrm{mgL}^{-1} \mathrm{com} \text { fator de diluição } \\
1: 2\end{array}$ \\
\hline Recipiente do teste & Béquer de $50 \mathrm{ml}$ \\
\hline Temperatura & $25^{\circ} \mathrm{C} \pm 1^{\circ} \mathrm{C}$ \\
\hline Fotoperíodo & 16 de luz; $8 \mathrm{~h}$ de escuro \\
\hline Duração do teste & 7 dias \\
\hline Controle negativo & Agua de cultivo de C. tepperi \\
\hline Controle positivo & Sulfato de Cobre \\
\hline Efeito avaliado & Sobrevivência e crescimento \\
\hline Critérios de aceitabilidade & $\begin{array}{l}\text { A mortalidade no controle não exceder } 20 \% \text { e ao } \\
\text { final do teste o OD estar em } 60 \% \text { do valor da } \\
\text { saturação do ar na temperatura utilizada e o } \mathrm{pH} \\
\text { estar entre } 6-9 \text { para todos os béqueres }\end{array}$ \\
\hline
\end{tabular}

\subsubsection{Testes crônicos "Spiked Water" com C. tepperi}

Este método envolve a adição de uma ou mais substâncias químicas em amostras de água de cultivo para a avaliação dos efeitos dos composto testado sobre os organismos expostos.

Para a realização destes testes, somente o corante SN foi utilizado, pois após testes com outros organismos conclui-se que esse corante apresentou maior efeito tóxico, apresentando assim maior impacto ao meio ambiente.

O cultivo de $C$. tepperi utilizado segue o mesmo descrito no item 4.9.3. As amostras de sedimento foram coletadas, por agentes treinados do CSIRO, no Rio Murray, na cidade de Adelaide, Sul da Austrália por conterem baixos níveis de contaminação antrópica e ser extensivamente estudado. As amostras foram mantidas em baldes selados em geladeira a $4^{\circ} \mathrm{C} \pm 2$, totalmente no escuro e foram previamente peneiradas com peneira padrão de $800 \mu \mathrm{m}$ para a retirada de qualquer resíduo orgânico (como folhas e gravetos) e utilizadas como substrato pra os animais durante os testes.

Os testes foram semi-estaticos e constituíram-se em duas partes: (1) crescimento/sobrevivência, com duração de 5 dias; (2) metamorfose, com duração de 10 dias, e segue os mesmos parâmetros descritos na TAB. 9

Uma alíquota de água foi retirada de cada concentração e do controle, no início e fim de cada teste para posterior análise química. Parâmetros de qualidade de água como pH, EC, T e OD foram medidas cada renovação. 
Os testes foram realizados em béqueres de vidro de $500 \mathrm{ml}$, previamente lavados com ácido. Cada béquer continha $140 \mathrm{~g}$ de sedimento que foi utilizado como substrato e $200 \mathrm{ml}$ de solução (água de cultivo + corante). As diluições foram feitas com um fator de diluição de 1:2 a partir de soluções estoque do corante na forma industrial, com concentrações variando de 1 à $80 \mathrm{mgL}^{-1}$. Todas as curvas de dose-resposta constituíram-se em pelo menos seis concentrações, cada uma com 10 réplicas além de controle, com 10 animais em cada béquer com 5 dias de idade e aeração constante.

Após 5 dias de exposição, primeira fase do teste, 4 béqueres de cada concentração foram selecionados e os organismos foram recuperados, contados e fixados em formol $10 \%$ para posterior medição. Os organismos não encontrados foram dados como mortos. Amostras de sedimento foram recolhidas em duplicata de cada concentração para posterior análise química.

A partir do dia 5, segunda fase do teste, os béqueres foram cobertos com uma tela a fim de que todas as larvas que se transformassem em mosquitos fossem contadas e separados por gênero. Os testes foram encerrados quando $80 \%$ das larvas se transformaram em mosquito no controle. No final desta fase, amostra de sedimentos foram recolhidas em duplicata, de cada concentração, para posterior análise química. anterior.

Os testes de sensibilidade seguiram a mesmo método descrito no item

\subsubsection{Testes crônicos "Spiked Sediment" com C. tepperi}

Este método envolve a adição de uma ou mais substâncias químicas em amostras de sedimento para a avaliação dos efeitos do composto testado sobre os organismos expostos.

As concentrações (de 1 à $80 \mathrm{mgL}^{-1}$ ) do corante SN foram adicionados aos sedimento, agitados em shaker por $24 \mathrm{~h}$ e encubados em geladeira a $4^{\circ} \mathrm{C} \pm 2$, totalmente no escuro por 7 dias. Após esse período os procedimentos seguidos foram os mesmos já descrito no item 4.9.3

A validação dos testes, assim como os testes de sensibilidade seguiram mesmo método descrita no item 4.9.3.

\subsection{Avaliação e identificação da toxicidade}

Com o objetivo de identificar quais substâncias estavam causando a toxicidade observada nas amostras, testes de Avaliação e Identificação da Toxicidade (AIT) fase I (USEPA, 2007) foram realizados. A abordagem AIT é dividido em três fases: caracterização; identificação e confirmação. O desempenho subsequente do bioensáio após cada manipulação comprova a redução ou não na toxicidade (EPA, 2007). A comparação da amostra manipulado com o original permite identificar os contaminantes ou de contaminantes responsáveis mistura dos efeitos adversos observados (Montero et al., 2013).

O método utilizado para os ensaios nos testes de AIT, antes e após manipulação das amostras, com $C$. dubia seguiu a mesma descrita no item 4.9.1. A metodologia para a preparação das amostras (corante+adsorventes) seguiu a mesma ordem descrita anteriormente (item 4.9.1).

Contudo a preparação das amostras para a identificação da toxicidade somente dos adsorventes (ZLM e ZPM) foi realizado agitando $1 \mathrm{~g}$ de cada adsorvente no tempo de equilíbrio encontrado para cada um. As amostras foram filtradas e os testes ecotoxicológicos realizados. As amostras após processo de adsorção foram chamadas de lixiviados, que partirão de uma concentração de 100\% (solução bruta, sem diluição). 


\subsubsection{Adição do agente quelante - EDTA}

De modo a reduzir a biodisponibilidade dos metais, $60 \mu \mathrm{L}$ de ácido etilenodiaminotetracético (EDTA) $1 \mathrm{gL}^{-1}$ foi adicionado em cada béquer com amostra e deixados em sala com temperatura ambiente para interagir durante $2 \mathrm{~h}$, antes de adicionar as neonatas de $C$. dubia.

\subsubsection{Extração em fase sólida}

Para a extração em fase sólida (SPE) foram utilizados colunas descartáveis com C18 da marca Waters Oasis ${ }^{8}$ HLB (6cc / $500 \mathrm{mg}$ ). Os testes foram realizados em um sistema a vácuo, onde as amostras dos corantes bruto passaram por meio de das colunas, a fim de reter compostos orgânicos não polares.

Os cartuchos utilizados foram ativados passando-se $10 \mathrm{~mL}$ de metanol $100 \%$, seguido de $10 \mathrm{~mL}$ de água Mili Q. O metanol e a água foram descartados e a seguiu-se a extração de um volume de $100 \mathrm{~mL}$ das amostras, por gotejamento contínuo e lento, para evitar a perda de substâncias por carreamento.

\subsection{Análises químicas dos testes de toxicidade}

Análises químicas foram realizadas para as amostras dos testes de toxicidade pela Analytical Chemist Unit, CSIRO (University of Adelaide - Austrália). Todas as amostras foram previamente filtradas $(0.45 \mu)$. As análises foram realizadas utilizando-se um sistema de cromatografia líquida com espectrometria de massa (HPLC-MS) (Thermo Surveyor com bomba de gradiente, mostrador automático e detector por arranjo de diodos - DAD) acoplado a um espectrômetro de massa Thermo LXQ Linear lon Armadilha com ionização por eletro-pulverização $(E S I+)$ e um detector de arranjo de diodos. As amostras foram filtradas por meio de de membranas de ultrafiltração (Millipore) com peso molecular de $50 \mathrm{kDa}$, antes da injeção no cromatógrafo. Um volume de $20 \mathrm{ml}$ da amostra foi injetado e a separação cromatográfica foi realizada utilizando uma coluna Hypersil GOLD (100 milímetros x 4,6 mm). Metanol/água (acidificada 1\%, v / v) foram utilizados como fase móvel com um fluxo de $0,4 \mathrm{~mL} \mathrm{~min}{ }^{-1}$. 


\section{5- RESULTADOS E DISCUSSÃO \\ 5.1 Caracterização dos adsorventes}

A primeira parte do presente estudo consistiu em caracterizar as cinzas leve e pesada da Usina Termoelétrica de Figueira, e suas respectivas zeólitas e zeólitas modificadas por surfactante.

\subsubsection{Determinação do pH e condutividade}

$\mathrm{Na}$ TAB. 10 estão listados os valores do $\mathrm{pH}$ e condutividade das cinzas de carvão leve $(\mathrm{CL})$ e pesada $(\mathrm{CP})$ e suas respectivas zeólitas e zeólitas modificadas.

TABELA 10: Valores de pH e da condutividade, em água, para a cinza leve (CL), cinza pesada (CP) e suas respectivas zeólitas: zeólita leve (ZL), zeólita pesada (ZP), zeólita leve modificada (ZLM) e zeólita pesada modificada (ZPM).

\begin{tabular}{ccc}
\hline Amostra & pH & Condutividade $(\boldsymbol{\mu S})$ \\
\hline CP & 8,1 & 190 \\
CL & 8,1 & 430 \\
ZP & 9,7 & 585 \\
ZL & 9,9 & 691 \\
ZPM & 8,9 & 612 \\
ZLM & 10 & 562 \\
\hline
\end{tabular}

Os resultados observados na TAB. 10 indicam que os valores de $\mathrm{pH}$ do lixiviado obtidos para todos os adsorventes estudados são de natureza alcalina. Esta alcalinidade é justificada pela presença de compostos formados pelos cátions de $\mathrm{K}+$, $\mathrm{Na}+, \mathrm{Ca}^{2+}$ e $\mathrm{Mg}^{2+}$ combinados com carbonatos, óxidos ou hidróxidos de (Paprocki, 2009). $\mathrm{O}$ aumento do $\mathrm{pH}$ no material zeolítico (ZL e ZP) observado pode ser atribuído ao tratamento hidrotérmico com solução de $\mathrm{NaOH}$. Depoi et al. (2008) e Cardoso (2012) encontraram valores de $\mathrm{pH}$ de 9,18 e 11,2 para cinza leve e zeólita leve, respectivamente, valores esses bem próximos ao encontrados nesse estudo.

Os valores de condutividade se relacionam com a presença de determinados elementos presentes nas cinzas de carvão como As, B, Ba, Cd, Co, Cr, Cu, Li, Mo, Se, $\mathrm{Sr}$, entre outros, que podem sofrer dissolução (Depoi et al., 2008). Os valores encontrados para a cinza leve foi superior ao das cinzas pesada. Pode-se atribuir esse comportamento a solubilidade das cinzas leve, que apresentam maiores níveis de solubilidade. Os níveis totais elevados de solubilidade dos elementos nas cinzas leves podem ser originados pelas maiores áreas de superfície e pelas maiores abundâncias de espécies condensadas que as mesmas apresentam (Silva et al., 2010).

As zeólitas deste estudo apresentaram valores de condutividade próximos ou maiores que os valores encontrados para as cinzas percursoras. Isso pode ser explicado pela presença de cátions trocáveis nas estruturas dos adsorventes sintetizados por tratamento hidrotérmico alcalino (Bertolini, 2013).

\subsubsection{Determinação do ponto de carga zero}

Para entender o mecanismos de adsorção é necessário determinar o ponto de carga zero $\left(\mathrm{pH}_{\mathrm{pcz}}\right)$ de um adsorvente. O ponto de carga zero ( $\left.\mathrm{PCZ}\right)$ é definido como o $\mathrm{pH}$ em que a superfície do adsorvente possui carga neutra. $\mathrm{O} \mathrm{pH}$ PCZ de adsorventes depende de vários fatores como natureza da cristalinidade, razão Si/Al, conteúdo de impurezas, temperatura, eficiência de adsorção de eletrólitos, grau de adsorção de íons 
$\mathrm{H}+$ e $\mathrm{OH}$-, etc. e, portanto, ele deve variar de adsorvente para adsorvente (Fungaro e Borrely, 2012).

A adsorção de cátions é favorecida em $\mathrm{pH}>\mathrm{pH} \mathrm{PCz}$, enquanto a adsorção de ânions em $\mathrm{pH}<\mathrm{pH}$ Pcz. A adsorção de várias espécies aniônicas e catiônicas sobre os adsorventes pode ser explicada pela competitividade da adsorção de íons $\mathrm{H}^{+} \mathrm{e} \mathrm{OH}^{-}$com os adsorbatos. Esta é uma comum observação em que a superfície adsorve favoravelmente ânions em $\mathrm{pH}$ baixo devido a presença de íons $\mathrm{H}^{+}$, ao passo que a superfície é ativada para a adsorção de cátions em $\mathrm{pH}$ alto devido a deposição de íons $\mathrm{OH}$ (Srivastava et al., 2006).

$\mathrm{O} \mathrm{pH}_{\mathrm{PCZ}}$ foi determinado para os materiais avaliados nesse estudo com 0 intuito de verificar qual a carga superficial que os mesmos apresentavam em água e a configuração das moléculas dos surfactantes sobre as zeólitas. Assim, os resultados para ZL e ZLM foram de 7,5 e 6,5, e para ZP e ZPM de 8,5 e 5 respectivamente.

Os valores de $\mathrm{pH}_{\mathrm{PZC}}$ das zeólitas $\mathrm{ZL}$ e $\mathrm{ZP}$ foram inferiores ao $\mathrm{pH}$ em água, indicando que a superfície da zeólita apresenta carga negativa em solução aquosa ( $\mathrm{pH}>\mathrm{pH} \mathrm{PCZ}$ ) para ambos os adsorventes. O mesmo comportamento foi observado para ZLM e ZPM.

No caso de adsorvente modificado, entre os fatores que influenciam o $\mathrm{pH}_{\mathrm{PCZ}}$ está também a concentração do surfactante usado na modificação da superfície. A mudança do $\mathrm{pH}_{\mathrm{PCZ}}$ em relação à concentração está relacionada com a transição da configuração do surfactante de monocamada para bicamada na superfície do adsorvente (Li e Bowman, 1998). No presente estudo, a carga negativa das ZLM e ZPM indicou a ocorrência da formação de uma bicamada incompleta do surfactante sobre a superfície das zeólitas, enquanto ainda há sítios ativos de troca carregados negativamente disponíveis. Resultados semelhantes foram encontrados na literatura (Bertolini et al., 2013; Fungaro e Borrely, 2012).

\subsubsection{Determinação da massa específica e área específica}

Na TAB. 11 são mostrados os valores de massa específicas e área específica das cinzas, zeólitas e zeólitas modificadas determinadas por picnometria de He e BET, respectivamente.

TABELA 11: Valores de massa e área específica para a cinza leve (CL), cinza pesada $(\mathrm{CP})$ e suas respectivas zeólitas: zeólita leve (ZL), zeólita pesada (ZP), zeólita leve modificada (ZLM) e zeólita pesada modificada (ZPM). O desvio padrão se encontra em parêntesis.

\begin{tabular}{ccc}
\hline Amostra & Massa específica $\left(\mathbf{g ~ c m}^{\mathbf{3}}\right)$ & $\begin{array}{c}\text { Área superficial específica BET } \mathbf{~ ( m}^{\mathbf{2}} \\
\left.\mathbf{g}^{-\mathbf{1}}\right)\end{array}$ \\
\hline CP & $1,32( \pm 0,0001)$ & 5,25 \\
ZP & $1,76( \pm 0,0002)$ & 39,9 \\
ZPM & $1,68( \pm 0,0001)$ & 36,0 \\
CL & $2,45( \pm 0,0002)$ & 2,85 \\
ZL & $2,43( \pm 0,0001)$ & 68,3 \\
ZLM & $2,38( \pm 0,0002)$ & 64,4 \\
\hline
\end{tabular}

A literatura reporta que partículas ricas em fase vítreas e fases cristalinas de mulita e quartzo, partículas com fase vítrea de aluminossilicatos cálcicos e partículas com presença abundante de óxidos desligados da fase vítrea (tais como óxido de cálcio e ferro) e seus sais derivados, apresentam massa específica na faixa de 2 a $2,6 \mathrm{~g} \mathrm{~cm}^{-3}$. Estes compostos serão identificados nas amostras posteriormente pela técnica de difração de raios X. (Umanã-Penã, 2012; Hemmings e Berry, 1985). Como observado 
na TAB. 11, os valores de massa específica para todos os adsorventes deste estudo foram próximos e variaram entre $1,32-2,45 \mathrm{~g} \mathrm{~cm}^{-3}$ e estão concordante com a literatura. Izidoro (2013) encontou um valor de 2,40 e 2,00 $\mathrm{g} \mathrm{cm}^{-3}$ para cinzas leve e zeólita leve, respectivamente, para as cinzas da usina amostrada no presente trabalho.

Os valores encontrados da massa para as CP e ZP estão de acordo com a literatura da mesma cinza utilizada no trabalho por Magdalena (2015).

Com relação a área superficial específica para a CP e suas zeólitas, apresentaram um valor menor quando comparado com CL e suas respectivas zeólitas. Esse resultado já era esperando uma vez que as CL apresentam partículas menores e mais porosas, enquanto a CP partículas maiores e menos porosas. Cinzas com maiores superfícies de contato possuem maior reatividade com os agentes de ativação durante a síntese de zeólitas, resultando em maior rendimento de síntese. Isso ocorre devido a maior facilidade de solubilização dos compostos formadores de zeólita na matriz das cinzas com elevada área (Izidoro, 2013).

Observou-se que os valores da área superficial específica das zeólitas foi maior do que o das cinzas percursoras. Este aumento é devido ao estágio de cristalização sobre as partículas esféricas lisas das cinzas depois do tratamento hidrotérmico. Os valores da área superficial específica da ZL e da ZP foram de $\sim 1,1$ vez maiores do que aqueles da ZLM e ZPM, indicando a cobertura da superfície pelas moléculas do HDTMA (Bertolini, 2013; Fungaro e Borrely, 2012).

\subsubsection{Morfologia}

Para avaliar a morfologia das partículas presentes nas amostras de cinzas e das zeólitas sintetizadas foi utilizada a técnica de Microscopia Eletrônica de Varredura (MEV). As micrografias das cinzas leves (CL) e pesadas (CP) utilizadas neste estudo como matéria prima para a síntese das zeólitas são mostradas na FIG.9,

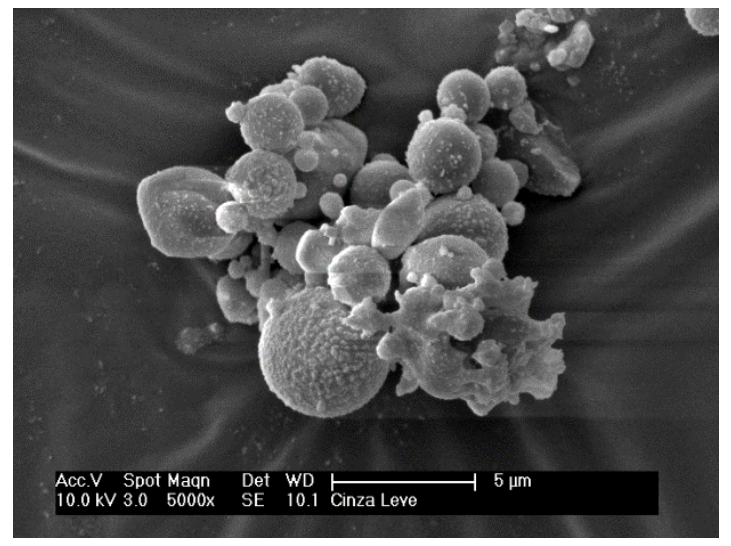

(a)

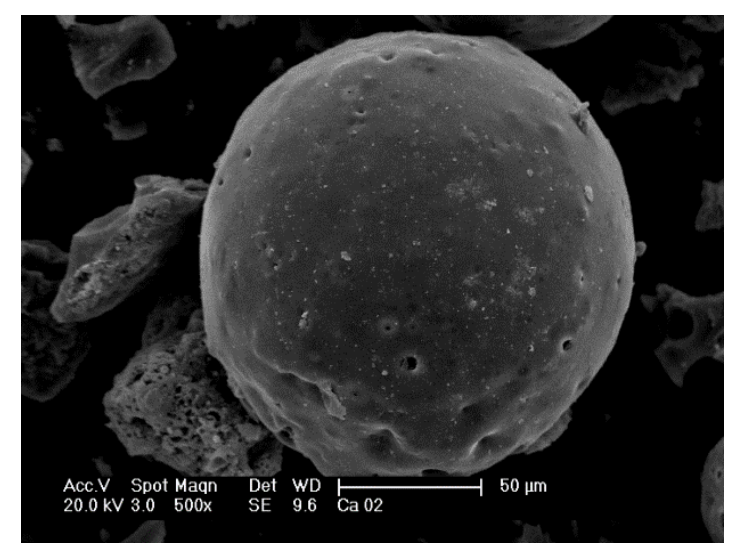

(b)

FIGURA 9: Micrografia das cinzas leve (a) e pesada (b) de carvão obtidas por microscopia eletrônica de varredura.

A micrografia da cinza pesada (FIG. 9 b) foi a única apresentada com aumento de 500x para que suas partículas fossem melhor observadas.

Observou-se que as partículas da CL e da CP são esféricas de superfícies lisas com diâmetros diferentes. Além das partículas esféricas, há também partículas de tamanhos irregulares que são características de carvão não queimado e de partículas amorfas que sofreram difusão em intercontato com outras partículas ou rápido resfriamento (Silva, 2011). Diferentes estados físicos da sílica presente em amostras de cinzas de carvão são responsáveis pela forma das partículas de tamanho irregulares (Sarbak et al., 2004). A forma esférica apresentada por esses materiais é resultado da 
força de tensão superficial atuante durante a queima do carvão em elevadas temperaturas nas usinas termoelétricas (Hemmings e Berry, 1988; Umanã, 2002).

As micrografias da zeólita leve (ZL) e zeólita pesada (ZP) são mostradas na FIG. 10. Isto ocorre devido à dissolução da fase amorfa aluminosilicato das cinzas e posterior cristalização sobre a superfície das partículas de cinzas. Os cristais zeolíticos que precipitam durante a síntese aparecem normalmente como cristalitos de hastes orientados aleatoriamente, formando aglomerados de partículas esféricas rugosas e irregulares com forma esponjosa e de tamanhos variados (Shoumkova e Stoyanova, 2013).

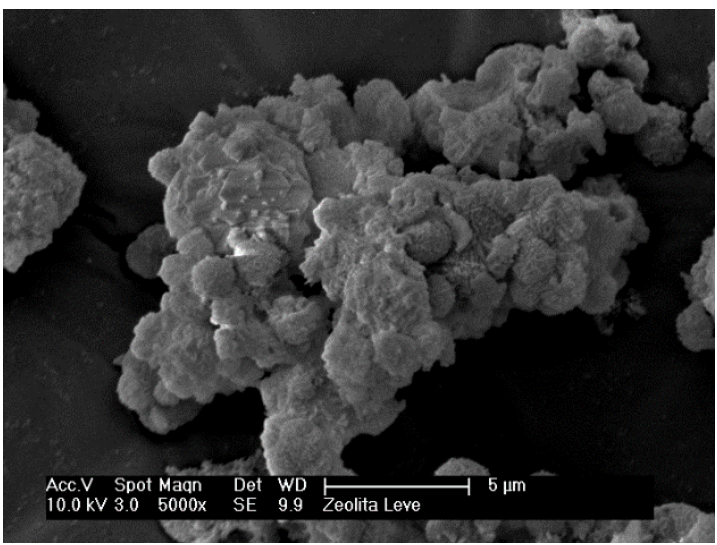

(a)

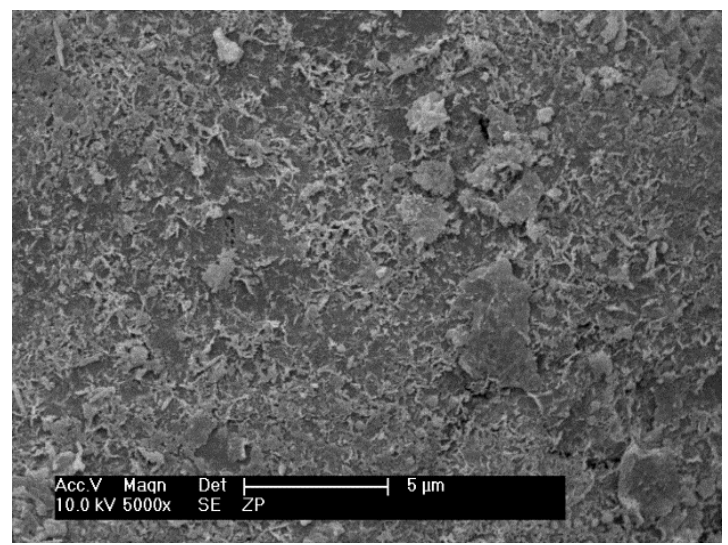

(b)

FIGURA 10: Micrografia das zeólita leve (a) e pesada (b) de carvão obtidas por microscopia eletrônica de varredura.

As micrografias das zeólitas leve (ZLM) e pesada (ZPM) modificada por surfactante são apresentadas na FIG. 11.

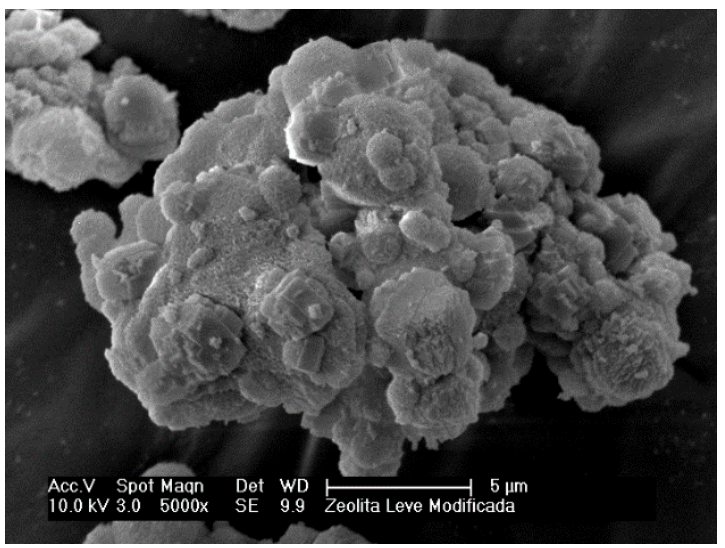

(a)

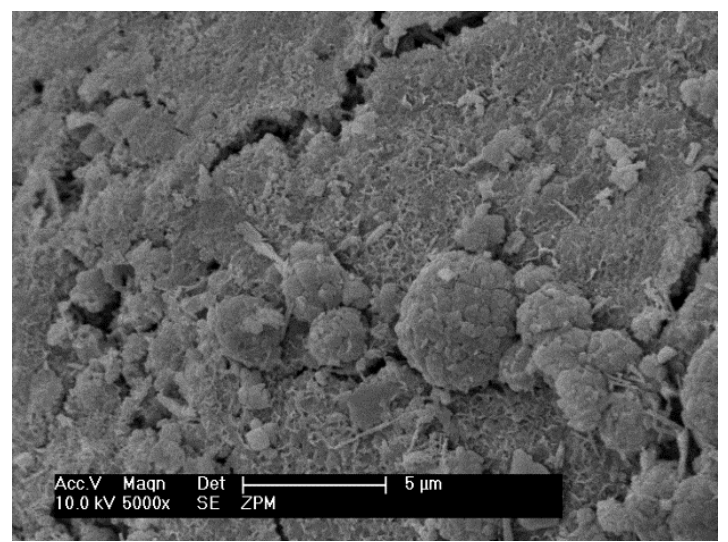

(b)

FIGURA 11: Micrografia das zeólitas modificadas leve (a) e pesada (b) de carvão obtidas por microscopia eletrônica de varredura.

A diferença morfológica entre as zeólitas modificadas e as zeólita não modificadas não foi observada. Depois da modificação com o surfactante, a superfície das zeólitas foi coberta com uma camada orgânica. Desta maneira, os poros tornaramse mais densamente empacotados, mas sem o total desaparecimento das extremidades dos cristais da zeólita (Lin et al., 2011).

\subsubsection{Composição química}

Nas TAB. 12 estão apresentadas as composições químicas obtidas por fluorescência de raios $X$ (em \% de massa), das cinzas leves (CL) e pesadas (CP) de 
carvão e suas respectivas zeólitas (ZL e ZP) e das zeólitas modificadas por surfactante (ZLM e ZPM).

A composição química encontrada para os materiais zeolíticos foi principalmente sílica $\left(\mathrm{SiO}_{2}\right)$, alumina $\left(\mathrm{Al}_{2} \mathrm{O}_{3}\right)$ e óxido férrico $\left(\mathrm{Fe}_{2} \mathrm{O}_{3}\right)$. Encontraram-se os óxidos de cálcio, titânio, enxofre e outros compostos em quantidades $\leq 7,0 \%$. $O$ aumento do conteúdo de sódio encontrado na zeólita sintética não modificada (ZL e ZP) em relação às cinzas está relacionado com a sua incorporação no material zeolítico pela síntese hidrotérmica onde utilizou-se solução de $\mathrm{NaOH}$ como agente de ativação. A presença do brometo nas ZLM e ZPM foi detectada, já que a carga positiva do cátion HDTMA adsorvido na superfície da zeólita é contrabalanceada por ânions brometo (Bertolini, 2013).

O conteúdo dos principais compostos formadores de estruturas de zeólitas, $\mathrm{SiO}_{2}$ e $\mathrm{Al}_{2} \mathrm{O}_{3}$ correspondeu a 75 e $62 \%$ para $\mathrm{CL}$ e $\mathrm{ZP}$, respectivamente. O conteúdo de $\mathrm{SiO}_{2}$ variou de 50 e $41 \%$ para CL e CP e o conteúdo de $\mathrm{Al}_{2} \mathrm{O}_{3}$ de 25 e $21 \%$ para $\mathrm{CL}$ e $\mathrm{CP}$, respectivamente.

TABELA 12: Análise química dos compostos presentes nas cinzas de carvão leve (CL) e pesada (CP), suas respectivas zeólitas (ZL e ZP) e zeólitas modificadas (ZLM e ZPM)

\begin{tabular}{lcccccc}
\hline \multicolumn{1}{c}{ Elementos (\% massa) } & $\mathrm{CL}$ & $\mathrm{ZL}$ & $\mathrm{ZLM}$ & $\mathrm{CP}$ & $\mathrm{ZP}$ & $\mathrm{ZPM}$ \\
\hline $\mathrm{SiO}_{2}$ & 50 & 38 & 39 & 41 & 32 & 35 \\
$\mathrm{Al}_{2} \mathrm{O}_{3}$ & 25 & 28 & 28 & 21 & 22 & 25 \\
$\mathrm{Fe}_{2} \mathrm{O}_{3}$ & 11 & 14 & 14 & 12 & 12 & 11 \\
$\mathrm{~K} 2 \mathrm{O}$ & 4,5 & 1,4 & 1,5 & & 1,3 & 1,2 \\
$\mathrm{CaO}$ & 2,4 & 2,9 & 2,9 & 5,6 & 6,7 & 5,5 \\
$\mathrm{MgO}$ & 1,7 & 2,3 & 2,3 & 1,6 & 2,9 & 3 \\
$\mathrm{TiO}_{2}$ & 1,7 & 2,2 & 2,1 & 2,3 & 2,5 & 2,2 \\
$\mathrm{SO}_{3}$ & 1,6 & 0,6 & 0,4 & 6,1 & 8,8 & 7,4 \\
$\mathrm{Na}_{2} \mathrm{O}$ & 0,9 & 9,2 & 7,9 & 0,8 & 12 & 9,9 \\
$\mathrm{ZnO}_{\mathrm{As}} \mathrm{O}_{3}$ & 0,6 & 08 & 0,7 & 0,15 & 0,10 & 0,9 \\
$\mathrm{P}_{2} \mathrm{O}_{5}$ & 0,4 & 0,14 & 0,8 & 0,07 & $<0,02$ & $<0,02$ \\
$\mathrm{~V}_{2} \mathrm{O}_{5}$ & 0,18 & 0,03 & 0,03 & $<0,02$ & 0,06 & 0,04 \\
$\mathrm{MnO}$ & 0,16 & $<0,02$ & $<0,02$ & & $<0,02$ & 0,12 \\
$\mathrm{PbO}_{\mathrm{U}_{3} \mathrm{O}_{8}}$ & 0,13 & 0,20 & 0,09 & 0,10 & 0,11 & 0,19 \\
$\mathrm{ZrO}_{2}$ & 0,12 & 0,11 & 0,11 & 0,06 & 0,14 & 0,11 \\
$\mathrm{Cr}_{2} \mathrm{O}_{3}$ & 0,08 & 0,09 & 0,09 & 0,06 & 0,05 & 0,05 \\
$\mathrm{GeO}_{2}$ & 0,07 & 0,09 & 0,08 & 0,05 & 0,05 & 0,05 \\
$\mathrm{NiO}$ & 0,06 & 0,05 & 0,04 & 0,05 & 0,06 & 0,06 \\
$\mathrm{SrO}_{\mathrm{CuO}}$ & 0,05 & 0,02 & 0,03 & 0,04 & 0,02 & $<0,02$ \\
$\mathrm{Br}^{\mathrm{SiO}} / \mathrm{Al}_{2} \mathrm{O}_{3}$ & 0,02 & 0,03 & 0,03 & 0,03 & 0,04 & 0,03 \\
& 0,02 & 0,03 & 0,03 & 0,03 & 0,02 & 0,03 \\
& 0,02 & 0,03 & 0,02 & 0,02 & 0,03 & 0,03 \\
& $<0,02$ & $<0,02$ & 0,05 & $<0,02$ & $<0,02$ & 0,12 \\
& 2 & 1,35 & 1,39 & 1,95 & 1,45 & 1,41 \\
\hline & & & & & &
\end{tabular}

A razão $\mathrm{SiO}_{2} / \mathrm{Al}_{2} \mathrm{O}_{3}$ calculada para as cinzas de carvão apresentaram pouca variação, com valor de 2. Esse valor indica uma boa possibilidade de síntese de zeólita (Shiguemoto et al., 1993).

Os conteúdos de óxidos de $\mathrm{Ca}, \mathrm{Mg}$ e $\mathrm{S}$ apresentaram valores de 5,7 para CL e 13,3\% para CP respectivamente. Segundo Ferret (2004) esses elementos são prejudiciais na formação da zeólita, assim como o conteúdo de Fe, que é considerado inibidor para a formação da zeólita, por não ser reativo (Ferret, 2004; Umanã, 2002) e nesse trabalho apresentou valores de 11 e $12 \%$ para CL e CP, respectivamente. 
A razão $\mathrm{SiO}_{2} / \mathrm{Al}_{2} \mathrm{O}_{3}$ está associada à capacidade de troca catiônica das zeólitas. De modo geral, quanto menor for essa relação, maior é a quantidade de $\mathrm{Al}^{3+}$ na amostra e consequentemente, maior é a capacidade de troca catiônica do material, já que para cada Si que foi substituído por um Al é gerada uma carga negativa, a qual é compensada por um cátion (Querol et al., 2002)

Os materiais zeolíticos que apresentam valor menor desta relação apresentam uma alta capacidade das partículas de trocarem íons positivamente carregados. De acordo com a TAB. 12, os valores para ZL, ZP, ZLM e ZPM são inferiores àqueles encontrados para as cinzas de origem, indicando que o tratamento hidrotérmico alcalino contribuiu para o aumento do potencial de utilização dos materiais zeolíticos como trocadores iônicos.

Segundo Ferreira (1998) os valores da relação $\mathrm{SiO}_{2} / \mathrm{Al}_{2} \mathrm{O}_{3}$ não podem ser considerados como absolutos uma vez que os átomos detectados por fluorescência de raios $\mathrm{X}$ podem ou não fazer parte da rede cristalina das zeólitas formadas. Assim, a relação $\mathrm{SiO}_{2} / \mathrm{Al}_{2} \mathrm{O}_{3}$ encontrada bem como os cátions trocáveis são da amostra e não necessariamente da estrutura cristalina (Izidoro, 2013).

\subsubsection{Composição mineralógica}

A técnica de difratometria de raios- $X$ permitiu a identificação das fases cristalinas presentes nas amostras de cinza de carvão leve (CL) e pesada, assim como das zeólitas formadas a partir desses materiais (ZL, ZP, ZLM e ZPM). Na FIG. 12 são apresentados os difratogramas das amostras de cinza leve e cinza pesada de carvão estudadas.
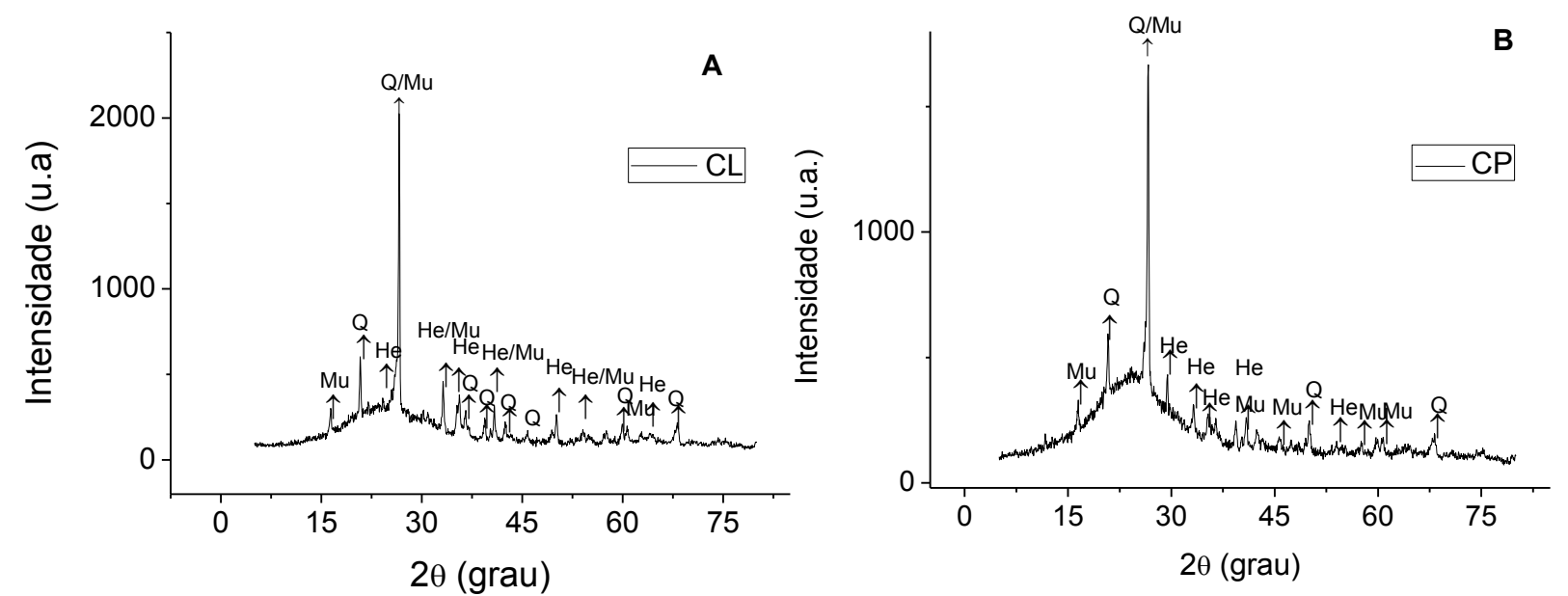

FIGURA 12: Difratograma de raios-X da cinzas leve ( $C L-A)$ e cinzas pesada (CP - B) ( $Q=$ Quartzo; He=Hematita; Mu=Mulita)

Os compostos cristalinos predominantes identificados na cinza foram quartzo (ICDD 001-0649), mulita (ICDD 002-0430) e Hematita (ICDD 089- 0598). A mulita presente nas cinzas é resultante das reações que ocorrem durante o processo de combustão do carvão. $O$ quartzo está presente no carvão percursor e não funde nas condições de queima nas usinas termelétricas. A presença de hematita é decorrente da oxidação de sulfetos de ferro na forma de pirita (mineral sulfeto) (Izidoro, 2014, Rohde et al., 2006). Na FIG. 13 são mostradas os difratogramas de raios $X$ das zeólitas leve e pesada (ZL e ZP), respectivamente. 

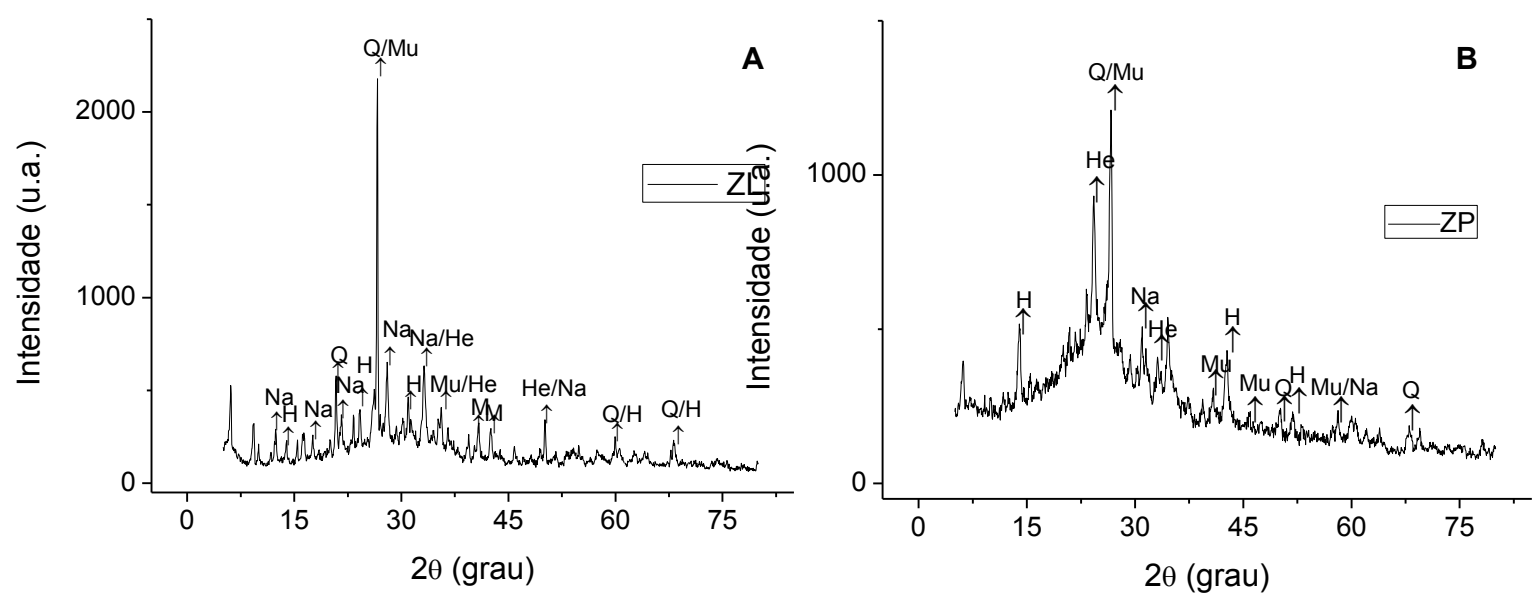

FIGURA 13: Difratograma de raios-X da zeólita leve (ZL - a) e zeólita pesada (ZP - b) $(\mathrm{Q}=$ Quartzo; He=Hematita; Mu=Mulita; H=zeólita hidroxissodalita; $\mathrm{Na=}$ zeólita NaP1)

Os produtos zeolíticos formados foram identificados como hidroxissodalita (ICDD 011-0401) e zeólita NaP1 (ICDD 74-4143). Observou-se na zeólita e zeólita modificada a presença de quartzo e mulita provenientes das cinzas de carvão que não foram convertidas no tratamento hidrotérmico. A FIG. 14 são mostrados os difratogramas das zeólitas leve e pesada modificadas (ZLM e ZPM), respectivamente.
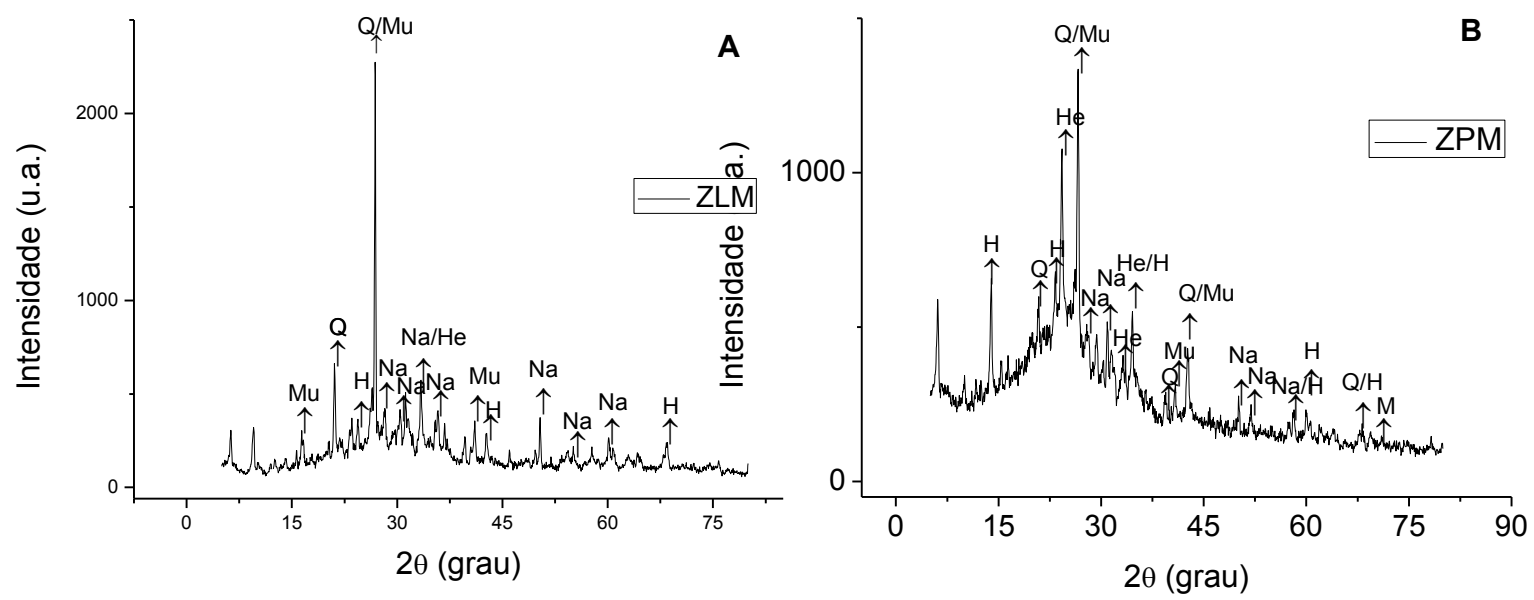

FIGURA 14: Difratograma de raios-X da zeólita leve modificada (ZLM - a) e zeólita pesada modificada (ZPM - b) (Q=Quartzo; He=Hematita; Mu=Mulita; H=zeólita hidroxissodalita; $\mathrm{Na}=$ zeólita $\mathrm{NaP} 1)$

Como observado nas FIG. 13 e 14, a zeólita hidroxissodalita $(\mathrm{H})$ foi formada em todos os produtos zeolíticos. Esse tipo de zeólita possui alta estabilidade mediante a variações de temperatura que podem ocorrer durante a síntese de zeólitas usando cinzas de carvão como matéria prima e normalmente cristaliza-se entre 80 e $140 \stackrel{\circ}{\circ}$ (Poole et al., 2000). Com relação a zeólita NaP1 é uma das zeólitas consideradas com um grande potencial de aplicação industrial, devido ao alto valor da capacidade de troca catiônica (Querol et al., 2001). Cinzas com alta concentração de Si e baixa de Al favorecem a formação da zeólita NaP1.

Os parâmetros estruturais das zeólitas modificadas por surfactante foram muito próximos daqueles da correspondente zeólita não modificada, indicando que a natureza cristalina da zeólita permaneceu intacta após a adsorção das moléculas do HDTMA-Br e o aquecimento para secagem do material adsorvente. 
A fim de verificar a possível modificação estrutural da estrutura cristalina e a identidade dos materiais zeolíticos após a modificação com surfactante e adsorção dos corantes, análises de difração de raios X foram realizadas. A FIG. 15 mostra os difratogramas das ZLM e ZPM após a adsorção dos corantes ST e SN.
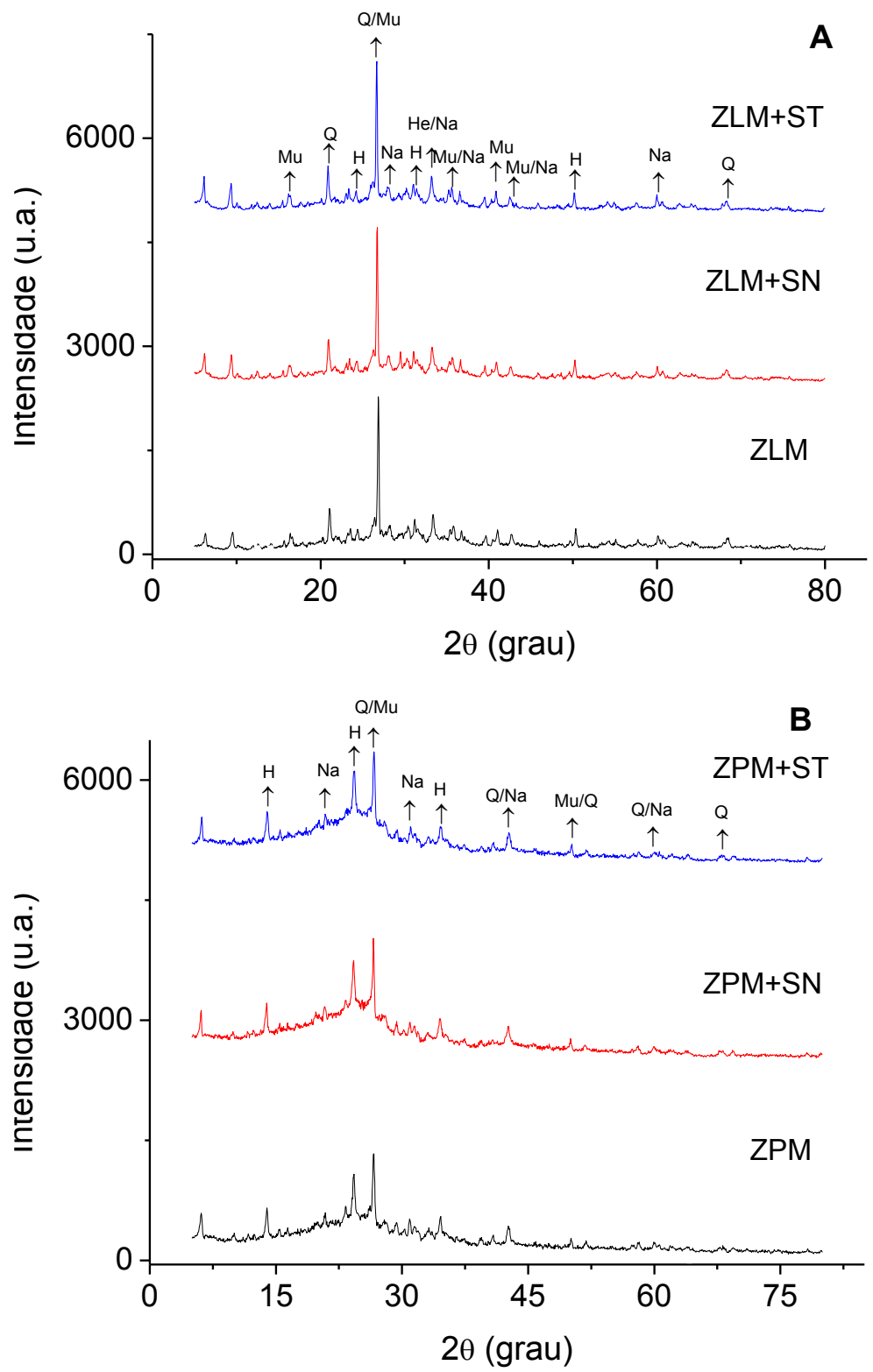

FIGURA 15: Difratograma de raios-X da zeólita leve modificada (ZLM) e saturada com os corantes Solophenyl Navy e Turquesa (SN e ST - a) e zeólita pesada modificada (ZPM) e saturada com os corantes SN e ST - b (Q=Quartzo; He=Hematita; Mu=Mulita; $\mathrm{H}=$ zeólita hidroxissodalita; $\mathrm{Na}=$ zeólita $\mathrm{NaP} 1$ )

O processo de adsorção pode levar a mudanças na estrutura cristalina do adsorvente, portanto, a compreensão destas estruturas e das alterações resultantes podem fornecer informações valiosas sobre a adsorção. De acordo com os parâmetros estruturais apresentados nas FIG. 15, as zeólitas modificadas saturadas dos corantes apresentaram um perfil semelhante ao das zeólitas modificadas por surfactante. Após a adsorção do SN e do ST, a natureza cristalina dos sistemas corante/zeólita modificada permaneceu intacta (Lin et al., 2011). 


\subsubsection{Determinação da capacidade de troca catiônica}

Os valores da capacidade de troca catiônica (CTC) encontrados para as cinzas de carvão, zeólitas de cinza de carvão e zeólitas modificadas leve e pesada são mostradas na TAB. 13, assim como os valores da capacidade troca catiônica externa (CTCE) para as zeólitas leve e pesada.

TABELA 13: Valores de Capacidade de Troca Catiônica (CTC) e Capacidade de Troca Catiônica Externa (CTCE) para as zeólitas de cinza de carvão e seus materiais percursores.

\begin{tabular}{lcccccc} 
& & \multicolumn{5}{c}{ Adsorventes } \\
& CL & ZL & ZLM & CP & ZP & ZPM \\
\hline CTC $\left(\mathrm{meq} \mathrm{g}^{-1}\right)^{\mathrm{a}}$ & 0,249 & 2,52 & 2,73 & 0,0985 & 1,12 & 2,51 \\
CTCE $\left(\text { meq g }^{-1}\right)^{\mathrm{b}}$ & --- & 0,628 & & --- & 0,266 & \\
\hline
\end{tabular}

(a) capacidade de troca catiônica; (b) capacidade de troca catiônica externa.

Com relação às CL e CP, ambas apresentaram valores baixos de CTC $\left(0,249\right.$ e 0,0985 meq $\mathrm{g}^{-1}$ para CL e CP, respectivamente) e são semelhantes aos valores relatados em literatura (Izidoro, 2013; Paproki, 2009). Apesar dos baixos valores de CTC para CL e CP, os produtos da sua zeolitização apresentam um aumento significativo (11 e 25 vezes para ZLM e ZPM, respectivamente), o qual garante uma melhor possibilidade de troca de íons, que por sua vez permite a utilização dos materiais zeolíticos obtidos para diferentes processos de tratamento (Franus, 2011). Estes baixos valores de CTC encontrados para as cinzas evidenciam a necessidade e importância da conversão deste resíduo em materiais com uma maior capacidade de adsorção, sendo a conversão zeolítica deste material muito apropriada para esta finalidade (Paproki, 2009).

Os valores de CTC obtidos para as zeólitas leve e pesadas não modificadas e modificadas foram próximos e variaram entre 2,52 e 2,73 meq g ${ }^{-1}$ para ZL e ZLM. Contudo, para a ZP e ZPM esses valores variaram entre 1,12 e 2,51 meq g-1, respectivamente. Os maiores valores da CTC para as zeólitas modificadas são explicados pela modificação da superfície do adsorvente, que apresenta maior capacidade de adsorção.

Os valores da capacidade de troca catiônica externa (CTCE) para a ZL e ZP correspondem a $25 \%$ e $20 \%$ dos valores da CTC, respectivamente, resultados semelhantes foram descritos por Magdalena (2015). A adsorção do HDTMA sobre a zeólita envolve somente a CTCE deixando a CTC interna inalterada. As dimensões do cátion do HDTMA são muito grandes, assim o HDTMA não consegue penetrar nos canais das estruturas das zeólitas. Como resultado, os sítios internos da zeólita estão ainda acessíveis a pequenos íons. A capacidade de troca catiônica total da zeólita não modificada é a soma de CTCE e CTC (Fungaro e Borrely, 2012).

\subsubsection{Identificação dos grupos funcionais}

A técnica de espectroscopia de infra vermelho (IV) é relevante para o estudo das interações entre os grupos ativos do adsorbato e dos adsorventes. As amostras de zeólita leve, zeólita pesada e suas respectivas zeólitas modificadas além de zeólitas modificadas saturadas com o os corantes foram submetidas à análise por IV para verificação de mudanças estruturais entre os materiais após a modificação com surfactante e a adsorção dos corantes. Os resultados são mostrados nas FIG. 16 e 17 para zeólita leve e pesada, respectivamente. 


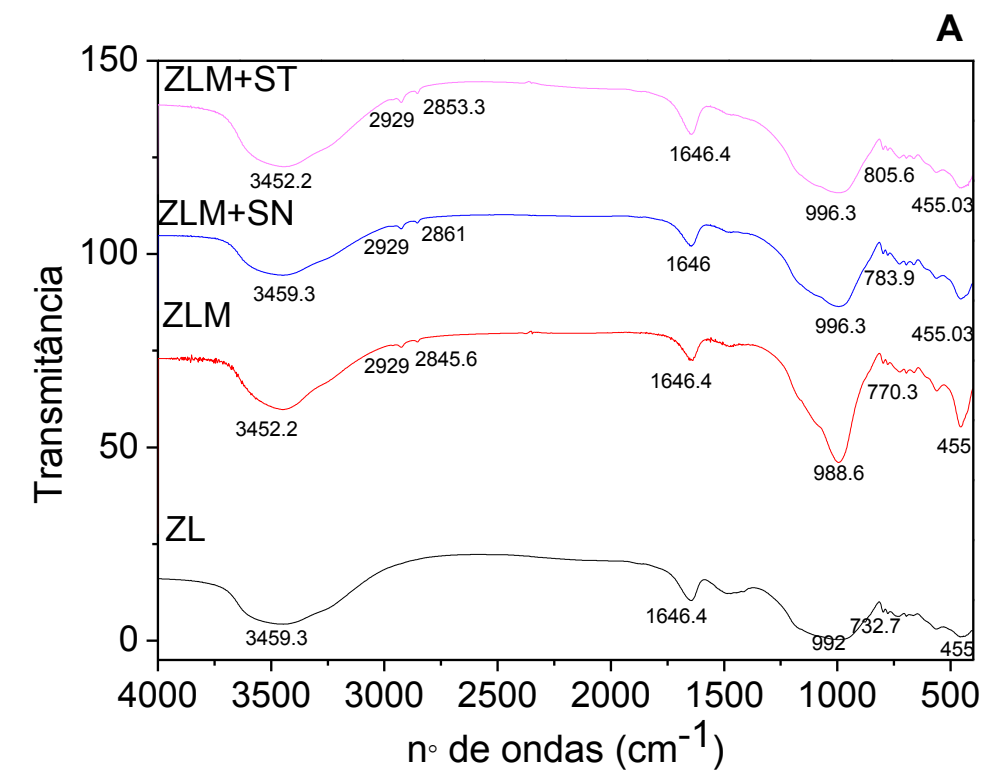

FIGURA 16: Espectros de infravermelho dos adsorventes zeólita leve (ZL), zeólita leve modificada (ZLM), ZLM saturada com Solophenyl Navy (SN) e Turquesa (ST)

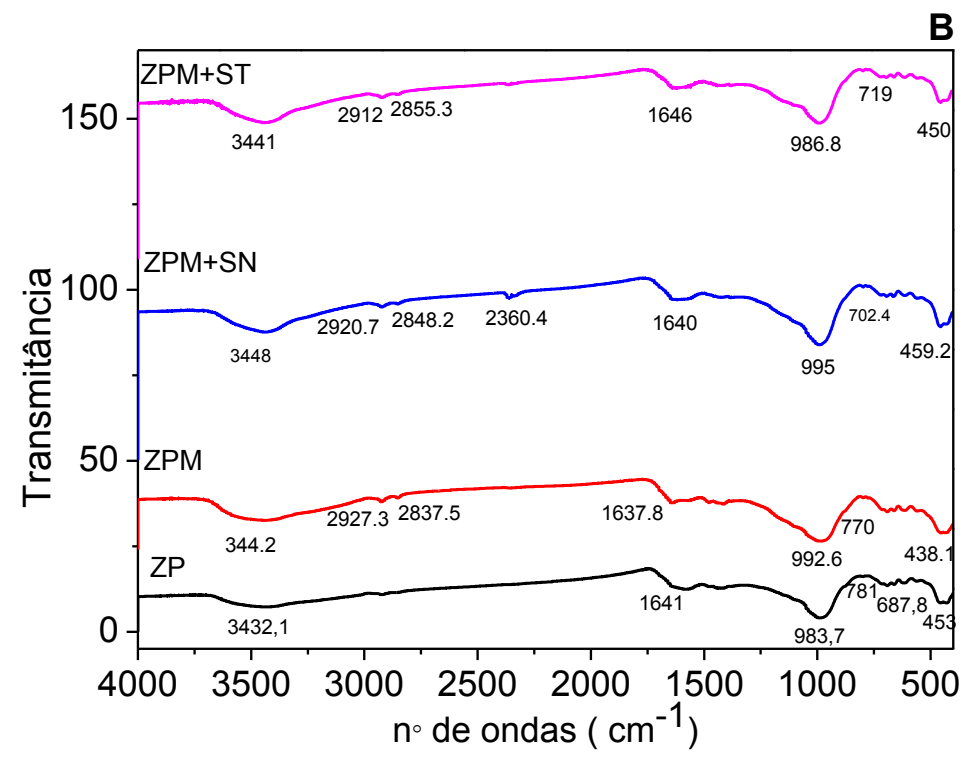

FIGURA 17: Espectros de infravermelho dos adsorventes zeólita pesada (ZP), zeólita pesada modificada (ZPM), ZPM saturada com Solophenyl Navy (SN) e Turquesa (ST)

As atribuições das bandas do espectro IV dos adsorventes estudados são apresentadas na TAB. 14 e 15, respectivamente. 
TABELA 14: Atribuições das bandas do espectro IV da zeólita leve (ZL), zeólita leve modificada por surfactante (ZLM) e modificada e saturada com os corantes corante (ST e SN)

\begin{tabular}{|c|c|c|c|c|}
\hline \multicolumn{5}{|c|}{ NÚMERO DE ONDAS $\left(\mathrm{cm}^{-1}\right)$} \\
\hline ATRIBUIÇÃO & $\mathrm{ZL}$ & ZLM & ZLM+SN & ZLM+ST \\
\hline$v(\mathrm{O}-\mathrm{H})_{\text {simétrica e assimétrica }}$ & 3459 & 3452 & 3459 & 3452 \\
\hline estiramento $\mathrm{CH}_{2}$ assimétrico do & - & 2929 & 2929 & 2929 \\
\hline \multicolumn{5}{|l|}{ HDTMA-Br } \\
\hline estiramento $\mathrm{CH}_{2}$ simétrico do & - & 2845 & 2861 & 2853 \\
\hline \multicolumn{5}{|l|}{ HDTMA-Br } \\
\hline $\mathrm{H}_{2} \mathrm{O}$ & 1646 & 1646 & 1646 & 1646 \\
\hline Estiramento assimétrico da Hidroxissodalita & 992 & 988 & 996 & 996 \\
\hline Quartzo & 793 & 770 & 783 & 805 \\
\hline $\begin{array}{c}\text { Sílica amorfa deformação angular } \\
\text { T-O }\end{array}$ & 455 & 455 & 455 & 455 \\
\hline
\end{tabular}

TABELA 15: Atribuições das bandas do espectro IV da zeólita pesada (ZP), zeólita pesada modificada por surfactante (ZPM) e modificada e saturada com os corantes corante (ST e SN)

\begin{tabular}{|c|c|c|c|c|}
\hline \multicolumn{5}{|c|}{ NÚMERO DE ONDAS $\left(\mathrm{cm}^{-1}\right)$} \\
\hline ATRIBUIÇÃO & ZP & ZPM & ZPM+SN & ZPM+ST \\
\hline$v(\mathrm{O}-\mathrm{H})_{\text {simétrica e assimétrica }}$ & 3432 & 3442 & 3448 & 3441 \\
\hline estiramento $\mathrm{CH}_{2}$ assimétrico do & - & 2927 & 2920 & 2912 \\
\hline \multicolumn{5}{|l|}{ HDTMA-Br } \\
\hline estiramento $\mathrm{CH}_{2}$ simétrico do & - & 2837 & 2848 & 2855 \\
\hline \multicolumn{5}{|l|}{ HDTMA-Br } \\
\hline $\mathrm{H}_{2} \mathrm{O}$ & 1641 & 1637 & 1640 & 1646 \\
\hline Estiramento assimétrico da Hidroxissodalita & 983 & 992 & 995 & 986 \\
\hline Quartzo & 781 & 770 & 702 & 719 \\
\hline $\begin{array}{c}\text { Sílica amorfa deformação angular } \\
\text { T-O }\end{array}$ & 453 & 438 & 459 & 450 \\
\hline
\end{tabular}

As cinzas leves de carvão são constituídas principalmente de quartzo $\left(\mathrm{SiO}_{2}\right)$, mulita $\left(\mathrm{Al}_{6} \mathrm{Si}_{2} \mathrm{O}_{13}\right)$ e sílica amorfa. As bandas em $1078 \mathrm{~cm}^{-1}$ e $459 \mathrm{~cm}^{-1}$ são características das vibrações internas no tetraedro $\mathrm{TO}_{4}(\mathrm{~T}=\mathrm{Al}$, Si) e estão associadas às vibrações de estiramento assimétrico e deformação angular T-O, respectivamente. Estes tetraedros são as unidades básicas de construção da mulita, quartzo e sílica. Os picos entre 702 e $805 \mathrm{~cm}^{-1}$ é correspondente ao quartzo e entre 438 e $459 \mathrm{~cm}^{-1}$ corresponde à sílica. As 
conclusões foram baseadas na comparação dos espectros de infravermelho obtidos para os sólidos puros de mullita, quartzo e sílica amorfa apresentados em literatura (Paprocki, 2009).

A banda em $3432-3459 \mathrm{~cm}^{-1}$ é atribuída às vibrações simétricas e assimétricas $\mathrm{v}(\mathrm{O}-\mathrm{H})$, sugerindo a presença de material silicato amorfo (vidro) ou possivelmente silicatos de alumínio hidratado. Esta banda aumentou de intensidade e de largura no espectro da zeólita leve. Isto pode ser explicado pelo aumento da concentração de produtos hidratados e por diferenças no caráter ácido do grupo terminal $\mathrm{O}-\mathrm{H}$ (Mouhtaris et al., 2003).

As bandas em 1637-1646 $\mathrm{cm}^{-1}$ podem ser atribuídas à presença do modo de vibração de flexão da molécula de $\mathrm{H}_{2} \mathrm{O}$ e mostra que a completa desidratação não foi alcançada na amostra de zeólita (Somerset et al., 2004).

As bandas dos espectros das zeólitas $982-966 \mathrm{~cm}^{-1}$ correspondem à formação da zeólita hidroxissodalita (Covarrubias et al., 2006).

A identificação de bandas entre 2929 e $2912 \mathrm{~cm}^{-1}$ e entre 2837-2845 nos espectros da ZLM e da ZPM correspondem aos modos de vibração do estiramento $\mathrm{C}-\mathrm{H}$, dos grupos metileno, assimétrico $\left(\mathrm{V}_{\mathrm{as}} \mathrm{CH}_{2}\right)$ e simétrico $\left(\mathrm{v}_{\mathrm{s}} \mathrm{CH}_{2}\right)$, respectivamente, devido às moléculas do surfactante (Covarrubias et al., 2006). O aparecimento destas bandas principais do HDTMA-Br e a similaridade dos espectros da zeólitas não modificadas e das modificadas evidenciam que ocorreu a adsorção do surfactante na superfície dos adsorventes sem comprometer a estabilidade estrutural dos mesmos.

Os espectros de IV dos corantes SN e ST encontram-se nos ANEXO A e B e as respectivas atribuições das bandas encontradas em literatura são apresentadas na TAB 16.

TABELA 16: Atribuições das bandas do espectro de infra vermelho dos corantes Solophenyl Navy (SN) e Turquesa (ST)

\begin{tabular}{|c|c|c|c|}
\hline \multirow[t]{2}{*}{ Atribuição } & \multicolumn{2}{|c|}{ Número de onda $\left(\mathrm{cm}^{-1}\right)$} & \multirow[t]{2}{*}{ Referência } \\
\hline & SN & ST & \\
\hline Estiramento do grupo $-\mathrm{N}=\mathrm{N}-$ & 3040 & 3430 & Cheng et al., 2012 \\
\hline Estiramento do grupo C-H & 2919,945 & $\begin{array}{c}2926 \\
901\end{array}$ & Mc Murry, 2005 \\
\hline Estiramento do grupo $\mathrm{C}=\mathrm{C}$ (aromático) & 1581 & 1463 & Cheng et al., 2012 \\
\hline Estiramento do grupo C-C (aromático) & 1544 & 1550 & Mc Murry, 2005 \\
\hline Vibração do esqueleto aromático & 1581 & 1500 & Mc Murry, 2005 \\
\hline Grupo -N-H- (forma hidrazona) & 1459 & --- & Mc Murry, 2005 \\
\hline Flexão O-H & 1450 & & $\begin{array}{l}\text { Lucarelli et al., } \\
2012\end{array}$ \\
\hline Estiramento assimétrico do grupo $\mathrm{CH}_{3}$ & -- & 1384 & Cheng et al., 2012 \\
\hline Vibração $-\mathrm{N}=\mathrm{N}-$ & 1208 & 1157 & Cheng et al., 2012 \\
\hline Estiramento simétrico do grupo $\mathrm{SO}_{3}$ & 1124 & 1106 & Elías et al., 2012 \\
\hline Estiramento do grupo C-O & 1050 & 1150 & Mc Murry, 2005 \\
\hline Estiramento do grupo C-O-C & 1047 & 1025 & Oliveira et al., \\
\hline Vibração do anel benzênico & 802 & 799 & Cheng et al., 2012 \\
\hline
\end{tabular}

Nos espectros IV dos corantes, as bandas observadas entre 425 e $1673 \mathrm{~cm}^{-1}$ são características dos grupos $\mathrm{SO}_{3}{ }^{-}$e $\mathrm{N}=\mathrm{N}$. As bandas entre 1500 e $1581 \mathrm{~cm}^{-1}$ são devido à vibração do esqueleto aromático existente na estrutura química. Estas bandas não formam mais perceptíveis nos espectros das zeólitas saturadas de corantes (FIG. 16 e 17). Assim, foi concluído que houve uma ligação dos corantes com as zeólitas. 


\subsection{Mecanismo de hidrólise}

Hidrólise é um termo aplicado às reações orgânicas e inorgânicas em que a água efetua uma dupla troca com outro composto. Na química orgânica, hidrólise inclui, entre outras reações, saponificação de ácidos graxos e outros ésteres, inversão de açúcares e quebra de proteínas (hidrólises enzimáticas). Por conveniência, têm sido considerada como hidrólise a reação onde um álcali $(\mathrm{NaOH}$, por exemplo) é utilizado no lugar da água, obtendo um sal alcalino de um ácido no final. É conhecida como hidrólise básica.

As estruturas químicas dos corantes $\mathrm{ST}$ e $\mathrm{SN}$ não foram encontradas na literatura. Assim, as possíveis estruturas desses corantes foram deduzidas baseadas em estruturas químicas de corantes similares com outros colour index number (usado para identificação de corantes) e informações pessoais de autores. Essas estruturas químicas estão mostradas na FIG. 18 para SN e ST, respectivamente.

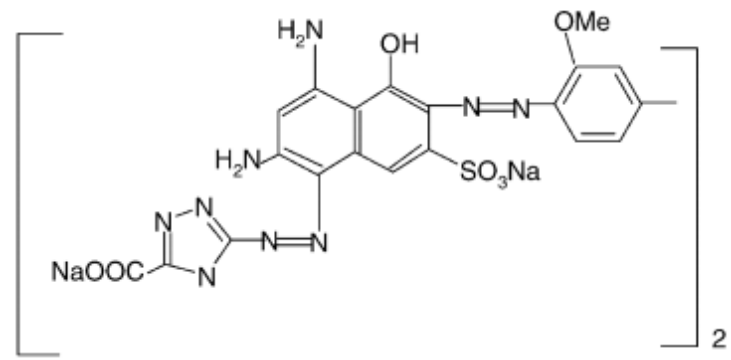

(a)

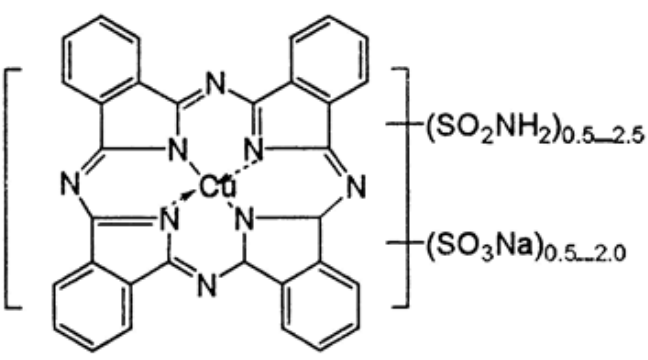

(b)

Figura 18: Possível estrutura química dos corantes SN (a). Massa molar $=1100 \mathrm{~g} / \mathrm{mol} ; \mathrm{e}$ do (b) ST. Massa molar $=775,17 \mathrm{~g} / \mathrm{mol}$

Conforme observado na FIG. 18, o corante SN apresenta uma estrutura química maior quando comparado com o corante ST, apresentando mais átomos de sódio $(\mathrm{Na})$ e oxigênio $(\mathrm{O})$. Ambos os corantes apresentam grupos sulfonados $\left(-\mathrm{SO}_{3}{ }^{-}\right)$e sendo estes compostos do tipo ftalocianina, o metal encontrado em ambos os corantes seria o Cu. Análises químicas posteriores confirmarão a presença do mesmo.

Assim, as reações de hidrólise básica dos corantes SN e ST podem ser representadas da seguinte forma:

$$
\mathrm{R}-\mathrm{SO}_{3} \mathrm{Na}+2 \mathrm{NaOH} \longrightarrow \mathrm{R}-\mathrm{O}-\mathrm{Na}^{+}+\mathrm{Na}_{2} \mathrm{SO}_{3}+\mathrm{H}_{2} \mathrm{O}
$$

Como observado pelo mecanismo proposto tem-se como resultado final a possível formação de um composto amino-naftol e a redução da molécula de ambos os corantes. O trabalho realizado por Gottieb et al. (2003) com o corante Reativo Preto 5, Ácido Laranja 7 e Amarelo mostrou que após a hidrólise desses corantes houve a formação de ácido sulfanílico seguido pela redução da ligação azo e compostos aminonaftois.

\subsection{Estudos com as zeólitas leve e pesada modificada de cinzas de carvão 5.3.1 Efeitos do tempo de contato e concentração inicial dos corantes na adsorção}

O efeito do tempo de agitação na adsorção dos corantes ST, SN, STH e SNH pela zeólita ZLM e ZPM foi investigado. As FIG. 19, 20, 21 e 22 mostram as curvas das quantidades adsorvidas de corante ( $\mathrm{mg} \mathrm{g}^{-1}$ ) em função do tempo de contato (min), em diferentes concentrações iniciais do ST e SN e suas formas hidrolisadas. 

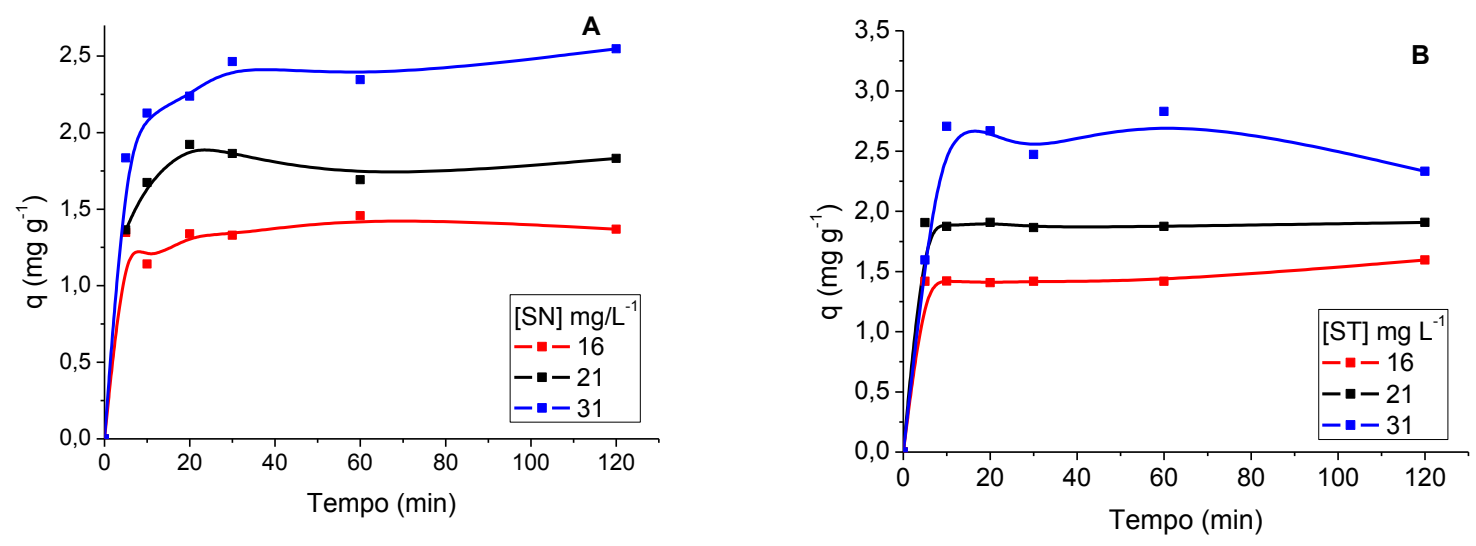

FIGURA 19 - Efeito do tempo de agitação e da concentração do SN (A) e ST (B) sobre a capacidade de adsorção da ZLM $\left(T=25^{\circ} \mathrm{C} ; \mathrm{pH}=5\right)$
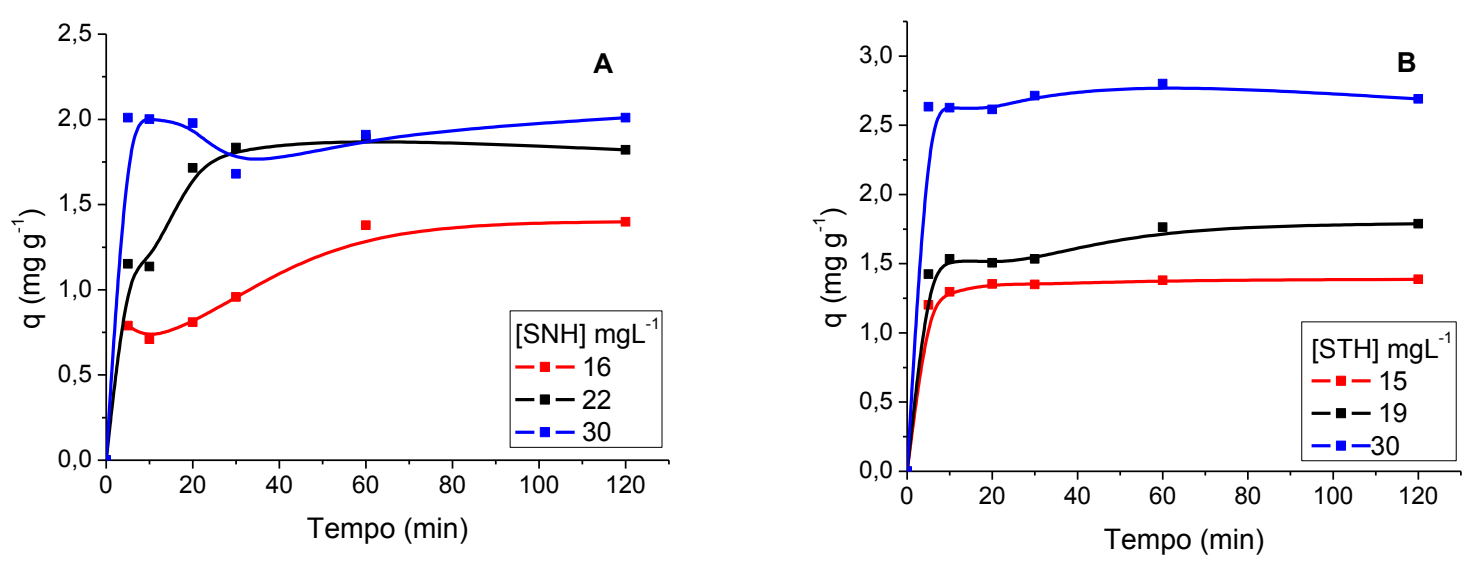

FIGURA 20 - Efeito do tempo de agitação e da concentração do SNH (A) e STH (B) sobre a capacidade de adsorção da ZLM $\left(\mathrm{T}=25^{\circ} \mathrm{C} ; \mathrm{pH}=9\right)$
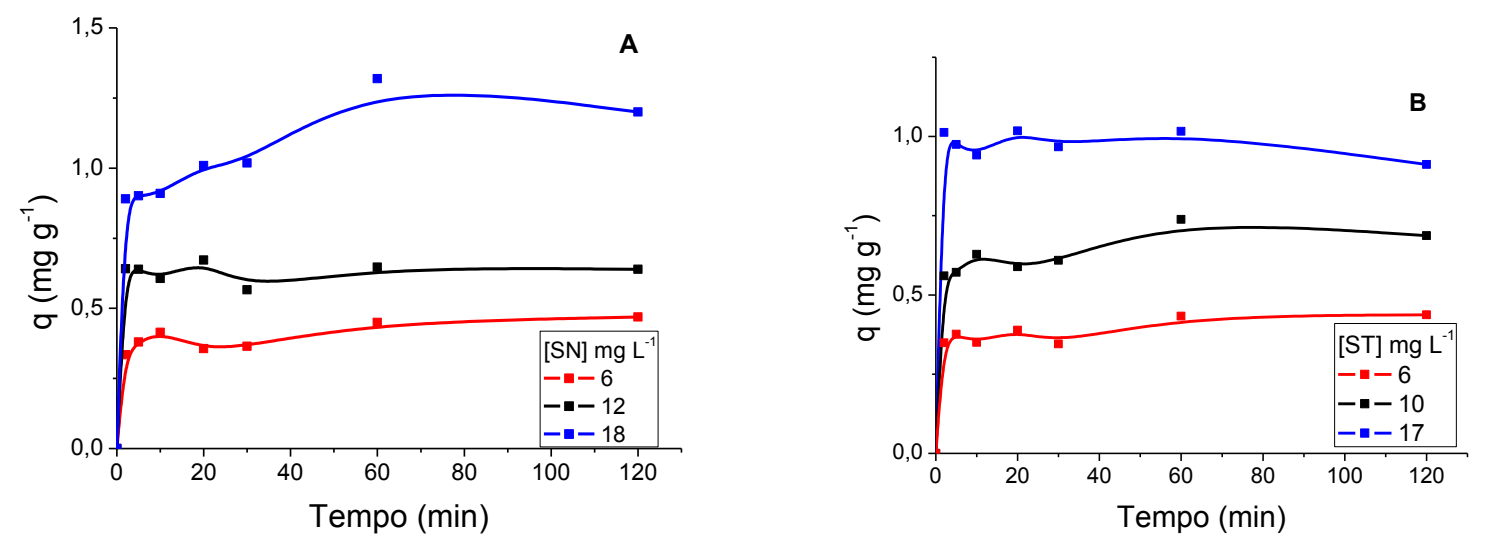

FIGURA 21 - Efeito do tempo de agitação e da concentração do SN (A) e ST(B) sobre a capacidade de adsorção da ZPM $\left(T=25^{\circ} \mathrm{C} ; \mathrm{pH}=5\right)$ 

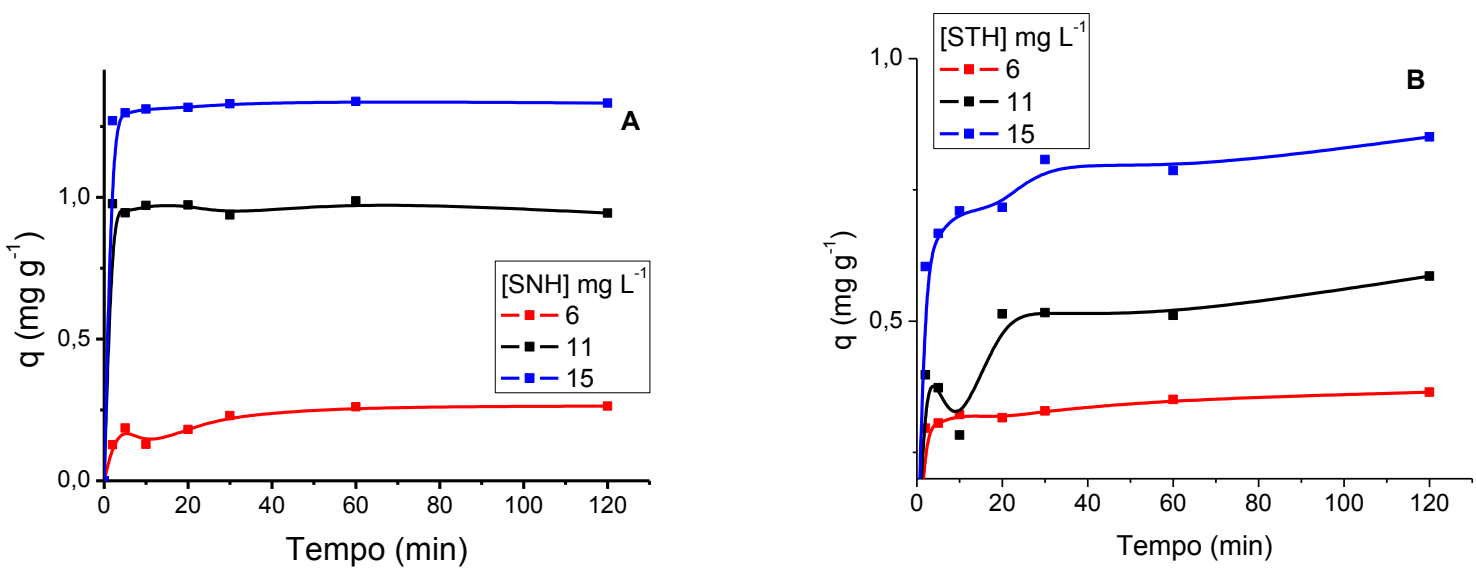

FIGURA 22 - Efeito do tempo de agitação e da concentração do SNH (A) e STH (B) sobre a capacidade de adsorção da ZPM $\left(\mathrm{T}=25^{\circ} \mathrm{C} ; \mathrm{pH}=9\right)$

A TAB. 17 mostra os resultados obtidos no estudo da cinética de adsorção dos corantes sobre as zeólitas modificadas.

Tabela 17: Comparação dos resultados obtidos no estudo de cinética de adsorção dos corantes sobre as zeólitas modificadas

\begin{tabular}{cccc}
\hline Adsorvente & Corante & $\begin{array}{c}\text { Tempo de equilíbrio } \\
\text { (min) }\end{array}$ & $\begin{array}{c}\text { Remoção } \\
(\%)\end{array}$ \\
\hline ZLM & SN & 20 & 78 \\
& ST & 20 & 85 \\
& SNH & 30 & 66 \\
& STH & 30 & 91 \\
\hline ZPM & SN & 60 & 70 \\
& ST & 60 & 67 \\
& SNH & 20 & 69 \\
& STH & 30 & 53 \\
\hline
\end{tabular}

É possível observar que o tempo de equilíbrio foi independente da concentração inicial dos corantes. A taxa de adsorção foi rápida no início (primeiros 10 min) e tornou-se mais lenta nas fases posteriores do processo de adsorção para ambos os corantes na forma hidrolisada e não hidrolisada.

Como observado na TAB. 17 o tempo de equilíbrio para ST e SN sobre ZLM foi de $20 \mathrm{~min}$. Esse tempo foi de $60 \mathrm{~min}$ para SN e ST sobre ZPM, o triplo do valor encontrado para ZLM.

Esses resultados já eram esperados uma vez que a ZLM possui partículas com diâmetros menores quando comparados a ZPM devido às características granulométricas das cinzas de carvão que serviram como matéria-prima para a sintetização das zeólitas. Assim pode-se concluir que na modificação das zeólitas, mesmo com a quantidades idênticas de surfactante para ambas as zeólitas, a ZL adsorve mais surfactante quando comparada a ZP, fazendo com que esse adsorvente seja mais efetivo para remoção desses corantes. Esse resultado é corroborado pela CTCE das zeólitas, que apresentam valores de 0,628 e 0,266 meq $\mathrm{g}^{-1}$ para ZL e ZP, respectivamente.

Em relação aos corantes hidrolisados, pode-se concluir que possivelmente após a hidrólise, com a redução do tamanho da molécula de ambos os corantes, o tempo de equilíbrio apresentou diferença pouco significativa quando comparamos os adsorventes ZLM e ZPM ( $30 \mathrm{~min})$. O corante SN apresenta uma molécula maior que a 
do corante ST, contudo não foi observado uma interferência na velocidade de adsorção desse corantes após a hidrólise.

A eficiência da adsorção aumentou com o aumento da concentração inicial dos corantes, em ambas as formas para ambos os adsorventes. A remoção rápida do adsorbato e o alcance de equilíbrio em um período curto de tempo são uma das indicações que o adsorvente é eficiente e também possibilita que o tratamento de efluentes seja mais econômico

\subsubsection{Modelagem cinética}

As cinéticas de adsorção foram descritas pelos modelos de pseudo-primeiraordem e de pseudo-segunda-ordem utilizando-se as equações de Lagergren e Ho (equação 1 e 2, respectivamente). As FIG. 23, 24, 25 e 26 mostram os ajustes dos resultados do processo de adsorção aos vários modelos cinéticos. Os respectivos parâmetros obtidos a partir dos gráficos lineares encontram-se na TAB. 18 e 19.

TABELA 18: Parâmetros cinéticos para a remoção do Solophenyl Navy (SN) e Solophenyl Turquesa (ST) e suas formas hidrolisadas (SNH e STH) sobre a zeólita leve modificada por surfactante (ZLM).

\begin{tabular}{|c|c|c|c|c|c|}
\hline \multirow[b]{2}{*}[\mathrm{C}_{\mathrm{in}}]{$\left(\mathrm{mgL}^{-1}\right)$} & \multicolumn{4}{|c|}{ Pseudo primeira-ordem } & \\
\hline & $\mathrm{K}_{1}(\mathrm{~min})^{-1}$ & $\mathrm{q}_{\mathrm{e}}$ calc $(\mathrm{mg} / \mathrm{g})$ & $q_{e} \exp (m g / g)$ & $R_{1}(1)$ & \\
\hline SN 16 & $1,14 \times 10^{-2}$ & 0,182 & 1,45 & 0,257 & \\
\hline SN 22 & $58,0 \times 10^{-2}$ & 5,97 & 1,69 & 0,999 & \\
\hline SN 31 & $9,90 \times 10^{-2}$ & 0,792 & 2,34 & 0,971 & \\
\hline SNH 16 & $1,51 \times 10^{-2}$ & 0,707 & 1,37 & 0,849 & \\
\hline SHN 22 & $11,2 \times 10^{-2}$ & 1,66 & 1,88 & 0,981 & \\
\hline SNH 31 & $3,33 \times 10^{-2}$ & 0,0846 & 1,91 & 0,999 & \\
\hline \multirow[b]{2}{*}[\mathrm{C}_{\mathrm{in}}]{$\left(\mathrm{mgL}^{-1}\right)$} & \multicolumn{4}{|c|}{ Pseudo segunda-ordem } & \\
\hline & $\mathrm{K}_{2}(\mathrm{~g} / \mathrm{mg} \min )$ & $\mathrm{h}(\mathrm{mg} / \mathrm{g} \mathrm{min})$ & qecalc $(\mathrm{mg} / \mathrm{g})$ & $q_{e} \exp (\mathrm{mg} / \mathrm{g})$ & $\mathrm{R}_{2}{ }^{(2)}$ \\
\hline SN 16 & 1,11 & 2,15 & 1,39 & 1,45 & 0,999 \\
\hline SN 22 & 0,616 & 2,05 & 1,82 & 1,69 & 0,998 \\
\hline SN 31 & 0,149 & 0,988 & 2,57 & 2,34 & 0,999 \\
\hline SNH 16 & 0,0783 & 0,171 & 1,48 & 1,37 & 0,988 \\
\hline SHN 22 & 0,246 & 0,861 & 1,87 & 1,88 & 0,998 \\
\hline SNH 31 & 0,416 & 1,66 & 2,002 & 1,91 & 0,998 \\
\hline \multirow[b]{2}{*}{ [Cin] $\left(\mathrm{mgL}^{-1}\right)$} & \multicolumn{4}{|c|}{ Pseudo primeira-ordem } & \\
\hline & $\mathrm{K}_{1}(\min )^{-1}$ & $\mathrm{qe}_{\mathrm{e}}$ calc $(\mathrm{mg} / \mathrm{g})$ & $\mathrm{q}_{\mathrm{e}} \exp (\mathrm{mg} / \mathrm{g})$ & $\mathrm{R}_{1}{ }^{(1)}$ & \\
\hline ST 16 & $0,011 \times 10^{-2}$ & $17,9 \times 10^{-2}$ & 1,41 & 0,0832 & \\
\hline ST 21 & $3,91 \times 10^{-2}$ & $0,368 \times 10^{-2}$ & 1,86 & 0,484 & \\
\hline ST 31 & $2,53 \times 10^{-2}$ & $47,5 \times 10^{-2}$ & 2,47 & 0,281 & \\
\hline STH 15 & $20,3 \times 10^{-2}$ & 0,404 & 1,34 & 0,999 & \\
\hline STH 19 & $2,81 \times 10^{-2}$ & 0,204 & 1,53 & 0,943 & \\
\hline STH 30 & $1,41 \times 10^{-2}$ & 0,749 & 2,71 & 0,997 & \\
\hline \multirow[b]{2}{*}[\mathrm{C}_{\text{in}}]{$\left(\mathrm{mgL}^{-1}\right)$} & \multicolumn{3}{|c|}{ Pseudo segunda-ordem } & & \\
\hline & $\mathrm{K}_{2}(\mathrm{~g} / \mathrm{mg} \min )$ & $\mathrm{h}(\mathrm{mg} / \mathrm{g} \mathrm{min})$ & qecalc $(\mathrm{mg} / \mathrm{g})$ & $q_{e} \exp (\mathrm{mg} / \mathrm{g})$ & $\mathrm{R}_{2}{ }^{(2)}$ \\
\hline ST 16 & 0,231 & 0,592 & 1,61 & 1,41 & 0,998 \\
\hline ST 21 & 1,72 & 6,28 & 1,91 & 1,86 & 0,999 \\
\hline ST 31 & 0,263 & 1,48 & 2,37 & 2,47 & 0,994 \\
\hline STH 15 & 0,974 & 1,74 & 1,39 & 1,34 & 0,999 \\
\hline STH 19 & 0,254 & 0,594 & 1,82 & 1,53 & 0,999 \\
\hline STH 30 & 0,469 & 0,334 & 2,71 & 2,71 & 0,999 \\
\hline
\end{tabular}

(1) $R_{1}=$ Coeficiente de correlação do modelo de pseudo-primeira-ordem; (2) $R_{2}=$ Coeficiente de correlação do modelo de pseudo segunda-ordem. 
TABELA 19: Parâmetros cinéticos para a remoção do Solophenyl Navy (SN) e Solophenyl Turquesa (ST) e suas formas hidrolisadas (SNH e STH) sobre a zeólita pesada modificada por surfactante (ZPM).

\begin{tabular}{|c|c|c|c|c|c|}
\hline \multicolumn{6}{|c|}{ Pseudo primeira-ordem } \\
\hline$\left[\mathrm{C}_{\mathrm{in}}\right]\left(\mathrm{mgL}^{-1}\right)$ & $\mathrm{K}_{1}(\min )^{-1}$ & $\mathrm{q}_{\mathrm{e}}$ calc $(\mathrm{mg} / \mathrm{g})$ & $q_{e} \exp (\mathrm{mg} / \mathrm{g})$ & $\mathrm{R}_{1}{ }^{(1)}$ & \\
\hline SN 6 & $4,01 \times 10^{-2}$ & 0,181 & 0,365 & 0,413 & \\
\hline SN 10 & $24,8 \times 10^{-2}$ & 5,97 & 0,000305 & 0,971 & \\
\hline SN 17 & $1,43 \times 10^{-2}$ & 0,0846 & 1,91 & 0,999 & \\
\hline SNH 6 & $0,472 \times 10^{-2}$ & 0,0545 & 0,181 & 0,999 & \\
\hline SNH 11 & $15,6 \times 10^{-2}$ & 0,885 & 0,973 & 0,973 & \\
\hline SNH 15 & $44,9 \times 10^{-2}$ & 0,325 & 1,31 & 0,997 & \\
\hline \multicolumn{6}{|c|}{ Pseudo segunda-ordem } \\
\hline$\left[\mathrm{C}_{\mathrm{in}}\right]\left(\mathrm{mgL}^{-1}\right)$ & $\mathrm{K}_{2}(\mathrm{~g} / \mathrm{mg} \min )$ & $\mathrm{h}(\mathrm{mg} / \mathrm{g} \min )$ & qecalc $(\mathrm{mg} / \mathrm{g})$ & $q_{e} \exp (\mathrm{mg} / \mathrm{g})$ & $\mathrm{R}_{2}{ }^{(2)}$ \\
\hline SN 6 & 1,24 & 0,168 & 0,472 & 0,365 & 0,997 \\
\hline SN 10 & 3,01 & 1,26 & 0,641 & 0,647 & 0,999 \\
\hline SN 17 & 0,273 & 0,468 & 1,24 & 1,31 & 0,996 \\
\hline SNH 6 & 1,36 & 0,044 & 0,277 & 0,181 & 0,996 \\
\hline SNH 11 & 3,04 & 2,91 & 0,948 & 0,973 & 0,999 \\
\hline SNH 15 & 6,09 & 10,4 & 1,29 & 1,31 & 0,999 \\
\hline \multicolumn{6}{|c|}{ Pseudo primeira-ordem } \\
\hline$\left[\mathrm{C}_{\mathrm{in}}\right]\left(\mathrm{mgL}^{-1}\right)$ & $\mathrm{K}_{1}(\min )^{-1}$ & $q_{e}$ calc $(\mathrm{mg} / \mathrm{g})$ & $q_{e} \exp (m g / g)$ & $\mathrm{R}_{1}{ }^{(1)}$ & \\
\hline ST 6 & $0,0856 \times 10^{-2}$ & 0,00212 & 0,433 & 0,0141 & \\
\hline ST 12 & $0,817 \times 10^{-2}$ & 0,161 & 0,738 & 0,482 & \\
\hline ST 18 & $37,3 \times 10^{-2}$ & 6,74 & 1,016 & 0,885 & \\
\hline STH 6 & $237,2 \times 10^{-2}$ & 1,06 & 0,329 & 0,709 & \\
\hline STH 11 & $23,6 \times 10^{-2}$ & 0,471 & 0,516 & 0,567 & \\
\hline STH 15 & $168 \times 10^{-2}$ & 0,184 & 0,808 & 0,834 & \\
\hline \multicolumn{6}{|c|}{ Pseudo segunda-ordem } \\
\hline$\left[\mathrm{C}_{\mathrm{in}}\right]\left(\mathrm{mgL}^{-1}\right)$ & $\mathrm{K}_{2}$ (g/mg $\left.\min \right)$ & $\mathrm{h}(\mathrm{mg} / \mathrm{g} \mathrm{min})$ & qecalc $(\mathrm{mg} / \mathrm{g})$ & $q_{e} \exp (\mathrm{mg} / \mathrm{g})$ & $\mathrm{R}_{2}{ }^{(2)}$ \\
\hline ST 6 & 0,871 & 0,163 & 0,444 & 0,443 & 0,997 \\
\hline ST 12 & 0,799 & 0,435 & 0,702 & 0,738 & 0,998 \\
\hline ST 18 & 1,41 & 1,45 & 0,925 & 1,016 & 0,998 \\
\hline STH 6 & 1,751 & 0,191 & 0,367 & 0,329 & 0,999 \\
\hline STH 11 & 0,432 & 0,115 & 0,599 & 0,516 & 0,995 \\
\hline STH 15 & 0,588 & 0,383 & 0,856 & 0,808 & 0,999 \\
\hline
\end{tabular}

(1) $R_{1}$ = Coeficiente de correlação do modelo de pseudo-primeira-ordem; (2) $R_{2}=$ Coeficiente de correlação do modelo de pseudo segunda-ordem

A avaliação quantitativa dos modelos foi realizada pela comparação dos coeficientes de correlação (R). Verifica-se pelas FIG. 23 e 24 e pelos dados das TAB. 18 e 19 que os coeficientes de correlação $R_{2}$ foram maiores que aqueles de $R_{1}$ para quase todos os sistemas corante/adsorvente, confirmando que o mecanismo de adsorção segue o modelo de pseudo segunda-ordem.

É possível confirmar esse mecanismo também pela comparação dos valores de qe calculado ( $\left.q_{e} c a l c\right)$ com os valores de qe determinado experimental ( $q_{e}$ exp), onde a maior proximidade dos valores sugere uma melhor aplicabilidade ao modelo.

Observam-se também pelas TAB. 18 e 19 que as constantes de velocidade $\left(\mathrm{k}_{2}\right)$ decrescem com o aumento da concentração inicial da solução de corante para o sistema SN/ ZLM e STH/ZPM, indicando que a adsorção é mais rápida para menores concentrações de soluto. O processo inverso é observado para SNH pela ZLM e ZPM, onde os valores de $\mathrm{k}_{2}$ aumentam com o aumento da concentração inicial da solução. Para os demais sistemas corante/adsorvente, no entanto, não foi observado esse comportamento, sendo que não houve uma variação proporcional de $\mathrm{k}_{2} \mathrm{com}$ a concentração do corante. Ainda que alguns trabalhos da literatura mencionem que se um processo de adsorção segue a cinética do modelo de pseudo segunda-ordem é porque o mecanismo determinante é a quimissorção, acredita-se que atualmente não há nenhum ensaio que forneça evidencia experimental para tal afirmação. Isso não ocorre 
mesmo quando o coeficiente de determinação for próximo da unidade e houver proximidade entre os resultados de qe obtidos experimentalmente e de qe calculado usando-se a equação do modelo de pseudo segunda-ordem. Assim, outros estudos precisariam ser realizados para corroborar tal afirmação (Carvalho, 2010).

Embora os coeficientes de correlação de pseudo primeira-ordem $\left(R_{1}\right)$ sejam maiores que 0,9 para as concentrações 22 e $31 \mathrm{mgL}^{-1}$ para SN e SNH e 16, 21 e $31 \mathrm{mgL}^{-}$ 1 para STH desses sistemas, não há ajuste dos dados ao modelo de pseudo primeiraordem, pois os valores de qe obtidos experimentalmente (qe exp) são diferentes dos de qe calculado $\left(q_{\text {calc }}\right)$. Portanto os valores dos coeficientes de correlação do modelo pseudo primeira-ordem não foram aplicáveis para os sistemas estudados.

Estudos realizados por Azizian (2004) revelaram que, com o aumento inicial da concentração do soluto, a correlação dos dados experimentais ao modelo cinético de pseudo segunda-ordem diminui enquanto que, para o modelo de pseudo primeira-ordem, aumenta, isto é, quando a concentração inicial do soluto é baixa, o processo obedece ao modelo de pseudo segunda-ordem.
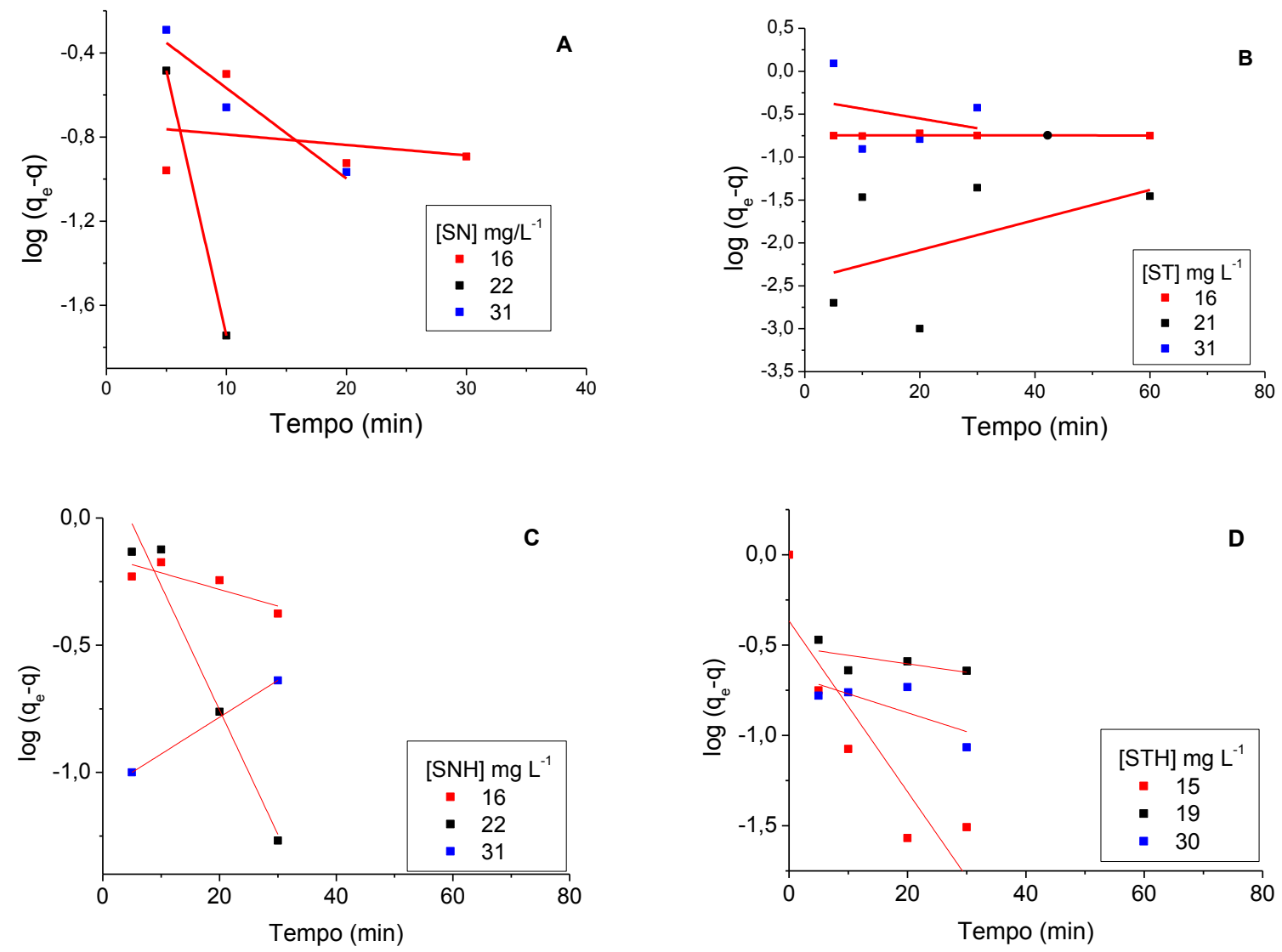

FIGURA 23: Comparação entre os modelos cinéticos da adsorção do $S N(A), S T(B)$, SNH (C) e STH (D) sobre zeólita leve modificada por surfactante (ZLM): cinética de pseudo primeira-ordem 

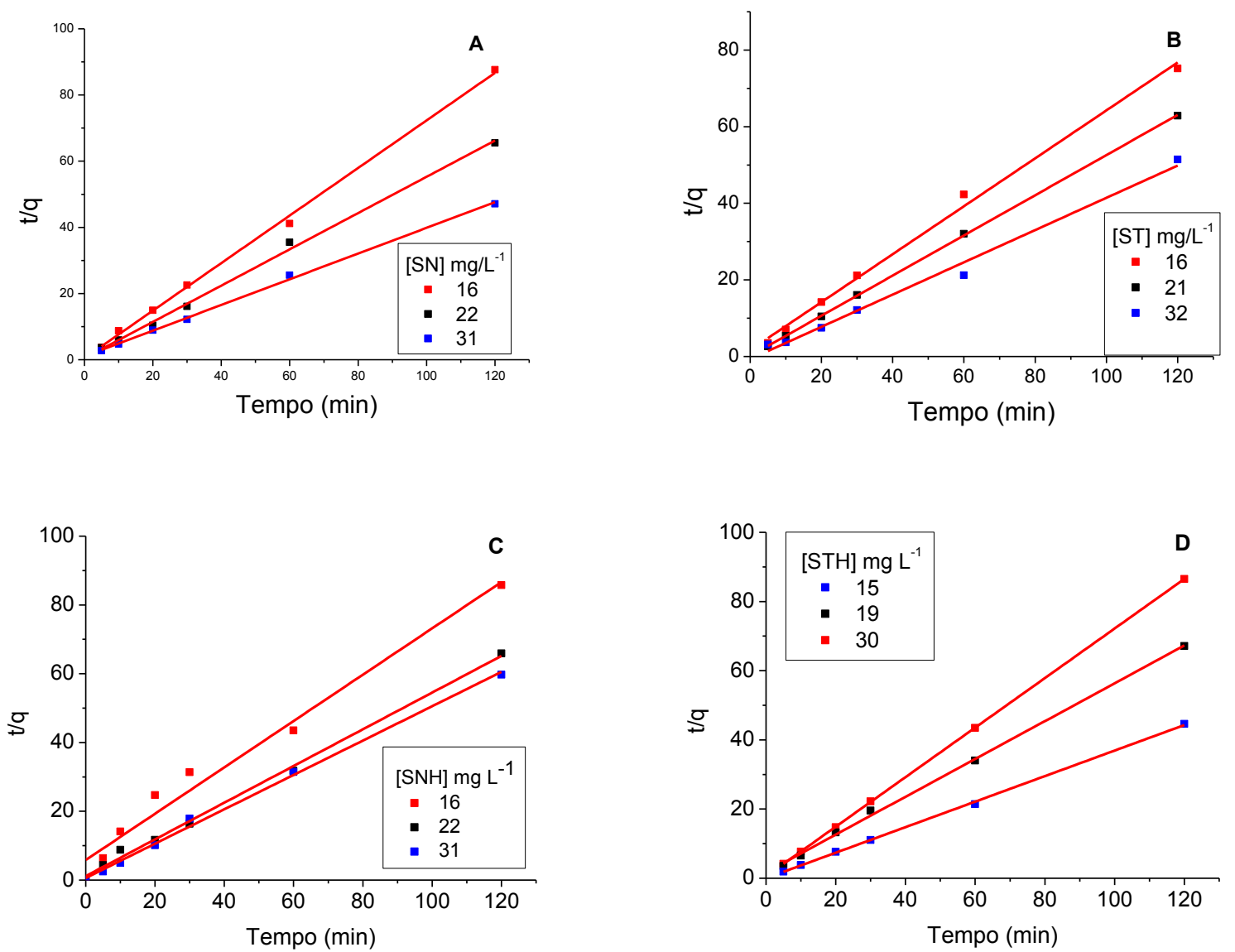

FIGURA 24: Comparação entre os modelos cinéticos da adsorção do $S N(A), S T(B)$, SNH (C) e STH (D) sobre zeólita leve modificada por surfactante (ZLM): cinética de pseudo segunda-ordem 

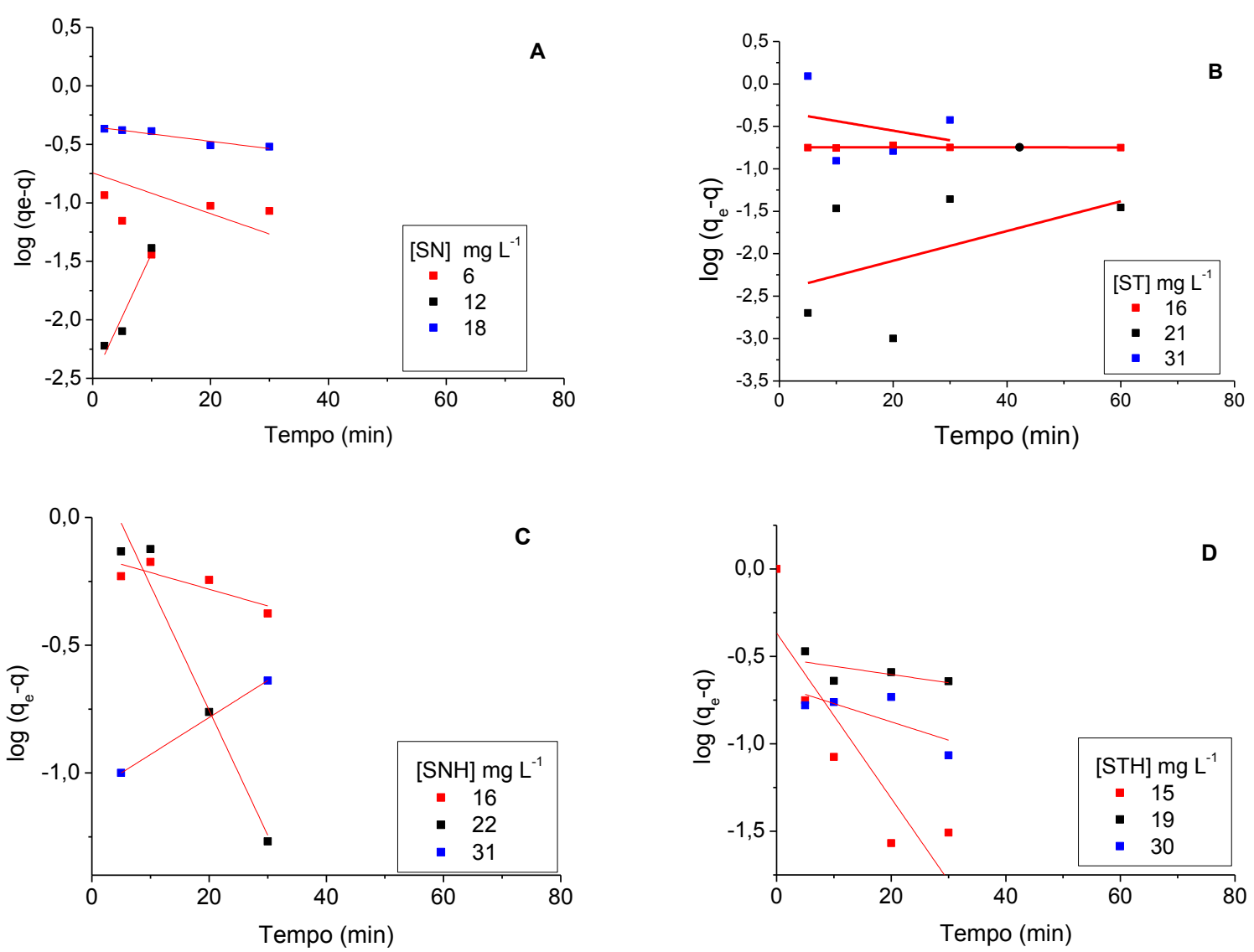

FIGURA 25: Comparação entre os modelos cinéticos da adsorção do SN (A), ST (B), SNH (C) e STH (D) sobre zeólita pesada modificada por surfactante (ZPM): cinética de pseudo primeira-ordem 

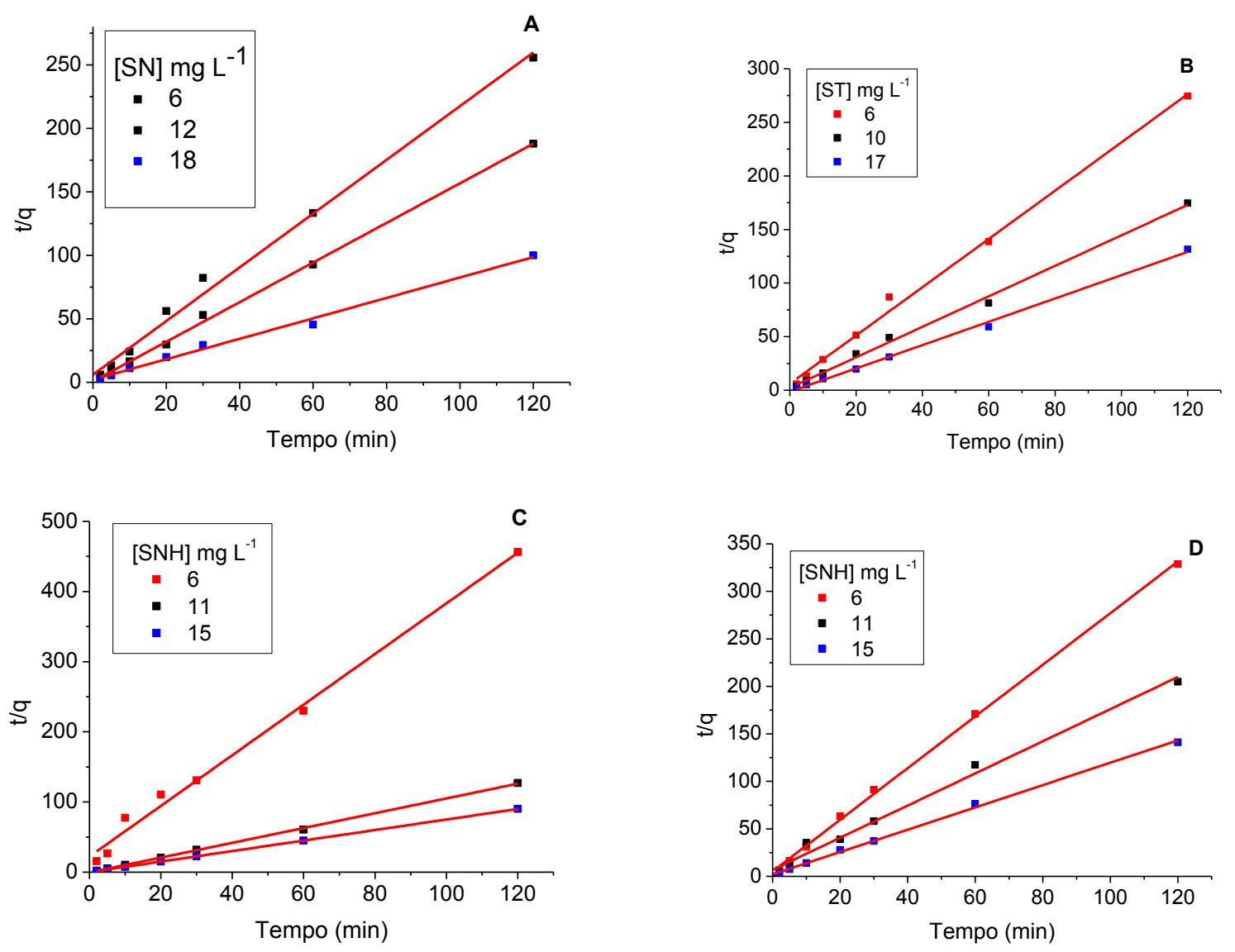

FIGURA 26: Comparação entre os modelos cinéticos da adsorção do SN (A), ST (B), SNH (C) e STH (D) sobre zeólita pesada modificada por surfactante (ZPM): cinética de pseudo segunda-ordem

A difusão externa em processos de adsorção tem sido estudada segundo o modelo proposto por Lee et al. (1999). Essa etapa é associada à velocidade inicial da adsorção e é caracterizada pelo coeficiente de difusão externa ( $\beta$ ). Nas FIG. 27 e 28 são apresentadas as curvas de $\mathrm{Ln} \mathrm{C}_{\mathrm{e}} / \mathrm{C}_{0}$ (sendo $\mathrm{C}_{\mathrm{e}}$ e $\mathrm{C}_{0}$ as concentrações no tempo te inicial do corante) em função do tempo; as quais permitem determinar o valor dos parâmetros cinéticos para a difusão externa. 

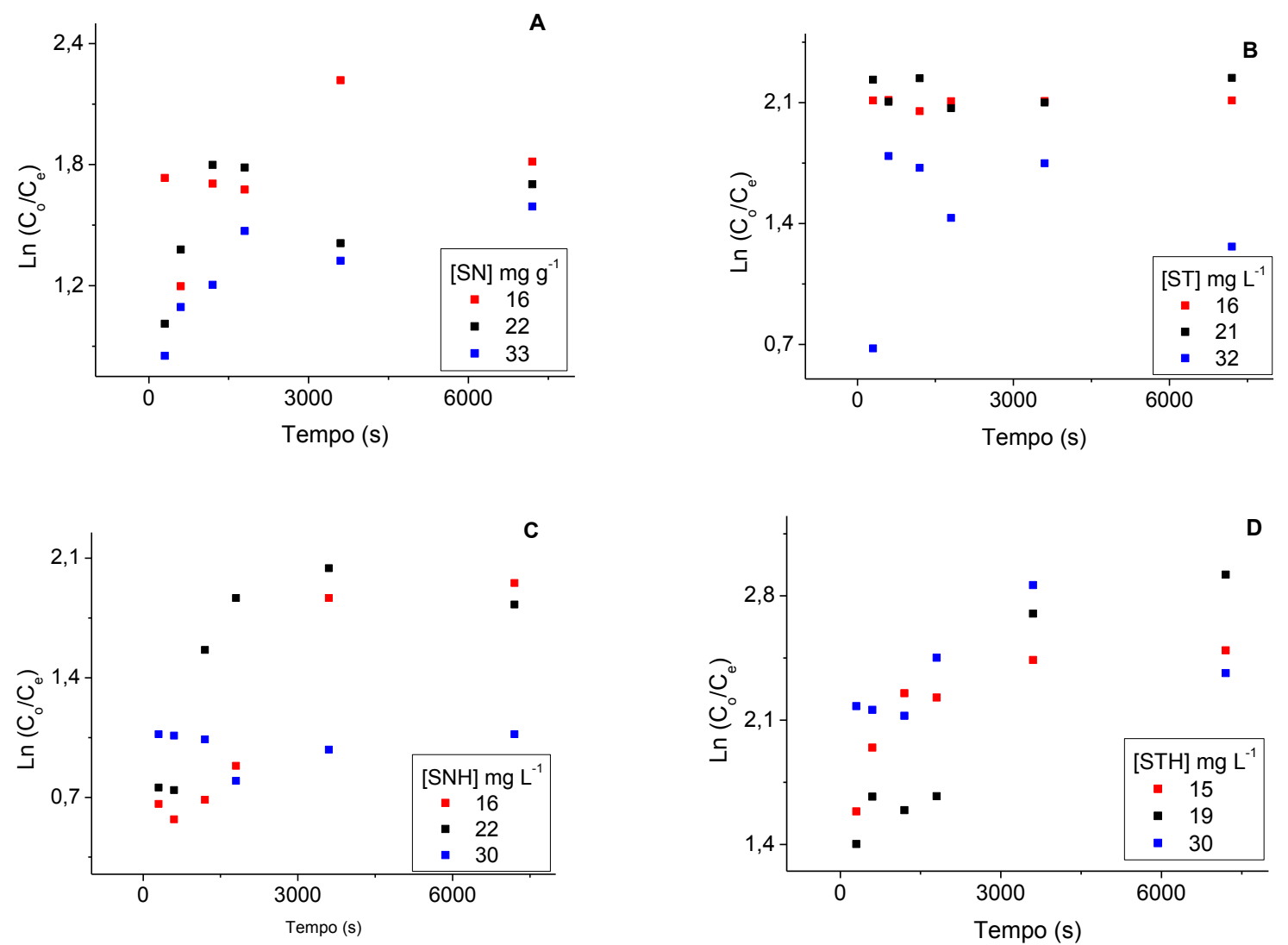

FIGURA 27: Curvas para a sorção dos corantes SN (A), ST(B), SNH (C) e STH (D) sobre a zeólita leve modificada por surfactante (ZLM) de acordo com o modelo da difusão externa. 

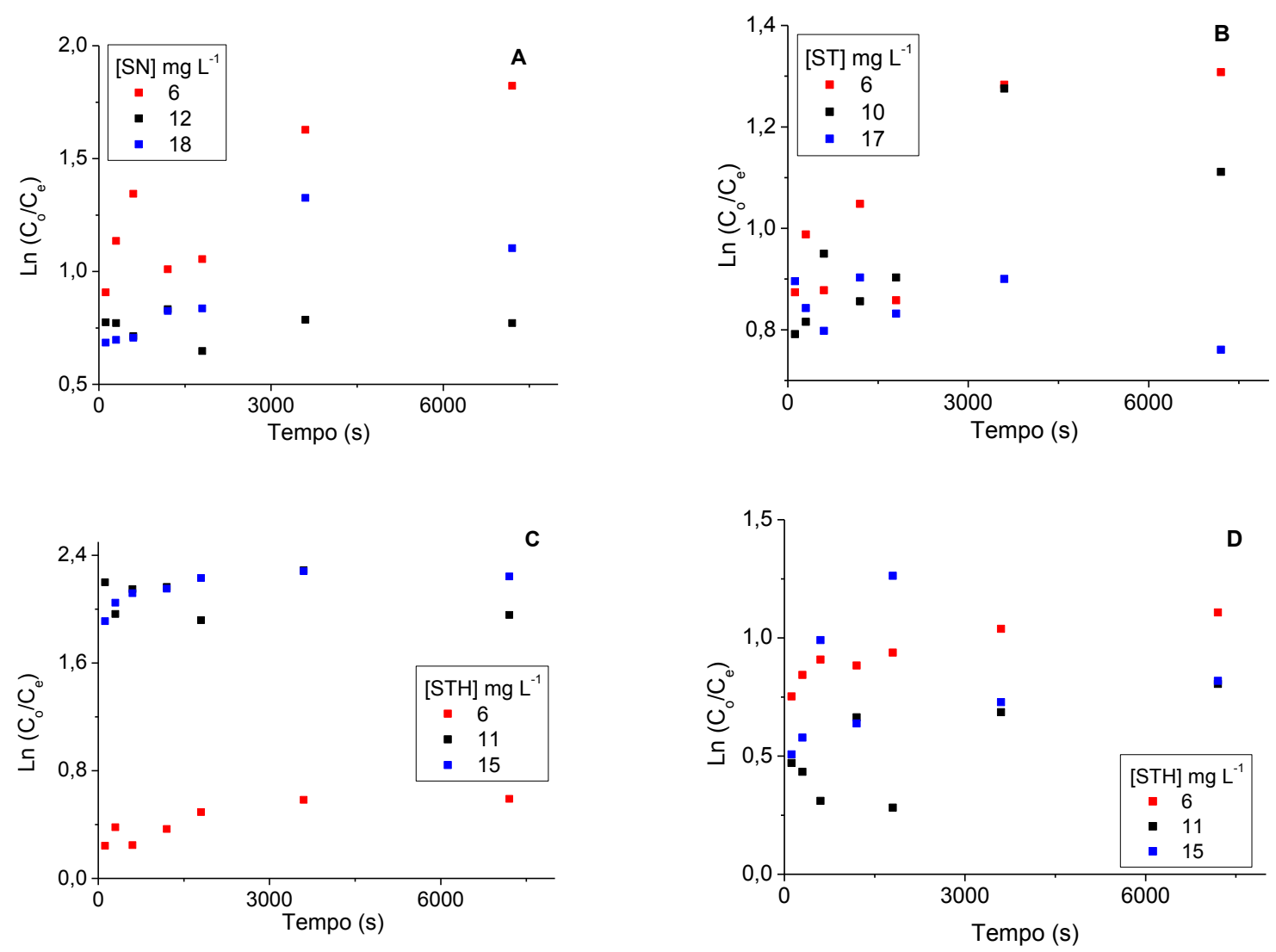

FIGURA 28: Curvas para a sorção dos corantes SN (A), ST(B), SNH (C) e STH (D) sobre a zeólita pesada modificada por surfactante (ZPM) de acordo com o modelo da difusão externa.

$\mathrm{Na}$ TAB.20 estão apresentados os valores determinados para os sistemas zeólitas/corantes para a constante $\beta$. O modelo de difusão externa pode ser importante no mecanismo de adsorção dos corantes pela zeólita modificada. $O$ coeficiente de transferência externa de massa ( $\beta$ ) fornece a velocidade de difusão do corante pelo filme que envolve a partícula da zeólita, passo associado à velocidade inicial do processo de adsorção. 
TABELA 20: Parâmetros cinéticos para os sistemas ZLM e ZPM para os corantes ST e $\mathrm{SN}$ e suas formas hidrolisadas pela difusão externa

\begin{tabular}{|c|c|c|c|c|}
\hline ZLM & $\mathrm{SN}\left(\mathrm{mgL}^{-1}\right)$ & $\beta\left(\mathrm{m} \mathrm{s}^{-1}\right)$ & $\mathrm{SNH}\left(\mathrm{mgL}^{-1}\right)$ & $\beta\left(\mathrm{m} \mathrm{s}^{-1}\right)$ \\
\hline & 16 & $91,9 \times 10^{-10}$ & 16 & $3,43 \times 10^{-10}$ \\
\hline & 22 & $72,1 \times 10^{-10}$ & 22 & $2,22 \times 10^{-10}$ \\
\hline & 32 & $1,26 \times 10^{-10}$ & 30 & $5,77 \times 10^{-10}$ \\
\hline & ST $\left(\mathrm{mgL}^{-1}\right)$ & $\beta\left(\mathrm{m} \mathrm{s}^{-1}\right)$ & STH $\left(\mathrm{mgL}^{-1}\right)$ & $\beta\left(\mathrm{m} \mathrm{s}^{-1}\right)$ \\
\hline & 16 & $328 \times 10^{-10}$ & 15 & $1,54 \times 10^{-10}$ \\
\hline & 21 & $10,5 \times 10^{-10}$ & 19 & $3,56 \times 10^{-10}$ \\
\hline & 32 & $794 \times 10^{-10}$ & 30 & $7,31 \times 10^{-10}$ \\
\hline ZPM & $\mathrm{SN}\left(\mathrm{mgL}^{-1}\right)$ & $\beta\left(\mathrm{m} \mathrm{s}^{-1}\right)$ & SNH $\left(\mathrm{mgL}^{-1}\right)$ & $\beta\left(\mathrm{m} \mathrm{s}^{-1}\right)$ \\
\hline & 6 & $3,23 \times 10^{-10}$ & 6 & $1,31 \times 10^{-10}$ \\
\hline & 12 & $611 \times 10^{-10}$ & 11 & $34,2 \times 10^{-10}$ \\
\hline & 18 & $2,04 \times 10^{-10}$ & 15 & $97 \times 10^{-10}$ \\
\hline & ST $\left(\mathrm{mgL}^{-1}\right)$ & $\beta\left(\mathrm{m} \mathrm{s}^{-1}\right)$ & STH $\left(\mathrm{mgL}^{-1}\right)$ & $\beta\left(\mathrm{m} \mathrm{s}^{-1}\right)$ \\
\hline & 6 & $1,75 \times 10^{-10}$ & 6 & $1,18 \times 10^{-10}$ \\
\hline & 10 & $1,41 \times 10^{-10}$ & 11 & $1,59 \times 10^{-10}$ \\
\hline & 17 & $30,2 \times 10^{-10}$ & 15 & $49,1 \times 10^{-10}$ \\
\hline
\end{tabular}

Como observado na TAB 20, o único sistema que apresentou uma tendência dos valores de $\beta$ decrescerem com o aumento da concentração do soluto foi o sistema ZLM/SN. Esse comportamento pode ser relacionado à maior competição pela superfície da zeólita e, também, pelas interações entre as moléculas do soluto. Para os sistemas ZLM/STH, ZPM/SNH e ZPM/STH o comportamento inverso foi observado, com os valores de $\beta$ aumentaram com o aumento da concentração inicial do corante. Para o restante dos sistemas (ZLM/ST, ZLM/SNH, ZPM/SN e ZPM/ST) não foi observada nenhuma correlação. Resultados semelhantes com relação a difusão externa da zeólita leve modificada sobre o corante Ácido Laranja 8 foram reportados por Magdalena (2015).

\subsection{Isotermas de adsorção}

A FIG. 29 mostram as isotermas de adsorção do ST e SN e suas formas hidrolisadas sobre a zeólita ZLM. As isotermas de adsorção dos corantes SN e ST e suas formas hidrolisadas sobre a ZPM são apresentadas na FIG. 30, obtida nos tempos de equilíbrio, em que $\mathrm{C}_{\mathrm{e}}\left(\mathrm{mgL}^{-1}\right)$ corresponde à concentração de equilíbrio do corante na fase líquida e $\mathrm{q}_{\mathrm{e}}\left(\mathrm{mg} \mathrm{g}^{-1}\right)$ é a capacidade de adsorção do adsorvente. 

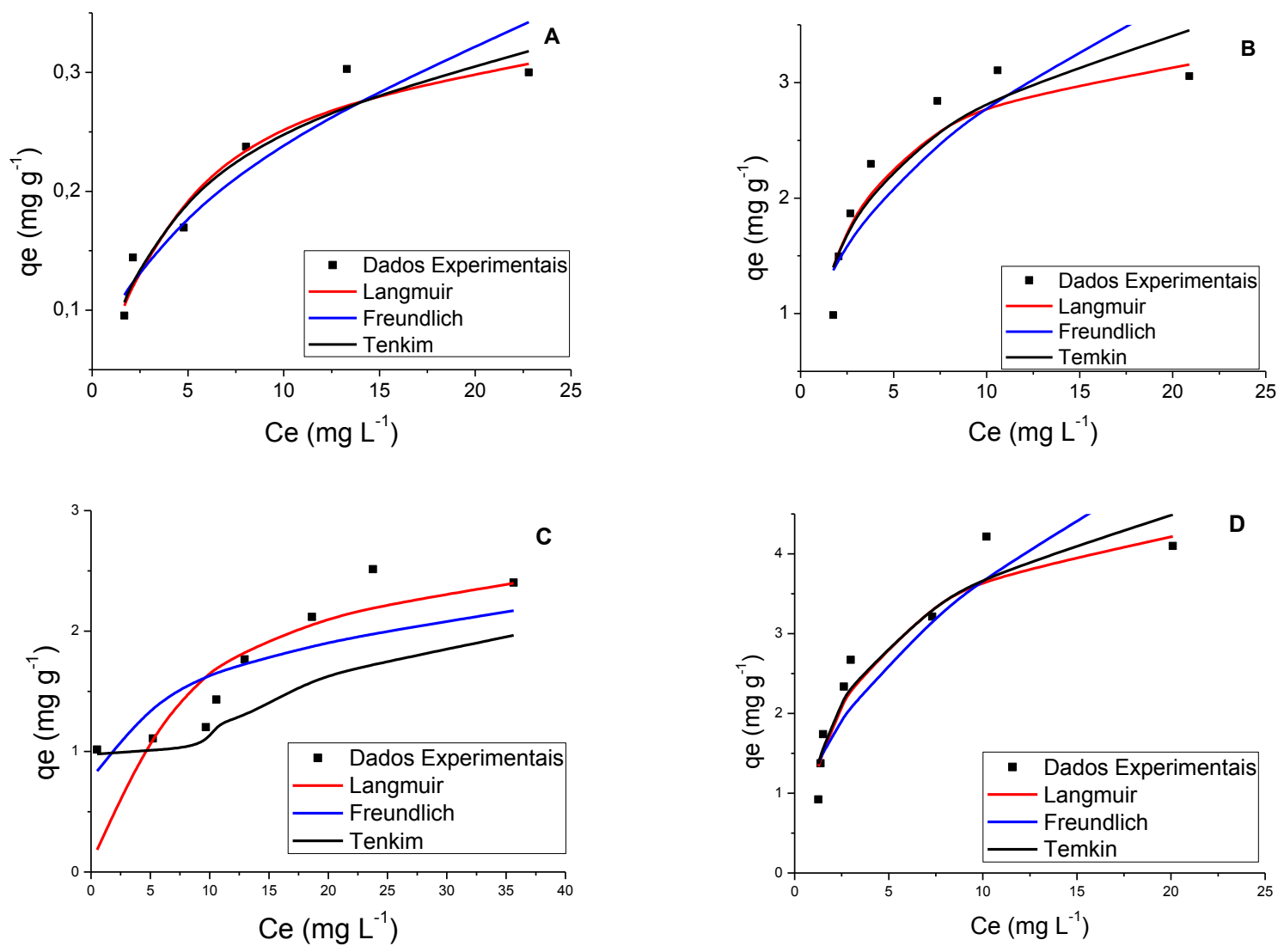

Figura 29: Isoterma de adsorção of Solophenyl Navy (A), Solophenyl Turquesa (B), Solophenyl Navy Hidrolisado (C) e Solophenyl Turquesa Hidrolisado (D) sobre a zeólita leve modificada por surfactante (ZLM) 

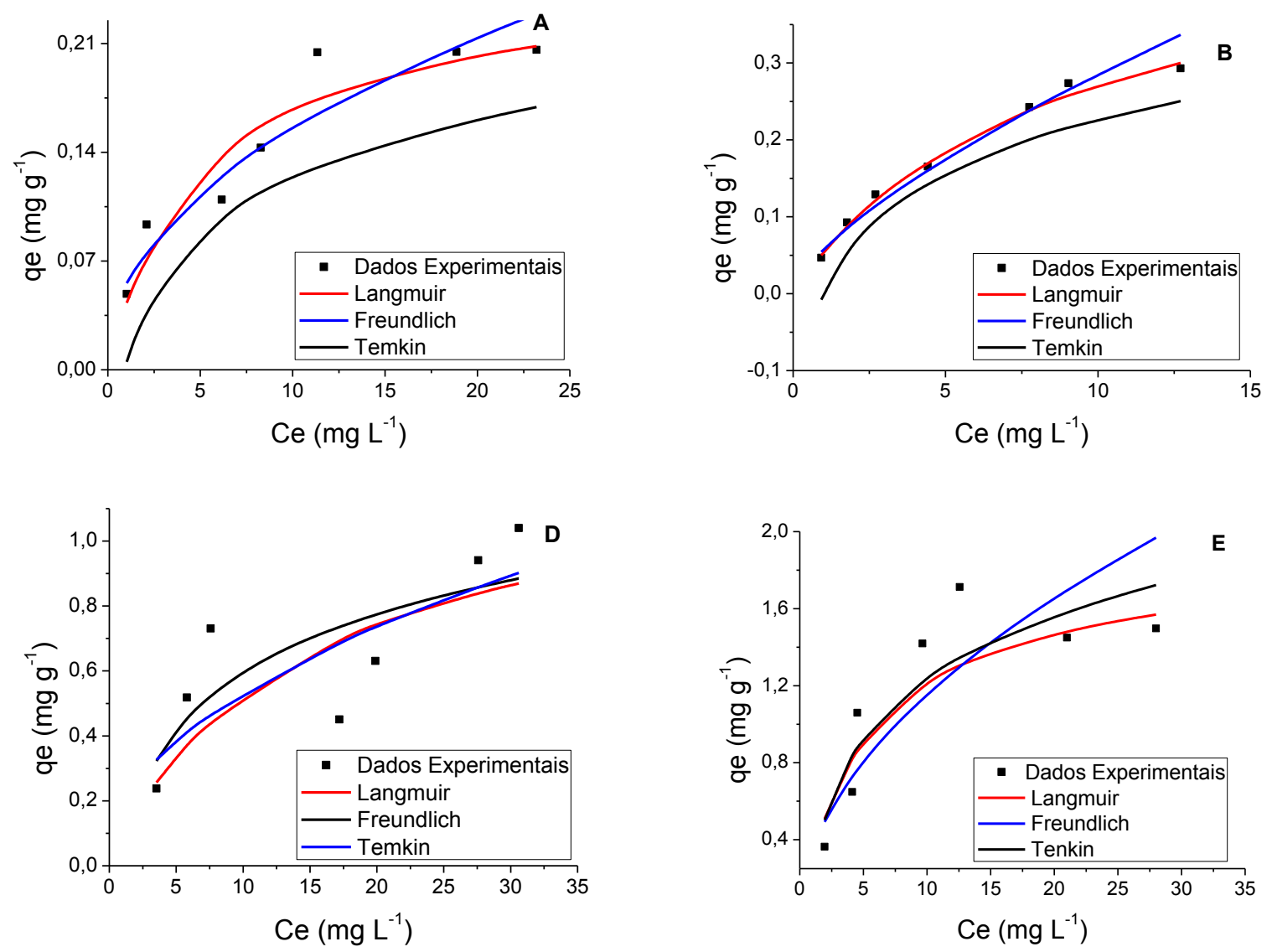

Figura 30: Isoterma de adsorção of Solophenyl Navy (A), Solophenyl Turquesa (B), Solophenyl Navy Hidrolisado (C) e Solophenyl Turquesa Hidrolisado (D) sobre a zeólita pesada modificada por surfactante (ZPM)

$\mathrm{Na}$ TAB. 21 pode-se observar de maneira resumida a classificação as isotermas segundo Giles (1960) dos corantes ST e SN e suas formas hidrolisadas.

TABELA 21: Classificação das isotermas dos corantes SN e ST e suas formas hidrolisadas, segundo Giles (1960)

\begin{tabular}{ccc}
\hline Corante & ZLM & ZPM \\
\hline SN & L4 & L4 \\
ST & L2 & L2 \\
SNH & S4 & L4 \\
STH & L2 & L2 \\
\hline
\end{tabular}

O formato das curvas das isotermas evidenciaram que os sistemas dos corantes na forma hidrolisada e não hidrolisada sobre ZLM apresentaram comportamento favorável ao processo de adsorção (FIG. 29 e 30).

As isotermas do tipo L2 e L4 indicam a formação de uma monocamada saturada de moléculas do soluto sobre na superfície do adsorvente e que a afinidade de adsorção aumenta com o aumento da concentração do adsorbato até a saturação (Giles et al., 1960).

As curvas do tipo $L$ são as mais conhecidas. Possuem curvatura inicial voltada para baixo devido à diminuição da disponibilidade dos sítios ativos (Giles et al., 1974). A curva L2 ocorre, provavelmente, na maioria dos casos de adsorção em soluções diluídas. (Giles et al., 1960). Esta classificação é típica de uma afinidade relativamente alta entre 
o adsorbato e o adsorvente e, normalmente, ocorre em processo de quimissorção (Giles et al., 1960).

Nas isotermas da classe $S$ (forma sigmoidal), o declive inicial é convexo ao eixo de concentração, e é frequentemente quebrado por um ponto de inflexão levando à forma característica S. Aumentos na concentração são paralelos àqueles da classe L. As isotermas do tipo $S$ tem duas causas. Em primeiro lugar, forças atrativas soluto-soluto na superfície podem causar adsorção cooperativa que leva a forma S. Em segundo lugar, a adsorção de um soluto pode ser inibida por uma reação concorrente dentro da solução, como uma reação de complexação (Giles et al., 1974).

Os parâmetros das isotermas foram determinados para os sistemas corante/adsorventes usando-se as equações linearizadas e não-linearizadas das isotermas. As curvas linearizadas de Langmuir, Freundlich e Temkin da ZLM e ZPM encontram-se nas FIG. 29 e 30. Os respectivos parâmetros obtidos por regressão linear e não-linearizadas são apresentados na TAB. 22 e 23.

Analisando a TAB. 22 e 23 pela comparação dos valores dos coeficientes de correlação $\left(R^{2}\right)$ obtidos dos modelos isotérmicos, verificam-se altos níveis de correlação $\left(R^{2} \geq 0,94\right)$ com o modelo de Langmuir para a maior parte dos sistemas adsorbato/adsorvente nesse estudo, com exceção do o sistema SNH/ZPM que apresentou melhor correlação com o modelo de Freundlich, indicando distribuições homogêneas e heterogêneas induzidas por adsorção em monocamada e multicamada. Isso pode ocorrer simultaneamente ou subsequentemente por ordem de tempo, ambos de forma aleatória (Din \& Hammed, 2010).

TABELA 22: Modelos das isotermas de adsorção para Solophenyl Navy (SN) e Turquesa (ST) e suas formas hidrolisadas (SNH e STH) pela ZLM

\begin{tabular}{|c|c|c|c|c|c|c|c|c|}
\hline & Linear & $\begin{array}{l}\text { Não } \\
\text { Linear }\end{array}$ & Linear & $\begin{array}{l}\text { Não } \\
\text { Linear }\end{array}$ & Linear & $\begin{array}{l}\text { Não } \\
\text { Linear }\end{array}$ & Linear & $\begin{array}{l}\text { Não } \\
\text { Linear }\end{array}$ \\
\hline & \multicolumn{2}{|c|}{ SN } & \multicolumn{2}{|c|}{ ST } & \multicolumn{2}{|c|}{ SNH } & \multicolumn{2}{|c|}{ STH } \\
\hline \multicolumn{9}{|l|}{ Langmuir } \\
\hline$Q_{0}\left(\mathrm{mg} \mathrm{g}^{-1}\right)$ & 3,64 & 3,71 & 3,57 & 3,79 & 2,91 & 3,37 & 4,93 & 5,02 \\
\hline $\mathrm{b}\left(\mathrm{L} \mathrm{mg}^{-1}\right)$ & 0,237 & 0,228 & 0,366 & 0,329 & 0,131 & 0,0832 & 0,295 & 0,306 \\
\hline $\mathrm{R}^{2}$ & 0,991 & -- & 0,988 & -- & 0,942 & -- & 0,984 & -- \\
\hline \multicolumn{9}{|l|}{ Freundlich } \\
\hline $\mathrm{K}_{\mathrm{f}}{ }^{\mathrm{a}}$ & 0,903 & 1 & 1,09 & 1,31 & 0,972 & 0,723 & 1,24 & 1,48 \\
\hline $\mathrm{N}$ & 2,35 & 2,65 & 2,44 & 3,13 & 4,45 & 2,90 & 2,11 & 2,65 \\
\hline $\mathrm{R}^{2}$ & 0,958 & -- & 0,882 & -- & 0,832 & -- & 0,909 & - \\
\hline \multicolumn{9}{|l|}{ Temkin } \\
\hline $\mathrm{Kt}\left(\mathrm{L} \mathrm{g}^{-1}\right)$ & 2,22 & 2,22 & 3,03 & 3,06 & 12,4 & 12,4 & 2,65 & 2,65 \\
\hline $\mathrm{B}_{\mathrm{t}}$ & 0,811 & 0,810 & 0,830 & 0,831 & 0,365 & 0,365 & 1,13 & 1,13 \\
\hline$b t^{b}$ & 306 & 306 & 298 & 298 & 695 & 695 & 218 & 218 \\
\hline $\mathrm{R}^{2}$ & 0,971 & -- & 0,932 & -- & 0,786 & -- & 0,961 & -- \\
\hline
\end{tabular}

a- $\left[\left(\mathrm{mg} \mathrm{g}^{-1}\right)\left(\mathrm{L} \mathrm{mg}^{-1}\right)^{1 / \mathrm{r}}\right] ; \mathrm{b}\left(\mathrm{kJ} \mathrm{mol}^{-1}\right)$ 
TABELA 23: Modelos das isotermas de adsorção para Solophenyl Navy (SN) e Turquesa (ST) e suas formas hidrolisadas (SNH e STH) pela ZPM

\begin{tabular}{lcccccccc}
\hline & Linear & $\begin{array}{c}\text { Não } \\
\text { Linear }\end{array}$ & Linear & $\begin{array}{c}\text { Não } \\
\text { Linear }\end{array}$ & Linear & $\begin{array}{c}\text { Não } \\
\text { Linear }\end{array}$ & Linear & $\begin{array}{c}\text { Não } \\
\text { Linear }\end{array}$ \\
\hline & \multicolumn{2}{c}{ SN } & \multicolumn{2}{c}{ ST } & \multicolumn{2}{c}{ SNH } & \multicolumn{2}{c}{ STH } \\
\hline Langmuir & & & & & & & & \\
\hline $\mathrm{Q}_{0}\left(\mathrm{mg} \mathrm{g}^{-1}\right)$ & 0,235 & 0,256 & 0,492 & 0,483 & 1,26 & 1,12 & 1,86 & 1,59 \\
$\mathrm{~b}\left(\mathrm{~L} \mathrm{mg}^{-1}\right)$ & 0,201 & 0,192 & 0,123 & 0,129 & 0,115 & 0,11 & 0,193 & 0,195 \\
$\mathrm{R}^{2}$ & $\mathbf{0 , 9 9 7}$ & -- & $\mathbf{0 , 9 9 8}$ & -- & 0,759 & -- & $\mathbf{0 , 9 6 4}$ & -- \\
\hline Freundlich & & & & & & & & \\
\hline $\mathrm{K}_{\mathrm{f}}{ }^{a}$ & 0,0552 & 0,0621 & 0,0567 & 0,0681 & 0,181 & 0,197 & 0,347 & 0,531 \\
$\mathrm{~N}$ & 2,21 & 2,46 & 1,44 & 1,66 & 2,13 & 2,22 & 1,92 & 2,83 \\
$\mathrm{R}^{2}$ & 0,962 & -- & 0,988 & -- & $\mathbf{0 , 7 8 3}$ & -- & 0,884 & -- \\
\hline Temkin & & & & & & & & \\
\hline $\mathrm{Kt}\left(\mathrm{L} \mathrm{g}^{-1}\right)$ & 2,31 & 2,31 & 1,51 & 1,51 & 0,982 & 0,982 & 1,52 & 1,52 \\
$\mathrm{~B}_{\mathrm{t}}$ & 0,0525 & 0,0525 & 0,0984 & 0,0984 & 0,260 & 0,260 & 0,459 & 0,459 \\
$\mathrm{bt}^{\mathrm{b}}$ & 72 & 72 & 251 & 251 & 935 & 935 & 541 & 541 \\
$\mathrm{R}^{2}$ & 0,950 & -- & 0,990 & -- & 0,776 & -- & 0,877 & -- \\
\hline
\end{tabular}

a- $\left[\left(\mathrm{mg} \mathrm{g}^{-1}\right)\left(\mathrm{L} \mathrm{mg}^{-1}\right)^{1 / 1 / 9}\right] ; \mathrm{b}\left(\mathrm{kJ} \mathrm{mol}^{-1}\right)$

Os valores da constante $n(2<n<10)$ indicaram que o processo de adsorção foi favorável para as faixas de concentrações de corantes estudadas (Carvalho, 2010).

O corante ST na sua forma hidrolisada apresentou um valor de capacidade máxima de adsorção $\left(Q_{0}\right)$ maior se comparado com sua forma não hidrolisada tanto para ZLM como para ZPM. O mesmo comportamento foi observado para o sistema SNH/ZPM (TAB. 23). Possivelmente, pode-se atribuir a isso, ao fato de que a molécula de ambos os corantes resultante do processo de hidrólise é menor fazendo com que a adsorção seja mais eficiente para os corantes hidrolisados.

Quando compados os valores da capacidade máxima de adsorção de SN e ST pela ZLM, observa-se que esse valor é maior em ST do que em SN. Pode-se atribuir a isso ao tamanho da molécula de SN, que é maior quando comparada ao do ST.

Como observa-se na TAB. 22 a capacidade máxima de adsorção para a zeólita ZLM foi maior do que os valores encontrados para ZPM para todos os sistemas estudados. Portanto o valor da capacidade máxima de adsorção para os corantes SN, ST, SNH e STH sobre a ZPM é 92, 86, 56 e 62\% menores que os valores da capacidade máxima de adsorção da ZLM, respectivamente.

Os surfactantes têm moléculas muito largas para entrar na estrutura porosa interna das zeólitas, com isso pode-se concluir que a ZLM por ter menor granulometria e maior área disponível para a ligação entre o surfactante e a zeólita apresenta melhor capacidade de adsorção se comparada com a ZPM que apresenta maior granulometria e grãos mais assimétricos. Esse resultado já foi observado e discutido no item 5.3.2

As TAB. 24, 25, 26 e 27 mostram a comparação entre os valores das estimativas de desvio para as análises lineares e não-lineares e os coeficientes de correlação para cada modelo de isoterma dos sistemas SN, ST, SNH e STH sobre a ZLM e SN, ST, SNH e STH sobre a ZPM, respectivamente. 
TABELA 24: Estimativa de desvio dos modelos de isoterma linear e não linear para os corantes Solophenyl Navy e Turquesa sobre a zeólita leve modificada (ZLM)

\begin{tabular}{cccccccccc}
\hline Corante & Regressão & Modelos & $\mathbf{R}^{\mathbf{2}}$ & ARE & SSE & MPSED & HYBRID & SAE & $\mathbf{X}^{\mathbf{2}}$ \\
\hline \multirow{3}{*}{ SN } & \multirow{3}{*}{ Linear } & Langmuir & $\mathbf{0 , 9 9 1}$ & $\mathbf{8 , 2 9}$ & $\mathbf{0 , 0 0 1 8 9}$ & $\mathbf{1 4 , 1}$ & $\mathbf{0 , 3 3 4}$ & $\mathbf{0 , 0 8 9 3}$ & $\mathbf{0 , 0 0 1 8 9}$ \\
& & Freundlich & 0,957 & 11,2 & 0,00379 & 17,1 & 0,550 & 0,134 & 0,00379 \\
& & Temkin & 0,932 & 19,5 & 0,00569 & 22,1 & 0,884 & 0,224 & 0,00569 \\
\hline \multirow{6}{*}{ Não linear } & Langmuir & -- & $\mathbf{8 , 4 1}$ & $\mathbf{0 , 1 8 7}$ & $\mathbf{5 , 6 7}$ & $\mathbf{3 , 3 3}$ & $\mathbf{0 , 9 2 0}$ & $\mathbf{0 , 1 0 3}$ \\
& & Freundlich & -- & 11,6 & 0,330 & 19,4 & 5,63 & 1,29 & 0,159 \\
& & Temkin & -- & 20,1 & 0,517 & 20,2 & 8,97 & 2,21 & 0,263 \\
\hline \multirow{3}{*}{ ST } & \multirow{3}{*}{ Linear } & Langmuir & $\mathbf{0 , 9 9 8}$ & $\mathbf{1 0 , 8}$ & $\mathbf{0 , 3 2 5}$ & $\mathbf{9 , 1 4}$ & $\mathbf{5 , 6 3}$ & $\mathbf{1 , 2 9}$ & $\mathbf{0 , 1 7 8}$ \\
& & Freundlich & 0,882 & 17,4 & 0,851 & 32,5 & 13,3 & 2,19 & 0,413 \\
& & Temkin & 0,932 & 28,3 & 1,17 & 33,7 & 18,9 & 3,48 & 0,251 \\
\hline \multirow{6}{*}{} & \multirow{3}{*}{ Não linear } & Langmuir & -- & $\mathbf{1 1 , 3}$ & $\mathbf{0 , 3 7 0}$ & $\mathbf{1 0 , 0}$ & $\mathbf{6 , 1 8}$ & $\mathbf{1 , 3 8}$ & $0, \mathbf{2 0 2}$ \\
& & Freundlich & -- & 16,7 & 1,11 & 26,6 & 10,0 & 2,41 & 0,454 \\
& & Temkin & -- & 12,9 & 1,48 & 28,4 & 18,7 & 3,79 & 0,251 \\
\hline
\end{tabular}

TABELA 25: Estimativa de desvio dos modelos de isoterma linear e não linear para os corantes Solophenyl Navy hidrolisado e Turquesa hidrolisado sobre a zeólita leve modificada (ZLM)

\begin{tabular}{cccccccccc}
\hline Corante & Regressão & Modelos & $\mathbf{R}^{\mathbf{2}}$ & ARE & SSE & MPSED & HYBRID & SAE & $\mathbf{X}^{\mathbf{2}}$ \\
\hline \multirow{3}{*}{ SNH } & \multirow{3}{*}{ Linear } & Langmuir & $\mathbf{0 , 9 8 4}$ & 20,1 & 1,04 & 41,2 & 18,5 & $\mathbf{2 , 0 2}$ & 0,538 \\
& & Freundlich & 0,909 & $\mathbf{1 7 , 4}$ & $\mathbf{0 , 7 4 1}$ & $\mathbf{2 5 , 1}$ & $\mathbf{9 , 1 0}$ & 2,16 & $\mathbf{0 , 4 3 9}$ \\
& & Temkin & 0,961 & 17,5 & 1,38 & 30,1 & 12,7 & 2,71 & 0,864 \\
\hline \multirow{4}{*}{} & \multirow{3}{*}{ Não linear } & Langmuir & -- & 18,6 & 0,985 & 41,1 & 17,8 & 1,88 & 0,985 \\
& & Freundlich & -- & $\mathbf{1 6 , 1}$ & $\mathbf{0 , 5 5 9}$ & $\mathbf{2 6 , 7}$ & $\mathbf{8 , 5 4}$ & $\mathbf{1 , 7 7}$ & $\mathbf{0 , 5 5 9}$ \\
& & Temkin & -- & 21,5 & 0,942 & 32,1 & 13,2 & 2,48 & 0,942 \\
\hline \multirow{3}{*}{ STH } & \multirow{3}{*}{ Linear } & Langmuir & $\mathbf{0 , 9 4 2}$ & $\mathbf{1 2 , 8}$ & $\mathbf{0 , 6 9 4}$ & $\mathbf{2 2 , 9}$ & $\mathbf{7 , 1 1}$ & $\mathbf{2 , 0 2}$ & $\mathbf{0 , 3 1 8}$ \\
& & Freundlich & 0,832 & 18,1 & 2,09 & 29,1 & 15,6 & 3,29 & 0,710 \\
& & Temkin & 0,786 & 13,6 & 0,781 & 24,1 & 7,75 & 2,21 & 0,330 \\
\hline \multirow{4}{*}{} & \multirow{2}{*}{ Não linear } & Langmuir & -- & $\mathbf{1 3 , 2}$ & $\mathbf{0 , 6 3 5}$ & 25,0 & $\mathbf{7 , 5 0}$ & $\mathbf{1 , 0 6}$ & $\mathbf{0 , 2 9 7}$ \\
& & Freundlich & -- & 19,1 & 1,49 & 37,1 & 16,8 & 2,87 & 0,634 \\
& & Temkin & -- & 13,5 & 0,781 & $\mathbf{1 2 , 8}$ & 7,73 & 2,21 & 0,330 \\
\hline
\end{tabular}

TABELA 26: Estimativa de desvio dos modelos de isoterma linear e não linear para os corantes Solophenyl Navy e Turquesa sobre a zeólita leve modificada (ZLM)

\begin{tabular}{|c|c|c|c|c|c|c|c|c|c|}
\hline Corante & Regressão & Modelos & $\mathbf{R}^{2}$ & ARE & SSE & MPSED & HYBRID & SAE & $x^{2}$ \\
\hline \multirow{6}{*}{ SN } & \multirow{3}{*}{ Linear } & Langmuir & 0,997 & 11,3 & 0,273 & 21,1 & 5,47 & 1,06 & 0,273 \\
\hline & & Freundlich & 0,962 & 11,2 & 0,263 & 20,3 & 4,06 & 1,04 & 0,263 \\
\hline & & Temkin & 0,965 & 22,6 & 0,356 & 29,3 & 9,53 & 2,10 & 0,277 \\
\hline & \multirow{3}{*}{ Não linear } & Langmuir & -- & 13,1 & 0,00252 & 21,3 & 0,508 & 0,113 & 0,0185 \\
\hline & & Freundlich & -- & 12,3 & 0,00243 & 20,0 & 0,428 & 0,101 & 0,0173 \\
\hline & & Temkin & -- & 25,5 & 0,00496 & 20,3 & 0,937 & 0,214 & 0,0153 \\
\hline \multirow{6}{*}{ ST } & \multirow{3}{*}{ Linear } & Langmuir & 0,964 & 4,33 & 0,000414 & 6,21 & 0,0538 & 0,0466 & $\begin{array}{c}0,0021 \\
9\end{array}$ \\
\hline & & Freundlich & 0,887 & 8,03 & 0,00231 & 12,9 & 0,254 & 0,0881 & 0,0094 \\
\hline & & Temkin & 0,884 & 12,3 & 0,0122 & 14,3 & ,0308 & 0,0281 & 0,261 \\
\hline & \multirow{3}{*}{ Não linear } & Langmuir & -- & 4,34 & 0,000419 & 7,15 & 0,0588 & 0,0450 & $\begin{array}{c}0,0022 \\
4\end{array}$ \\
\hline & & Freundlich & -- & 9,14 & 0,00122 & 19,9 & 0,255 & 0,0759 & 0,0083 \\
\hline & & Temkin & -- & 8,95 & 0,00106 & 17,6 & 0,229 & 0,0689 & 0,0109 \\
\hline
\end{tabular}


TABELA 27: Estimativa de desvio dos modelos de isoterma linear e não linear para os corantes Solophenyl Navy hidrolisado e Turquesa hidrolisado sobre a zeólita pesada modificada (ZPM)

\begin{tabular}{cccccccccc}
\hline Corante & Regressão & Modelos & $\mathbf{R}^{\mathbf{2}}$ & ARE & SSE & MPSED & HYBRID & SAE & $\mathbf{X}^{\mathbf{2}}$ \\
\hline \multirow{3}{*}{ SNH } & \multirow{3}{*}{ Linear } & Langmuir & 0,759 & 27,2 & 0,199 & $\mathbf{4 2 , 4}$ & 8,89 & 1,06 & 0,305 \\
& & Freundlich & $\mathbf{0 , 7 8 3}$ & $\mathbf{2 7 , 1}$ & $\mathbf{0 , 1 7 7}$ & 42,7 & $\mathbf{8 , 3 5}$ & $\mathbf{1 , 0 0}$ & $\mathbf{0 , 3 0 3}$ \\
& & Temkin & 0,776 & 26,5 & 0,186 & 35,0 & 8,48 & 1,02 & 0,306 \\
\hline \multirow{6}{*}{} & \multirow{3}{*}{ Não linear } & Langmuir & -- & $\mathbf{2 4 , 9}$ & 0,215 & 39,0 & 8,63 & 1,08 & 0,389 \\
& & Freundlich & -- & 26,4 & $\mathbf{0 , 1 8 1}$ & $\mathbf{3 1 , 9}$ & $\mathbf{7 , 9 1}$ & $\mathbf{1 , 0 1}$ & 0,323 \\
& & Temkin & -- & 26,5 & 0,186 & 35,0 & 9,23 & 1,02 & \\
& & & & $\mathbf{0 , 2 8 6}$ \\
\hline \multirow{3}{*}{ STH } & \multirow{3}{*}{ Linear } & Langmuir & $\mathbf{0 , 9 6 4}$ & $\mathbf{1 8 , 7}$ & $\mathbf{0 , 2 9 6}$ & $\mathbf{2 9 , 4}$ & $\mathbf{6 , 7 2}$ & $\mathbf{1 , 2 3}$ & $\mathbf{0 , 2 8 1}$ \\
& & Freundlich & 0,887 & 24,0 & 0,649 & 33,3 & 12,1 & 1,92 & 0,513 \\
& & Temkin & 0,884 & 20,4 & 0,320 & 29,8 & $\mathbf{7 , 1 7}$ & $\mathbf{1 , 4 1}$ & 0,282 \\
\hline \multirow{6}{*}{} & \multirow{3}{*}{ Não linear } & Langmuir & -- & 20,5 & 0,646 & 29,6 & 11,2 & 1,73 & 0,631 \\
& & Freundlich & -- & 28,3 & 0,461 & 49,5 & 13,6 & 1,67 & 0,444 \\
& & Temkin & -- & $\mathbf{2 0 , 4}$ & $\mathbf{0 , 3 2 0}$ & $\mathbf{2 9 , 5}$ & $\mathbf{7 , 1 4}$ & $\mathbf{1 , 4 1}$ & $\mathbf{0 , 2 8 1}$ \\
\hline
\end{tabular}

Segundo Din e Hammed (2010), a forma mais comum para validar as isotermas é pela avaliação da qualidade do ajuste usando-se coeficientes de correlação linear $\left(R^{2}\right)$. O $R^{2}$ na faixa de 0,9 a 1 indica que as isotermas são adequadas para o sistema de adsorção em que o valor próximo de 1 é altamente desejável.

Quando se compara os modelos de ajuste e o coeficiente de correlação, é esperado observar-se um maior valor para os coeficientes de correlação $\left(R^{2}\right)$ e valores mais baixos para os ajustes dos modelos (ARE, SSE, MPSED, HYBRID, SAE e X2). Para a regressão não-linear a comparação é feita pelos menores valores de cada estimativa de desvio, pois esse tipo de regressão não apresenta valores de $R^{2}$.

Os valores mais baixos para as estimativas de desvio foram observados para o modelo de equilíbrio de Langmuir na maior parte dos sistemas estudados, tanto para as regressões lineares como para as regressões não lineares. Esse ajuste ao modelo de Langmuir também foi observado pela análise linear dos coeficientes de correlação $\left(R^{2}\right)$ (TAB. 24, 25, 26 e 27). As exceções foram para os sistemas SN/ZPM, SNH/ZPM e $\mathrm{SNH} / \mathrm{ZLM}$, os quais seguiram o modelo de Freundlich.

O sistema STH/ZPM apresentou uma melhor correlação ao modelo de Langmuir pela regressão linear e um melhor ajuste ao modelo de Temkin para a regressão não linear. Cabe ressaltar, no entanto, que alguns valores das estimativas dos modelos de Langmuir e Temkin, para as regressões não lineares eram muito próximos das lineares, como pode ser observado na TAB. 27.

\subsection{Mecanismos de adsorção}

É proposto que múltiplos mecanismos estejam envolvidos na adsorção de corantes sobre a ZLM e a ZPM devido à grande variedade de grupos funcionais que as moléculas dos corantes possuem e às propriedades superficiais das zeólitas.

A literatura reporta múltiplos mecanismos de adsorção. Magdalena (2015) estudou a adsorção de corante por zeólita modificada por HDTMA (ZMS), e reportou que os mecanismos envolvidos na adsorção são devido à um grande número de ligações de hidrogênio entre o $\mathrm{C}$ ou $\mathrm{N}$ do HTDMA e os grupos aromáticos e sulfônicos do corante que deve garantir a adsorção efetiva (Stefov et al., 2003).

Bertolini (2014) reportou a adsorção de corantes por ZMS. Os resultados sugeriam que a adsorção do corante pela ZMS poderiam ocorrer pela partição da molécula do corante no grupo cauda do surfactante, além da interação eletrostática do $\mathrm{N}^{+}$- sobre a superfície negativa da ZMS, a troca catiônica e a complexação com espécies de Si e Al também estão atuando no mecanismo de adsorção. Além disso, os corantes 
desse estudo possuíam grupos aromáticos e sulfônicos que possuem forma planar e ligações $\pi$ deslocadas que podem interagir fortemente com os íons amônio da molécula de HDTMA, sendo esse outro possível mecanismo de adsorção. Fungaro et al. (2013), chegaram as mesmas conclusões.

Xi et al. (2012) estudaram a adsorção do fenol pela ZMS e reportaram que os possíveis mecanismos de adsorção sugeridos foram: interações Coulômbicas, interação hidrofóbica e eletrostáticas.

Os materiais zeolíticos modificados possuem carga negativa em água, conforme foi demonstrado pela determinação dos $\mathrm{pH}_{\mathrm{PCZ}}$ (item 5.1.2), indicando a formação de uma bicamada incompleta do HTDMA-Br na superfície. Os corantes utilizados nesse estudo (SN e ST) contêm grupos sulfonados (-SO3-) e portanto são corantes aniônicos em solução aquosa. Assim, a partição de sua molécula dentro do grupo "cauda" hidrofóbico da molécula do surfactante adsorvido sobre a superfície das zeólitas modificadas ZLM e ZPM deve ser o principal mecanismo envolvido na adsorção (FIG. 31).

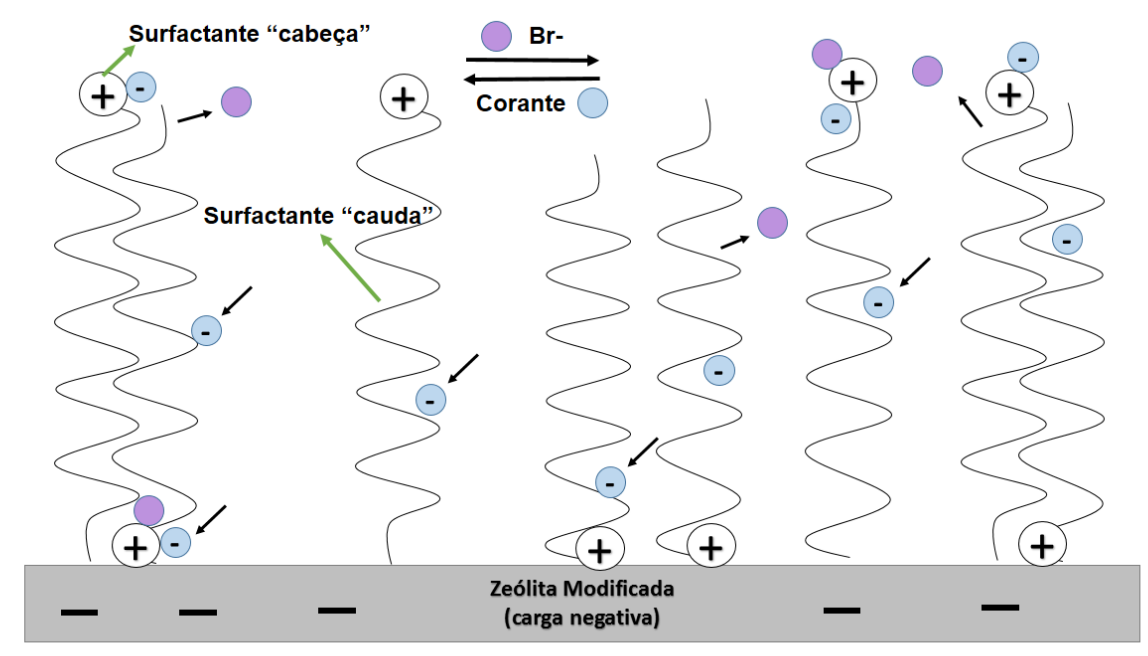

FIGURA 31: Mecanismos de adsorção de corante sobre a zeólita modificada com surfactante HDTMA-Br

O corante $\mathrm{SN}$ apresenta o grupo $\mathrm{OH}^{-}$em sua estrutura, sendo assim, a hidroxila poderá se ligar ao grupo "cabeça" do surfactante de carga positiva presente na superfície da zeólita por troca iônica com o $\mathrm{Br}^{-}$e por atração eletrostática, constituindo outro mecanismo de adsorção.

Quanto aos corantes após a hidrólise, com a possível formação de um composto $\mathrm{OH}^{-}$no produto final, o mesmo mecanismo descrito acima para SN poderia ser considerado para as formas hidrolisadas SNH e STH.

\subsection{Testes toxicológicos}

A segunda parte do presente estudo consistiu na realização de ensaios toxicológicos com as zeólitas utilizadas como adsorbatos neste estudo, assim como dos corantes, a fim de identificar possíveis efeitos adversos ao meio ambiente. 


\subsubsection{Testes toxicológicos com os corantes \\ 5.6.1.1 Avaliação da toxicidade aguda dos corantes com Lemna minor}

Os ensaios com a planta Lemna minor, foram realizados com os corantes Solophenyl Navy (SN), Turquesa (ST) e suas formas hidrolisadas, por um período do 7 dias, como descrito anteriormente. Os resultados dos testes são mostrados na TAB. 32. A toxicidade foi expressa como como a concentração letal mediana $\left(\mathrm{CE}_{50}\right)$, onde pode ser observado as concentrações tóxicas que promovem a redução de $50 \%$ do número de folhas (frondes) para $L$. minor foram de 18,9 e $69,4 \mathrm{mgL}^{-1}$ para SN e ST, consecutivamente.

TABELA 32: Diferentes valores de $\mathrm{CE}_{50}$ correlacionados aos corantes SN e ST e suas formas hidrolisadas STH e SNH para planta Lemna minor após 7 dias de exposição. Os intervalos de confiança (95\%) são fornecidos entre parênteses

\begin{tabular}{cccccc}
\hline Corante & $\begin{array}{c}\text { CL50 n. de } \\
\text { frondes }{\left(\mathbf{m g L}^{-1}\right)}^{-1}\end{array}$ & $\begin{array}{c}\text { CL50 Peso } \\
\text { Fresco }(\mathbf{g})\end{array}$ & $\begin{array}{c}\text { CL50 Clorofila } \\
\text { A }\end{array}$ & $\begin{array}{c}\text { CL50 Clorofila } \\
\text { B }\end{array}$ & CL50 Carotenoide \\
\hline SN & $18.9(13.1-27.1)$ & $10.3(5.88-18.3)$ & $8.63(5.85-12.7)$ & $8.91(5.51-14.3)$ & $8.31(5.07-13.6)$ \\
ST & $69.4(54.1-89.2)$ & $96.3(39.1-237)$ & $122(104-143)$ & $138(99.6-191)$ & $100(50.9-196)$ \\
SNH & $10.9(6.48-18.3)$ & $14.4(8.91-23.3)$ & $9.53(7.91-11.5)$ & $5.22(3.37-8.08)$ & $6.95(1.76-27.3)$ \\
STH & $70.9(48.4-103)$ & $31.8(19.1-53.1)$ & $178(95.5-335)$ & $260(168-402)$ & $120(34.2-424)$ \\
\hline
\end{tabular}

Ambos os corantes testados nas formas hidrolisada e não hidrolisada, foram classificados como nocivos para o meio ambiente aquático, e isso significava que eles podem causar efeitos a longo prazo ao meio ambiente (Waeterschoot, 2014). A hidrólise do SN e ST, como ocorreria durante o processo de tingimento, resultou em um composto tóxico ( $\mathrm{CE}_{50}$ 10,9 comparado com 18,9 $\mathrm{mgL}^{-1}$ para SNH e SN, consecutivamente) mas não mostrou diferença significativa para ST. Sob condições ácidas, como as que ocorrem a hidrólise dos corantes, os átomos de Hidrogênio $\left(\mathrm{H}^{+}\right)$podem protonar os grupos amina (por ex. quando $\circ \mathrm{H}^{+}$se liga a um átomo, molécula ou íon) tornando-os em formas catiônicas $\left(-\mathrm{NH}^{+}\right)$. Por outro lado, os corantes em solução aquosa são dissolvidos e os grupos sulfonados são dissociados e convertido a ânions (Crini \& Badot, 2008; Kyzas \& Lazaridinis, 2009; Sakkyawong et al, 2005).

Além dos efeitos tóxicos, as respostas imediatas observadas nas plantas às maiores concentrações dos corantes foram: fragmentação dos frondes (frondes não pareadas), perda de raízes, folhas esbranquiçadas no efluente simulado (SIS + corante). Outras lesões foram, contudo, dose e tempo dependentes, e foram observadas redução (86-91\%) em tamanho do fronde, espessura de folhas e clorose (frondes com coloração amarelada). Os corantes foram depositados nas folhas (superfície inferior) e raiz.

Na FIG. 33 pode-se observar algumas dessas respostas. Assim, as lesões apresentadas pelas plantas podem ser consideradas como biomarcadores de toxicidade de efluentes têxteis.

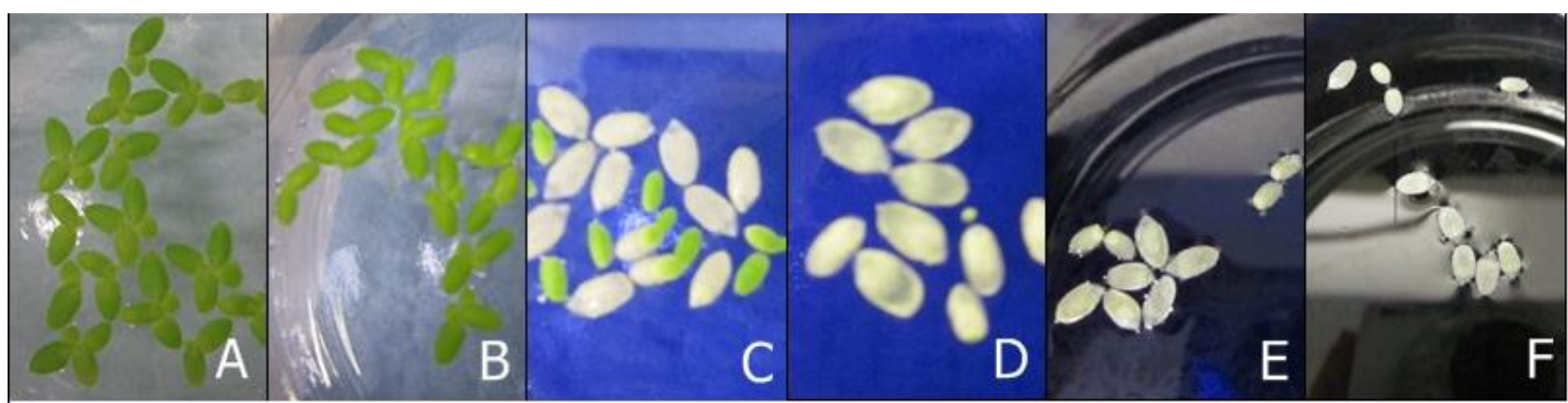

FIGURA 33: Mudança estrutural dos frondes de L. minor após 7 dias de exposição em corante Solophenyl Navy. A (controle); B (5 mgL-1); C (10 $\left.\mathrm{mgL}^{-1}\right)$; D (20 mgL-1); E (40 $\left.\mathrm{mgL}^{-1}\right)$ e $\mathrm{F}\left(80 \mathrm{mgL}^{-1}\right)$ 
Durante os ensaios, o número de frondes se mostrou um parâmetro mais sensível em comparação ao peso fresco e clorofila para ST, contudo, SN e SNH mostraram uma boa correlação entre peso fresco dos frondes, clorofilas e carotenoides, enquanto STH não apresentou esse comportamento, como pode-se observar na FIG. 34 e 35 .

Como mostrado na FIG. 34 e 35, a diminuição do número de frondes e do peso fresco aumentou com o aumento da concentração inicial dos corantes. No entanto, este comportamento não foi observado para SNH que mostrou em baixas concentrações ( 3 à $9 \mathrm{mgL}^{-1}$ ) um aumento no peso fresco. Esse resultado sugere que os efeitos adversos sobre a propagação vegetativa nas plantas foram graves em sua fotossíntese, o que causou um aumento em seu peso fresco ou afetou a produção de clorofila pela fotossíntese (Sharma et al., 2007).
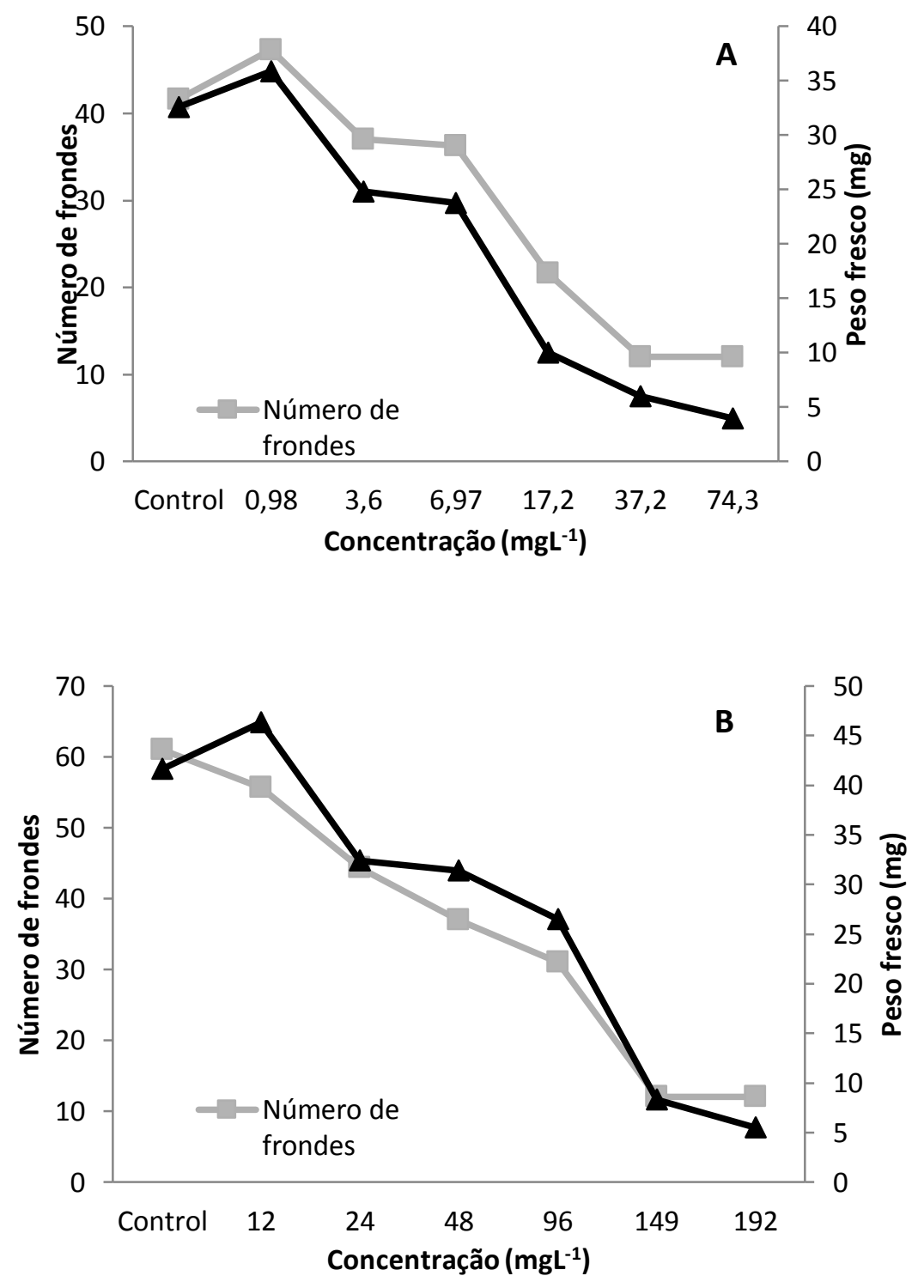

FIGURA 34: Comparação entre a média do número de frondes do peso fresco de $L$. minor após 7 dias de exposição à diferentes concentrações dos corantes Solophenyl Navy (A), Turquesa (B). 

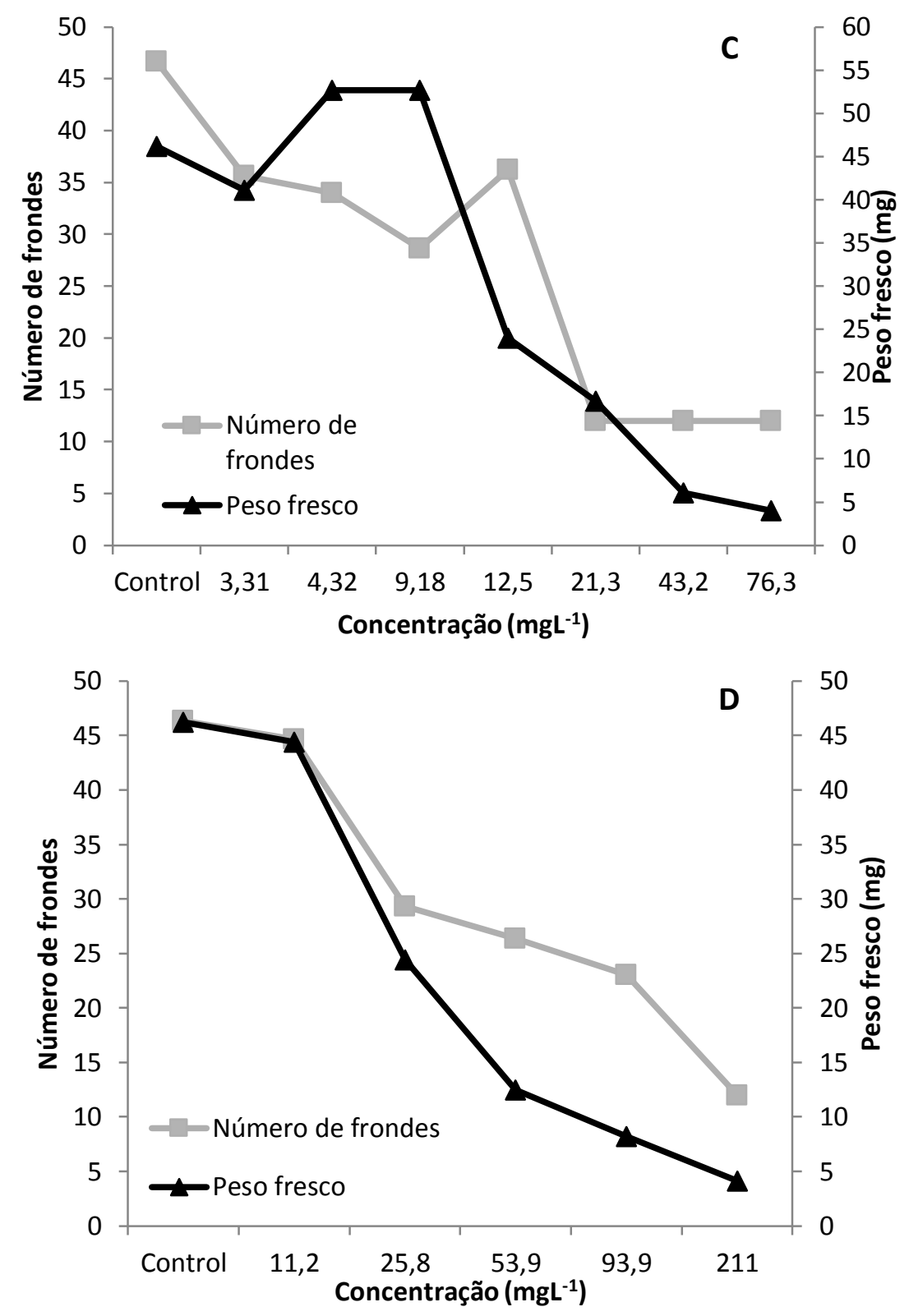

FIGURA 35: Comparação entre a média do número de frondes do peso fresco de $L$. minor após 7 dias de exposição à diferentes concentrações dos corantes hidrolisados Solophenyl Navy Hidrolisado (C) e Turquesa Hidrolisado (D)

De acordo com o CONAMA 430 (2011) o efluente não deverá causar ou ter o potencial para causar efeitos tóxicos aos organismos aquáticos no corpo d'água receptor. Nas TAB. 28 e 29 podem ser observados os elementos que não estão de acordo com o CONAMA 430 (2011) encontrados pelas análises químicas de cada corante. Os valores acima e abaixo dos valores encontrados para cada corante pela $\mathrm{CL}_{50}$ são mostrados juntos, para comparação. 
TABELA 28: Análises químicas e física do corante Solophenyl Navy (SN) e sua forma hidrolisada (SNH). Os valores abaixo da $\mathrm{CL}_{50}(\mathrm{~B})$ e acima da $\mathrm{CL}_{50}$ (C) são mostrados juntos com o CONAMA 430 (A) para comparação, assim como os valores de $\mathrm{CL}_{50}$ encontrados na literatura (D) para L. minor

\begin{tabular}{|c|c|c|c|c|c|c|c|}
\hline Elemento & Controle & $\begin{array}{c}\text { SN 17 } \\
\text { mgL }^{-1 ~ B ~}\end{array}$ & $\begin{array}{c}\text { SN 37 } \\
\text { mgL }^{-1} \text { C }\end{array}$ & $\begin{array}{l}\mathrm{SNH} 21 \\
\mathrm{mgL}^{-1 ~ B ~}\end{array}$ & $\begin{array}{l}\text { SNH 43 } \\
\text { mgL }^{-1 C}\end{array}$ & $\begin{array}{c}\text { CONAMA } \\
430\left(\mathrm{mLL}^{-1}\right)^{\mathrm{A}}\end{array}$ & $\begin{array}{c}\text { CL50 Lemna } \\
\left(\mathrm{mgL}^{-1}\right)^{\mathrm{D}}\end{array}$ \\
\hline $\mathrm{Cu}\left(\mathrm{mgL}^{-1}\right)$ & $<0,25$ & 1.07 & 2.66 & 1.34 & 2.25 & 1 & 0.5 \\
\hline $\mathrm{B}\left(\mathrm{mgL}^{-1}\right)$ & $<2,5$ & 1.02 & 1.76 & 1.7 & 3.22 & 5 & 0.2 \\
\hline $\mathrm{Na}\left(\mathrm{mgL}^{-1}\right)$ & 45 & 175 & 306 & 334 & 602 & NA & NA \\
\hline $\mathrm{Cl}^{-}\left(\mathrm{mgL}^{-1}\right)$ & 19 & 260 & 480 & 470 & 900 & 250 & 930 \\
\hline Condutividade & 324 & 1200 & 1996 & 2420 & 2650 & NA & NA \\
\hline
\end{tabular}

A - Diretrizes Brasileiras; B- Valores a baixo da $\mathrm{CL}_{50}$ encontrado para Lemna; C - Valores a cima da $\mathrm{CL}_{50}$ encontrado para Lemna; D - Valores da $\mathrm{CL}_{50}$ encontrado para Lemna na literatura; NA - não aplicável

TABELA 29: Análises químicas e física do corante Solophenyl Turquesa (ST) e sua forma hidrolisada (STH). Os valores abaixo da $\mathrm{CL}_{50}(\mathrm{~B})$ e acima da $\mathrm{CL}_{50}(\mathrm{C})$ são mostrados juntos com o CONAMA 430 (A) para comparação, assim como os valores de CL50 encontrados na literatura (D) para L. minor

\begin{tabular}{|c|c|c|c|c|c|c|c|}
\hline Elemento & Controle & $\begin{array}{c}\text { ST 96 } \\
\text { mgL }^{-1 \text { B }}\end{array}$ & $\begin{array}{l}\text { ST 192 } \\
\text { mgL }^{-1 C}\end{array}$ & $\begin{array}{l}\text { STH 93 } \\
\text { mgL }^{-1 ~ B ~}\end{array}$ & $\begin{array}{c}\text { STH } 211 \\
\text { mgL }^{-1 C}\end{array}$ & $\begin{array}{c}\text { CONAMA } \\
430\left(\mathrm{mLL}^{-1}\right)^{A}\end{array}$ & $\begin{array}{c}\text { CL50 Lemna } \\
\left(\mathrm{mgL}^{-1}\right)^{\mathrm{D}}\end{array}$ \\
\hline $\mathrm{Cu}\left(\mathrm{mgL}^{-1}\right)$ & $<0,25$ & 2.87 & 3.98 & 2.45 & 4.81 & 1 & 0.5 \\
\hline $\mathrm{B}\left(\mathrm{mgL}^{-1}\right)$ & $<2,5$ & 0.181 & 0.289 & 0.132 & 0.315 & 5 & 0.2 \\
\hline $\mathrm{Na}\left(\mathrm{mgL}^{-1}\right)$ & 45 & 505 & 809 & 433 & 815 & NA & NA \\
\hline $\mathrm{Cl}^{-}\left(\mathrm{mgL}^{-1}\right)$ & 19 & 850 & 920 & 610 & 925 & 250 & 930 \\
\hline $\mathrm{Cr}\left(\mathrm{mgL}^{-1}\right)$ & $<0.25$ & $<0.021$ & $<0.004$ & $<0.004$ & $<0.004$ & 1 & 22.7 \\
\hline Condutividade & 324 & 2780 & 5098 & 3280 & 5170 & NA & NA \\
\hline
\end{tabular}

A - Diretrizes Brasileiras; B- Valores a baixo da $\mathrm{CL}_{50}$ encontrado para Lemna; C - Valores a cima da $\mathrm{CL}_{50}$ encontrado para Lemna; D - Valores da $\mathrm{CL}_{50}$ encontrado para Lemna na literatura; NA - não aplicável

Como mostrado na TAB. 28 e 29 o elemento Boro (B) mostrou um valor alto quando comparado com os valores da $\mathrm{CL}_{50}$ encontrados em literatura. Contudo, esse elemento está presente na solução estoque de SIS, promovendo todos os nutrientes necessários para o crescimento da planta durante o período de teste.

Os altos valores encontrados para Sódio $(\mathrm{Na})$ e Cloreto $(\mathrm{Cl})$ podem ser atribuídos ao cloreto de sódio $(\mathrm{NaCl})$ encontrado na solução estoque de ambos os corantes. As soluções estoque dos corantes foram preparadas semelhantes ao processo industrial, onde $\mathrm{NaCl}$ e corante são misturados em água.

Embora os valores encontrados para o Cloreto $\left(\mathrm{Cl}^{-}\right)$estarem além do permitido pelo CONAMA 430, esse elemento pode não ser a causa da toxicidade para $L$. minor, uma vez que os valores de $\mathrm{CL}_{50}$ observados nas amostras são inferiores aos encontrados na literatura $\left(C_{50} 930 \mathrm{mg}^{-1}\right)$. Sharma et al. (2007) encontraram valores de $\mathrm{CL}_{50}$ de cloreto residual para peixes sendo mais tóxico quando comparado a $L$. minor. No entanto estudos prévios mostraram que corantes em $\mathrm{pH}$ variando entre neutro a ligeiramente alcalino são menos tóxicos, quando comparados ao meio ácido. Essa toxicidade pode ser aumenta também em combinação com o cobre (Sharma et al., 2007). O efluente produzido pelo banho de tingimento no reator contém corantes hidrolisados, auxiliares de tingimento e de eletrólitos, sendo esse último o responsável pelo alto teor de salinidade na água residual, que contém altos valores de $\mathrm{pH}(10 \sim 11)$ (Allegre et al., 2006).

Com relação ao Cobre (Cu), segundo Khellf \& Zerdaoui (2009) o valor da $\mathrm{CL}_{50}$ da $L$. minor para $\mathrm{Cu}$ é de $0,5 \mathrm{mgL}^{-1}$ e o valor encontrado para $\mathrm{Cu}$ nas amostras dos corantes estava entre 1 e $4 \mathrm{mgL}^{-1}$, o que aponta que o cobre pode ser a causa da 
toxicidade no presente estudo. Testes posteriores comprovarão esse resultado. Resultados semelhantes com relação à respostas de plantas e toxicidade para Cu foram encontrados por Razinger et al. (2007); Khellf \& Zerdaoui $(2009,2010)$ e Sharma et al. (2007).

A fim de comparar se houve diferença na fotossíntese causada por metais pesados, o total de clorofila A (Chl A), clorofila B (Chl B) e carotenoides (Caro) foram determinados nas folhas das $L$. minor (Zeynep, 2013). Os efeitos da exposição dos corantes sobre as quantidades totais de clorofila nos tecidos de $L$. minor são mostrados na FIG. 36 e 37.
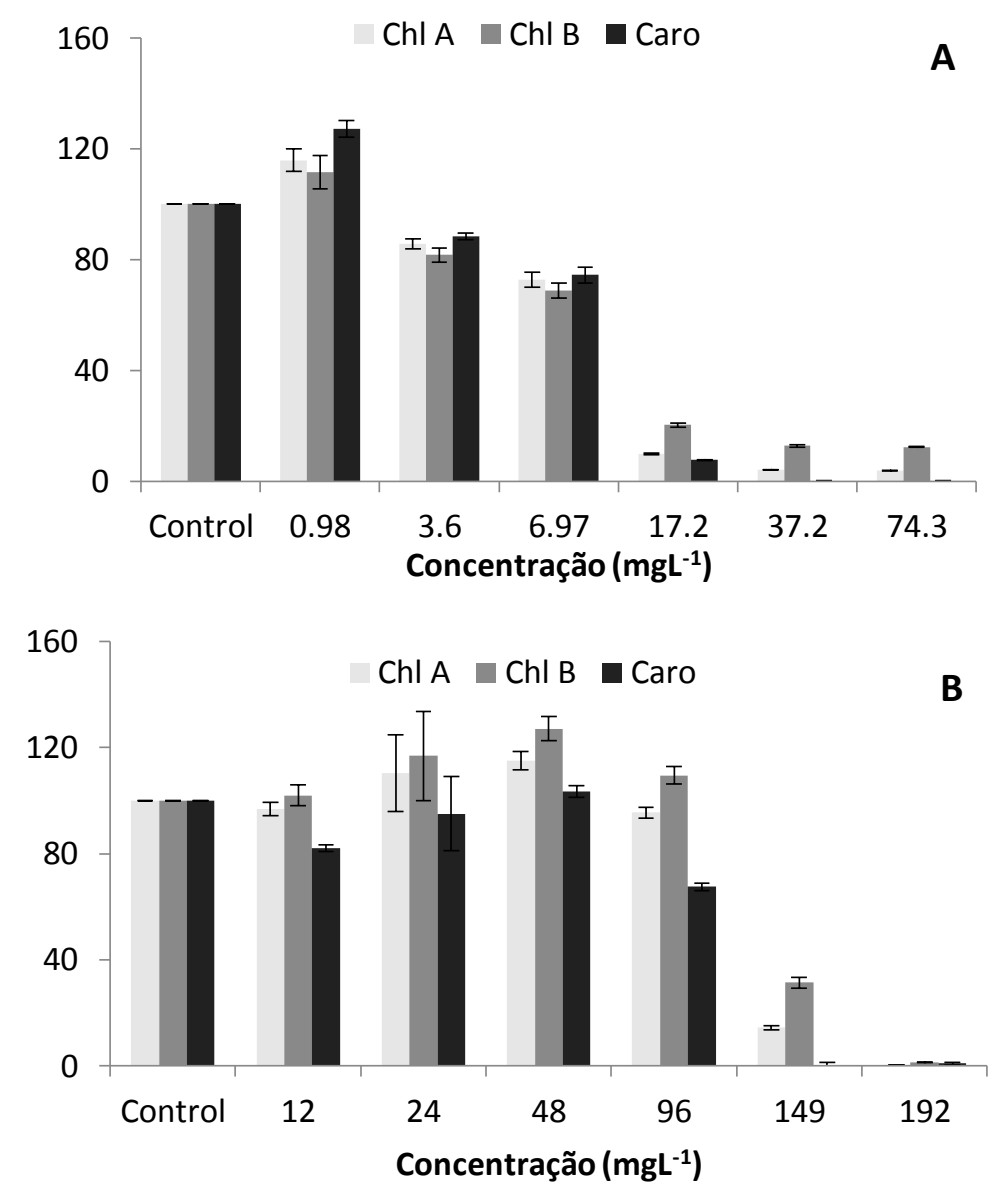

FIGURA 36: Média e desvio padrão na mudança de clorofila $A, B$ e carotenoides para $L$. minor após 7 dias de exposição a diferentes concentrações dos corantes Solophenyl Navy (A), Turquesa (B) 

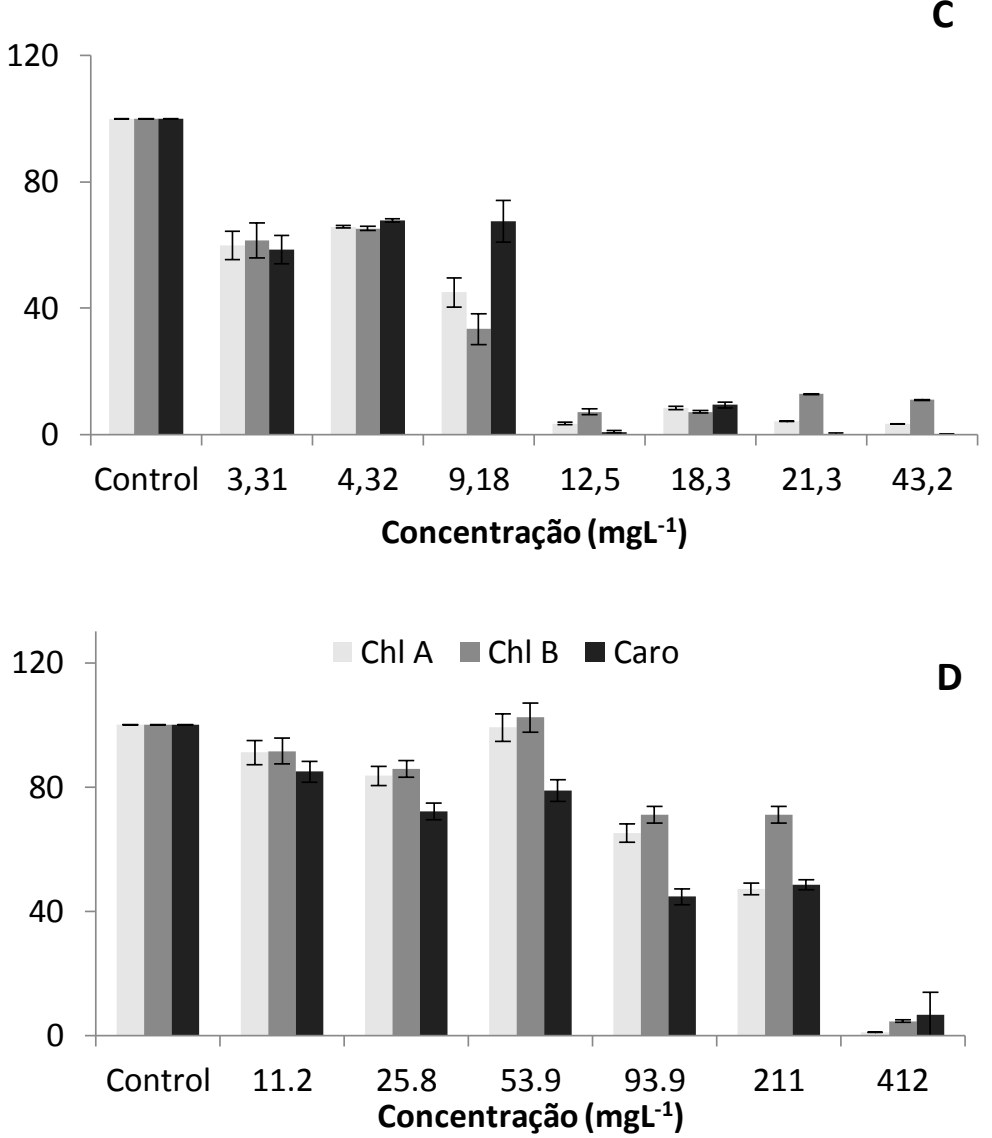

FIGURA 37: Média e desvio padrão na mudança de clorofila $A, B$ e carotenoides para $L$. minor após 7 dias de exposição a diferentes concentrações dos corantes Solophenyl Navy Hidrolisado (C) e Turquesa Hidrolisado (D)

Uma diminuição geral no teor de pigmentos ocorreu com o aumento das concentrações elevadas dos corantes. O corante SN mostrou-se mais tóxico, quando comparado ao ST, e causou uma maior diminuição no total do conteúdo de clorofila e carotenoides, quando comparados ao controle. Os maiores decréscimos com relação a pigmentação foram apresentados nas concentrações mais elevadas (17, 12, 149 e 412 $\mathrm{mgL}^{-1}$ para SN, SNH, ST e STH, consecutivamente).

Mudanças no conteúdo de pigmentos de plantas sob estresse de metais pesados são usados como um indicador de danos fotossintéticos. O cobre, um elemento traço essencial, é necessário para a biossíntese de clorofila e está presente em muitas metaloenzimas (enzimas que usam íons metálicos) envolvidas em reações de redução e oxidação (Ouzounidou, 1994). No entanto, o excesso de Cu pode alterar vários eventos fisiológicos e bioquímicos, como a fotossíntese, metabolismo do nitrogênio e metabolismo de aminoácidos (Megateli et al., 2009).

Além disso, aumentos significativos no conteúdo de pigmentos foram detectados para 0,05 e $0,1 \mathrm{mgL}^{-1}$ de cobre em Lemna gibba (Zeynep, 2013). Este aumento no teor de pigmento pode ser atribuído à estimulação induzida por cobre, em baixos níveis, na síntese de pigmentos. No entanto, níveis elevados de cobre causaram inibição da síntese de L. minor. De acordo com Hou et al. (2007) a redução dos pigmentos em plantas pode ser devido a peroxidação de lipídios nas membranas do cloroplasto. A redução de pigmentos fotossintéticos foi relatada em diversas plantas aquáticas tais como Potomogeton pusillus, Eichornia crassipes, L. gibba, L. minor, Wolffia arrhiza e Chlorella pyrenoidosa (Lewis, 1993; Vavilin et al., 1995; Misra et al., 
2007, Monferran et al., 2009, Olah et al., 2010; Piotrowska et al., 2010, Rolli et al., 2010, Zeynep, 2013).

\subsubsection{Avaliação da toxicidade aguda com Ceriodaphnia dubia antes e após processo de adsorção}

A fim de identificar os possíveis efeitos adversos ao meio ambiente causados pelo processo de adsorção, a avaliação da toxicidade dos corantes foram realizadas antes do processo de adsorção (solução inicial) e após o processo de adsorção com ZLM e ZPM, no tempo de equilíbrio para cada corante, pelo micro crustáceo Ceriodaphnia dubia.

Para efeitos classificativos foram considerados como muito tóxicos ao meio ambiente aquático compostos com CL ${ }_{50}$ menor que $1 \mathrm{mgL}^{-1}$, tóxicos valores entre 1 e 10 $\mathrm{mgL}^{-1}$, prejudicial valores entre 10 e $100 \mathrm{mgL}^{-1}$ e não tóxicos valores maiores do que 100 $\mathrm{mgL}^{-1}$ (Haeterschoot, 2014).

Os resultados de toxicidade para $C$. dubia são mostrados na TAB. 30, onde pode ser observado que a concentração que causou efeito (imobilização) para $C$. dubia foi de 1,25 e $54,5 \mathrm{mgL}^{-1}$ para SN e ST e de 0,78 e $2,56 \mathrm{mgL}^{-1}$ para SNH e STH, consecutivamente. A hidrólise do SN e ST, como ocorreria durante o processo de tingimento, resultou em um composto mais tóxico. Os mesmos resultados foram encontrados e discutidos previamente para L. minor.

TABELA 30: Toxicidade aguda de C. dubia aos corantes Solophenyl Navy (SN) e Turquesa (ST) e suas formas hidrolisadas (SNH e STH). Intervalos de confiança (95\%) são providos em parênteses

\begin{tabular}{ccccc}
\hline Corante & $\mathbf{C L}_{\mathbf{5 0}}\left(\begin{array}{c}\mathbf{4 8} \mathbf{~ h}) \mathbf{( \mathbf { m g L } ^ { - }} \\
\mathbf{1})\end{array}\right.$ & Média & $\begin{array}{c}\text { Desvio } \\
\text { Padrão }\end{array}$ & $\begin{array}{c}\text { Classificação da } \\
\text { toxicidade }\end{array}$ \\
\hline SN & $1,25(0,96-1,63)$ & 1,21 & 4,94 & Tóxico \\
ST & $54,5(46,6-64,6)$ & 58 & 0,325 & Prejudicial \\
SNH & $0,78(0,64-0,95)$ & 0,905 & 0,049 & Muito tóxico \\
STH & $2,56(2,13-3,07)$ & 2,79 & 0,176 & Tóxico \\
\hline
\end{tabular}

Como observado na TAB. 30 o corante SN mostrou-se mais tóxico. Esse resultado já era esperado, uma vez que as análises químicas, realizadas na forma bruta dos corantes (antes da preparação da solução estoque) desse corante mostraram maiores concentrações de alguns elementos como $\mathrm{Cu}$, As, Cr, Mn, Co, Zn, Zr, Sn, Ba, $\mathrm{Ph}$ and Ni quando comparado com o corante ST (TAB. 31).

TABELA 31: Análise química, na forma bruta dos corantes, dos elementos majoritários nos corantes Solophenyl Navy (SN) e Turquesa (ST). Resultados são mostrados juntos para comparação

\begin{tabular}{cccccccccccc}
\hline & & \multicolumn{10}{c}{ Elemento $(\mathbf{m g} / \mathbf{K g})$} \\
Corante & Cr & Mn & Co & Ni & Cu & Zn & As & Zr & Sn & Ba & Pb \\
\hline SN & 54 & 7,9 & 22 & 17 & 52 & 46 & 2,2 & 4,7 & 10 & 3,3 & 86 \\
ST & 3 & 0,8 & 0,1 & 3,2 & 35 & 3,1 & 0 & 1,2 & 0,1 & 1,4 & 0,2 \\
\hline
\end{tabular}

Ambos os corantes em sua forma bruta e hidrolisada tem o potencial de causar efeitos a longo prazo ao meio ambiente aquático, o que significa que as concentrações dos corantes utilizadas neste estudo são consideradas prejudiciais ao meio ambiente aquático e a remoção de sua cor é necessária. Na TAB. 32 podem ser 
observados os resultados da toxicidade aguda antes e após o processo de adsorção com ZLM e ZPM.

TABELA 32: Toxicidade aguda dos corantes Solophenyl Navy (SN) e Turquesa (ST) e suas formas hidrolisadas (SNH e STH) após o processo de adsorção com a zeólita leve modificada (ZLM) e zeólita pesada modificada (ZPM) por $C$. dubia. Intervalos de confiança (95\%) são mostrados em parêntesis

\begin{tabular}{ccccc}
\hline ZLM & SN & SNH & ST & STH \\
\hline Concentração inicial $\left(\mathrm{mgL}^{-1}\right)$ & 15 & 15 & 15 & 15 \\
CL50 $(48 \mathrm{~h})\left(\mathrm{mgL}^{-1}\right)$ & $\mathrm{NT}^{1}$ & $\mathrm{NA}^{2}$ & $\mathrm{NA}$ & $\mathrm{NA}$ \\
Remoção da cor $(\%)$ & 100 & 100 & 100 & 100 \\
Média & -- & -- & -- & -- \\
Desvio Padrão & -- & -- & -- & -- \\
\hline ZPM & SN & SNH & ST & STH \\
\hline Concentração inicial $\left(\mathrm{mgL}^{-1}\right)$ & 15 & 15 & 15 & 15 \\
CL50 (48 $\mathrm{h}$ ) (mgL $\left.\mathrm{mg}^{-1}\right)$ & $1,19(0,85-1,66)$ & $\mathrm{NA}$ & $3,67(1,74-7,73)$ & $\mathrm{NA}$ \\
Remoção da cor $(\%)$ & 0 & 10 & 31 & 56 \\
Média & 2,81 & -- & 3,71 & - \\
Desvio Padrão & 0,0636 & -- & 2,27 & -- \\
\hline
\end{tabular}

1- NT: Não Tóxico; 2 - NA: Não aplicável

A toxicidade de ST e SN (formas bruta e hidrolisada) diminuiu após processo de adsorção com ZLM, apresentando ausência de toxicidade e a remoção de $100 \%$ da cor nas condições ótimas de cada corante para este tratamento.

Contudo, o tratamento com a ZPM para ST e SN apresentou um aumento na toxicidade, quando comparado a ZLM, e ausência ou menor porcentagem de remoção da cor (0 e 31\% para SN e ST, respectivamente), resultados semelhantes com processo de adsorção por zeólita pesada foram encontrados por Gottlieb et al. (2003) e Fungaro et al. (2013).

O tratamento com ZPM para STH e SNH mostrou ausência de toxicidade e uma remoção de cor cerca de $10 \%$ para SNH e $56 \%$ para STH, respectivamente. A remoção do STH foi maior do que SNH. Esse resultado pode ser explicado pelas diferentes estruturas e massas moleculares de ambos os corantes. De acordo com Cunico et al. (2015), após o processo de hidrólise, para ambos os corantes, há uma redução do tamanho das suas moléculas, o que favoreceu a adsorção dos corantes na forma hidrolisada. Esse comportamento foi observado e discutido anteriormente no item 5.3 .2

Ambos os corantes apresentam grupos sulfonados $\left(\mathrm{SO}_{3}{ }^{-}\right)$e aminas aromáticas nas suas moléculas e sendo esses corantes do tipo ftalocianina, o metal encontrado para ambos os corantes seria o $\mathrm{Cu}$. De acordo com trabalhos realizados por Gottlieb et al. (2003) corantes com anéis aromáticos podem gerar ácido sulfanílico seguido de redução do ligamento azo (por descoloração), mas diferentes compostos amino-naftóis. Padrões de 1-amino-2-naftol mostraram-se muito tóxico ( $\left.\mathrm{CL}_{50} 0,1 \mathrm{mgL}^{-1}\right)$. A toxicidade dos compostos naftol variaram de acordo com o tipo e posição do seu grupo de substituição, que pode explicar a diferença entre corantes ST e SN.

A fim de comparar a eficiência do método, análises químicas foram realizadas nas amostras líquidas antes e depois do processo de adsorção com ZLM e ZPM, e os resultados das análises são mostradas na $T A B .33$ 
TABELA 33: Elementos majoritários removidos após o processo de adsorção dos corantes SN e ST pela zeólita leve modificada (ZLM) e zeólita pesada modificada (ZPM)

\begin{tabular}{cccc|ccc} 
& Antes $^{1}$ & \multicolumn{2}{c}{ Após $^{2}$} & \multicolumn{2}{c}{ Antes } & \multicolumn{2}{c}{ Após } \\
Elemento & SN & SN+ZMF & SN+ZMB & ST & ST+ZMF & ST+ZMB \\
\hline $\mathrm{Cu}(\mu \mathrm{g} / \mathrm{L})$ & 698 & 8 & 29,5 & 395 & 7 & 74,6 \\
$\mathrm{Zn}(\mu \mathrm{g} / \mathrm{L})$ & 23 & 16 & 8 & 17 & 11 & 6 \\
$\mathrm{~Pb}(\mu \mathrm{g} / \mathrm{L})$ & 2,2 & $<0,8$ & $<0,4$ & 0,7 & $<0,4$ & $<0,1$ \\
\hline $1-$ - antes do processo de adsorção; 2- após processo de adsorção.
\end{tabular}

A ZLM mostrou ser mais eficiente quando comparada a ZPM na remoção da toxicidade e cor dos corantes SN e ST. Além dos resultados mostrados e discutidos na primeira parte desse trabalho, essa eficiência na remoção da toxicidade pode ser atribuída a sua capacidade de reter, principalmente, o $\mathrm{Cu}$, elemento encontrado em altas concentrações para ambos os corantes. No entanto, a ZPM provou ser um bom absorvente de $\mathrm{Zn}$ e $\mathrm{Pb}$, como mostrado na TAB. 33.

\subsubsection{Avaliação da toxicidade aguda e crônica com Chironomus tepperi}

$\mathrm{Na}$ TAB. 34 são mostrado os resultados para os testes agudos (48h) realizados com os corantes Solophenyl Navy e Solophenyl Turquesa a fim de identificar a toxicidade a organismos mais resistentes, como é o caso do C. tepperi.

TABELA 34: Teste agudo (48h) dos corantes Solophenyl Navy (SN) e Solophenyl Turquesa (ST) com o organismo-teste C. tepperi. Os intervalos de confiança (95\%) são mostrado em parênteses

\begin{tabular}{ccccc}
\hline Amostra & $\begin{array}{c}\text { Concentração } \\
\text { Inicial }\left(\mathbf{m g L}^{-1}\right)\end{array}$ & $\mathbf{C L}_{50}(\mathbf{4 8 h})\left(\mathbf{m g L}^{-1}\right)$ & Média & $\begin{array}{c}\text { Desvio } \\
\text { Padrão }\end{array}$ \\
\hline SN & 119 & $70.8(57,9-86,5)$ & 67,9 & 4,10 \\
ST & 440 & $211(173-256)$ & 208 & 4,24 \\
\hline
\end{tabular}

Como observado na TAB. 34, os valores obtidos pela $\mathrm{CL}_{50}$ (48h) foi consideravelmente maior do que os valores encontrados para $C$. dubia, o que evidencia a necessidade da realização de testes toxicológicos com mais de um organismo representativo.

Algumas vezes somente resultados relativos a mortalidade ou imobilidade não são suficientes para o completo entendimento do agente agressor ao impacto ambiental causado pelo mesmo. Sendo assim outras observações complementares como crescimento, gênero, desenvolvimento entre outros são utilizados para complementar os resultados. Assim, além do testes agudos de 48h, testes crônicos complementares de 7 dias foram realizados para ambos os corantes a fim de verificar não somente mortalidade, mas o crescimento das larvas de $C$. tepperi. $O$ resultados de sobrevivência podem ser observados nas FIG. 38.

Cabe salientar que, como observado nos gráficos, o número total de organismos decresce com o tempo como observado nos controles. Isso se deve ao método utilizado, que tem como objetivo também de acompanhar o crescimento das larvas pelo tempo. Assim após $48 \mathrm{~h}$ de teste, das 9 réplicas de cada concentração, 3 réplicas são fixadas em formol. Após $96 \mathrm{~h}$ de teste, das 7 réplicas restantes, 3 são fixadas em formal e assim consecutivamente.

Pode-se observar na FIG. 38 que após 48h de teste, nas concentrações mais altas de ambos os corantes (39,2 e $220 \mathrm{mgL}^{-1}$ para SN e ST, respectivamente) houve uma diminuição no número de larvas sobreviventes de $\sim 40 \%$ para SN e ST, quando 
comparados ao controle. Contudo, na concentração de $440 \mathrm{mgL}^{-1}$ do ST não foram observadas larvas sobreviventes ao final das $48 \mathrm{~h}$.

Após $96 \mathrm{~h}$ de teste para todas as concentrações do SN houve uma diminuição de $~ 50 \%$ no número de organismos sobreviventes e após 144h a diminuição do número de organismos foi observada mais acentuadamente a partir da concentração $4,9 \mathrm{mgL}^{-1}$ $(\sim 46 \%)$.
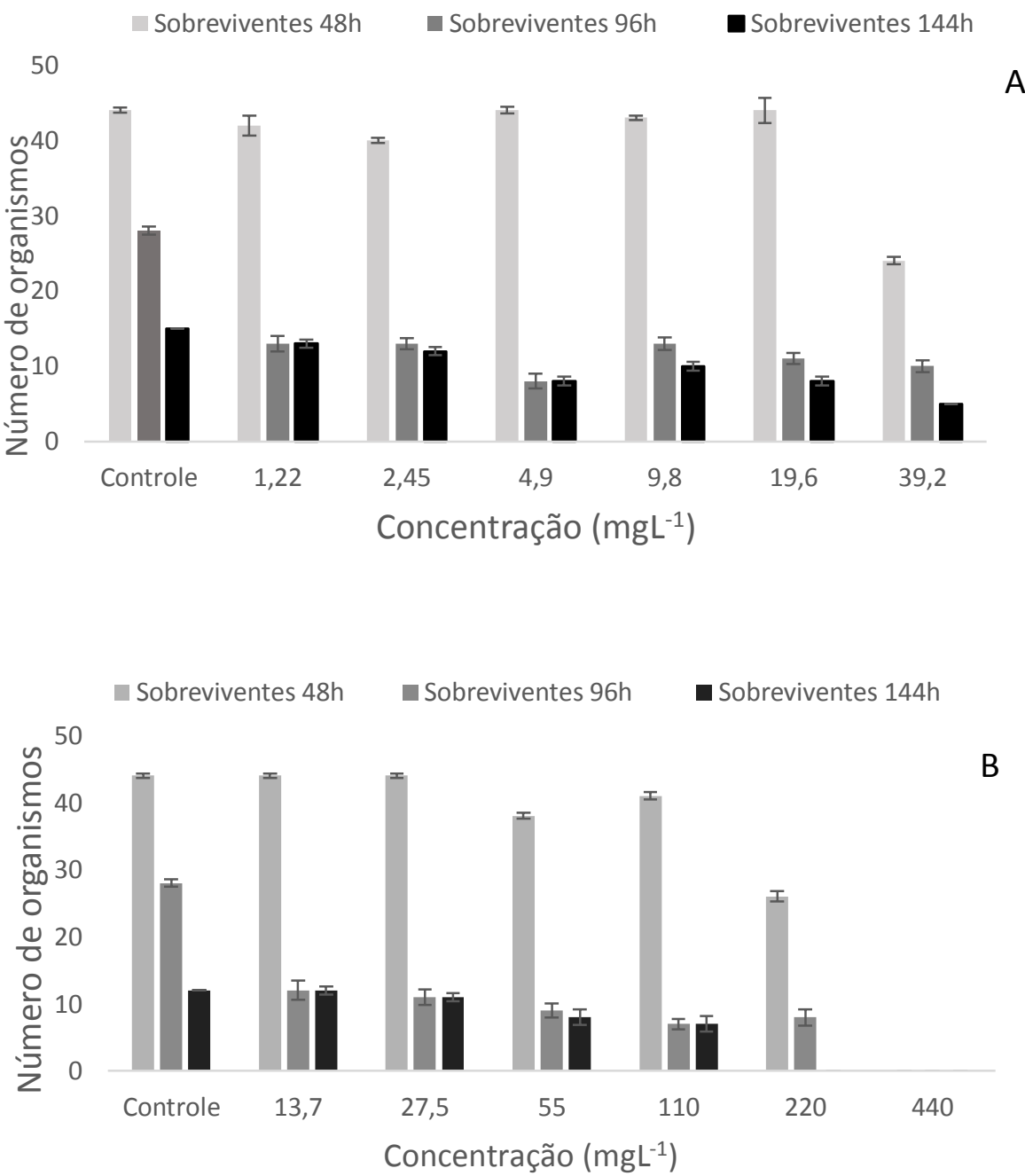

FIGURA 38: Média e desvio padrão da sobrevivência de $C$. tepperi após 7 dias de exposição a diferentes concentrações dos corantes Solophenyl Navy $(A)$ e Solophenyl Turquesa (B)

Com relação do corante ST, após $96 \mathrm{~h}$ de teste foi possível observar uma diminuição na sobrevivência de $57 \%$ em sua concentração mais baixa $\left(13,7 \mathrm{mgL}^{-1}\right)$ seguindo menores taxas de sobrevivência com o aumento das concentrações testadas.

Após $144 \mathrm{~h}$ de teste até a concentração de $55 \mathrm{mgL}^{-1}$ houve uma estabilização da mortalidade quando comparado ao controle, e após essa concentração foi possível observar novamente uma queda no número de sobreviventes, sendo que na mais alta concentração com larvas sobreviventes $\left(220 \mathrm{mgL}^{-1}\right)$ nenhum organismo foi dado como vivo ao final das $144 \mathrm{~h}$ de teste.

Na FIG. 39 pode-se observar o crescimento das larvas de $C$. tepperi durante o período de teste de 7 dias. 

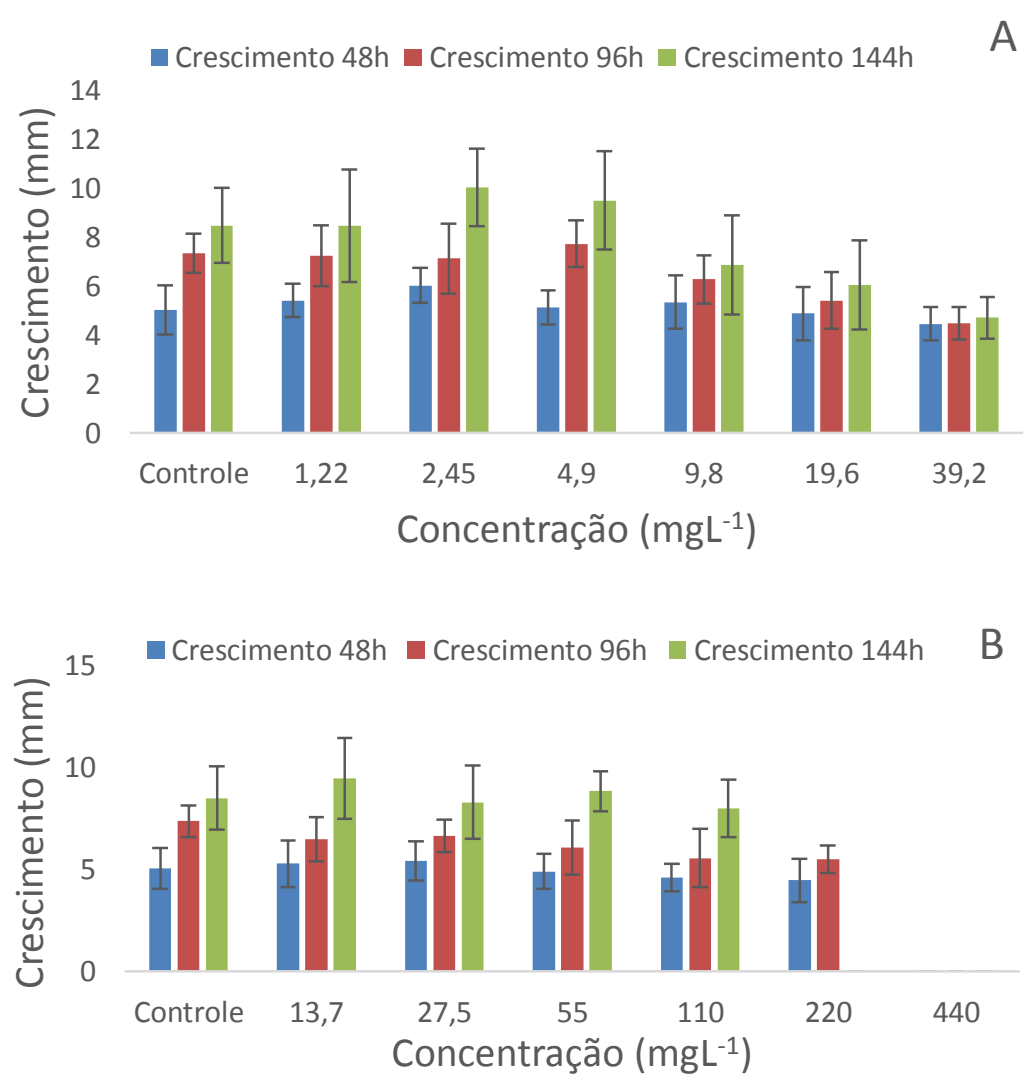

FIGURA 39: Média e desvio padrão do crescimento das larvas de C. tepperi durante 7 dias de exposição à diferentes concentrações dos corantes Solophenyl Navy (A) e Turquesa (B)

Como observado na FIG. 39, após 48h de teste ambos os corantes apresentaram um crescimento das larvas compatível com o controle $(5,04 \mathrm{~mm})$. Como citado anteriormente, na concentração mais alta no corante ST $\left(440 \mathrm{mgL}^{-1}\right)$ todas as larvas foram dadas como mortas.

Após $96 \mathrm{~h}$ de teste pode-se observar uma diferença no crescimento das larvas, principalmente após a concentração de $9,8 \mathrm{mgL}^{-1}$ para SN e $55 \mathrm{mgL}^{-1}$ para ST. Quando comparados ao controle, as maiores concentrações apresentaram um decréscimo no crescimento de $\sim 38$ e $25 \%$ para SN e ST, respectivamente $(7,37,4,50$ e $5,49 \mathrm{~mm}$ para controle, SN e ST, respectivamente).

Com $144 \mathrm{~h}$ de teste pode-se observar para o corante $\mathrm{SN}$ que nas concentrações 2,45 e $4,9 \mathrm{mgL}^{-1}$ houve um aumento no crescimento quando comparado ao controle $\left(8,50\right.$ e $10,06 \mathrm{~mm}$ para controle e $2,45 \mathrm{mgL}^{-1}$, respectivamente). A partir da concentração $9,8 \mathrm{mgL}^{-1}$ pode-se observar o decréscimo no crescimento das larvas de $44 \%$ (8,50 e 4,73 mm para controle e 39,2 $\left.\mathrm{mgL}^{-1}\right)$. A partir da concentração $9,8 \mathrm{mgL}^{-1}$ houve um decréscimo acentuado no crescimento das larvas até a concentração de 39,2 $\mathrm{mgL}^{-1}$, onde após 48, 96 e 144h de teste o crescimento das larvas não apresentou diferença $(4,48,4,50$ e $4,73 \mathrm{~mm}$ para 48,96 e $144 \mathrm{~h}$ de teste).

Para o corante ST após $144 \mathrm{~h}$ de teste a concentração de $220 \mathrm{mgL}^{-1}$ não apresentou nenhum sobrevivente. Contudo, o crescimento das larvas para as demais concentrações apresentaram um crescimento equivalente ao controle $(8,50$ e $8 \mathrm{~mm}$ para controle e $\left.110 \mathrm{mgL}^{-1}\right)$.

Assim, três estágios foram observados: 1) Em baixas concentrações dos corantes não foram observados efeitos tóxicos, o que resultou em uma sobrevivência e crescimento dos organismos compatíveis com o controle; 2) Em concentrações intermediárias, os corantes mostraram efeitos adversos às larvas em relação ao 
crescimento e 3) Em altas concentrações dos corantes foram observados efeitos tóxicos em relação a sobrevivência dos organismos, como pode ser observada na FIG. 40.

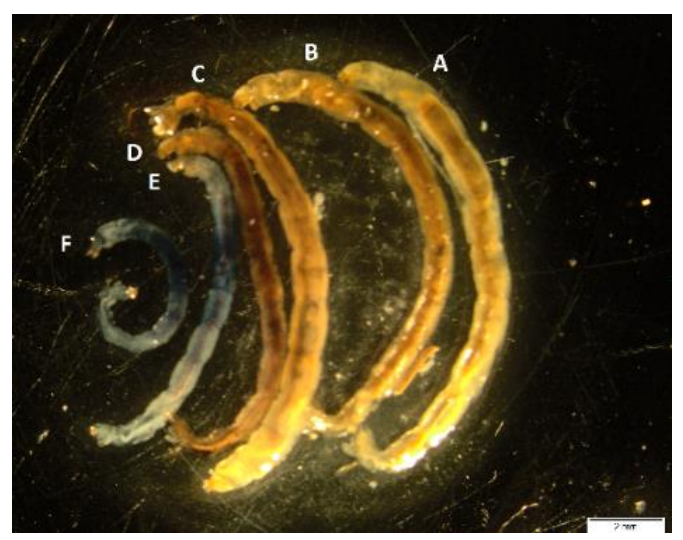

FIGURA 40: Diferença no crescimento das larvas de C. tepperi durante 7 dias de exposição a diferentes concentrações do corante Solophenyl Navy (A-controle; B- 1,22; C- 2,45; D- 4,9; E- 9,8 e F- 19,6 mgL $^{-1}$ )

\subsubsection{Avaliação da toxicidade em sedimento com Chironomus tepperi}

Após verificação da toxicidade do corante Solophenyl Navy pelo organismo $L$. minor, C. dúbia e C. tepperi somente esse corante foi utilizado nos testes com sedimento, pois o mesmo apresentou maior potencial poluidor, tanto para os corpos de água receptores como para o sedimento dos mesmos.

O sedimento representa um compartimento no sistema aquático responsável pelo acumulo de substâncias, tornando-se, portanto, um sumidouro desses elementos. Contudo, as condições ambientais, tais como mudanças no $\mathrm{pH}$ e condições de anoxia, o sedimento pode se tornar uma fonte de substâncias tóxicas para a coluna d'água, causando uma alteração geral nas condições do sistema em estudo. Assim, os bioensaios ecotoxicológicos com sedimentos são ferramentas importantes que fornecem informações sobre o nível de contaminação ou locais que podem proporcionar risco a biota aquática (Dornfeld, 2006).

\subsubsection{1 "Spiked sediment"}

Na FIG. 41 são mostrados os resultados de sobrevivência e número de organismos emergidos após 10 dias de teste com corante no sedimento. Os parâmetros da qualidade da água são mostrados no APÊNDICE F. 


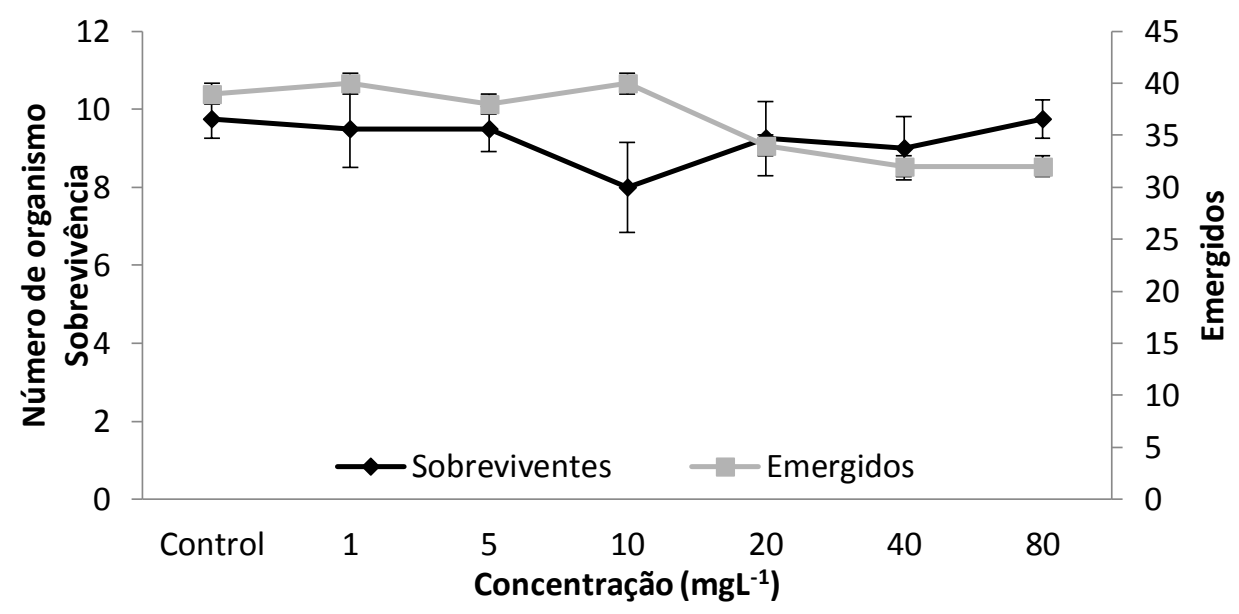

FIGURA 41: Média e desvio padrão do número de larvas sobreviventes e emergidas após 10 dias de teste "Skiped Sediment" com corante Solophenyl Navy

Na FIG. 42 podem ser observados os resultados de crescimento das larvas ao final de 10 dias de teste.

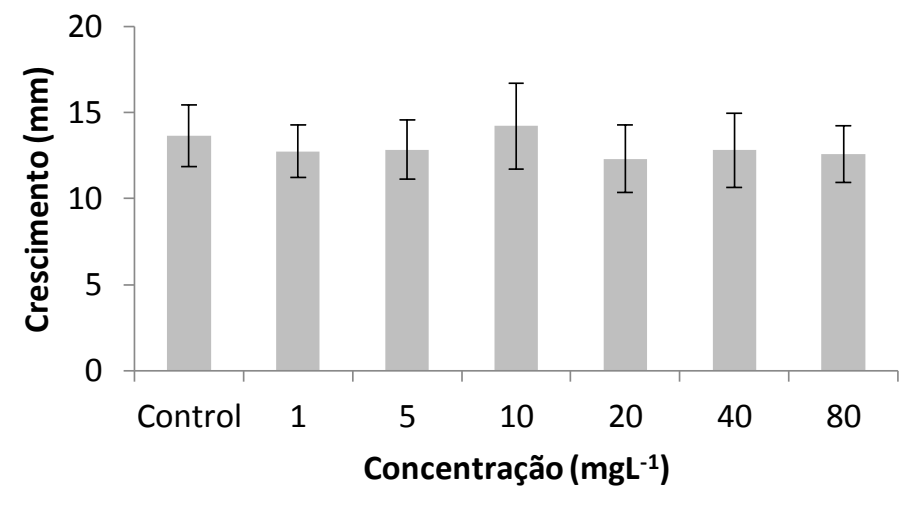

FIG. 42: Média e desvio padrão no crescimento das larvas após 10 dias de testes "Spiked Sediment" com o corante Solophenyl Navy

Não foi observado efeito na sobrevivência ou no crescimento das larvas quando comparadas ao controle, como observado nas FIG. 41 e 42 . Contudo, uma redução no número de larvas emergidas foi observada após a concentração de $20 \mathrm{mgL}$ 1 de $\sim 12 \%$.

Com relação ao gênero, nas concentrações mais baixas do corante (de 1 à $10 \mathrm{mgL}^{-1}$ ) foram observadas uma maior quantidade de fêmeas emergidas, quando comparado ao controle. Contudo o resultado inverso foi observado após $20 \mathrm{mgL}^{-1}$, como observado na FIG. 43. 


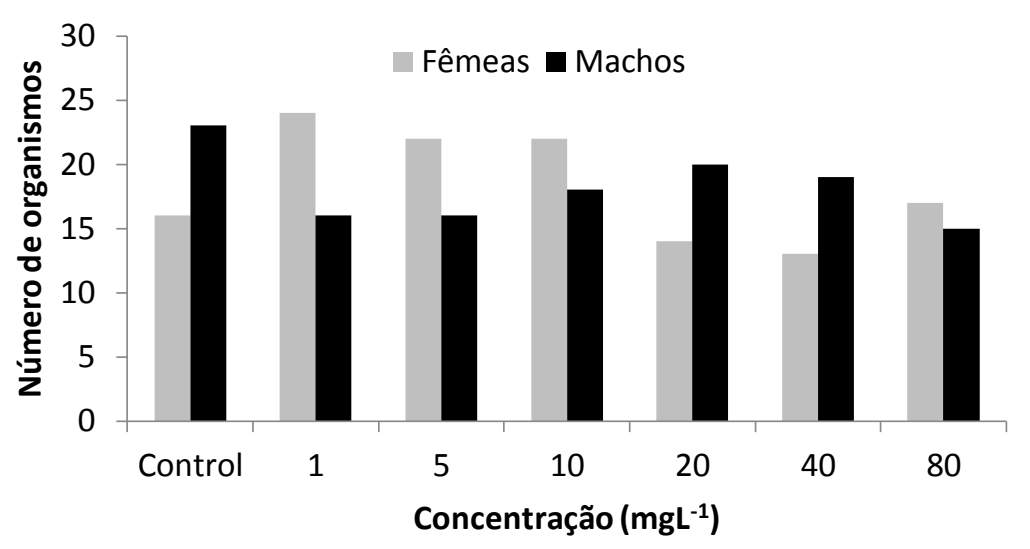

FIGURA 43: Média por gênero das larvas emergidas após 10 dias de teste "Spiked Sediment" à várias concentrações do corante Solophenyl Navy

Outra observação realizada durante os testes foi em relação ao tempo de emersão. As larvas do controle começaram a emergir no $6^{\circ}$ dia de teste, enquanto que para todas as concentrações do corante as larvas começaram a emergir um dia antes. No quinto dia de teste, onde as larvas são preservadas em formol para posterior medição, foi observado que na concentração de $20 \mathrm{mgL}^{-1} \mathrm{e}$ a partir dela, algumas larvas já se encontravam em estado de pupa, uma vez que foram observadas estruturas de "transição" entre a fase larval e como mosquito adulto, como pode ser observado na FIG. 44.

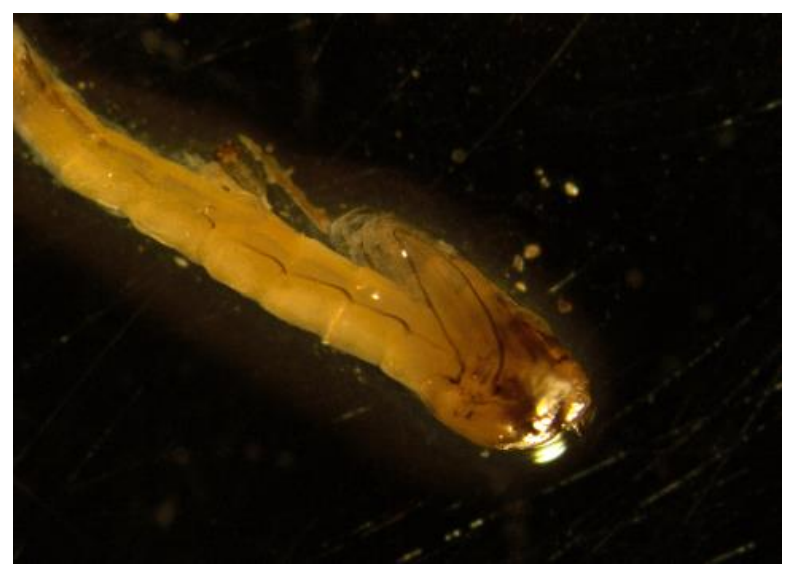

FIGURA 44: Estágio de pupa na larva de C. tepperi após 5 dias de teste

\subsubsection{2 "Spiked Water"}

Como pode-se observar pela FIG 45, houve uma diminuição na sobrevivência das larvas após $20 \mathrm{mgL}^{-1} \mathrm{de} ~ 67,5 \%$, sendo que na mais alta concentração $\left(80 \mathrm{mgL}^{-1}\right)$ não foram observados sobreviventes. Os parâmetros da qualidade da água são mostrados no Anexo G. 


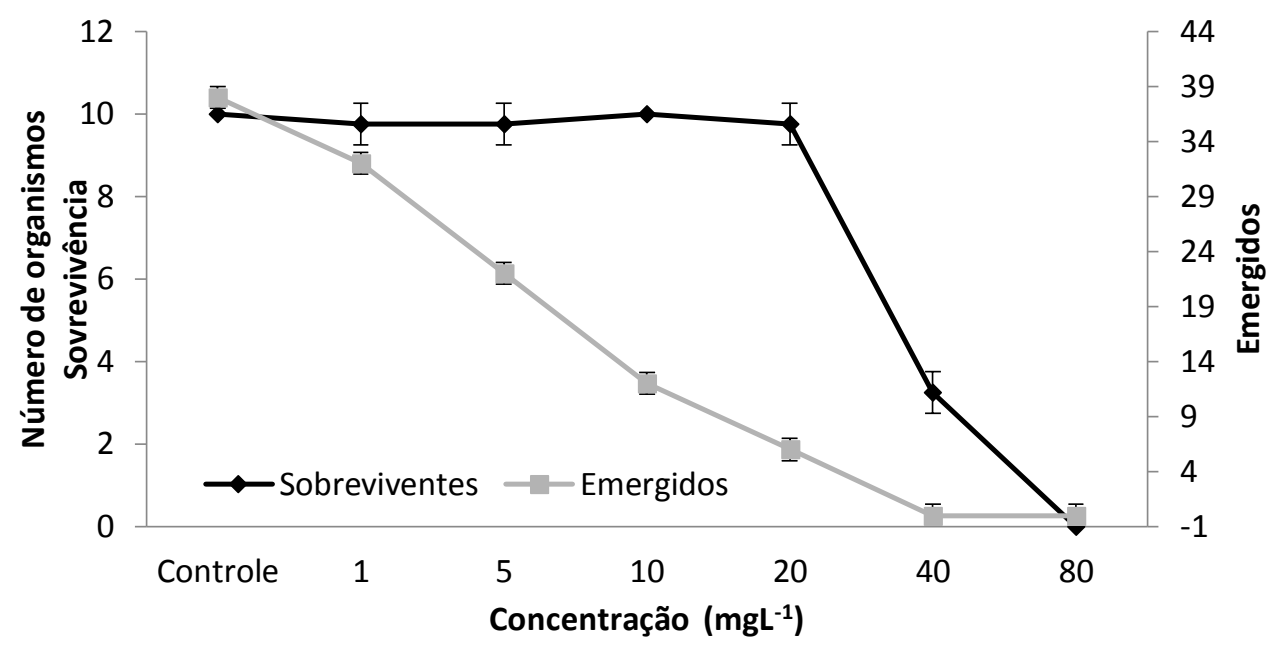

FIGURA 45: Média e desvio padrão do número de larvas sobreviventes e emergidas após 10 dias de teste "Skiped Water" com corante Solophenyl Navy

Houve uma diminuição do número de larvas emergidas com o aumento da concentração do corante e após $40 \mathrm{mgL}^{-1}$ não foram observadas larvas emergidas ao final de 10 dias de teste.

O mesmo comportamento dose-efeito foi observado para o crescimento das larvas, onde uma diminuição de 22\% já pôde ser observada na concentração de 10 $\mathrm{mgL}^{-1}$, quando comparada ao controle. Na concentração de $40 \mathrm{mgL}^{-1}$ essa diminuição foi de $\sim 58 \%$ em relação ao controle, como observado da FIG. 46 .

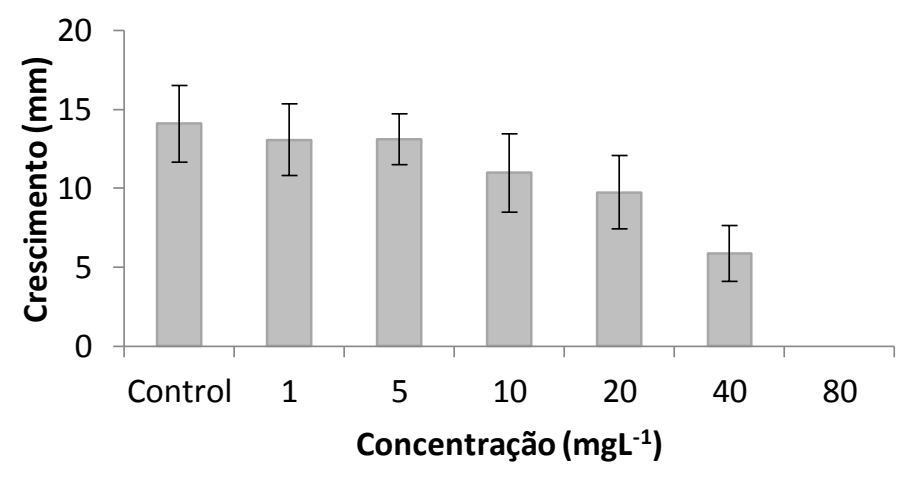

FIGURA 46: Média e desvio padrão no crescimento das larvas após 10 dias de testes "Spiked Water" com o corante Solophenyl Navy

Quando se observa a diferença de gêneros, podemos perceber que a quantidade de machos emergidos é maior que a de fêmeas nos controles, para ambos os testes e esse resultado já era esperado. Contudo, observando a FIG. 47 para o testes Spiked Water, podemos perceber diferença nesse resultado, uma vez que nas concentrações mais baixas o número de machos e fêmeas foram iguais, e em $10 \mathrm{mgL}^{-1}$ o número de machos se apresentou desproporcional ao número de fêmeas, e em 20 $\mathrm{mgL}^{-1}$ o número de fêmeas foi maior que o de machos. 


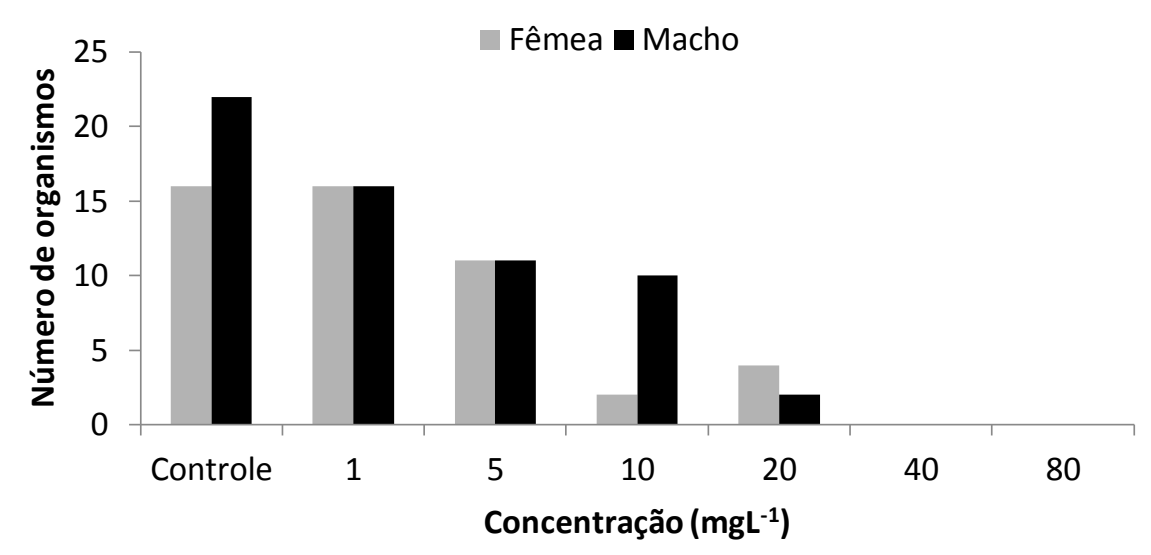

FIGURA 47: Média por gênero das larvas emergidas após 10 dias de teste "Spiked Water" à várias concentrações do corante Solophenyl Navy

A taxa de sobrevivência, crescimento e número de chironomideos emergidos são endpoints amplamente aceito para medir a toxicidade aguda e crônica em sedimentos (OECD, 2010). Os resultados ilustraram que efeitos subcrônicos e até mesmo letais foram observados com mais efetividade no teste "Spiked Water", onde mesmo nas menores concentrações de SN foram observados efeitos adversos no crescimento das larvas, número de organismos emergidos e diferenciação de gênero em mosquitos adultos.

No teste "Spiked Sediment" foram observados uma diferenciação no tempo de emergência dos organismos, assim como maior quantidade de fêmeas, nas menores concentrações do $\mathrm{SN}$, o que indica um fator de stress ao organismo. A maior sensibilidade de respostas subletais ao stress é um princípio bem estabelecido na ecotoxicologia, e é consistente com o conhecimento atual do gênero Chironomus (Hale et al., 2014; Ingersoll et al., 2001).

A redução do crescimento de larvas de Chironomus nas concentrações mais altas do SN pode ser explicado pelo aumento da energia utilizada para processos de desintoxicação (Arambourou et al., 2013; Choi et al., 2001), enquanto que baixas concentrações provavelmente não são suficientes para induzir o atraso no crescimento ou emergência prematura. Arambourou (2014), utilizaram sedimentos contaminados com metais e resultados semelhantes foram observados.

Nos APÊNCIDE B e C podem ser observados os resultados das análises químicas da água para ambos os testes. O teste "Spiked Water", onde o corante foi adicionado a água de cultivo dos organismos, apresentou maiores concentrações de alguns elementos na água, como: Al, Ti, Mn, $\mathrm{Fe}, \mathrm{Cu}, \mathrm{Zn}, \mathrm{As}, \mathrm{Rb}, \mathrm{Sr}, \mathrm{Ba}, \mathrm{Ca}, \mathrm{K}, \mathrm{Mg}, \mathrm{Na}$, $\mathrm{S}, \mathrm{Cl}^{-}$, Carbono Total (TC), Carbono Orgânico Total (TOC) e Nitrogênio Total (TN), quando comparado com "Spiked Sediment". Apresentando também maiores concentrações da maior parte desses elementos ao passar dos dias.

Alguns elementos como o $\mathrm{Al}, \mathrm{Ti}, \mathrm{Cr}, \mathrm{Fe}$ e As somente apresentaram altas concentrações a partir da concentração de $20 \mathrm{mgL}^{-1}$, o que pode justificar os resultados observados para sobrevivência, emersão e crescimento dos organismos.

Quando comparado o $\mathrm{Cu}$, metal encontrado em altas concentrações nesse corante, os resultados químicos apontam que para o teste "Spiked Water" ele se encontra em mais concentrado para todas as concentrações testadas $\left(0,25-4,32 \mathrm{mgL}^{-1}\right)$, enquanto que para o teste "Spiked Sediment" os valores ficaram próximos a $0,25 \mathrm{mgL}^{-1}$, o que pode justificar a diferença observada para ambos os testes realizados.

Para o "Spiked Sediment", onde o corante foi adicionado ao sedimento, alguns elementos foram observados inicialmente em baixas concentrações na água e com o passar dos dias essas concentrações foram aumentando, como é o caso do $\mathrm{Na}, \mathrm{Al}, \mathrm{Ti}$, 
Mn e Cu. Pode-se deduzir que esses elementos se encontravam concentrados no sedimento e provavelmente passaram para a água.

Contudo, testes relativos a bioacumulação devem ser realizados a fim de um melhor entendimento dos efeitos subletais, como os que foram observados nesse estudo. A literatura reporta que larvas de $C$. riparius expostas a cobre $(0,005-0,05 \mathrm{mg} / \mathrm{L}$ de $\mathrm{Cu}$ ) por $48 \mathrm{~h}$ apresentaram produção de aberrações cromossômicas estruturais e funcionais (Michailova et al., 2006). Mudanças similares foram observadas com elementos traço Cr, Pb e Al (Michailova et al., 2001a, Michailova et al., 2001b and Michailova et al., 2003). Este estudo indicou que os metais vestigiais agiram sobre os cromossomos apresentando assim importantes mudanças no desenvolvimento e crescimento das larvas.

\subsection{Avaliação e identificação da toxicidade \\ 5.7.1 Avaliação e identificação da toxicidade dos corantes}

A fim de esclarecer quais toxicantes estavam causando a toxicidade observada para os corantes SN e ST em sua forma bruta (sem tratamento), testes de Avaliação e Identificação da Toxicidade (AIT) foram realizados.

Os ensaios de toxicidade foram realizados como descrito no item 4.9.1 Para todos ensaios de AIT realizados um teste base foi feito simultaneamente, utilizando as amostra brutas (não manipuladas) para comparação com as amostras manipuladas com EDTA e SPE. Os resultados são mostrados na TAB. 35.

TABELA 35: Avaliação e Identificação da Toxicidade dos corantes Solophenyl Navy (SN) e Turquesa (ST) com amostras brutas e após manipulação com EDTA e SPE, para identificação de metais catiônicos e compostos orgânicos, respectivamente

\begin{tabular}{|c|c|c|c|c|c|c|c|}
\hline $\mathrm{mgL}^{-1}$ & SN & SN+EDTA & SN+SPE & & ST & ST+EDTA & ST+SPE \\
\hline & n. de vivos & & & & n. de vivos & & \\
\hline Controle & 10 & 10 & 10 & Controle & 10 & 10 & 10 \\
\hline 2.06 & 0 & 8 & 0 & 55.6 & 0 & 8 & 0 \\
\hline 1.03 & 0 & 9 & 0 & 27.8 & 0 & 9 & 0 \\
\hline 0.515 & 0 & 9 & 0 & 13.9 & 0 & 9 & 0 \\
\hline
\end{tabular}

Como mostrado na TAB. 35, nas concentrações para as amostras brutas de ambos os corantes (ST e SN) foram observadas toxicidade significativa para $C$. dubia. Da mesma forma, a manipulação de troca iônica com SPE não afetou a toxicidade desses corantes, o que indica que a toxicidade dessas amostras não são oriundas de compostos orgânicos não-polares.

No entanto, a toxicidade foi substancialmente reduzida após manipulação com EDTA, indicando ausência de toxicidade nas concentrações testadas. Estes resultados sugerem que a toxicidade destes corantes na forma bruta foi influenciada pelo tratamento com EDTA, indicando que os produtos tóxicos encontrados nas amostras são principalmente metais catiônicos, corroborando os resultados obtidos pelas análise química. Estes procedimentos são uma primeira tentativa de aplicar AIT em corantes do tipo ftalocianina a base de cobre, e se mostraram promissor para identificar as causas da toxicidade nestas classe de corante.

\subsection{Testes de toxicidade aguda com $C$. dúbia e Avaliação e Identificação da Toxicidade das zeólitas modificadas com surfactante}

No presente estudo a avaliação da toxicidade para os lixiviados da ZMF e ZPM foram realizados em concentrações de 3,12-100\% a fim de determinar os valores 
de $\mathrm{CL}_{50}$ para $C$. dubia. Como observado na TAB. 36, a ZPM mostrou-se mais tóxica, quando comparada a ZLM.

TABELA 36: Toxicidade aguda dos lixiviados dos adsorventes zeólita leve modificada por surfactante (ZLM) e zeólita pesada modificada por surfactante (ZPM)

\begin{tabular}{ccc}
\hline Adsorvente & Concentração inicial (\%) & CL $_{50}$ (48 $\left.\mathbf{h}\right)(\%)$ \\
\hline ZLM & 100 & $35,2(27,1-45,6)$ \\
ZPM & 100 & $8,48(8,34-8,61)$ \\
\hline
\end{tabular}

Com relação a avaliação e identificação da toxicidade dos lixiviados da ZLM e ZPM, os resultados podem ser observados na TAB. 37

TABELA 37: Avaliação e Identificação da toxicidade dos lixiviados da ZLM e ZPM antes e após manipulação com EDTA e SPE para identificação de metais catiônicos e compostos orgânicos, respectivamente

\begin{tabular}{|c|c|c|c|c|c|c|c|}
\hline (\%) & ZLM & ZLM+EDTA & ZLM+SPE & $(\%)$ & ZPM & ZPM+EDTA & ZPM+SPE \\
\hline & n. de vivos & & & & n. de vivos & & \\
\hline Controle & 10 & 10 & 10 & Controle & 10 & 10 & 10 \\
\hline 100 & 0 & 7 & 8 & 100 & 0 & 7 & 7 \\
\hline 50 & 2 & 9 & 9 & 50 & 0 & 8 & 9 \\
\hline 25 & 7 & 10 & 10 & 25 & 0 & 10 & 10 \\
\hline 12,5 & 9 & 10 & 10 & 12,5 & 0 & 10 & 10 \\
\hline 6,25 & 10 & 10 & 10 & 6,25 & 10 & 10 & 10 \\
\hline 3,12 & 10 & 10 & 10 & 3,12 & 10 & 10 & 10 \\
\hline
\end{tabular}

As amostras escolhidas para a AIT mostraram uma toxicidade relevante na forma bruta. Os resultados mostram que ambos os tratamentos foram capazes de eliminar a toxicidade nas amostras testadas (TAB. 37). Estes resultados sugerem que a toxicidade do adsorvente no efluente bruto lixiviado foi influenciado pela manipulação com EDTA e SPE, sugerindo que os produtos tóxicos são principalmente metais e compostos orgânicos não-polares, respectivamente.

A fim de identificar a toxicidade devido aos metais, verificou-se, por análise química, que a concentração de As seria capaz de causar efeitos agudos a $C$. dúbia para ambos os lixiviados, como observado na TAB. 38.

TABELA 38: Elementos encontrados nos lixiviados das zeólitas leve (ZLM) e pesada (ZPM) modificada por surfactante sem diluições ou purificações. Os valores da CL50 são mostrados juntos para comparação

\begin{tabular}{cccccccc}
\hline Adsorvente & \multicolumn{7}{c}{ Elemento (mg/L) } \\
& $\mathbf{C l}^{-}$ & $\mathbf{B r}^{-}$ & $\mathbf{N a}$ & As & $\mathbf{B}$ & $\mathbf{U}$ \\
\hline ZLM & & 79 & 4 & 119 & 0,95 & 1,4 & 0,11 \\
ZPM & 46 & 3,9 & 75,3 & 0,65 & 0,78 & 0,02 \\
& $\mathbf{C L}_{50^{1}}$ & $\mathrm{NA}^{2}$ & 0,18 & $\mathrm{NA}$ & 0,5 & 56 & 0,39 \\
\hline
\end{tabular}

1- Valores encontrados em literatura; 2- Não aplicável

Uma possível razão para esta toxicidade após o contato do adsorvente com água poderia ser devido à presença de surfactante residual no lixiviado, assim o lixiviado poderia conter cátions de HDTMA+.

Tem sido postulado que a toxicidade de um agente tensoativo é altamente específico para cada organismo testado. Garcia et al (2007) mostraram que o valor encontrado da $\mathrm{CL}_{50}$ para $D$. magna foi de $0,38 \mathrm{mgL}^{-1}$ para HDTMA-Br. De acordo com Sandback et al., Daphnia são particularmente susceptíveis a agentes tensoativos catiônicos, tais como o brometo de hexadeciltrimetilamónio. Resultados semelhantes 
para toxicidade de HDTMA para $C$. dubia também foram encontrados na literatura (Garcia et al., 2007; Mark e Soilbé, 1998).

O cloreto e o sódio estão presentes no meio de cultura da $C$. dúbia, a fim de promover todos os nutrientes necessários para um bom crescimento do organismo. Contudo, os valores encontrado para $\mathrm{Br}^{-}$estão acima dos valores da $\mathrm{CL}_{50}$ encontrados na literatura $\left(0,18 \mathrm{mgL}^{-1}\right.$, para Daphnia magna, Montgomery, 1995), no entanto, os resultados das análises químicas na água de cultivo para $C$. dubia mostrou altos valores de $\mathrm{Br}^{-}$após $48 \mathrm{~h}$ de teste $\left(3,8 \mathrm{mgL}^{-1}\right)$, o que indica que esse elemento não causou toxicidade observada.

De acordo com Fikirdesici et al. (2010), os valores de $\mathrm{CL}_{50}$ para dafinídeos é de $0,5 \mathrm{mgL}^{-1}$ para Arsénio (As). Os valores encontrados nas amostras para As foi de 0,95 e $0,65 \mathrm{mgL}^{-1}$ para ZLM e ZPM, respectivamente.

A toxicidade do As para os organismos aquáticos é um tanto complicada pela existência de duas espécies orgânicas diferentes de As: As (III) e As (V), e ambas podem ser encontradas neste estudo.

Uma complicação adicional resulta quando o As (III) é lentamente oxidado em As (V) em condições ricas em oxigênio, que geralmente são empregadas nos testes de toxicidade aquáticos. É geralmente aceito que o As (III) é mais tóxico do que o As (V), uma hipótese apoiada por estudos com invertebrados de água doce (Borgmann et al., 1980; Spehar e Fiandt, 1986; Golding et al., 1997). Assim, é possível que o As possa causar a toxicidade observada neste estudo.

Com relação aos testes de TIE, o EDTA, utilizado nas amostras manipuladas, é um agente quelante que forma complexos não-tóxicos com os metais $\mathrm{Al}^{3+}, \mathrm{Ba}^{2+}, \mathrm{Cd}^{2+}$, $\mathrm{Co}^{2+}, \mathrm{Cu}^{2+}, \mathrm{Fe}^{2+}, \mathrm{Pb}^{2+}, \mathrm{Mn}^{2+}, \mathrm{Ni}^{2+}, \mathrm{Se}^{2+}$ e $\mathrm{Zn}^{2+}$. A quelação é dependente do $\mathrm{pH}$, o tipo de metal, a presença de outros ligantes na solução, e a afinidade do metal com o EDTA (USEPA, 1997). Para os metais $\mathrm{Zn}^{2+}, \mathrm{Pb}^{2+}$ e $\mathrm{Cu}^{2+}$, o $\mathrm{pH}$ dos testes realizados neste estudo (média de 8,08) poderia explicar a capacidade quelante do EDTA (USEPA, 1991). Assim, após a manipulação com EDTA e seu potencial de quelação, o As não teria mais potencial tóxico para C. dubia.

Após o tratamento com SPE, a toxicidade para o lixiviado de ZMF e ZPM foi eliminada (TAB. 38). O processo de SPE retém espécies orgânicas não-polares, tais como $\mathrm{HDTMA}^{+}$, na coluna, resultando na redução da toxicidade na amostra testada.

Contudo, a toxicidade observada nas amostras dos lixiviados poderia ser resultante da mistura, em baixas concentrações, de $\mathrm{Cd}, \mathrm{Cr}, \mathrm{Cu}, \mathrm{Pb}, \mathrm{Zn}, \mathrm{Mn}$ e U. A literatura reporta que a ação conjunta dos metais em concentrações próximas aos níveis de efeito adverso não observável (NOEL), poderia ser tóxico para os organismos aquáticos (Spehar e Fiandt, 1986; Cooper et al., 2009).

\subsection{Sensibilidade de diferentes organismos}

As três espécies, que pertencem a diferentes níveis tróficos diferentes, mostraram sensibilidade diferente aos quatro efluentes testados.

C. dubia foi o organismo testado mais sensível. Como o efluente após o processo de adsorção contém surfactantes proveniente da zeólita modificada, o teste com C. dubia é provavelmente útil para avaliar os efeitos da toxicidade devido a surfactantes, não detectáveis por outros organismos.

A angiosperma $L$. minor foi o organismo menos sensível e em alguns casos até mesmo mostrou bioestimulação quando em contato com o efluente simulado. No entanto, alguns cuidados devem ser expressos a esse respeito, porque estes bioensaios foram testes de curto prazo (toxicidade aguda) e, portanto, eles não poderiam fornecer informações sobre eventuais efeitos a longo prazo (toxicidade crónica) (Tigini et al., 2011). Além disso, os efeitos da bioestimulação, como mostrado para os corante ST e 
STH, devem ser seriamente levados em conta, uma vez que poderia prever o potencial de eutrofização em águas residuais e este fenómeno deve se tornar progressivamente mais significativa dentro de avaliação toxicológica e de avaliação de risco (Calabrese, 2008).

Na Austrália, Chironomus é conhecido como um organismo relativamente resistente a poluição (Chessman, 1995). Esta resistência contribui para sua popularização como um organismo de bioensaio (OECD, 2010) e sua resistência a concentrações moderadas de contaminantes, resultado esse que pôde ser observado nesse estudo. Testes crônicos com sedimentos pelo $C$. tepperi mostraram efeitos letais e subletais no desenvolvimento das larvas e em mosquitos adultos, mostrando-se um organismo potencial para testes em sedimentos.

\section{CONCLUSÕES}

O presente estudo avaliou o uso de zeólitas de cinza de carvão modificadas com surfactante como um adsorvente de baixo custo para remover tanto os corantes ST e SN, como as suas formas hidrolisadas, de solução aquosa e permitindo concluir:

a) Os estudos cinéticos mostraram que o tempo de equilíbrio de adsorção foi de 20 min para ZLM e de 60 min para ZPM para ambos os corantes. Os corantes na forma hidrolisada apresentaram tempos de equilíbrio entre 20 30 min para ambos adsorventes.

b) A eficiência de remoção dos corantes foi na faixa de 78 e $85 \%$ para ST e SN e de 91 e 66\% para STH e SNH pela ZLM, respectivamente. Para a ZPM esses valores ficaram próximos a 70\% para ST e SN e 53 e 69\% para STH e $\mathrm{SNH}$, respectivamente.

c) O modelo cinético de pseudo segunda-ordem apresentou melhor correlação para todos os sistemas de adsorção estudados.

d) As isotermas de equilíbrio para os sistemas ZLM/ST, ZLM/STH, ZPM/ST e ZPM/STH apresentaram curvas com comportamento correspondente à classe do Tipo L2.

e) Os sistemas ZLM/SN, ZPM/SN e ZPM/SNH apresentaram isotermas do tipo L4 e o sistema ZLM/SNH apresentou isoterma correspondente a classe S4.

f) O modelo de Langmuir foi o mais adequado para o ajuste aos dados experimentais de equilíbrio para a maioria dos sistemas estudados, fato também corroborado pelos valores encontrados pelas estimativas de desvio.

g) A ZLM apresentou capacidade máxima de adsorção maior o que a ZPM para ambos os corantes nas formas hidrolisadas e não hidrolisadas, devido ao fato de que a zeólita de cinzas leve adsorve uma maior quantidade de HDTMA em sua superfície.

h) $\mathrm{Na}$ avaliação da toxicidade aguda com $C$. dúbia, foi evidenciado que o tratamento proposto com ZLM resultou em um resíduo menos tóxico, para ST e SN na forma bruta e hidrolisada. No entanto, o tratamento com ZPM aumentou a toxicidade dos corantes para as formas brutas e reduziu a toxicidade nas formas hidrolisadas. Isso indica que a modificação da estrutura reativa, isoladamente, não determina a toxicidade dos corantes e sugere que outros componentes estruturais estejam envolvidos na indução do efeito tóxico.

i) Os testes com L. minor para SN em baixas concentrações mostraram que houve uma bioestimulação com relação do crescimento dos frondes. Contudo em altas concentrações houve um detrimento dos frontes, assim como observado para o corante ST. 
j) Para os testes agudos, com relação ao $C$. tepperi, esse organismo se mostrou menos sensível, quando comparado a C. dubia.

k) Os resultados para TIE apontaram uma redução da toxicidade após o tratamento com EDTA, mostrando que a maior parte dos agentes tóxicos deste estudo são íons metálicos. Este resultado foi corroborado pela análise química sugerindo que o $\mathrm{Cu}^{2+}$ é o principal metal que pode causar toxicidade para os dois corantes. Os resultados deste estudo demonstraram a grande importância da realização de ensaios toxicológicos associados aos testes de remoção de cor.

I) Foi observado neste trabalho que dentre todos os organismos utilizados $\mathrm{C}$. dubia se mostrou o mais sensível, possivelmente por causa do surfactante proveniente da zeólita modificada, que não foi detectável pelos outros organismos.

m) Com relação aos ensaios crônicos, "Spiked Water" se mostrou mais eficientes com relação aos efeitos subletais quando comparado ao teste "Spiked Sediment", apresentando mudanças na sobrevivência, crescimento e desenvolvimento das larvas, porém ambos os testes apontaram para uma alteração com relação a diferenciação de gênero para mosquitos adultos. Assim, sedimentos poluídos podem impactar na sobrevivência e retardar o crescimento das larvas.

n) Assim, as zeólitas de cinzas de carvão modificadas por surfactante apresentadas nesse estudo poderão ser aplicadas como adsorvente de baixo custo em uma etapa terciária no processo de tratamento de efluentes contendo os corantes SN e ST e suas formas hidrolisadas.

\section{SUGESTÕES PARA FUTUROS TRABALHOS}

Visando a continuidade da pesquisa, sugere-se:

1. Estudar a bioacumulação nos organismos $C$. tepperi, para os ensaios "Spiked Water", tendo em vista que esse ensaio mostrou maior efeito nos organismos, assim como as análises químicas dos solos expostos para os testes;

2. Estudar diferentes gerações de C. dubia, ou D. similis expostos a concentrações sub-crônicas dos corantes, a fim de observar os diferentes efeitos causados em diferentes gerações pela exposição dos mesmos;

3. Realização de análises químicas (orgânicas e inorgânicas) das colunas utilizadas para os testes de AIT, a fim de entender melhor qual ou quais substâncias ficaram retidas na coluna durante os testes;

4. Realização de testes de lixiviação e solubilização com os adsorbatos desse estudo, a fim de uma melhor classificação e disposição final dos mesmos;

5. Realização de análises cromatográficas a fim estabelecer os sítios de hidrólise dos corantes após processo de hidrólise;

6. Estudar a remoção com efluente real de indústria têxtil com ZLM e ZPM;

7. Estudar a remoção dos compostos tóxicos das cinzas antes da aplicação as cinzas apresentam toxicidade;

8. Quantificar a vida útil dos adsorventes e repetibilidade dos ensaios da capacidade de adsorção em:

a) Tanque com chicana e impulsor mecânico com rotação variável, geometria padronizada e controle de temperatura; 
b) Coluna de recheio em operação contínua com controle da vazão e temperatura com as variáveis: adsorvete, granulometria, técnica de empacotamento e velocidade superficial. 
ANEXO 
ANEXO A: Composição do meio SIS

\begin{tabular}{|c|c|c|c|c|}
\hline \multirow[b]{2}{*}{ Stock } & \multirow[b]{2}{*}{ Substância } & \multicolumn{2}{|l|}{ Concentração } & \multirow{2}{*}{$\begin{array}{l}\text { Solução Estoque } \\
\text { adicionada por } \mathrm{L} \\
(\mathrm{mL})\end{array}$} \\
\hline & & $\begin{array}{c}\text { de Solução } \\
\text { Estoque (g/L) }\end{array}$ & Por & \\
\hline \multirow[t]{2}{*}{1} & $\mathrm{NaNO}_{3}$ & 1.7 & $200 \mathrm{~mL}$ & 10 \\
\hline & $\mathrm{KH}_{2} \mathrm{PO}_{4}$ & 0.26 & & \\
\hline 2 & $\mathrm{MgSO}_{4 .} .7 \mathrm{H}_{2} \mathrm{O}$ & 1.5 & $100 \mathrm{~mL}$ & 5 \\
\hline 3 & $\mathrm{CaCl}_{2} .2 \mathrm{H}_{2} \mathrm{O}$ & 0.72 & $100 \mathrm{~mL}$ & 5 \\
\hline 4 & $\mathrm{Na}_{2} \mathrm{CO}_{3}$ & 0.4 & $100 \mathrm{~mL}$ & 5 \\
\hline \multirow[t]{6}{*}{5} & $\mathrm{H}_{3} \mathrm{BO}_{3}$ & 1.0 & $1000 \mathrm{~mL}$ & 1 \\
\hline & $\mathrm{MnCl}_{2} .4 \mathrm{H}_{2} \mathrm{O}$ & 0.2 & & \\
\hline & $\mathrm{Na}_{2} \mathrm{MoO}_{4} \cdot 2 \mathrm{H}_{2} \mathrm{O}$ & 0.01 & & \\
\hline & 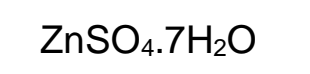 & 0.05 & & \\
\hline & $\mathrm{CuSO}_{4} .5 \mathrm{H}_{2} \mathrm{O}$ & 0.005 & & \\
\hline & $\mathrm{Co}\left(\mathrm{NO}_{3}\right)_{2} \cdot 6 \mathrm{H}_{2} \mathrm{O}$ & 0.01 & & \\
\hline \multirow[t]{2}{*}{6} & $\mathrm{FeCl}_{3} \cdot 6 \mathrm{H}_{2} \mathrm{O}$ & 0.017 & $100 \mathrm{~mL}$ & 5 \\
\hline & $\mathrm{Na}_{2}$ EDTA. $2 \mathrm{H}_{2} \mathrm{O}$ & 0.028 & & \\
\hline 7 & MOPS (buffer) & 9.8 & $20 \mathrm{~mL}$ & 1 \\
\hline
\end{tabular}

Fonte: OECD Guidline 221 (2002) 
ANEXO B: Análises químicas da água para o teste "Spiked Water" durante 10 dias

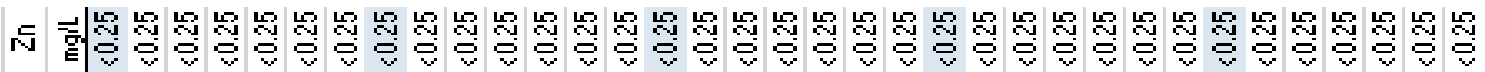

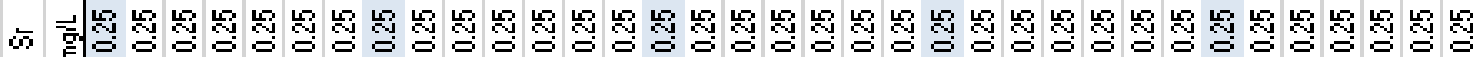
क क

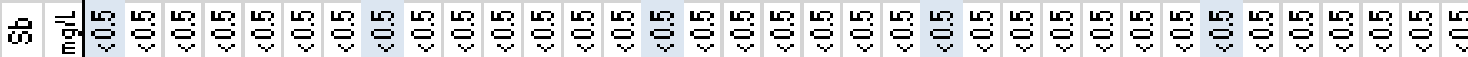

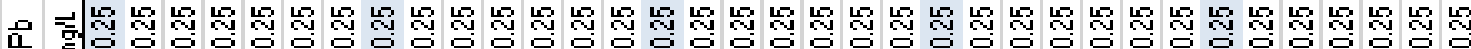

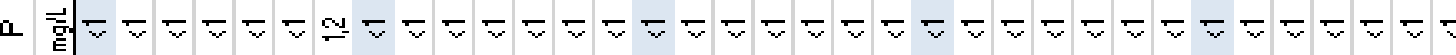
`

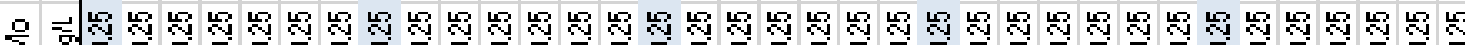
之

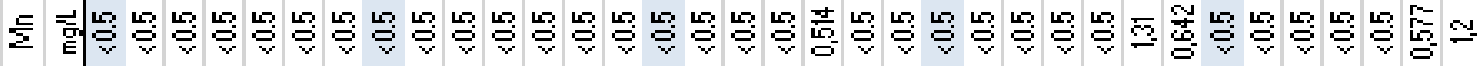

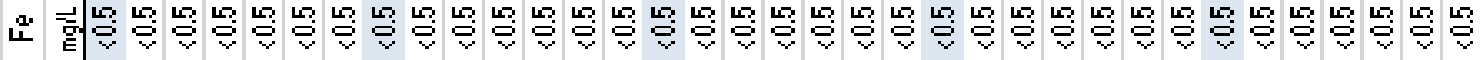

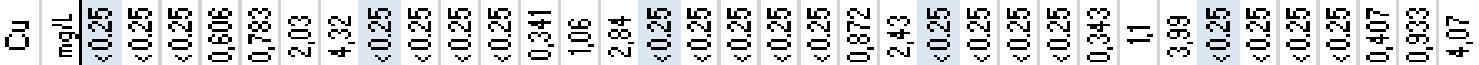

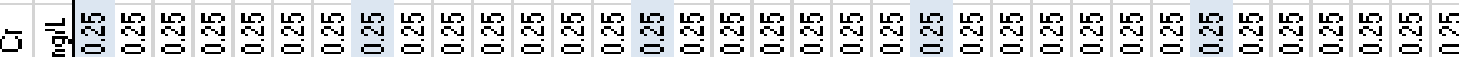

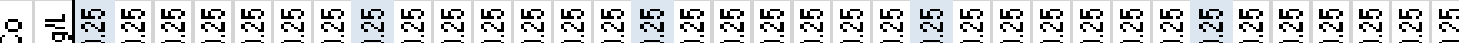

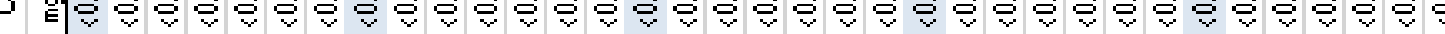

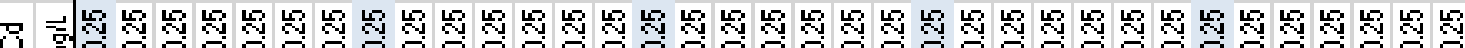

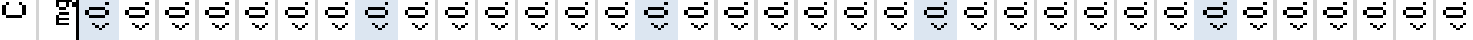

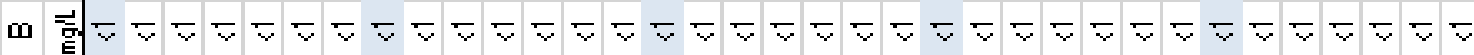
n 굽 х

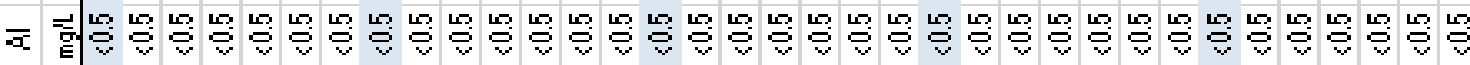

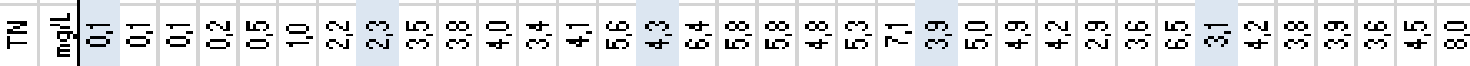

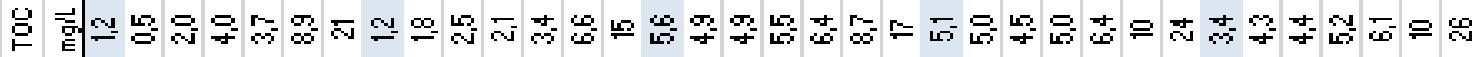

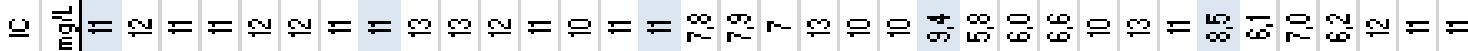

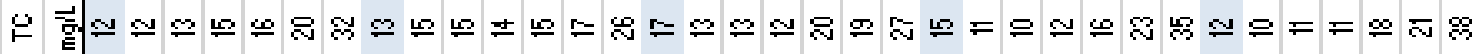
๘

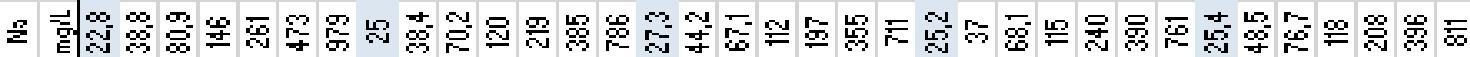

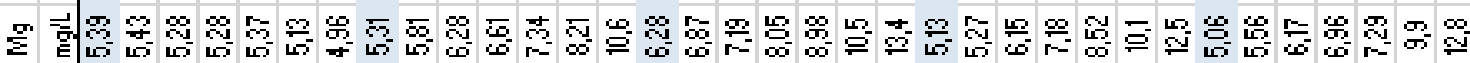
×

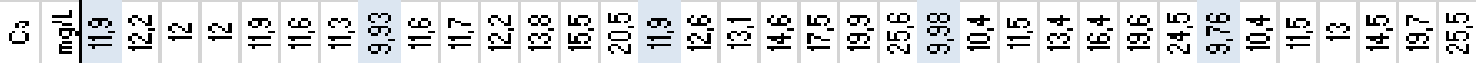

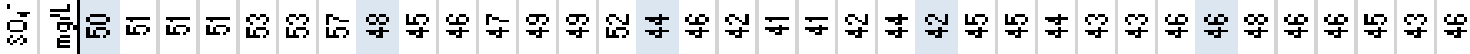

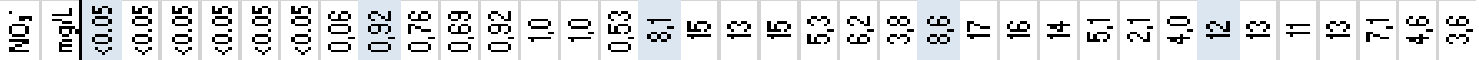

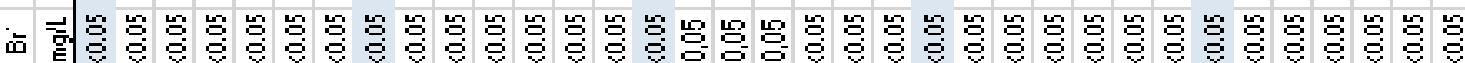

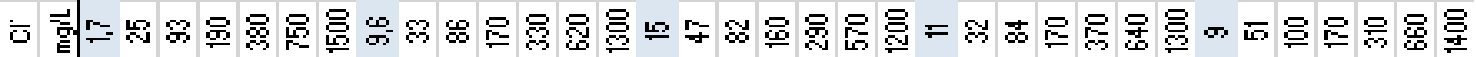

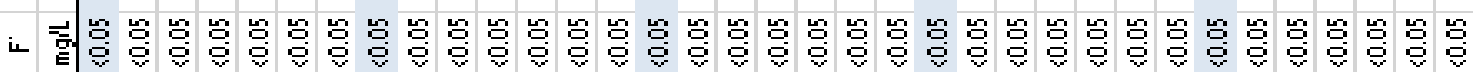
部容- 


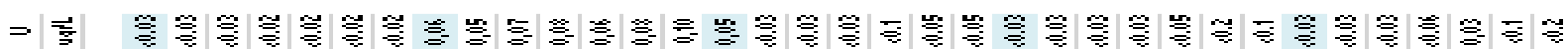

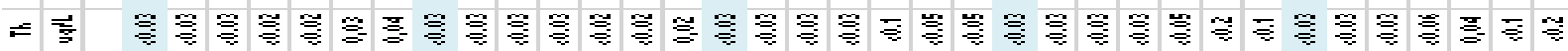
i

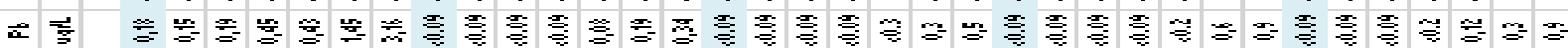

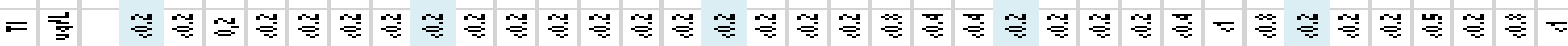

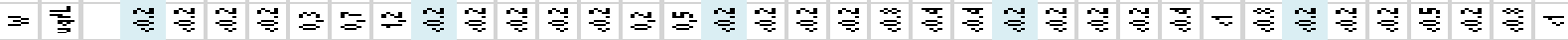
二뤃

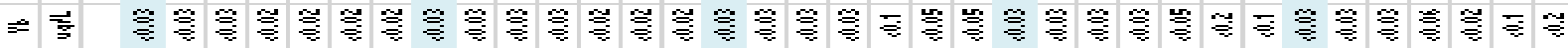

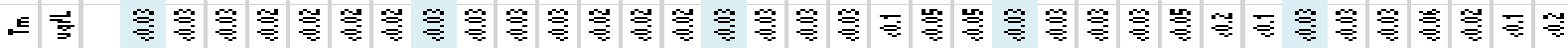

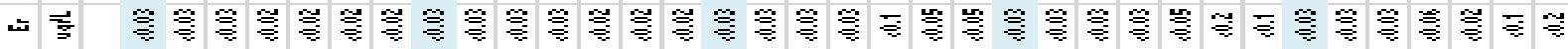

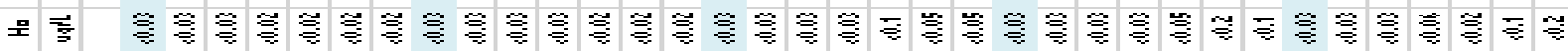
亏궁

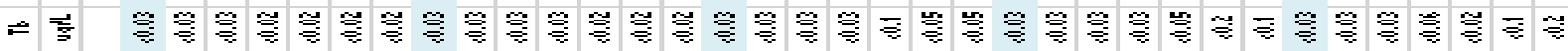

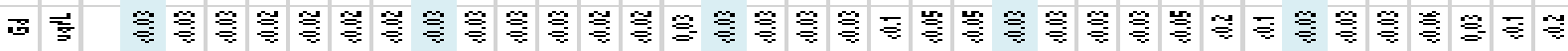

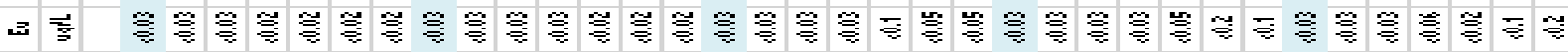
깈

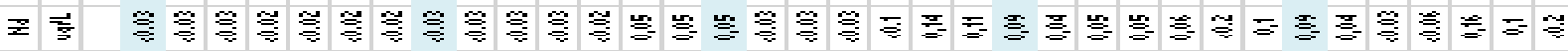

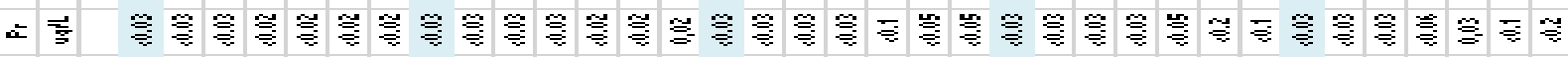

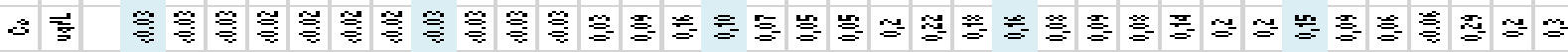

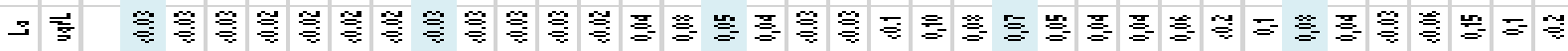

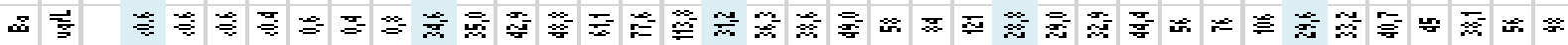

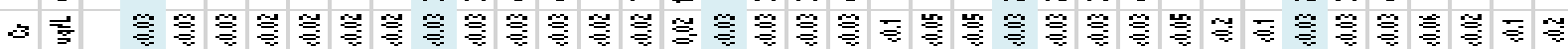

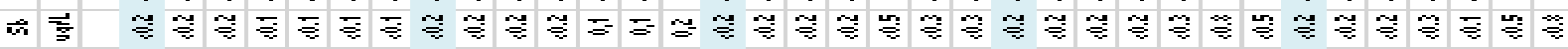

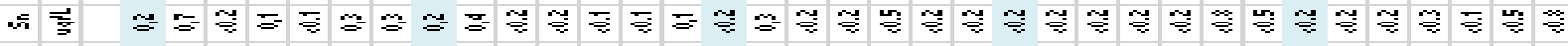

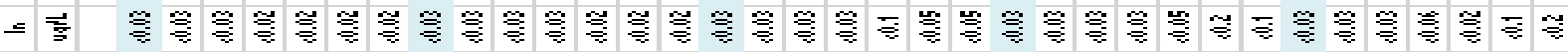

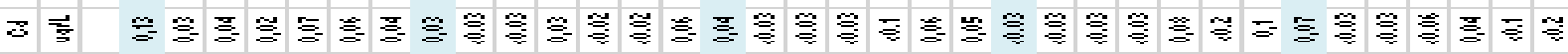

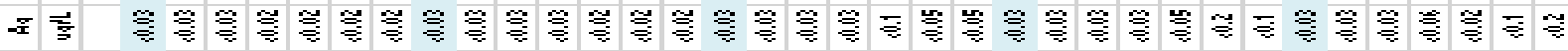
궇

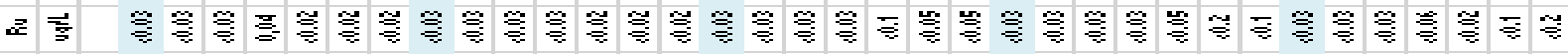

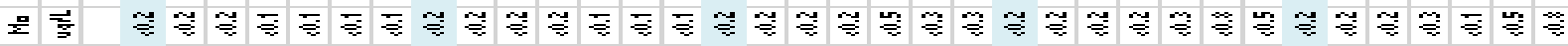

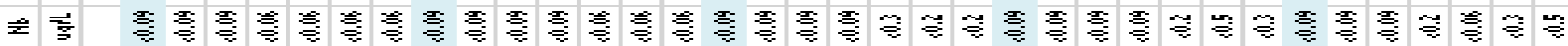

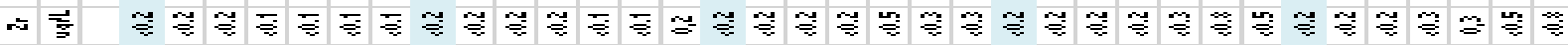
-

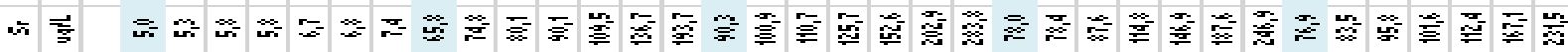

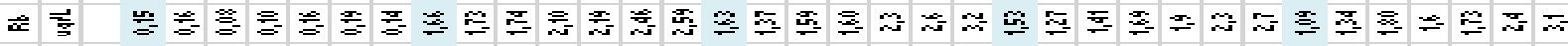

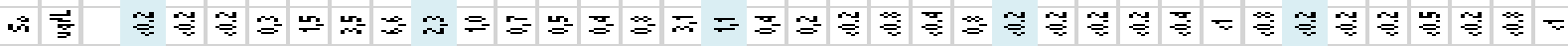

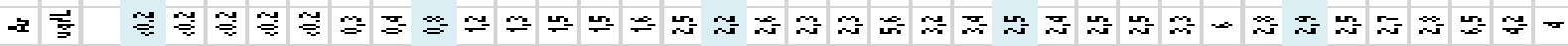

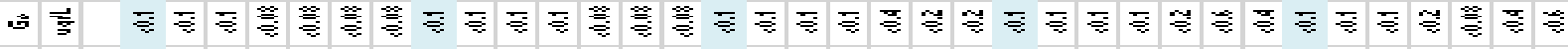

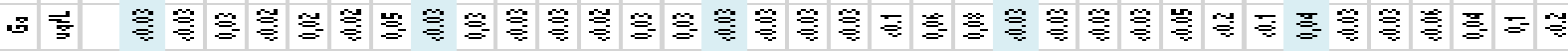

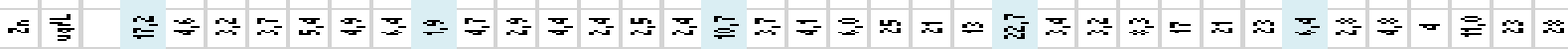

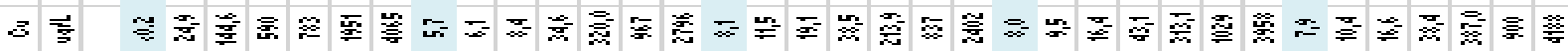

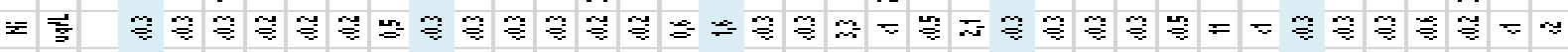

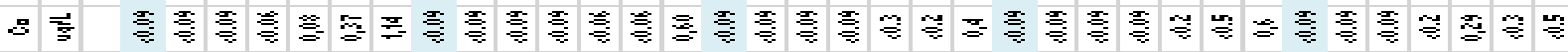

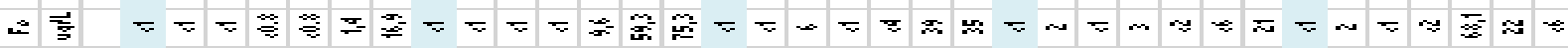

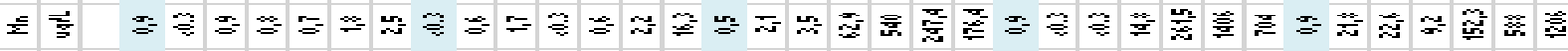

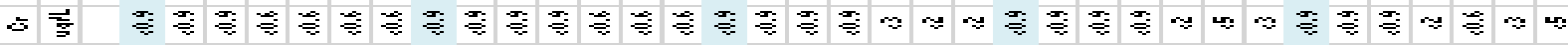

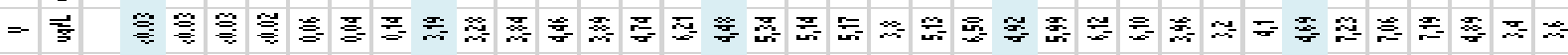

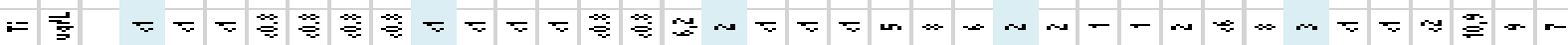

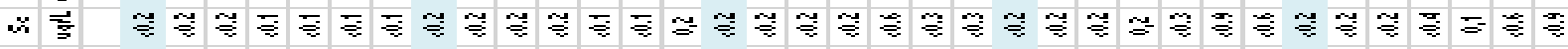

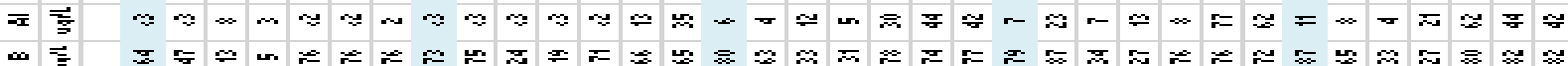

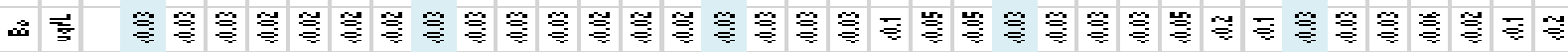

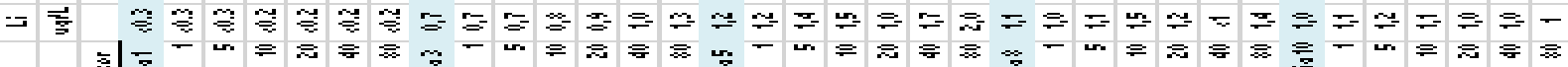
竞

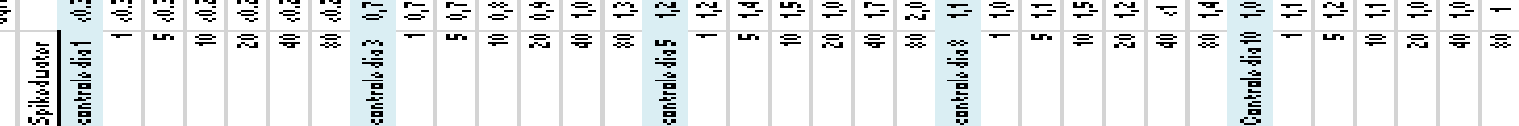


ANEXO C: Análises químicas da água para o teste "Spiked Sediment" durante 10 dias

أ

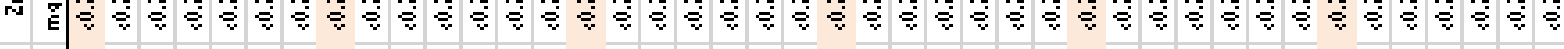

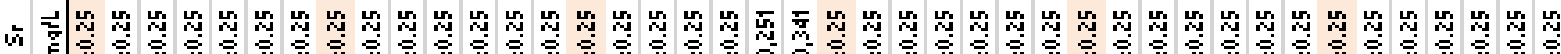

i ที

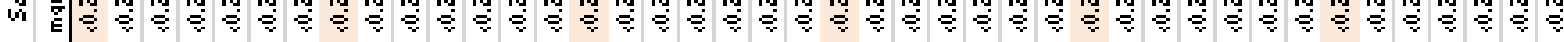

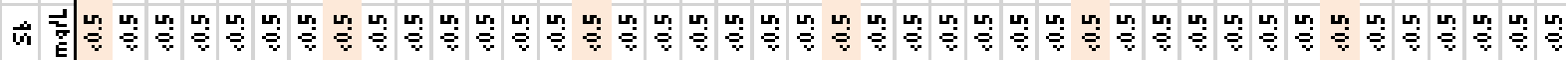
a

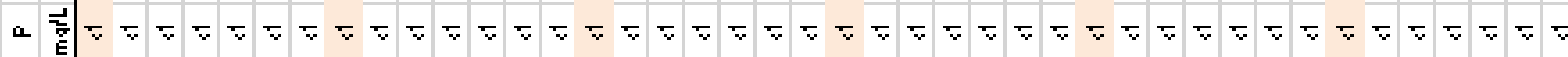
₹

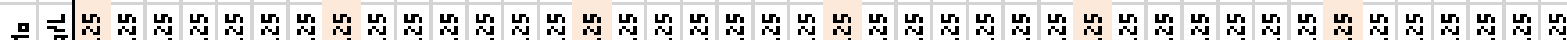

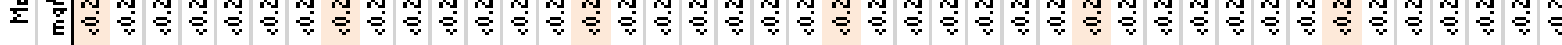

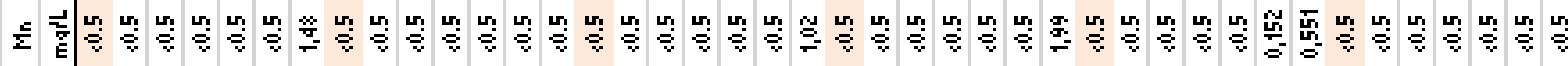

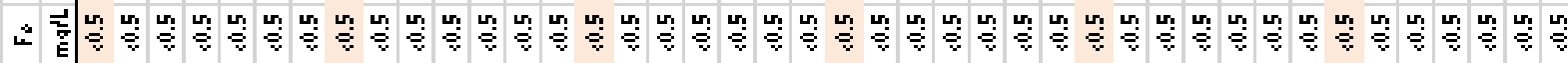
B D 口 D J D

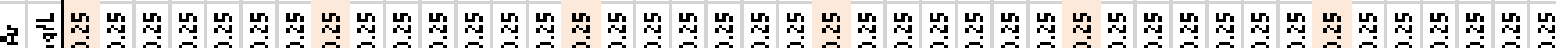
ব

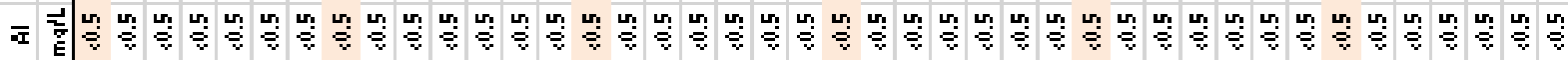

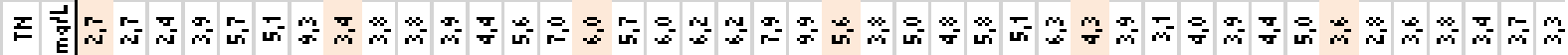

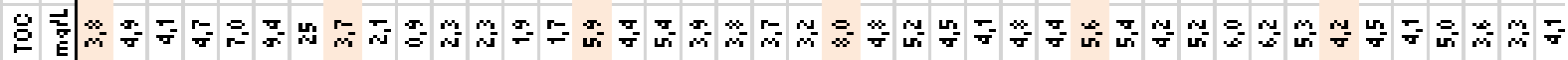

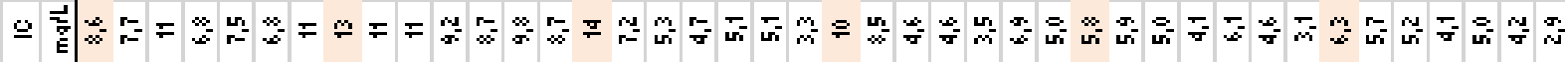

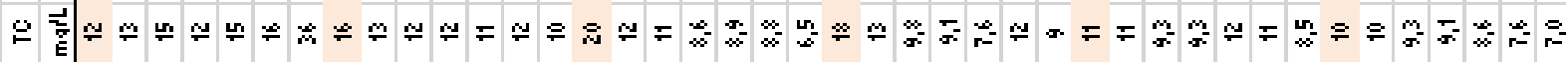

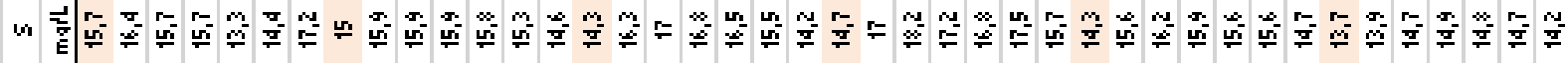

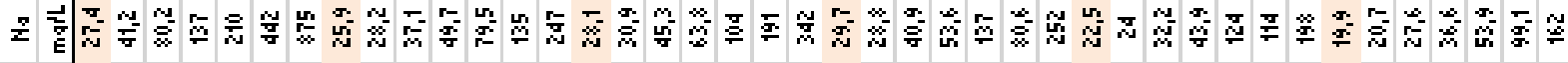

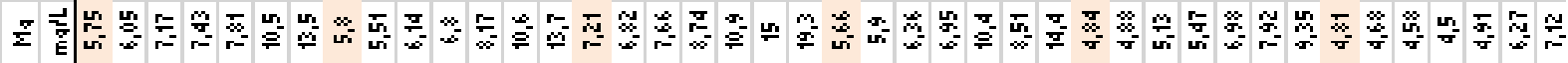

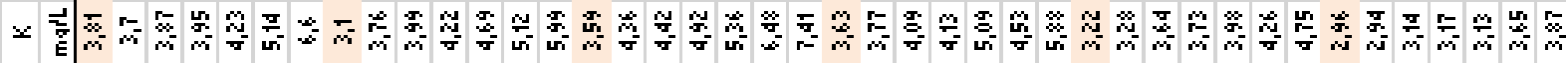

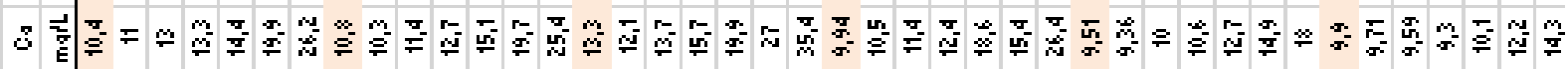

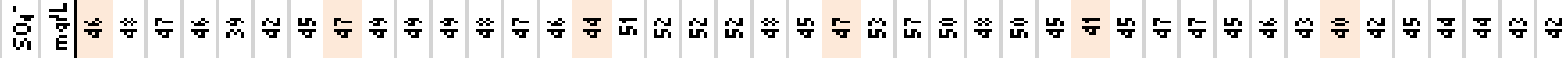

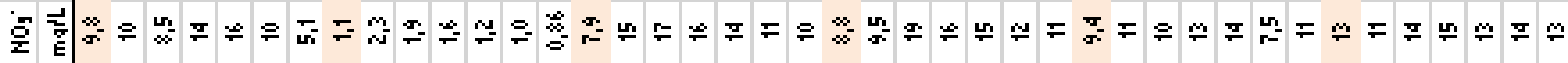
i

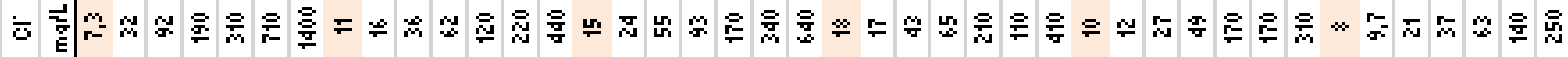
ㄴ

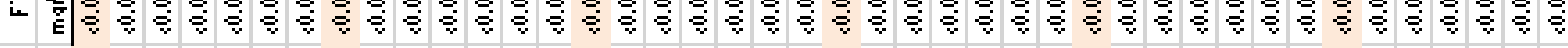
竞 
二롷 น 山

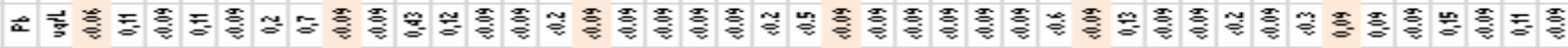

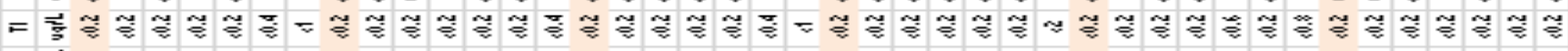

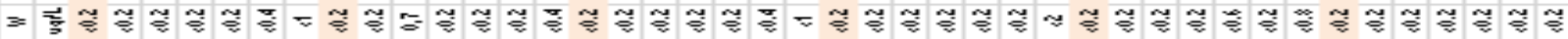
д ฟ

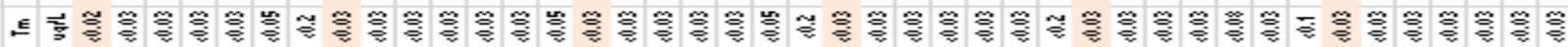

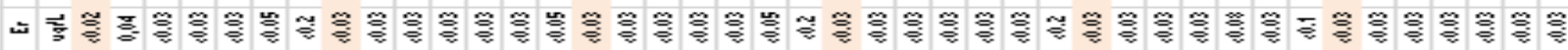

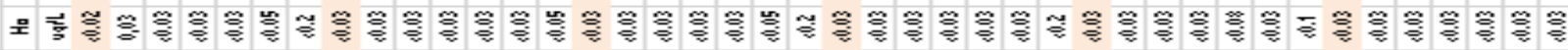
人 น

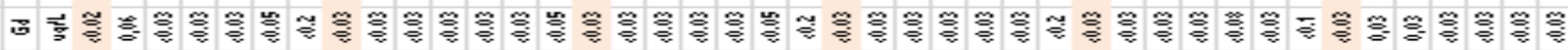

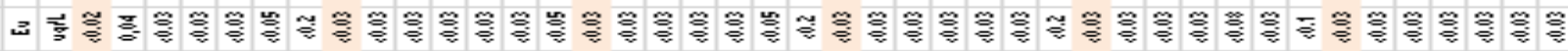
ผ

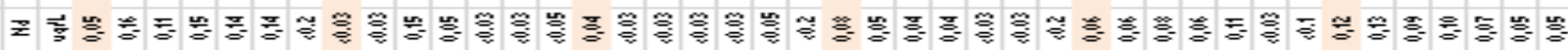
д

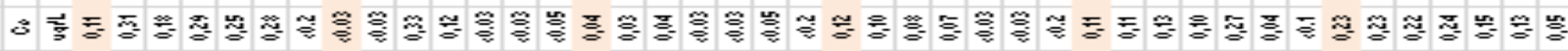

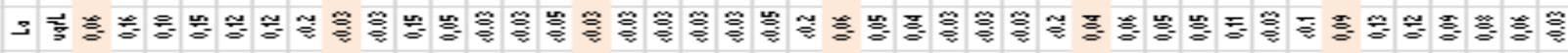

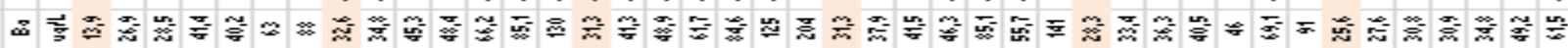
a

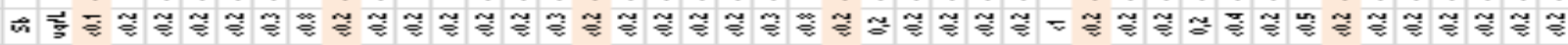

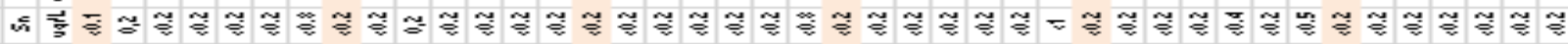
к 及 д ฉ ฉ

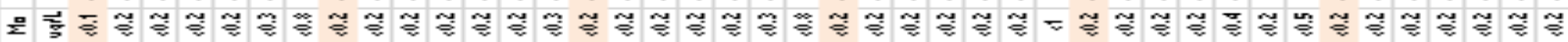

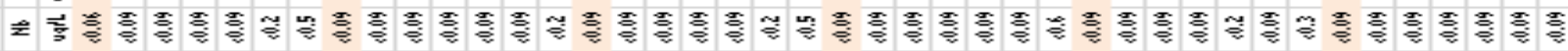

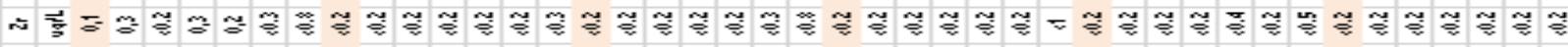
-

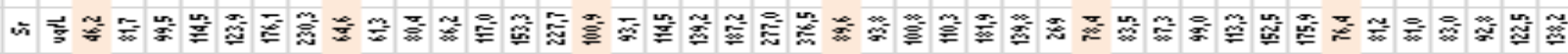

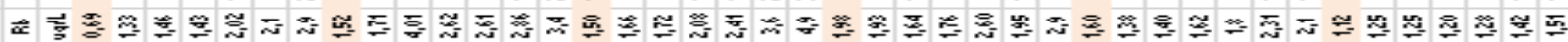

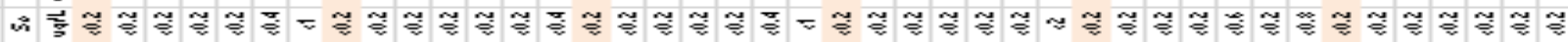

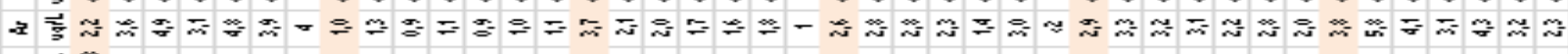

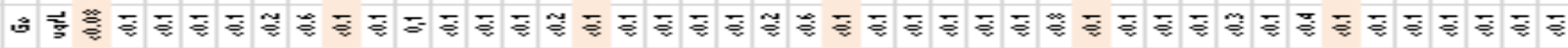

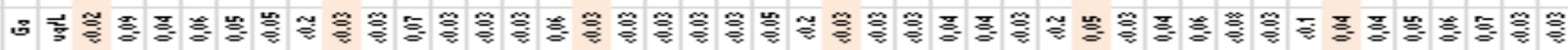

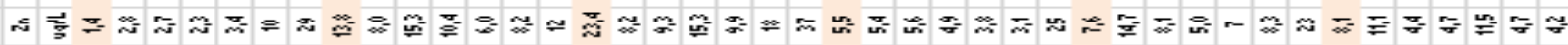

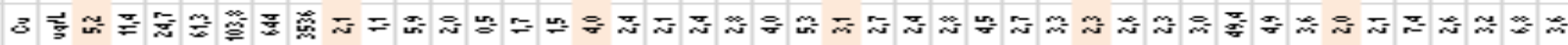

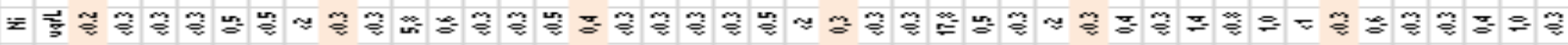
S

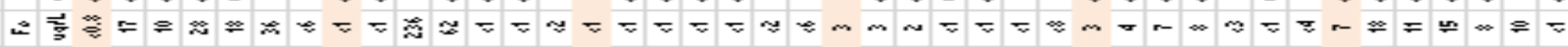

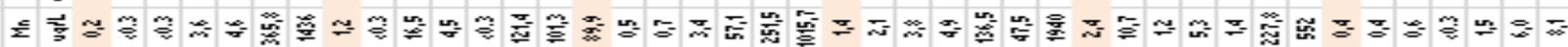

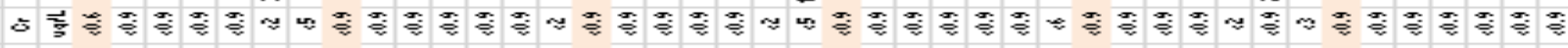

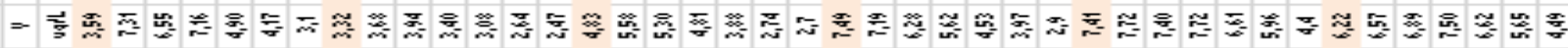

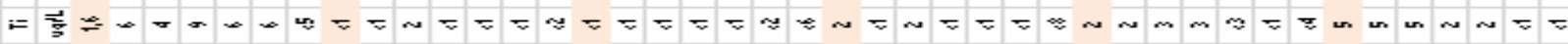

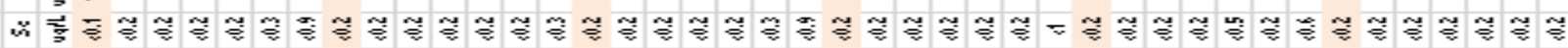

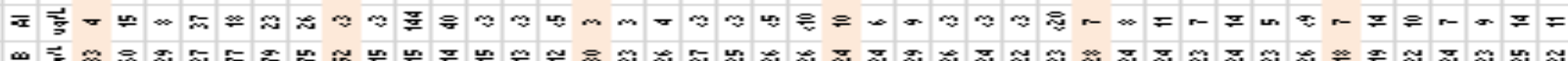
מ

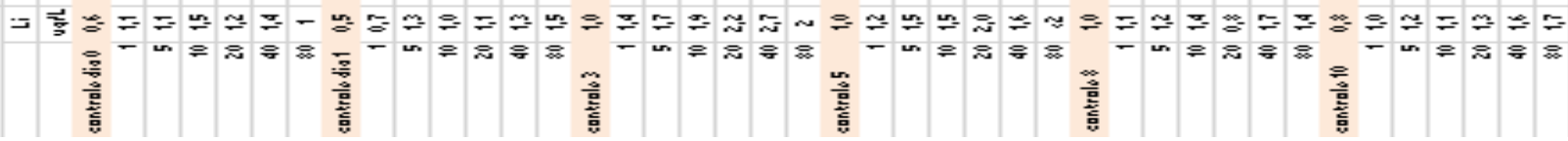


APÊNDICE 
APÊNDICE A: Espectro de varredura do comprimento de onda do ST

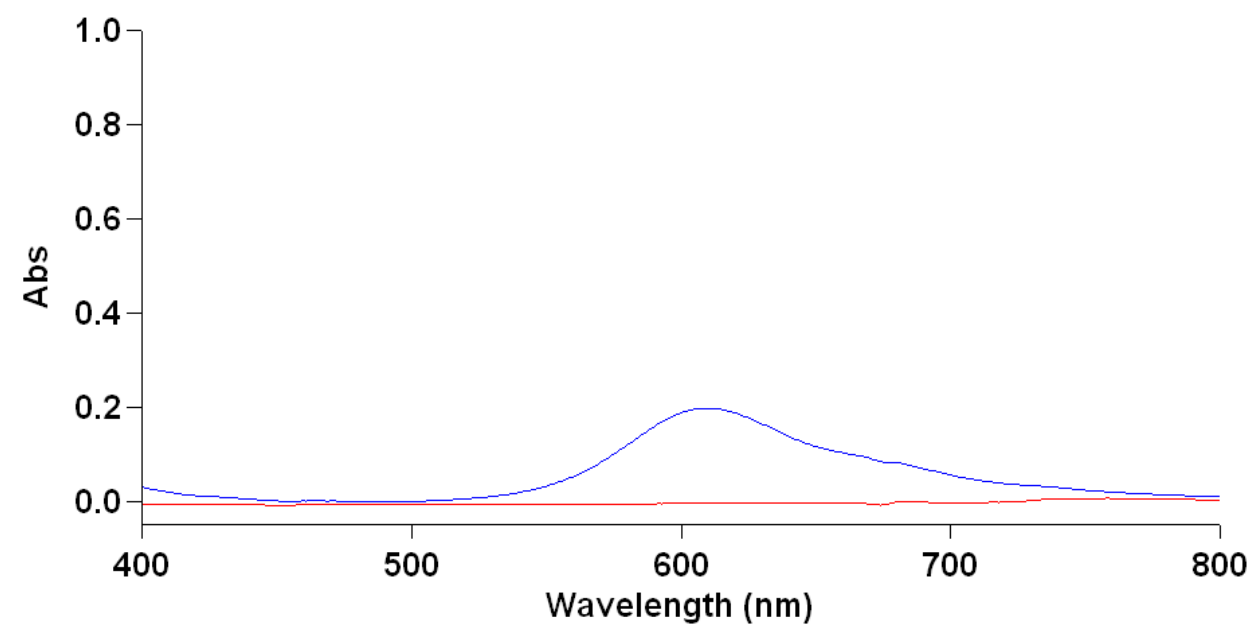

APÊNDICE B: Espectro de varredura do comprimento de onda do SN

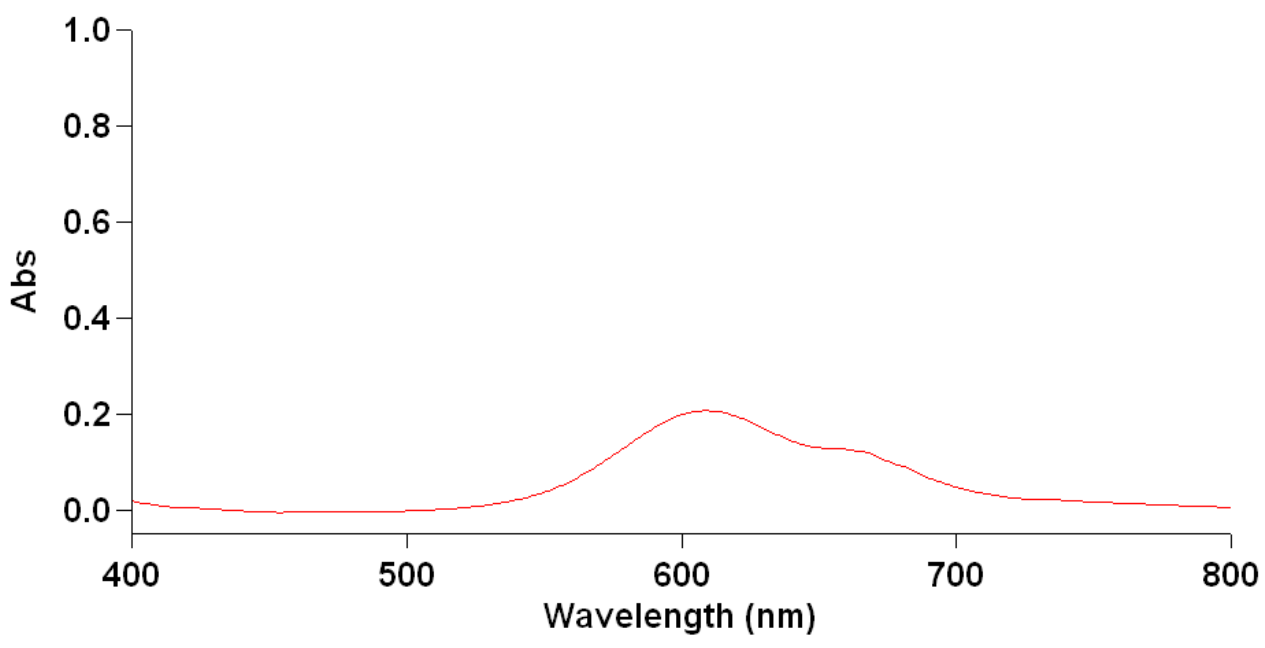


APÊNDICE C: Média dos testes de sensibilidade com C. dubia e parâmetros físicoquímicos entre os meses de Julho à Dezembro de 2013 para sulfato de cobre.

\begin{tabular}{|c|c|c|c|c|c|}
\hline $\begin{array}{c}\text { Conc. } \\
\left(\mathrm{mgL}^{-1}\right)\end{array}$ & $\begin{array}{c}\text { Organismos } \\
\text { Sobreviventes }\end{array}$ & \multicolumn{4}{|c|}{ Média dos Parâmetros Físico- Químicos } \\
\hline & Média & $\mathrm{pH}$ & $\begin{array}{c}\text { Oxigênio } \\
\text { Dissolvido } \\
\%)\end{array}$ & $\begin{array}{c}\text { Condutividade } \\
(\mu \mathrm{S})\end{array}$ & $\begin{array}{c}\text { Temperatura } \\
\left({ }^{\circ} \mathrm{C}\right)\end{array}$ \\
\hline Controle & 4,5 & 7,18 & 96,3 & 235 & 20 \\
\hline 5 & 4,31 & 8,13 & 95,5 & 232 & \\
\hline 10 & 2,37 & 8,13 & 95,2 & 231 & \\
\hline 15 & 0,751 & 8,14 & 95,2 & 232 & \\
\hline 20 & 0,125 & 8,15 & 95,2 & 233 & \\
\hline \multicolumn{7}{|c|}{ Média $\mathrm{EC}_{50} 9,32 \mathrm{mgL}^{-1}$} \\
\hline
\end{tabular}

APÊNDICE D: Testes de sensibilidade com $L$. minor e parâmetros físico-químicos entre os meses de Julho à Setembro de 2013 para cloreto de potássio

\begin{tabular}{|c|c|c|c|c|c|}
\hline $\begin{array}{c}\text { Conc. } \\
\left(\mathrm{mgL}^{-1}\right)\end{array}$ & $\begin{array}{c}\text { Número de } \\
\text { frondes }\end{array}$ & \multicolumn{4}{|c|}{ Média dos Parâmetros Físico- Químicos } \\
\hline & Média & $\mathrm{pH}$ & $\begin{array}{c}\text { Oxigênio } \\
\text { Dissolvido } \\
(\%)\end{array}$ & $\begin{array}{c}\text { Condutividade } \\
(\mathrm{S})\end{array}$ & $\begin{array}{c}\text { Temperatura } \\
\left({ }^{\circ} \mathrm{C}\right)\end{array}$ \\
\hline Controle & 43,2 & 6,43 & 62,2 & 0,322 & 19 \\
\hline 1,25 & 40,2 & 6,34 & 69,7 & 3,09 & \\
\hline 2,5 & 35,7 & 6,39 & 68,8 & 6,14 & \\
\hline 5 & 22,5 & 6,40 & 67,8 & 11,9 & \\
\hline 10 & 12 & 6,45 & 69,9 & 21,3 & \\
\hline 20 & 12 & 6,51 & 64,4 & 40,4 & \\
\hline \multicolumn{6}{|c|}{ Média $\mathrm{EC}_{50} 6,44 \mathrm{mgL}^{-1}$} \\
\hline
\end{tabular}


APÊNDICE E: Testes de sensibilidade com C. tepperie parâmetros físico-químicos entre os meses de Janeiro à Maio de 2014 para sulfato de cobre

\begin{tabular}{|c|c|c|c|c|c|}
\hline $\begin{array}{c}\text { Conc. } \\
\left(\mathrm{mgL}^{-1}\right)\end{array}$ & $\begin{array}{c}\text { Número de } \\
\text { sobreviventes }\end{array}$ & \multicolumn{4}{|c|}{ Média dos Parâmetros Físico- Químicos } \\
\hline & Média & $\mathrm{pH}$ & $\begin{array}{c}\text { Oxigênio } \\
\text { Dissolvido } \\
(\%)\end{array}$ & $\begin{array}{c}\text { Condutividade } \\
(\mu \mathrm{S})\end{array}$ & $\begin{array}{c}\text { Temperatura } \\
\left({ }^{\circ} \mathrm{C}\right)\end{array}$ \\
\hline Controle & 4,66 & 7,83 & 98,1 & 252 & 20 \\
\hline 31 & 4,66 & 7,89 & 98,8 & 147 & \\
\hline 62 & 4,33 & 8,05 & 98,2 & 137 & \\
\hline 125 & 4 & 8,16 & 98,4 & 137 & \\
\hline 250 & 2,33 & 8,22 & 99,1 & 135 & \\
\hline 500 & 0 & 8,25 & 98,2 & 136 & \\
\hline \multicolumn{6}{|c|}{ Média $\mathrm{EC}_{50} 248 \mathrm{mgL}^{-1}$} \\
\hline
\end{tabular}

APÊNDICE F: Parâmetros físico-químicos para o teste "Spiked Sediment"

\begin{tabular}{|c|c|c|c|c|c|c|c|c|c|c|c|c|}
\hline \multirow{3}{*}{$\begin{array}{l}\text { Test material: } \\
\text { Test organism: } \\
\text { Concentration }\end{array}$} & \multicolumn{3}{|l|}{$\begin{array}{l}\text { SN } \\
\text { Midge }\end{array}$} & \multicolumn{5}{|c|}{$\begin{array}{l}\text { Start Growth/Survival: } 7413 \\
\text { Finish Growth/Survival: } 19 / 3\end{array}$} & \multicolumn{4}{|c|}{$\begin{array}{l}\text { Start Emergence: } 1913 \\
\text { Finish Emergence: }\end{array}$} \\
\hline & \multicolumn{4}{|c|}{ Day 0} & \multicolumn{4}{|c|}{ Day 1} & \multicolumn{4}{|c|}{ Day 83} \\
\hline & $\mathrm{pH}$ & DO & EC & Temp & $\mathrm{pH}$ & DO & EC & Temp & $\mathrm{pH}$ & DO & Cond & Temp \\
\hline Control & & & & & 7.77 & 929 & & 21.2 & 769 & 91.9 & 285 & 01.2 \\
\hline $1 \mathrm{mg} / \mathrm{L}$ & & & & & 794 & 91.8 & 341 & & 2.48 & 92.4 & 366 & \\
\hline $5 \mathrm{mg} / \mathrm{L}$ & & & & & 7.93 & 91.0 & $49 a$ & & 7.55 & 92.7 & 478 & \\
\hline \multirow[t]{2}{*}{$10 \mathrm{mg} / \mathrm{L}$} & & & & & 7.95 & 934 & 754 & & 753 & 42.3 & 721 & \\
\hline & \multicolumn{4}{|c|}{ Day 65} & \multicolumn{4}{|c|}{ Day \& 8} & \multicolumn{4}{|c|}{ Day 104} \\
\hline Concentration & $\mathrm{pH}$ & DO & EC & Temp & $\mathrm{pH}$ & DO & EC & Temp & $\mathrm{pH}$ & DO & Cond & Temp \\
\hline Control & $7 \leq 5$ & 934 & 266 & 203 & 714 & 922 & 267 & 21.2 & 135 & 94.4 & 198.3 & 200 \\
\hline $1 \mathrm{mg} / \mathrm{L}$ & 2.94 & 92.9 & 302 & & 7.28 & 897 & 205 & & 7.60 & 97.4 & 314 & \\
\hline $5 \mathrm{mg} / \mathrm{L}$ & 748 & 93.1 & 475 & & 7.30 & 89.2 & 512 & & 7.79 & 95.1 & 498 & \\
\hline $10 \mathrm{mg} / \mathrm{L}$ & 7.15 & 93.5 & 743 & & 7.30 & 89.7 & 734 & & 1.77 & 94.0 & 778 & \\
\hline
\end{tabular}

APÊNDICE G: Parâmetros físico-químicos para o teste "Spiked Water"

\begin{tabular}{|c|c|c|c|c|c|c|c|c|c|c|c|c|}
\hline \multirow{3}{*}{$\begin{array}{l}\text { Test material: } \\
\text { Test organism: } \\
\text { Concentration } \\
\end{array}$} & \multicolumn{2}{|l|}{$\begin{array}{l}\mathrm{SN} \\
\text { Midge }\end{array}$} & \multicolumn{6}{|c|}{$\begin{array}{l}\text { Start Growth/Survival: } 14 / 02 \\
\text { Finish Growth/Survival: } 19 / 02\end{array}$} & \multirow{2}{*}{\multicolumn{4}{|c|}{ 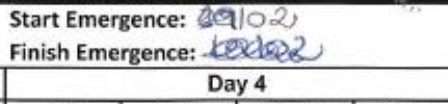 }} \\
\hline & \multicolumn{4}{|c|}{ Day 0} & \multicolumn{4}{|c|}{ Day 1} & & & & \\
\hline & $\mathrm{pH}$ & DO & EC & Temp & $\mathrm{pH}$ & DO & EC & Temp & $\mathrm{pH}$ & DO & Cond & Temp \\
\hline Control & & & & & 2.79 & 99.2 & नM $\mu S$ & 215 & 782 & 94.6 & 268 & 21.1 \\
\hline $20 \mathrm{mg} / \mathrm{L}$ & & & & & 783 & 999 & 1241 & & 785 & 937 & $M 81$ & \\
\hline $40 \mathrm{mg} / \mathrm{L}$ & & & & & 387 & $98 \cdot 8$ & 2152 & & 784 & 94.7 & 2017 & \\
\hline $80 \mathrm{mg} / \mathrm{L}$ & & & & & 778 & 991 & $4126 \mathrm{~ms}$ & & 7.82 & 944 & $3.85 \mathrm{mS}$ & \\
\hline $160 \mathrm{mg} / \mathrm{L}$ & & & & & 770 & 98.5 & 794 & & 7.77 & 953 & 2.22 & \\
\hline $320 \mathrm{mg} / \mathrm{L}$ & & & & & 7.67 & 995 & 1450 & & 7.59 & 76.5 & 43.69 & \\
\hline
\end{tabular}

\begin{tabular}{|c|c|c|c|c|c|c|c|c|c|c|c|c|}
\hline \multirow[b]{2}{*}{ Concentration } & \multicolumn{4}{|c|}{ Day 6} & \multicolumn{4}{|c|}{ Day 8} & \multicolumn{4}{|c|}{ Day 10} \\
\hline & $\mathrm{pH}$ & DO & EC & Temp & $\mathrm{pH}$ & DO & EC & Temp & $\mathrm{pH}$ & DO & Cond & \begin{tabular}{|l} 
Temp \\
\end{tabular} \\
\hline Control & 747 & 956 & 236 & 209 & 7.47 & 870 & $2,2,7$ & 20.21 & 7.55 & 93.6 & 727 & 201 \\
\hline $20 \mathrm{mg} / \mathrm{L}$ & 747 & 922 & 1399 & & 7.54 & 892 & 1198 & & $7 \leqslant 8$ & 89.6 & 1207 & \\
\hline $40 \mathrm{mg} / \mathrm{L}$ & 7.60 & 931 & 2.35 & & 7.51 & 887 & 2.25 & & 7.53 & 90.4 & 2.43 & \\
\hline $80 \mathrm{mg} / \mathrm{L}$ & 7.61 & 929 & 4 11 & & 7.57 & 88.8 & 430 & & 7.61 & 93.3 & 4.37 & \\
\hline $160 \mathrm{mg} / \mathrm{L}$ & 7.63 & 925 & 7.78 & & 7.59 & 892 & 18.01 & & $7 \cdot 8 \mathrm{C}$ & 92.3 & 9.40 & \\
\hline $320 \mathrm{mg} / \mathrm{L}$ & 7.59 & 93.1 & 74.43 & & 7.56 & 89.5 & 15.14 & & 7.75 & 91.7 & 14.33 & \\
\hline
\end{tabular}




\section{REFERÊNCIAS BIBLIOGRÁFICAS}

ABIQUIM- Associação Brasileira de Indústria Química. Corantes e pigmentos. Disponível em http://www.abiquim.org.br/corantes/cor aplicacoes.asp. Acessado em 22/09/2014.

AGÊNCIA ESTADUAL DE MEIO AMBIENTE E RECURSOS HÍDRICOS - CPRH, Diagnóstico ambiental das lavanderias de Toritama, Recife, 2005

AGUAYO, S.; MUNOZ, M.J.T.; ROSET, J.D.; CARBALHO, M. Identification of organic compounds and ecotoxicological assessment of sewage treatment plants (STP) effluents. Sci. Tot. Environ., v. 328,p. 69-81, 2004.

AGUIAR, M.R.M.P.; NOVAES, A.C.; GUARINO, A.W.S. Remoção de metais pesados de efluentes industriais por aluminossilicatos. Quim. Nova, v. 25, p. 1145-1154, 2002.

ALINSAFI, A.; daMOTTA, M.; LEBONTE, S.; PONS, M.N.; BENHAMMOU, A. Effect of variability on the treatment of textile dyeing wastewater by activated sludge. Dyes Pig., v. 69, p. 31-39, 2006.

ALLEGRE, C.; MOULIN, P.; MAISSEU, M.; CHRABIT, F. Treatment and reuse of reactive dyeing effluents. J. Membr. Sci., v. 269, p. 15-34, 2006.

ALLEN, S.J.; MCKAY, G.; KHADER, K.Y. Intraparticle diffusion of basic dye during adsorption onto sphagnum peat. Environ. Pollut., v. 56, p. 39-50, 1989.

ALLEN, S. J.; GAN, Q.; MATTHEWS, R.; JHONSON, P. A. Comparison of optimized isotherm models for basic dye adsorption by kudzu. Biores. Technol., v. 88, p. 143 152, 2003.

AMRHEIN, C.; HAGHNIA, G. H.; KIM, T. S.; MOSHER, P. A.; GAGAJENA, R. C.; AMANIOS, T.; LA TORRE, L. Synthesis and properties of zeolites from coal fly ash. Environ. Sci. Technol., v.30, p.735-742, 1996.

ARAMBOUROU, H.; GISMONDI, E.; BRANCHU, P.; BEISEL, J-N. Biochemical and morphological responses in Chironomus riparius (Diptera, Chironomidae) larvae exposed to lead-spiked-sediment. Environ. Toxicol. Chem. v. 32, p. 2558-2564, 2013.

ARAMBOUROU, H.; BEISEL, J-N.; BRANCHU, P., DEBAT, V. Exposure to sediments from polluted rivers has limited phenotypic effects on larvae and adults of Chironomus raparius. Sci. Total. Environ. v. 484, p. 92-101, 2014.

ASPLAND, J.R., Textile dyeing and coloration. American Association of Textile Chemists and Colorist. Research Triangle Park, EUA, Caronila, 416 pgs, 1997.

AZZIAN, S. Kinetic models of sorption: a theoretical analysis. J. Colloid Interf. Sci., v.276, p.47-52, 2004.

BALCI,B.; KESKINKAN,O.; AVCI, M. Use of BDST and an ANN model for prediction of dye adsorption efficiency of Eucalyptus camaldulensis barks in fixed-bed syste. Expert Syst Appl, v. 38, p. 949-956,2011.

BALDISSARELI, V.Z. Estudo da adsorção do corante reativo preto 5 sobre carvão ativado: Caracterização do adsorvente e determinação de parâmetros cinéticos e termodinâmicos. 2008. Dissertação (Mestrado) - Departamento de Química Universidade Regional de Blumenau, SC.

BANAT, M.I.; NIGAM, P.; SINGH, D.; MARCHANT, R. Microbial decolorization of textiledye-containing effluents: a review. Bioresource Thechnol., n. 58, p. 217 -227, 1996. 
BANG-SUP, S.; SUNG-OH, L.; NAM-PYO, K. Preparation of zeolitic adsorbent from waste coal fly ash. J. Chem. Eng., v.12, p. 352-356, 1995.

BERTOLINI, T.C.R.; IZIDORO, J.C.; MAGDALENA, C.P.; FUNGARO, D.A. Adsorption of crystal violet dye from aqueous solution onto zeolites from coal fly and bottom ashes. Orbital Elec. J. Chem. v. 5, p. 179-191, 2013.

BERTOLINI, T.C.R. Estudo comparativo sobre a adsorção de diferentes classes de corantes em zeólitas de cinza de carvão: Modelagem cinética e de equilíbrio. 2013. Dissertação (Mestrado) - Universidade de São Paulo, São Paulo.

BINOTTO, R. B.; TEIXEIRA, E. C.; MIGLIAVACCA, D.; DANI, A. S., Fuel, v. 79, p. 1547, 2000.

BORGMANN, U.; COVE, R.; LOVERIDGE, C. Effect of metals on the biomass production kinetics of freshwater copepods. Can. J. Fish. Aqua. Sci. v. 37, p. 567-578, 1980.

BOWMAN, B.S., Applications of surfactant-modified zeolites to environmental remediation. Review. Micropor. Mesopor. Mater., v. 61, p. 43 - 56, 2003.

BRECK, D. W., Zeolite molecular sieves: structure, chemistry and use, Jhon Wiley and Son, New York, 771 p., 1984.

BRUNO, M. Utilização de zeólitas sintetizadas a partir de cinzas de carvão na remoção de corante em água. 2008. Dissertação (Mestrado) - Instituto de Pesquisas Energéticas e Nucleares - USP, São Paulo.

BUHRKE, V.E., JENKINS, R., SMITH, D.K. Preparation of specimens for X-ray fluorescence and X-ray diffraction analysis. London: Wiley-VCH, 1998.

BURTON, G.A. Assessing the toxicity of fresh-water sediments, Environ. Toxicol. Chem., v. 10, p. 1585-1627, 1991.

CALABRESE, E.J. Hormesis: why it is important to toxicology and toxicologists. Environ. Toxicol. Chem. v. 27, p. 1451-1474, 2008.

CARVALHO, T. E. M.;FUNGARO, D. A.; IZIDORO, J. C. Adsorção do corante reativo laranja 16 de soluções aquosas por zeólita sintética Quim. Nova., v. 33, p. 358-363, 2010.

CARVALHO, T. E. M.;FUNGARO, D. A.; IZIDORO, J. C. Adsorção do corante reativo laranja 16 de soluções aquosas por zeólita sintética Quim. Nova.,v. 33, p. 358-363, 2011.

CASTRO, F.J. Avaliação ecotoxicológica dos percolados das colunas de cinzas de carvão e de solos com cinzas de carvão utilizando Lactuca sativa e Daphnia similis como organimos teste. 2013. Dissertação (Mestrado) - Instituto de Pesquisas Energéticas e Nucleares - USP, São Paulo.

CHANG, H. L.; SHIH, W. H. A general method for the conversion of fly ash into zeolites as ion exchangers for cesium. Ind.Eng. Chem. Res., v. 37, p. 71-78, 1995.

CHESSMAN, B.C. Rapid assessment of rivers using microinvertebrates: A produce based on habitat-specific sampling, family level identification and biotic index. Aust. J. Ecol. v. 20, p. 122-129, 1995.

CHOI, T-S.; SHIMIZU, Y.; SHIRAI, H.; HAMADA, K., Solubilization of disperse dyes in cationic gemini surfactant micelles. Dyes Pigments, v. 45, p. 145 - 152, 2001.

CHUTIA, P.; KATO, S.; KOJIMA, T.; SATOKAWA, S. Adsorption of As(V) on surfactant modified natural zeolites. J. Hazard. Mater., v. 162, p. 204-211, 2009. 
CONAMA- Conselho Nacional do Meio Ambiente Resolução n³57, de 17 de março de 2005. Dispõe sobre a classificação dos corpos de água e diretrizes ambientais para o seu enquadramento, bem como estabelece as condições e padrões de lançamento de efluentes, e dá outras providência.

CONAMA -Conselho Nacional do Meio Ambiente Resolução n 430 de 13 de Maio de 2011. Dispõe sobre as condições e padrões de lançamentos de efluentes, complementa e altera a Resolução 357.

COONEY, J.D. Sediment Test. In: RAND, G.M. Fundamentals of Aquatic Toxicology. Effects, environmental fate and risk assessment. Washington USA: Taylor and Francis, 1995.

COOPER, P.; Removing colour from dyehouse wastewater - a critical review of technology available. J. Soc. Dyers Colour, v. 109, p. 97 - 100, 1993.

COOPER, N.L.; BIDWELL, J.R.; KUMAR, A. Toxicity of copper, lead and zinc mixtures to Ceriodaphnia dubia and Daphnia carinata. Ecol. Environ. Sci. v. 72, p. 1523-1528.

CORELLA, C., Ion exchange equilibria in zeolite mineral, Miner. Deposita.., v. 31, p. 554-562, 1996.

COSTA, S.R.M.; FARIAS, T.J.; FERNANDES, T. S.; PAZ, C.S. Utilização de zeólitas modificadas em terras raras no craqueamento catalítico de petróleo.

COVARRUBIAS, C.; GARCÍA, R.; ARRIAGADA, R.; YÁNEZ, J.; GARLAND, M.T. Cr(III) exchange on zeolites obtained from kaolin and natural mordenite. Micropor. Mesopor. Mater., v. 88, p. 220-231, 2006.

CRINI, G.; BADOT, P.M. Application of chitosan, a natural aminopolysaccharide, for dye removal from aqueous solutions by adsorption process using batch studies: a review of recent literature, Prog. Polym. Sci., v. 33, p. 399-447, 2008.

CUNICO, P.; FUNGARO, D. A; MAGDALENA, C. P. Adsorção do reativo preto 5 de solução aquosa por zeólita de cinzas de carvão: estudos cinéticos e de equilíbrio. Periódico Tche Chímica. v. 8, p. 17-24, 2011.

DEPOI, F.S.; POZEBON, D.; KALKREUTH, W.D. Chemical characterization of feed coals and combustion-by-products from Brazilian power plants. Int. J. Coal Geol., v. 76, p. 227236, 2008.

DAVIS, S.M.; DRAKE, K.D.; MAIER, K.J.; 2002. Toxicity of boron to the duckweed, Spirodella polyrrhiza. Chemosphere, v. 48, p. 615-620, 2002.

DEPOI, F.S. Desenvolvimento de métodos analíticos para a caracterização dos carvões brasileiros e suas cinzas. 2007. Dissertação (Mestrado) - Universidade Federal do Rio Grande do Sul, Porto Alegre.

DIN, A.T.M; HAMEED, B.H. Adsorption of methyl violet dye on acid modified activated carbon: isotherms and thermodynamics. J. Appl. Sci. Environ. Sanitation, v. 5, p. 161170, 2010.

DORNFELD, C.B. Utilização de Chironomus sp (Diptera, Chironomidae) para a avaliação da qualidade de sedimentos e contaminação por metais. 2006. Tese (Doutorado), Escola de Engenharia de São Carlos, Universidade de São Paulo. SP.

EPA, Methods for Aquatic Toxicity Identification Evaluation, Phase I Toxicity Characterization Procedures, Environmental Protection Agency, USA, 1991

EPOLITO, W. J.; LEE. Y. H.; BOTTOMLEY, L. A.; PAVLOSTATHIS, S. G. Characterization of the textile anthaquinone dye Reactive Blue 4. Dyes Pigments, v. 67, p. 35-46, 2005. 
EREMEKTAR, G.; SELCUKB, H.; MERICC, S. Investigation of the relation between COD fractions and the toxicity in a textile finishing industry wastewater: effect of preozonation. Desalination, v. 211, p. 314-320, 2007,

FERREIRA, K.D. Uso de zeólitasna redução do teor do cátion níquel de efluentes galvânicos, 1998. Dissertação (mestrado) - Escola Politécnica da Universidade de São Paulo, São Paulo.

FERREIRA, C.P. Estudos sobre a adsorção do corante Reativo Preto 5 de solução aquosa usando zeólita de cinzas de carvão. 2011. Dissertação (Mestrado) - Instituto de Pesquisas Energéticas e Nucleares, São Paulo.

FERRET, L.S. Zeólitas de cinzas de carvão: síntese e uso. 2004. Tese (Doutorado) Universidade Federal do Rio Grande do Sul, Porto Alegre, RS.

FREUNDLICH, H., Adsorption in solution. Phys. Chemie., v. 57, p. 384 - 420, 1906.

FRICK, H., Boron tolerance and accumulation in the duckweed, Lemna minor. J. Plant Nutr. V.8, P. 1123-1129, 1985.

Fikirdesici, S.; Altinddag, A.; Ozdemir, E.; Invertigation of acute toxicity of cadmiumarsenic mixtures do Daphnia magna with toxic unit approach. Turk J. Zoll, v. 36, p. 543550,2010

FLUES, M., CAMARGO, I.M.C., SILVA, P.S.C., MAZZILLI, B.P. Radioactivity of coal and ashes from Figueira coal power plant in Brazil. J. Radioanal. Nucl. Chem., v. 270, n. 3, p. 597-602, 2006.

FONSECA, R.J. Monitoramento e avaliação da emissão de dutos e fontes estacionárias de indústrias cerâmicas por meio de método potenciométrico e fluorescência de raios $X$. 2007. Dissertação (Mestrado) - Universidade Estadual de Campinas, Campinas, São Paulo.

FRANUS, W. Characterization of X-type zeolite prepared from coal fly ash. Pol. J. Environ. Studies. v. 21, p. 337-343, 2011.

FUNGARO, D., BORRELY, S.I. Síntese e caracterização de zeólita de cinzas de carvão modificada por surfactante catiônico. Cerâmica., v.58, p.77-83, 2012

FUNGARO, D.A.; BRUNO, M. Utilização de zeólitas sintetizadas a partir de cinzas de carvão para remoção de azul de metileno em água. Orbital Elec. J. Chem., v.1, p.4963, 2009.

FUNGARO, D. A.; GRACIANO, J. E. A. Adsorption of Zinc lons from Water Using Zeolite/Iron Oxide Composites. Adsorpt. Sci. Technol., v. 10, p. 729 -740, 2007.

FUNGARO, D. A.; IZIDORO, J. C. Tratamento de efluentes industriais usando material zeolítico preparado com cinzas de carvão. In: Água - Fonte da Vida/ Prêmio Jovem Cientista e Prêmio Jovem Cientista do Futuro. Porto Alegre, RS: Gráfica e Editora Comunicação Impressa, 2004, p. 129-143.

FUNGARO, D. A.; IZIDORO, J. C. Modelagem cinética da remoção de $\mathrm{Cd}^{2+}$ por zeólitas de cinzas de carvão. Revista Brasileira de Ciências Ambientais, v.25, n. 16, p. 9-13, 2008.

FUNGARO, D.A; MAGDALENA, C.P. Adsorption of reactivered 198 from aqueous solution organozeolite from fly ash: Kinetic and equilibrium studies. International Journal of Chemical and Environmental Engineering Systems., v. 3, p.74-83, 2012.

FUNGARO, D.A.; BORRELY, S.I.; HIGA, M. Remoção de cor de efluentes industriais por adsorção usando zeólita de cinzas ciclone não modificada e modificada por surfactante. Tchê Química, v.1, p.7-14, 2014. 
FUNGARO, D.A.; BORRELY, S.I.; CARVALHO, T.E.M. Surfactant Modified Zeolite from Cyclone Ash as Adsorbent for Removal of Reactive Orange 16 from Aqueous Solution. Am. J. Env. Protection, 2013, vol. 1, p. 1-9, 2013. GHS, 2009a

FUNGARO, D. A.; BRUNO, M.; GROSCHE, L .C. Adsorption and kinetic studies of methylene blue on zeolite synthesized from fly ash. Desalin. Water. Treat., v.2, p. 231239, 2009b

FUNGARO, D.A.; BORRELY, S.I.; CARVALHO, T.E.M. Surfactant Modified Zeolite from Cyclone Ash as Adsorbent for Removal of Reactive Orange 16 from Aqueous Solution. Am. J. Env. Protection, 2013, vol. 1, p. 1-9, 2013.

FUNGARO, D. A. Aplicação de material zeolítico preparado com cinzas de carvão no tratamento de águas contaminadas. Revista Meio Filtrante, n.9, 2004.

FUNGARO, D. A. Tratamento de drenagem ácida de mina usando zeólitas sintetizadas a partir de cinzas de carvão. Revista Meio Filtrante, n. 18, 2006.

FUNGARO, D. A.; IZIDORO, J. C.; ALMEIDA, R. S.Remoção de compostos tóxicos de solução aquosa por adsorção com zeólita sintetizada a partir de cinzas de carvão. Eclética Quim., v.30, p. 31- 35, 2005.

FUNGARO, D.A.; SILVA, M.G. Utilização de zeólita preparada a partir de cinza residuária de carvão como adsorvedor de metais em água. Quím. Nova., v. 25, p. 1081 - 1085, 2002.

FUNGARO, D.A; IZIDORO, J.C. Remediação de drenagem ácida de mina usando zeólitas sintetizadas a partir de cinzas leves de carvão. Quím. Nova., v.29, p. 735-740, 2006

GARCIA, M.T.; RIBOSA, I.; GUINDULAIN, T.; SANCHEZ-LEAL, J.; VIVES-REGO, J. Fate and effect of monoalkyl quaternary ammonium surfactants in the aquatic environment. Environ. Pollut.., v. 111, p.169-175, 2001.

GEIDER, R.J.; OSBORNE, B. Algal photosynthesis: the measument of algal gas exchange. Springer Science+Business Media Dordrecht, 1992.

GHIACI, M., ABBASPOUR, A., KIA, R., SEYDEYN-AZARD, F., Equilibrium Isotherm Studies for the Sorption of Benzene, Toluene, and Phenol onto Organo-Zeolites and AsSynthesized MCM-41, Sep. Purif. Technol., v. 40, p. 217-229, 2004.

GIANNETTO, G. Zeolitas - caracteristicas, propiedades y aplicaciones industriales. Caracas: EdIT Editorial Innovación Tecnológica, 1990.

GILES, C.H.; MACEWAN, T.H.; NAKHUA, S.N.; SMITH, D. Studies in adsorption. A system of classification of solution adsorption isotherms, and its use in diagnosis of adsorption echanisms and in measumrement of specific surface areas of solids. J. Chem. Soc. London, p. 3973-3993, 1960.

GILES, C. H.; SMITH, D.; HUITSON, A. A general treatment and classification of the solute adsorption isotherm. I. Theoretical. J. Colloid Interf. Sci., v. 47, n. 3, p. 755-765, 1974.

GILES, C.H.; MACEWAN, T.H.; NAKHUA, S.N.; SMITH, D. Studies in adsorption,11. A system of classification of solution adsorption isotherms, and its use in diagnosis of adsorption mechanisms and in measurement of specific surface areas of solids. J. Chem. Soc. London., p. 3973-3993, 1960.

GOLDIN, L.A.; TIMPERLEY, M.H.; EVANS, C.W. Non-lethal responses of the freshwater snail Potamopygus ntipodarum to dissolved arsenic. Environ. Monit. Assess. v. 47, p. 239-254, 2009. 
GOTTILEB, A.; SHAW, C.; SMITH, A.; WHEATLEY, A.; FORSTHE, S. The toxicity of textile reactive azo dyes after hydrolysis and decolourisation. J. Biotch., v. 101, p. 4956, 2003.

GREENBERG, B.M.; HUANG, X.D.; DIXON, D.G. Applications of the higher plant Lemna gibba for ecotoxicological assessment. J. Aqua. Ecosys. Health., v.. 1, p. 147-155, 1992.

GUAN, Q.Y., HU, X.Z., WU, D.Y., SHANG, X., YE, C., KONG, H.N.,. Phosphate removal in marine electrolytes by zeolite synthesized from coal fly ash. Fuel, v. 88, p. 1643-1649, 2010.

GUARATINI, C. C. T.; ZANONI, M. V. B., Remediação de efluente têxtil: Combinação entre processos químicos (ozônio) e biológico ( $P$. Chrysosporium). Tese de Doutorado. Universidade Estadual de Campinas. Campinas, 1999.

GUARATINI, C.C.I.; ZANONI, M.V. Corantes têxteis. Quím. Nova., v. 23, p. 71-78, São Paulo, 2000.

GUISNET, M., RIBEIRO, F.R., Zeólitos: Um nanomundo a serviço da catálise, Fundação Calouste Gulbenkian, Lisboa, 2004.

GUPTA, V.K.; CARROTT, P.J.M.; RIBEIRO CARROTT, M.M.L.; SUHAS. Low-Cost Adsorbents: Growing Approach to Wastewater Treatment - A Review. Crit. Rev. Env. Sci. Technol., v. 39, p. 783-842, 2009.

HAGGERLY, G.M.; BOWMAN, R.S. Sorption of chromate and other inorganic anions by organo-zeolite. Environ. Sci. Technol., v. 28, p. 452-458, 1994.

HALE, R.; MARSHALL, S.; JEPPE, K.; PETTIGROVE, V. Separating the effects of water physicochemistry and sediment contamination on Chironomus tepperi (Skuse) survival, growth and development: A boosted regression tree approach. Aquatic Toxicol., v. 152, p. 66-73, 2014.

HAMILTON, M.A.; RUSSO, R.C.; THURSTON, R.V. Trimmed Spearman-Karber method for estimating median lethal concentrations in toxicity bioassays. Environ. Sci. Technol., Easton, v.11, p.714-719, 1977.

HELBY, W.A. Adsorption isotherm studies. Chem. Eng., v. 59, p. 153-158, 1952.

HENMI, T. Synthesis of hydroxi-sodalite ("zeolite") from waste coal ash. Soil Sci. Plant Nutr., v. 33, p. 517-521, 1987.

HEMMINGS, R.T.; BERRY,E.E. On the Glass in Coal Fly Ashes: Recent Advances. Cambridge Univ Press.,v.113,1987.

HENMI, T. Synthesis of hydroxi-sodalite ("zeolite") from waste coal ash. Soil Sci. Plant Nutr., v. 33, p. 517-521, 1987.

HO, Y. S., MCKAY, G., Soption of dye from aqueous solution by peat. Cheam. Eng. J., v. 70, p. $115-124,2004$

HO, Y.S.; MCKAY, G. A comparision of chemissorption kinetic models applied to pollutant removal on various sorbents. Trans. Chem. E., v. 76, p. 332-340, 1998.

HO, Y.S.; MCKAY, G. Pseudo-second order model for sorption processes. Process. Biochem., v. 34, n. 5, p.451-465, 1999.

HO, Y.S; WASE, D.A.J.; FORSTER, C.F. Kinetic studies of competitive heavy metal adsorption by sphagnum moss peat. Environ. Technol., v.17, p.71-77,1996.

HÖLLER, H.; WIRSCHING, G.U. Zeolite formation from fly ash. Fortschr. Mineral., v.63, p. 21-43, 1985. 
HOU, W.; CHEN, X.; SONG, G.; WANG, Q.; CHANG, C.C. Effects of copper and cadmium on heavy metal polluted waster body restoration by duckweed (Lemna minor). Physiol. Plant. Biochem. v. 45, p. 62-69, 2007.

IMMICH, A. P. S., Remoção de corantes de efluentes têxteis utilizando folhas de Azadirachta indica como adsorvente. 2006. Dissertação (Mestrado). Universidade Federal de Santa Catariana, Santa Catarina-PR.

INGERSOLL, C.G.; MACDONALD, D.D.; WANG, N.; CRANE, J.L.; FIELD, L.J.; HAVERLAND, P.S.; KEMBLE, N.E.; LINDSKOOG, R.A.; SEVERN, C.; SMORONG, D.E. Predictions of sediment toxicity using consesnsus-based freshwater sediment quality guidelines. Arch. Environ. Contam. Toxicol. v. 41, p. 8-21, 2001.

IZIDORO, J.C. Síntese e caracterização de zeólita pura obtida a partir de cinzas volantes de carvão. 2013. Tese (Doutorado) - Instituto de Pesquisas Energéticas e Nucleares, São Paulo.

IZIDORO, J. C.; FUNGARO, D. A. Utilização de resíduos de usinas termelétricas a carvão na síntese de zeólitas e sua aplicação na remoção de $\mathrm{Zn}^{2+} \mathrm{e} \mathrm{Cd}^{2+}$ em água. $\boldsymbol{R e v}$. Bras. Pesq. Des.,v.9, p. 101-106, 2007.

IZIDORO, J.C. Estudos sobre a remoção de íons metálicos em água usando zeólitas sintetizadas a partir de cinzas de carvão. 2008. Dissertação (Mestrado) - Instituto de Pesquisas Energéticas e Nucleares, São Paulo.

IZIDORO, J.C.; FUNGARO, D.A.; SANTOS, F.S.; WANG, S. Characteristics of Brazilian coal fly ashes and their synthesized zeolites. Fuel Process. Technol., v. 97, p. 38-44, 2012.

JHA K. V.; MATSUDA, M.; MIYAKE, M. Resource recovery from coal fly ash waste: na overview study. J. Ceram. Soc. Jpn., v.116, p. 167-175, 2008.

JIN, X.; JIANG, M.; SHAN, X.; PEI, Z.; CHEN, Z. Adsorption of methylene blue and orange II onto unmodified and surfactant-modified zeolite. J. Colloid Interface Sci., v. 328, p. 243-247, 2008.

KAMBLE, S.P.; MALGRULKAR, P.A.; BANSIWAL, A.K.; RAYALU, S. Adsorption of phenol and $o$-chlorophenol on surface altered fly ash based molecular sieves. Chem. Eng. J.., v. 138, p. 73-83, 2008.

KANT, R., Textile dyening industry an environmental hazard, Natual Sci., v. 4, p. 22-26, 2012.

KARA GOZOGLU, B.; TASDEMIR, M.; DEMIRBAS, E.; KOBYA, M. The adsorption of basic dye(AstrazonBlueFGRL) from aqueous solutions onto sepiolite, flyash and apricot shell activated carbon: kinetic and equilibrium studies. J. Hazard. Mater., v. 147, p. 297306,2007.

KATZ, L.E.; BOWMAN, R.S.; SULLIVAN, E.J. Treatment of Produced Oil and Gas Waters with Surfactant-Modified Zeolite. Final Technical Report, 2003.

KERR, G.T. Synthetic Zeolites. Sci. Am.,v.261, p. 82-87,1989.

KELLAF, N.; ZEDAOUI, M. Growth response of Lemna gibba L. (duckweed) to copper and nickel phytoaccumulation, Ecotoxicology. v. 19, p. 1363-1368, 2010.

KELLAF, N.; ZEDAOUI, M Growth response of the duckweed Lemna minor to heavy metal pollution. Iran J. Environ. Health. Sci. Eng., v. 6, p. 161-166, 2009.

KIMURA, I.Y., GONÇALVES JR, A.C., STOLBERG, J., LARANJEIRA, M.C.M.,FÁVERE, V.T., Efeito do $\mathrm{pH}$ e do tempo de contato na adsorção de corantes reativos por microesferas de quitosana, Polímeros, v. , 1999. 
KOLOUSEK, D.; SEIDL, V.; PROCHASKOVA, E.; OBSASNIKOVA, J., KUBLKOVA, L.; SVETLIK, I. Ecological utilization, application. Acta Univ. Carol. Geol., v. 41, p. 1651 1657, 1996.

KREUZ, A.L. Utilização de cinzas pesadas de termelétricas na substituição de cimento e areia na confecção de concretos. 2002. Dissertação (Mestrado). Universidade Federal de Santa Catarina, Florianópolis

KUMAR, P.; JADAHV, P.D.; RAYALU, S. S.; DEVOTT S. Surface-modified zeolite-Afor sequestration of arsenic and chromium anions. Current Science, v, 92, p. 512- 517, 2007

KUNZ, A.; PERALTA-ZAMORA, P.; MORAES, S. G.; DURÁN, N. Novas tendências no tratamento de efluentes têxteis. Quím. Nova., v.25, p. 78-82, 2002

KYZAS, G.Z.; LAZARIDIS, N.K. Reactive and basic dyes removal by sorption onto chitosan derivatives, J. Colloid Interface Sci., v. 331, p. 32-39, 2009.

LAGERGREN, S. Zur theorie der sogenannten adsorption geloster stoffe. Kungl. Svenska Vetenskapsakad. Handl. v. 24, p. 1-39, 1898.

LANCHANCE, G. R., CLAISSE, F. Quantitative X-ray fluorescence analysis -Theory and Aplication. London: Wiley, 1995.

LANGMUIR, I.,Adsorptionof gases on plane surfacesofglass, mica andplatinum. J. Am. Chem. Soc., v. 40, p. 1361 - 1403, 1918.

LANGE, C. N.; Contaminação do solo e mobilidade de S, Cd, Mo, Pd e Zn em coluna de solo franco arenoso com cinza de carvão. Dissertação (Mestrado). Universidade de São Paulo - SP, 2012

LEE, M-G.; YI, G.; AHN, B-J.; RODDICK, F. Conversion of coal flyashinto zeolite and heavymetal removal characteristics of theproducts. Korean Z. Chem. Eng., v. 17, n. 3, p.325-331, 2001.

LEE,J-W.; CHOI, S-P.; THIRUVENKATACHARI, R.; SHIM, W-G.; MOON, K. evaluationoftheperformanceofadsorptionandcoagulationprocessesforthe maximum removal of reactive dyes. Dyes. Pigments., ,v.69,p. 196-203,2006.

LI, C., DONG, Y., WU, D., PENG, L., KONG, H., Surfactant modified zeolite as adsorbent for removal of humic acid from water. Applied Clay Sci., v. 53, p. 353 - 357, 2011.

Li, Z.; Bowman, R. S., Counterion effects on the sorption of cationic surfactant and chromate on natural clinoptilolite. Environ. Sci. Technol., v. 31, p. 2407-2412,1997.

LI, Z.H., BOWMAN, R.S., Sorption of perchloroethylene by surfactant-modified zeolite as controlled by surfactant loading. Environ. Sci. Technol., V. 32, p.2278-2282, 1998.

LI, Z.H., BURT, T., BOWMAN, R.S., Sorption of ionizable organic solutes by surfactant modified zeolite. Environ. Sci. Technol., v. 34, p. 3756-3760, 2000.

LEE, J-W.; CHOI, S-P.; THIRUVENKATACHARI, R.; SHIM, W-G.; MOON, K. evaluation of the performance of adsorption and coagulation processes for the maximum removal of reactive dyes. Dyes. Pigments., v.69,p. 196-203,2006.

LEVANDOWSKI, j.; KALKREUTH, W., Chemical and petrographical characterization of feed coal, fly ash and bottom ash from the Figueira Power Plant, Paraná, Brazil. International J. of Coal Geology, v. 77, p. 269 - 281, 2009.

LEIW, M.Y.; GUAI, G.H.; WANG, X.; TSE, M.S.; NG, C.M.; TAN, O.K. Dark ambient degradation of Bisphenol $A$ and Acid Orange 8 as organic pollutants by perovskite SrFeO3- I metal oxide. J. Hazard. Mater., v. 260, p. 1-8, 2013. 
LIN, C.F.; HIS, H.C. Resource recovery of waste fly ash: synthesis of zeolite-like materials. Environ. Sci. Technol., v. 29, p. 1109-1117, 1995.

MAGDALENA,C.P. Adsorção de corante reativo remazol vermelho RB de solução aquosa usando zeólita de cinza de carvão e avaliação da toxicidade aguda com Daphinia similis. 2010. Dissertação (Mestrado). Instituto de Pesquisas Enérgicas e Nucleares - USP. São Paulo. SP.

MARIUZO, P. Diferenciação do produto: estratégia da indústria têxtil para enfrentar a concorrência estrangeira. Inovação Uniemp, v. 3, p. , 2007.

MARQUARDT, D. W. An algorithm for least squares estimation of non-linear parameters, J. Soc. Ind. App. Math., v. 11, p. 431 - 441, 1963.

ARÍN, C.M.D.-C., ORON, G., Boron removal by the duckweed Lemna gibba: a potential method for the remediation of boron-polluted waters. Water Res. v. 41, p. 4579-4584, 2007.

MARK, U.; SOLBÉ, J. Analysis of the ecetoc aquatic toxicity (EAT) database V - The relevance of Daphnia magna as a representative test species. Chemosphere., v.36, p. 155-166, 1998.

MATIJASEVIC, S.; DAKOVIC, A.; TOMASEVIC-CANOVIC, M.; STOJANOVIC, M.; ILES, D. Uranium(VI) adsorption on surfactant modified heulandite/clinoptilolite rich tuff, $J$. Serb. Chem. Soc., v. 71, p. 1323-1331, 2006.

McCABE, W.L., SMITH, J.C., HARRIOT, P., Unit operations of chemical engineering, 4a edição, McGraw-Hill Book Company, 1985.

MEGATELI, S.; SEMSARI, S.; COUDERCHET, M. Toxicity and removal of heavy metals (cádmium, copper and zinc) by Lemna giba. Ecotox. Environ. Saf., v. 72, p. 1774-1780, 2009.

MELO, C. Remoção de cor de efluente de tinturaria em leito poroso.2007. Dissertação ( Mestrado). Universidade Estadual de Campinas, Campinas, Brasil.

MICHAILOVA, P.; PETROVA, N.; SELLA, G.; BOVERO, S.; RAMELLA, L.; REGOLI, F.; ZELANO, V. Genotoxic effects of chromium on polytene chromosomes of Chironomus riparius Meigen 1804 (Diptera, Chironomidae), Caryologia, v. 54, p. 59-71, 2001a.

MICHAILOVA, P.; IIKPVA, J.; PETROVA, N.; WHITE, K.N. Rearrangements in the salivary gland chromosomes of Chironomus ripariusMg. (Diptera, Chironomidae) following exposure to lead. Caryologia, v. 54,p. 349-363, $2001 \mathrm{~b}$.

MICHAILOVA, P.; IIKPVA, J.; PETROVA, N.; WHITE, K.N. Functional and structural rearrangements of salivary gland polytene chromosomes of Chironomus riparius $\mathrm{Mg}$. (Diptera, Chironomidae) in response to freshly neutralized aluminium. Environ. Pollut., v. 123, p. 193-207, 2003.

MICHAILOVA, P.; PETROVA, N.; IILKOVA, J.; BOVERO, S.; BRUNETTI, S. WHITE, K.; SELLA, G. Genotoxic effect of copper on salivary gland polytene chromosomes ofChironomus riparius Meigen 1804 (Diptera, Chironomidae). Environ. Pollut. v. 144, p. 647-654, 2006.

MISHA, K.K.; RAI, U.N.; PRAKASH, O. Bioconcentration and phytotoxicity of Cd in Eichhornia crassipes. Environ. Monitor. Assess., v. 130, p. 237-243, 2007.

MONDRAGÓN. F.; RINCON, F.; SIERRA, L.; ESCOBAR, J.; RAMIREZ, J.; FERNANDEZ, J. New perspectives for coal ash utilization: system of zeolitic materials. Fuel, v. 69, p. 263-266, 1990. 
MONFERRAN, M.V.; SANCHEZ AGUDO, J.A.; PIGNATA, M.L.; WUNDERLIN, D.A. Copper-induced response of physiological parameters and antioxidant enzymes in the aquatic macrophyte Potamogeton pusillus. Environmental. Pollut., v. 157, p. 25702576, 2009.

MONTEIRO, N. B.; ARAUJO, L. B.; ANASTÁCIO, T. S.; SOUZA, F. C. D.; DA SILVA, L. P.; HENRIQUE, H. M.; TAVARES, R. G. Avaliação dos impactos ambientais no município de Toritama. X Jornada de Ensino, Pesquisa e Extensão, Recife, PE, 2010.

MONTERO, BELZUNCE-SEGARRA, M.J.; GONZALEZ, J-L.; MENCHACA, I.; GARMENDIA, J.M.; ETXEBARRIA, N.; NIETO, O.; FRANCO, J. Application of toxicity identification evaluation (TIE) procedures for the characterization and management of dredged harbor sediments. Mar. Pollut. Bull., v. 71, p. 259-268, 2013.

Mouhtaris, Th.; Charistos, D.; Kantiranis, N.; Filippidis , A.; Kassoli-Fournaraki, A.; Tsirambidis, A. GIS-type zeolite synthesis from Greek lignite sulphocalcic fly ashes promoted by NaOH solutions. Micropor Mesopor. Mater., v.61, p.57-67, 2003.

MURAYAMA, N.; YAMAMOTO, H.; SHIBATA, J. Mechanism of zeolite from coal fly ash by alkali hydrotermal reaction. Int. J. Miner. Process., v. 64, p. 1-17, 2002.

NCIBI, M.C., Applicability of some statistical tools to predict optimum adsorption isotherm after linear and non-linear regression analysis. J. Hazard. Mater., v. 153, p. $207-212$, 2007.

OECD Guideline for testing of chemicals 202. Daphnia sp, Acute Immobilization Test. Organisation for Economic Cooperation and Development, Paris, France, 2004.

OECD Guideline for testing of chemicals 221. Lemna sp. Growth Inhibition Test. Organisation for Economic Cooperation and Development, Paris, France, 2004.

OLAH, V.; LAKATOS, G.; BERTOK, C.; KANALAS, P.; SZPILLPSI, E.; KIS, J.; MESZAROS, I. Short-term chromium (VI) stress induces different photosynthetic responces in two duckweed species, Lemna gibba and Lemna minor. Photosynthetica, v. 48, 513-520, 2010.

OLIVEIRA, E.A. Estudo do potencial de utilização da biomassa de Luffa cylindrica na descontaminação de efluentes contendo íons metálicos e corantes têxteis.2007.Tese (Doutorado) - Universidade Estadual de Maringá, Maringá, Brasil.

ORTIZ, L.; Teixeira, E. B. Influência das atividades de processamento do carvão sobre a qualidade dos recursos hídricos superficiais. In: Meio Ambiente e Carvão: Impactos da exploração e utilização. Porto Alegre, p. 301-340, 2002.

OUZOUNIDOU, G. Copper-induced changes on growth, metal content and photosynthetic function of Alyssum montanum L. plants. Environ. Exp. Bot., v. 34, p. 165-172, 1994.

OZACAR, M., SENGIL, A., I., Adsorption of metal complex dyes from aqueous solution by pine sawdust, Biores. Technol., v. 96, p. $791-175,2005$.

ÖZCAN,A.S.;ÖZCAN,A. Adsorption of acid dyes fromaqueous solutions onto acidactivated bentonite. J. Colloid Interface. Sci., v. 276, p. 39-46, 2004.

OZDEMIR, O.; ARMAGAN, B.; TURAN, M.; CELIK, M.S. Comparison of the adsorption characteristics of azo-reactive dyes on mezoporous minerals. Dyes Pigments..., v. 62, p. $49-60,2004$.

PAPOCKI, A., Síntese de zeólita a partir de cinza de carvão visando sua utilização na descontaminação de drenagem ácida de mina. Dissertação (Mestrado), Universidade Católica do Rio Grande do Sul - RS, 2009. 
PARK, M., CHOL, J. Synthesis of philipsite from fly ash. Clay Sci., v. 9, p. 219-229, 1995.

PEARCE, C. I.; LLOYD, J. R.; GUTHRIE, J. T. The removal from textile wastewater using whole bacterial cells: a review. Dyes. Pigments., v. 61, p. 121-139, 2003.

PERRICH, J.R.; Actived Carbon Adsorption for Waste Water Treatment, CRC Press: Boca Raton, 1981.

PEREIRA, M. F. R., FIGUEIREDO, J. L., Oxidative dehydrogeneration of ethylbenzene on activated carbon catalysts. 1. Influence of surface chemical groups. Appl. Catal. A. General, v. 184, p. 153 - 160, 1999.

PINHEIRO, A de S. Avaliacao ta toxicidade e genotoxicidade dos corantes azo reativos Remazol Preto $B$ e Remazol Alaranjado $3 R$ e da eficiencia da radiacao com feixe de eletrons na reducao da cor e efeitos toxicos. 2011. Dissertacao (Doutorado), Universidade de Sao Paulo, Sao Paulo.

PIRES, M., QUEROL, X. Characterization of Candiota (South Brazil) coal and combustion by-product. Int. J. Coal. Geol.., v.60, p.57-72, 2004

PIOTROWSKA, A.; BAJGUZ, A.; GODLEWSKA-ZYLKIEWICZ, B.; ZAMBRZYCKA, E. Changes in Growth, Biochemical Components, and Antioxidant Activity in Aquatic Plant Wolffia arrhiza (Lemnaceae) Exposed to Cadmium and Lead. Arch. Environ. Con. Tox., v. 58, p. 594-604, 2010.

QUEROL, X.; UMAÑA, J. C.; PLANA, F.; ALASTUEY, A.; LÓPEZ-SOLER, A.; MEDINACELI, A.; VALERO, A.; DOMINGO, M. J.; GARCIA-ROJO, E. Synthesis of zeolites from fly ash at pilot plant scale. Examples of potential applications. Fuel, v.80, p. 857-865, 2001.

QUEROL, X., MORENO, N., UMANÃ, J. C., ALASTUEY, A., HERNANDÉZ, E., LÓPEZSOLER, A., PLANA, F. Synthesis of zeolites from coal fly ash: an overview. Int. J. Coal. Geol. v. 50, p. 413-423, 2002.

QUEROL, X.; ALASTUEY, A.; LOPEZ-SOlER, A.; PLANA, F.; ANDRES, J. M.;JUAN, R.; FERRER, P.; RUIZ, C. R.A fast method of recycling fly ash: microwave assisted zeolite synthesis. Environ. Sci. Technol.,v.31,p.2527-2532, 1997.

QUEROL, X.; UMAÑA, J. C.; PLANA, F.; ALASTUEY, A.; LÓPEZ-SOLER, A.; MEDINACELI, A.; VALERO, A.; DOMINGO, M. J.; GARCIA-ROJO, E. Synthesis of zeolites from fly ash at pilot plant scale. Examples of potential applications. Fuel, v.80, p. 857-865, 2001.

QUISPE, D.; PEREZ-LOPEZ, R.; SILVA, L.F.; NIETO, J.M. Changes in mobility of hazardous elements during coal combustion in Santa Catarina power plant (Brazil). Fuel, v. 94, p. 495-503, 2012.

RADOVIC L. R.; RODRIGUES-REINOSO, F., Carbon material in catalysis. In: Thorower PA, Ed. Chemistry and Physics of carbon. v. 25, p. $243-364,1997$.

RAND, G.M. Detection bioassay In: GUTHRIE, F.E. \& PERRY, J.J. Introduction to environmental toxicology. Elsevier, p. $390-401,1980$.

RAYALU, S.S.; BANSIWAL, A.K.; MESHRAM S.U.; LABHSETWAR, N.; DEVOTTA, S. Fly ash based zeolite analogues: versatile materials for energy and environmental conservation. Catal. Surv. Asia., v. 10,p.74 - 88, 2001.

RAZINGER, J.; DERMASTIA, M.; DRINOVEC, L.; DROBNE, D.; ZRIMEC, A.; KOCE, J.D. Antioxidative responses of duckweed (Lemna minor L.) to short-term copper exposure. Environ. Sci. Pollut. Res. Int., v. 14, p. 194-201, 2007. 
RAYALU, S.S.; BANSIWAL, A.K.; MESHRAM S.U.; LABHSETWAR, N.; DEVOTTA, S. Fly ash based zeolite analogues: versatile materials for energy and environmental conservation. Catal. Surv. Asia., v. 10,p.74 - 88, 2001.

ROBINSON, T.; MCMULLAN, G.; MARCHANT, R.; NIGAN, P. Remediation of dyes in textile effluent: a critical review on current treatment technologies with a proposed alternative. Bioresour. Technol., v. 77, p. $247-252,2001$.

RODRIGUES-REINOSO, F., The role of carbon material in the hererogeniuscatalyses, Carbon, v. 36, p. $159-175,1998$.

ROHDE, G.M.; ZWONOK, O.; CHIES, F.; SILVA, N.I.W. Cinzas de carvão fóssil no Brasil - Aspectos técnicos e ambientais. Porto Alegre: CIENTEC. v.1 (202 p), 2006.

ROLLI, N.M.; SUVARNALHANDI, S.S.; MULGUND, G.S.; RATAGERI, R.H.; TARANATH, T.C. Biochemical responses and accumulation of cadmium in Spirodela polyrhiza. .J. Environ. Biol., v. 31, p. 529-532, 2010.

ROOSTAEI.N.; TEZE,F.H. Removal of phenol from aqueous solutions by adsorption. J. Environ. Manag., v.70, p.157-164, 2004.

SALES, P.T.F., OLIVEIRA, M.B, KYIOMI, P., DUTRA, R.M.S., GOMES, W.V., T., PELEGRINI, R., Tratamento de corante dispersivo por processofotocatalítico com TiO2, III Fórum de Estudos Contábeis, FIC, Rio Claro SP,2003

SARBAK, Z.; STANCZYK, A.; KRAMER-WACHOWIACK, M. Characterization of surface properties of various fly ashes. Powder Technol., v. 145, p. 82-87, 2004.

SAVIN, I.I.; BUTBNARU, R. Wastewater characteristics in textile finishing mills. Environ. Eng. Manage. J., v. 7,p. 859-864, 2008.

SCAPIN, M. A. Aplicação da difração e fluorescência de raios X (WDXRF): ensaios em argilominerais. 2003. Dissertação (Mestrado) - Instituto de Pesquisas Energéticas e Nucleares, São Paulo.

SCHIMMEL, D. Adsorção dos corantes reativos azul G5 e azul turquesa QG em carvão ativado comercial. Dissertação (Mestrado). Universidade Estadual do Oeste do Paraná. Paraná. PR.

SEIDEL, A.; GELBIN, D.; On applying the ideal adsorbent solution theory to multicomponent adsorption equilibrium of dissolved organic components on activated carbon. Chem. Eng. Sci., v. 43, p. 79 - 98, 1988.

SEIDEL-MORGENSTEM, A.; GUIOCHON, G., Modelling of the competitive isotherms and the chromatographic separation of two enantiomers, Chemical Engineering Science, v. 48, p. 2787-2797, 1993.

SHARMA, K.P., SHARMA, S., SHARMA S., SINGH, P.K., KUMAR, S., GROVER, R., SHARMA, P.K. A comparative study on characterization of textile wastewaters (untreated and treated) toxicity by chemical and biological tests. Chemosphere, v. 69,p. 48-54, 2007.

SHORE, J. Cellulosic dyeing. Society of Dyers and Colourists, p. 178, 1995.

SHIGEMOTO, N., HAYASHI, N., MIYUARA, K., Selective formation of Na-X zeólita fron coal fly ash by fusion with hydroxide prior to hydrothermal reaction. J. Mater. Sci., v. 28, p. 4781 - 4786, 1995.

SHIGEMOTO, N.; HAYASHI, H.; MIYUARA, K. Selective formation of Na-X zeolite from coal fly ash by fusion with hydroxide prior to hydrothermal reaction. J. Mater. Sci.,v. 28, p. 4781-4786, 1993. 
SHIGEMOTO, N.;SHIRAKAMI, K.; HIRANO, S.; HAYASHI, H. Preparation and characterization of zeolites from coal ash. Nippon Kagaku Kaishi., v.5, p. 484-492, 1992.

SHU, H., LI, D., SCALA, A.A., MA, Y.H., Adsorption of small pollutants from aqueous streams by aluminosilicate-based microporous materials, Sep. Purif. Technol., v. 11, p. 27-36, 1997.

SILVA, G. L. Reducao de corante em efluente de processo de tingimento de lavanderias industriais por adsorcao de argila. 2005. Tese (Doutorado), Universidade Estadual de Campinas, Sao Paulo.

SILVA, L.F.O.; BOIT, K.M. Nanominerais e nanopartículas na produção de carvão e de fundo cinza: implicações para os efeitos na saúde humana. Environ. Monit. Assess, 2010.

SILVA,M.V. Desenvolvimento de tijolos com incorporação de cinzas de carvão e lodo provenientes de estação de tratamento de água. 2011. Dissertação (Mestrado) - Instituto de Pesquisas Energéticas e Nucleares, São Paulo.

SILVA, A.J. Estudo da viabilidade de utilização da cinza pesada em adição ao concreto compactado com rolo (ccr) destinado a camada de base de pavimentos híbridos. 2006. Dissertação (mestrado) - Universidade Federal De Santa Catarina, Florianóplois.

SILVA, G. S.; SILVA, V. L.; VIEIRA, M. G. A.; SILVA, M. G.G. Solophenyl navy blue dye removal by smectite Clay in a porous bed columm. Adsorp. Sci. Technol., v. 27, p.861 - 875, 2010.

SINGER, A., BERKAUT, V.,Cation exchange properties of hydrothermally treated coal fly ash. Environ. Sci. Technol., v. 29, p. 1748-1753, 1995.

SOMERSET, V. S.; PETRIK, L. F.; WHITE, R. A.; KLINK, M. J.; KEY, D.; IWUOHA, E. Talanta, v.64, p.109-114, 2004.

SOUPILAS, A., PAPADIMITRIOU, C.A., SAMARAS, P., GUDULAS, K., PETRIDISs, D. Monitoring of industrial effluent ecotoxicity in the greater Thessaloniki area. Desalination, v. 224,p. 261-270, 2008.

SPEHAR, R.L., FIANDT, J.T., Acute and chronic effects of water quality criteria-based metal mixtures on three aquatic species, Envirom. Toxicol. Chemist., v. 5, p. 917-931, 1986.

SPRYNSKYY, M.; LIGOR, T.; LEBEDYNETS, M.; BUSZEWSKI, B. Kinetic and equilibrium studies of phenol adsorption by natural and modified forms of the clinoptilolite, J. Hazard. Mater., v. 169, p. 847-854, 2009.

SRIVASTAVA, V.C.; MALL,I.D.; MISHRA, I.M. Characterization of mesoporous rice husk ash (RHA) and adsorption kinetics of metal ions from aqueous solution onto RHA. $J$. Hazard. Mater., v.134, p. 257-267, 2006.

STEFOV, V.; PEJOV, L.; SOPTRAJANOV, B. Experimental and quantum chemical study of pyrrole self-association through $\mathrm{N}-\mathrm{H} \cdots \pi$ hydrogen bonding. J. Molecular. Str., v. 649, p. 231-243, 2003.

TADROS,T. F., Applied Surfactants. Principles and applications. Weinheim, WILEYVCHVerlag GmbH \& Co., 631 p., 2005.

TAFFAREL,S.R.; RUBIO,J. Adsorption of sodium dodecyl benzene sulfonate from aqueous solution using a modified natural zeolite with CTAB. Miner. Eng., v. 23, p. 771779, 2010.

TAFFAREL, S. R., Mecanismos e parâmetros de adsorção de íons $\mathbf{M n + 2}$ e dodecil benzeno sulfonato em zeólitas naturais modificadas, 2010. Tese (Doutorado). Universidade Federal do Rio Grande do Sul - UFRS. Rio Grande do Sul. RS. 
TEMKIN, M.I.; PYZHEV, V. Kinetics of ammonia synthesis on promoted iron catalyst. Acta. Phys. Chim. USSR., v. 12, p. 327 - 356, 1940.

TEMKIN, M.I., Adsorption equilibrium and kinetics of processes on nonhomogeneous surfaces and in the interaction between adsorbed molecules, Zh. Fiz. Chim., v. 15, p. $296-332,1941$.

TWARDOKUS, R.G. Reúso de água no processo de tingimento da indústria têxtil. 2000. Dissertação (Mestrado) - Centro Tecnológico da Universidade de Santa Catarina. Santa Catarina. SC

TIGINI, V.; GIANSANTI, P.; MANGIAVILLANO, A.; PANNCCHIA, A.; VARESE, G.C. Evaluation of toxicity, genotoxicity and environmental risk of simulated textile and tannery wastewaters with a battery of biotests. Ecotox. Environ. Safe., v. 74, p. 866-873, 2011.

TOPUZ, B.B.; GUNDUZ, G.; MAVIS, B.; ÇOLAK, Ü. The effect of tin dioxide (SnO2) on the anatase-rutile phase transformation of titania (TiO2) in mica-titania pigments and their use in paint. Dyes Pigments., v. 96, p. 31-37, 2013.

UMANÃ-PENÃ, J. C. Síntesis de zeolitas a partir de cenizas volantes de centrales termoeléctricas de carbón. 2002. Tese (Doutorado) - Universitat Politécnica de Catalunya, Barcelona, Espanha.

UMBUZEIRO, G.A.; ROUBICEK, D.A.; RECH, C.M.; SATO, M.I.Z.; CLAXTON, L.D. Investigating the sources of the mutagenic activity found in a river using the Salmonella assay and different water extraction procedures. Chemosphere., v. 54, p.1589-1597, 2004.

USEPA, Sediment Toxicity Identification Evaluation (TIE) Phases I, II and III Guidance Document, Office Research and Development. Washington, DC.

VANDEVIVERE, P. C., BIANCHI, R., VERSTRAETE, W., Treatment and reuse of wastwater from the textile wetprocessing industry: Review of emerging technologies.J. Chem. Technol. Biotechnol., v. 72, p. 289 - 302, 1998.

VASQUES, A.R. Caracterização e aplicação de adsorvente para remoção de corantes de efluentes têxteis em batelada e colunas de leito fixo. 2008. Dissertação (Mestrado) - Universidade Federal de Santa Catarina, Florianópolis.

ALVILIN, D.V.; POLYNOV, V.A.; MATORIN, D.N.; VENEDIKTOV, P.S. Acute toxicity assessment of textile dyes and textile and dyes industrial effluents using Daphnia magna bioassay. J. Plant Physiol., v. 146, p. 609-614, 1995.

VIJARAGHAVAN, N.S., Environmental unit in textile industry. Director BIS, bhopal science tech. Entrepreneur, v. 7,p. 3-9, 1999.

WATERSCHOOT, H. 2014. Ecotox classification under GHS in the EU. Disponível em: www.reach-metals.eu/force-download.php?.../GHS.... Acessado em : 03/07/2015.

WALKER, G.M.; WEATHERLEY,L.R. Adsorption of dyes from aqueous solution- the effect of adsorbent pores size distribution and dye aggregation. Chem. Eng.J., v. 83, p. 201-206, 2001.

WANG, M.; YANG, W.; WANG, W.; SHEN, Z.; BIAN, S.; ZHU, Z. Radiation induced decomposition and decoloration of reactive dyes in the presence of $\mathrm{H} 2 \mathrm{O} 2$. Radiat. Phys. Chem., v. 75, p. 286 - 291, 2006.

WEBER E. J., STICKNEY, V. C.; Hydrolysis kinetics of Reactive Blue 19 - Vinyl Sulfone, Wat. Res., v. 27, p. $63-67,1993$.

WEBER, W. J.; MORRIS, J.C. Kinetics of adsorption carbon from solutions. J. Sanit. Eng. Div., American Society Chemical Engineering, v. 89, p. 31-60, 1963. 
XU, S., BOYD, S. Cationic Surfactant Adsorption by Swelling and Nonswelling Layer Silicates. Langmuir, v. 11, p. 2508-2514, 1995.

ZAGATTO, P.A.; BERTOLETTI, E. Ecotoxicologia Aquática - Princípios e Aplicações. São Carlos BR: Rima. 2006. p.478.

ZAMZOW, M. J.; EICHBAUM, B. R.; SANDGREN, K. R.; SHANKS, D. E., Removal of heavy metals and other cations from wastewater using zeolites, Separ. Sci. Technol., v. 25, p, 1555-1569, 1990.

ZANONI, M.V.B.; CARNEIRO, P.A. O descarte dos corantes têxteis. Ciência Hoje., v. 29, p.61-64, Araraquara, 2001.

ZEYNEP, B. D. Metal accumulation and physiological responses induced by copper and cadmium in Lemna gibba, L. minor and Spirodela polyrhiza, Chem. Spec. Bioavailab., v. 25, p. 79-84, 2013.

ZHANG, P.F.; AVUDZEGA, D.M.; BOWMAN, R.S. Removal of perchlorate from contaminated waters using surfactant-modified zeolite, J. Environ. Qual., v. 36, p. 10691075, 2007.

ZOLLINGER, H., Color Chemistry: Syntheses, properties and applications oforganic dyes and pigments, 2a Ed., Editora VCH, p. 496, 1991.

ZSIGMOND, A.; NOTHEISZ, F. JAN-E, B.; Rate enhancement of oxidation reactions by the encapsulationof metal phthalocyanine complexes, Catal. Lett., v. 65, p. $135-139$, 2000. 